\title{
FAST FLUX TEST FACILITY PERIODIC TECHNICAL REPORT
}

MARCH, APRIL, MAY, JUNE 1970

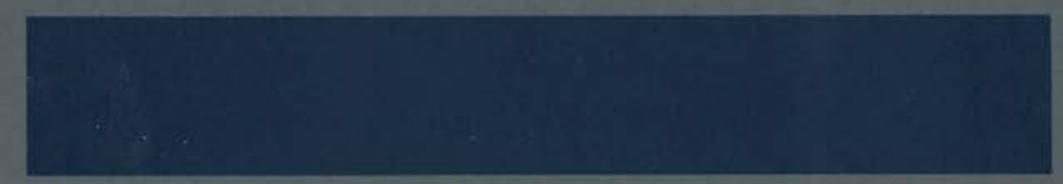

\section{AEC RESEARCH \& DEVELOPMENT REPORT}




\section{LEGAL NOTICE}

This report was prepared as an account of work sponsored by the United Stotes Government. Neither the United. States nor the United States Atomic Energy Commission, nor any of their emptoyees, nor any of their contractors, subcontractors, or their employees, makes ony warranty, express or implied, or assumes any legal liability or responsibility for the accuracy, completeness or usefulness of any information, apparatus, product or process disclosed, or represents that its use would not infringe privately owned rights.

\section{PACIFIC NORTHWEST LABORATORY \\ RICHLAND, WASHINGTON \\ 'operated by \\ BATTELLE MEMORIAL INSTITUTE}

for the

UNITED STATES ATOMIC ENERGY COMMISSION UNDER CONTRACT AT(45-1)-1830 


\author{
FAST FLUX TEST FACILITY \\ PERIODIC TECHNICAL REPORT \\ MARCH, APRIL, MAY, JUNE 1970 \\ B. Wolfe(a) \\ Acting Project Manager
}

Compiled by C. P. Cabe $11^{(a)}$

August 1970

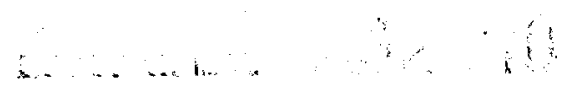

BATTELLE MEMORIAL INSTITUTE

PACIFIC NORTHWEST LABORATORIES

RICHLAND, WASHINGTON 99352

(a) Now employed by WADCO Corp., a Subsidary of Westinghouse Electric Corporation, under AEC Contract No. AT(45-1)-2170. 
BNWL -1394

Printed in the United States of America Available from

Clearinghouse for Federal Scientific and Technical Information National Bureau of Standards, U.S. Department of Commerce Springfield, Virginia 22151

Price: Printed Copy $\$ 3.00 ;$ Microfiche $\$ 0.65$ 


\section{FAST FLUX TEST FACILITY \\ PERIODIC TECHNICAL REPORT \\ MARCH, APRIL, MAY, JUNE 1970}

\section{$\underline{\text { ABSTRACT }}$}

This report was prepared by Battelle-Northwest under Contract No. AT(45-1)-1830 for the Atomic Energy Commission, Division of Reactor Development and Technology, to summarize technical progress made in the Fast Flux Test Facility Program during March, April, May and June 1970.

\section{PRIOR REPORTS IN THIS SERIES}

$\begin{array}{lllrrr}\text { BNWL-325 } & \text { FFTF Summary Technical Report } & 1-1-66 & \text { to } & 12-31-66 \\ \text { BNWL-501 } & \text { FFTF Quarterly Technical Report } & 1-1-67 & \text { to } & 3-31-67 \\ \text { BNWL-541 } & \text { FFTF Quarterly Technical Report } & 4-1-67 & \text { to } & 6-30-67 \\ \text { BNWL-567 } & \text { FFTF Periodic Technical Report } & 7-1-67 & \text { to } & 12-31-67 \\ \text { BNWL-660 } & \text { FFTF Quarterly Technical Report } & 1-1-68 & \text { to } & 3-31-68 \\ \text { BNWL-880 } & \text { FFTF Quarterly Technical Report } & 4-1-68 & \text { to } & 6-30-68 \\ \text { BNWL-917 } & \text { FFTF Quarterly Technical Report } & 7-1-68 & \text { to } & 9-30-68 \\ \text { BNWL-941 } & \text { FFTF Periodic Technical Report } & 10-1-68 & \text { to } & 2-28-69 \\ \text { BNWL-1090 } & \text { FFTF Quarterly Technical Report } & 3-1-69 & \text { to } & 5-31-69 \\ \text { BNWL-1174 } & \text { FFTF Quarterly Technical Report } & 6-1-69 & \text { to } & 8-31-69 \\ \text { BNWL-1275 } & \text { FFTF Quarterly Technical Report } & 9-1-69 & \text { to } & 11-30-69 \\ \text { BNWL-1328 } & \text { FFTF Quarterly Technical Report } & 12-1-69 & \text { to } & 2-28-70\end{array}$




\section{CONTENTS}

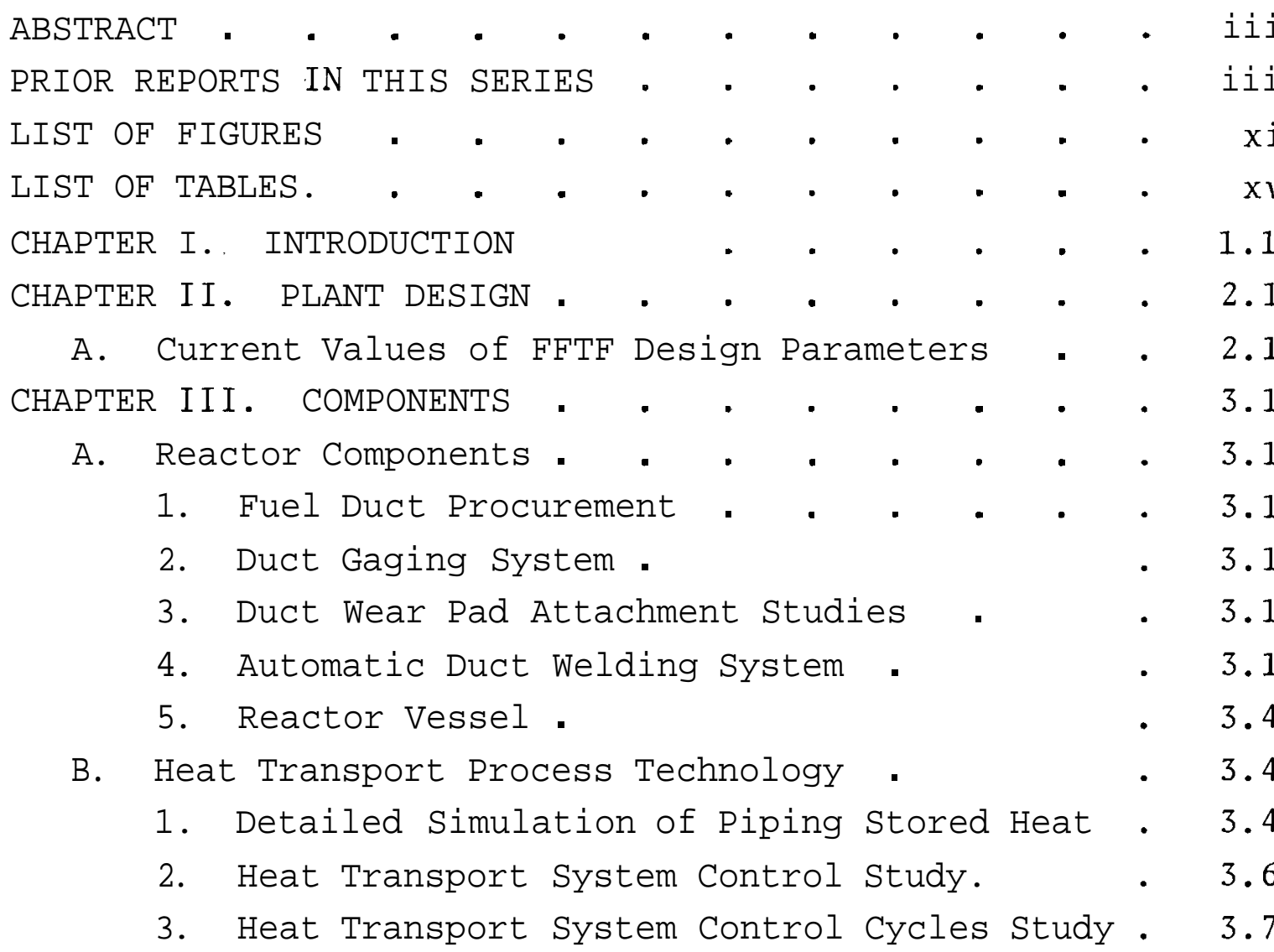

CHAPTER IV. INSTRUMENTATION AND CONTROLS . 4.1

A. FFTF Instrumentation and Control Systems . . 4.1 1. New System Titles and Numbers. . 4.1

2. In-Vessel Sodium Level Sensor. 4.2

B. Instrumentation and Control Development. . . 4.2

1. Mixed-Mean Coolant Temperature Measurement at Subassembly Outlet . . . . . . 4.2

2. Fuel Failure Monitoring. . . . . . 4.3

3. Low-Level Neutron Flux Instrumentation . . 4.12

CHAPTER V. SODIUM TECHNOLOGY . • • • • • • • 5.1 CHAPTER VI. CORE DESIGN . . . . . . . . . 6.1

A. Core Mechanics • 1. Core Model . . . . . . . . . 6.1 2. Cladding and Spacer Wire Stresses . . . 6.1 
B. Core Process Technology . . . . . . . 6.5

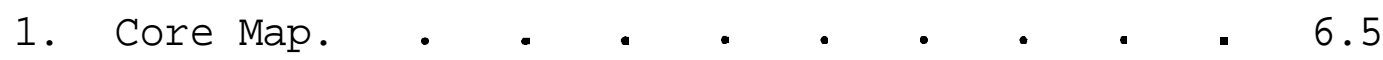

2. Control Rod Worth Requirements. $\quad 6.5$

3. CCTL Mk II Hydraulic Life Test . 6.8

4. Subassembly Hydraulic Testing . $\quad 6.12$

C. Irradiation Testing . 6.13

1. Closed Loop Top Closure Development Program . 6.13

2. Closed Loop System Design . 6.14

3. FFTF Closed Loop Test Characteristics . . 6.15

4. Open Test Assembly . . . . . . . 6.15

D. Other Core Design . . . . . . . . . 6.18 1. Examination Specimen Decay Heat
Removal Development.

CHAPTER VII. FUELS AND MATERIALS . 7.1

A. Fuels and Materials Evaluation . 7.1

1. EBR-II Structural Materials Irradiations. : 7.1

2. EBR-II Subassembly Irradiations . 7.2

3. Irradiation of Hypostoichiometric $\mathrm{UO}_{2}-\mathrm{PuO}_{2} \cdot 7.5$

4. Transient Irradiations . 7.7

5. Effect of Cold Work on Irradiation-Induced Swelling of Type 316 SS . 7.11

6. Damage Analysis for Solution-Treated 304 SS . 7.11

7. Analysis of Irradiation-Induced Voids in Stainless Steels. 7.16

8. Cladding Thickness Loss. 7.20

9. Mechanical Testing of Fuel Pin Cladding . . 7.20

10. Controlled Clad Failure Techniques . . 7.21

11. Detection of Irradiation-Induced Fuel Pin Swelling by Vibration Measurement . 7.22

12. In-Cell Profilometry on Irradiated Fuel Pins. 7.23

B. Materials Technology. . . . . . . . 7.24

1. High Strain Rate Effects. . 7.24

2. PSAR "Leak-Before-Break" Analysis for Vessel
and Primary Piping. 
3. Weldment Studies . . . . . . 7.28

4. Uniaxial Creep-Rupture. . • . . . 7.33

5. Tensile Studies . . . • . . . 7.37

6. Fluence Limits. • . . • . • • 7.38

7. Carbon Transport . • • • • • • 7.39

8. Construction Codes for Nonradioactive Sodium Loops at PNL . . . . . 7.40

9. Irradiated $\mathrm{B}_{4} \mathrm{C}$ Pellet Fragmentation . . 7.40

10. Sodium-B ${ }_{4} \mathrm{C}$ Compatibility . • • • • 7.41

11. Lithium-B ${ }_{4} \mathrm{C}$ Effects . . . • . . 7.43

12. $\mathrm{B}_{4} \mathrm{C}$ Gas Release in Irradiation. . . . 7.44

13. Radiation Effects on Tantalum Absorbing
Material for Control Rods. . . . . 7.44

CHAPTER VIII. FUELS RECYCLE . • • • • . • . 8.1

A. Fuels Technology • • . • . • • • • 8.1

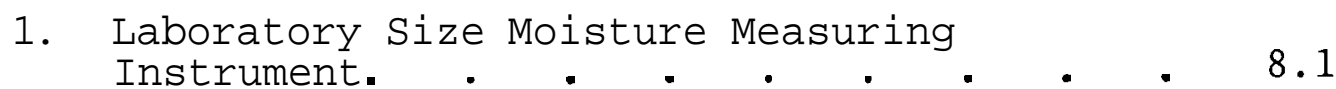

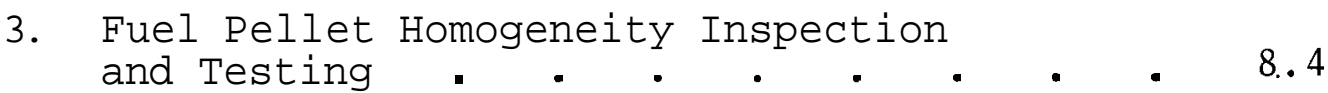

4. Fabrication of Mixed Oxide Fuel

for EBR-II Subassemblies . $\quad 8.5$

5. FTR Fuel Specifications . • • . 8.6

6. Void Size Distribution Measurements . 8.7

7. Pellet Sintered Density Control . 8.7

8. Pre-irradiation Characterization $\quad$. . 8.9

9. Fuel Performance Prediction and Analysis . 8.11

10. Prequalification of LMFBR Fuel Suppliers • 8.13

B. Cladding Technology . $\quad$. $\quad$ e . $\quad$. 8.14

1. Vendor Qualification Criteria . • • • 8.14

2. LMFBR Fuel and Cladding
Information Center. . . . . . . 8.14

3. Acceptance Testing and Clad
Characterization . . . . . . 8.16

4. Interaction of Cladding Defects . 8.16 
C. Fuel Pin Technology . . . . . . . 8.20

1. Fuel-Pin End-Closure Welding Anomalies . . 8.20

2. Fuel-Pin End-Closure Weld Development. 8.24

3. Prototypic FTR Fuel Pin Fabrication Development

D. Fuel Subassembly Technology

.8 .27

1. CCTL Mark II Test Assembly Fabrication Development . $\quad$. $\quad$. . . . 8.27

2. CCTL Mark I I Subassembly Compression Test. . 8.41 CHAPTER IX. PHYSICS. $\quad$ • $\quad$ •

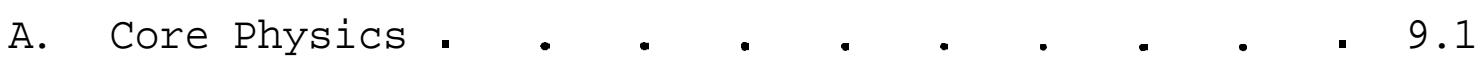

1. Dependence of the Diffusion-Transport Correction on the Reactor Composition and the Number of Energy Groups . 9.1

2. FFTF Critical Experiments. 9.2

3. Anomaly Detection in a Reactor at Power . . 9.10

4. Reactivity Effects of Incoherent Sodium Voiding Within a Ring of Subassemblies . . 9.11

5. Critical Approach and Exponential Experiments with 25.2 wt: $\mathrm{PuO}_{2}$-U (Nat.) $\mathrm{O}_{2}$ Rods in Water. 9.14

B. Radiation and Shielding . . 9.16

1. Fission Product Decay Heat . . 9.16

2. Na and Mn Disintegration Rate Distributions in the ZPPR.

.9 .18

3. ZPPR Stored Fuel Analysis.

.9 .18

4. ZPPR Gamma Ray Shielding Experiments . . 9.19

5. Decay Heat Measurements . . . . . 9.23

6. Shield Development Program . . 9.23

ChAPTER X. SAFETY . .

A. Plant Safety Analysis Studies. 10.1

1. Theoretical Work Energy for Core Disassembly Accidents.

. 10.1

2. Containment Transients . . 10.5

3. Space-Time Decay Heat Distribution from Fission Products in the Reactor Cavity . . 10.9

4. Sodium Pool Fire Analyses for New FTR Equipment Cell Volumes 
$\begin{array}{lll}\text { 5. Containment Analyses - SOHOT Code . } & 10.12 \\ \text { 6. Site Radiological Analysis. } & 10.13\end{array}$

APPENDIX A

FFTF BNWL Reports and Documents Issued

March 1 - June 15 . . . . . . . . . A-1 


\section{LIST OF FIGURES}

2.1 Core Map - January 1970

Automatic Duct Welding Fixture Showing Sample Fuel Duct in Position for Welding

Piping Stored Heat Study Na Response to Inlet Temperature Ramp, Detailed Models

Mixer for FFTF Instrument Package

Typical Guarded Fission Counter and Two Cable "Test Assembly" Prepared for Combined

Gamma and Temperature Testing

View of Top of Structural Core Model

Overall View of Structural Core Model

6.3

6.3

Wire Stress as a Function of Time, with and Without In-Reactor Creep

6.4 CCTL MK II as Received at Argonne National Laboratory, March 2, 1970

Mark II Test Assembly and Magnified View of Pressure Transducer

6.6 Magnified View of Final Machined

Surface of Lower Support Ring

Open Test Assembly in Reactor Shortened

Transient Irradiation Changes in PNL-1-2

Fuel Pellet Interface Disappearance

Swelling in AISI 304 SS at 400 to $420{ }^{\circ} \mathrm{C}$ 
7.9 Measuring Frame and Electrical Control for 324 Building East Cell Remote Profilometer

7.10 The Effect of Strain Rate on the Strength of Unirradiated and Irradiated Type 304 SS at $1000^{\circ} \mathrm{F}$

7.11 The Effect of Strain Rate on the Ductility of Unirradiated and Irradiated Type 304 SS a't $1000^{\circ} \mathrm{F}$

7.12 Summary of Fatigue-Crack Propagation Behavior of Type 304 SS

7.13 Strength of Weld-Deposited Materials as a

Function of Test Temperature and Weld Process 7.31

7.14 Ductility of Weld Deposited Materials as a

Function of Test Temperature and Weld Process 7.32

7.15 Macrograph of 65\% TD Pellet (4-5) Irradiated to $11 \%$ Burnup at $350{ }^{\circ} \mathrm{C}$ with Pronounced

Splitting and Radial Cracks

7.16 Macrograph of $90 \%$ TD Pellet (4-4) Irradiated to $9 \%$ Burnup at $370{ }^{\circ} \mathrm{C}$ and Containing Both

Radial and Circumferential Cracks

7.17 Macrograph of $99 \%$ TD Pellet (4-14) Irradiated to $\sim 7 \%$ Burnup at $300{ }^{\circ} \mathrm{C}$

7.18 Helium Gas Release of Boron Carbide Irradiated i n a Thermal Flux

8.1 Laboratory Size Moisture Measuring Instrument

8.2

Comparison of Void Size Distributions Found

by Examination of Microprobe Traces and

Photographs

8.8

8.3 Effect of Methyl Cellulose in Decreasing Density

8.4 Proposed Advanced Characterization Schematic 8.10

8.5 Schematic Showing Proximity of an OD and an

ID Tubing Defect Whereby Combined Defects Will

Result in Decreased Effective Wall Thickness

8.6 Curve Illustrating Probability of Coincidence of OD and ID Defects Based on Schematic Shown in Figure 8.1

8.7 Welding Procedure for Vacuum-Me1ted End-Cap Material 
BNWL -

8.8 Welding Procedure \#19, 15A, $12 \mathrm{sec} /$ revolution 8.22

8.9 Reference FFTF Fuel Pin End Closure Weld Penetration $\quad 8.25$

8.10 Prototypic FTR Fuel Pin for Test Demonstration Fabrication 8.28

8.11 Fuel Pellet Loading Station $\quad 8.30$

8.12 Fuel Pellet Seating 8.31

8.13 Wire Wrap Machine 8.32

8.14 Removal of Fuel Pin from Wire Wrap Machine 8.33

8.15 Lower Grid Plate Electron Beam Weld 8.34

8.16 Strip Layer Assembly 8.36

$\begin{array}{lll}8.17 & \text { Pin Bundle Assembly } & 8.37\end{array}$

$\begin{array}{lll}\text { 8.18 Top Grid Assembly } & 8.38\end{array}$

$\begin{array}{lll}8.19 & \text { Nose Piece Assembly } & 8.39\end{array}$

8. 20 Completed Subassembly 8.40

8.21 Typical Subassembly Compression Test

Data Curve 8.43

8.22 Subassembly Compression Test Apparatus and Instrumentation $\quad 8.44$

8.23 Summary of Mark II Compressibility Tests Run Numbers: One, Two, and Three Average and Range

8.45

8.24 Summary Comparison of Mark II and Mark I Subassembly Compressibility Test Run Curves 8.46

9.1 Reactivity Ramp Rate Variations as a Function of Voiding Incoherences Within a Radial Channel 9.13

9.2 $\begin{aligned} & \text { Decay Gamma Power After a Fast Neutron Burst } \\ & \text { in } 239 \mathrm{Pu}\end{aligned}$

$9.3 \quad 238_{U(n, f)}$ Reaction Rate Distribution--R-Z Calculation

9.20

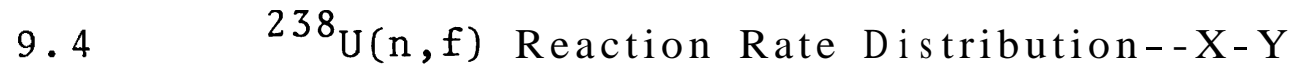
Calculation

9.21

9.5 Midp1ane Radial Gamma Distribution in ZPPR/FTR-2 with Stored Fuel Present

9.22

9.6 Midplane Radial Gamma Distribution in ZPPR/FTR-2 Without Stored Fuel Present 
BNWL - 1394

10.1

Model for Molten Fuel-Sodium Interaction

10.2

10.2

Effect of Fuel Fragmentation on Work Energy

10.4

10.3

Effect of Initial Fuel Temperature on Work

Energy

10.6

10.4

Effect of Initial Sodium Temperature on Work Energy

10.7 


\section{LIST OF TABLES}

2.1 Current Values of FFTF Design Parameters 2.1

3.1 Design Cycles for Heat Transport System

4.1 Instrumentation and Control Systems Titles and Numbers

4.2 ${ }^{129} \mathrm{Xe} /{ }^{124} \mathrm{Xe}$ Isotopic Ratios for 80 Distinct Tags

4.3 Calculated Tag Isotope Cross Sections

Gas Requirements Per Core

4.8

4.5

Cost for 80 Unique Tags

6.1

Primary System Worth Requirements

4.10

6.2

Secondary System Worth Requirements

6.6

7.1

Summary of Experiments Discharged from EBR-II

6.7

7.2

Summary Status of Irradiation Experiments

7.3

7.3

Irradiation Data on Pin No. 24

7.6

7.4

Fluence Limits for FTR Vessel, Core

Barrel and Core Support Structure

Swelling of Tantalum Irradiated in EBR-I I

7.46

8.1 Diametral Control Data for Preslug-

Granulate-Compact Fabricated Fuel

\section{5}

8.2 Status of RDT Standards Preparation for

$$
\text { FTR Driver Fuel }
$$

8.3 Comparison of Frequency of 8- $\mu$ Diameter

Voids in an MEE-63-4 Fuel Pellet as Found by Three Methods

8.4 Advanced Characterization Outline

8.5 Reference Data for FFTF Peak Power Fuel $\mathrm{Pin}\left(\mathrm{Q} / \mathrm{L}{ }_{3} 12.2 \mathrm{~kW} / \mathrm{ft}\right)$

8.6 Sensitivity of Unrestrained Pellet Expansion to Variables

8.7 Fuel Pin Inspection Acceptance Rates

9.1

Reactor Compositions and Dimensions

9.1

9.2 Ratio of Transport Theory Eigenvalue to Diffusion Theory Eigenvalue

9.

Effective Multiplication Constant

9.3

$9: 4$

Changes in the Multiplication Constant

9.3

9.5 Inferred Experimental Worth of the FTR-2 Control Ring 
BNWL - 1394

9.6 Percent Difference, Approximations Versus Precise Transport Model

9.8

9.7 Pheripheral Control Worth Versus Shield Thickness in FTR-3

9.8 Reactivity Changes in Engineering Mockup Caused by Differences Between Desired and Anticipated Atom Densities

9.9 Results of Critical Approach Experiments with 25.2 wt $\% \mathrm{PuO}_{2}$-U (Nat.) $\mathrm{O}_{2}$ Fuel Rods for Water

9.10 Tentative Results of Critical Approach Experiments with 25.2 wt $\% \mathrm{PuO}_{2}-\mathrm{UO}_{2}$ Fuel Pins in Water Containing Boron 


\section{FAST FLUX TEST FACILITY \\ PERIODIC TECHNICAL REPORT \\ MARCH, APRIL, MAY, JUNE 1970 \\ CHAPTER I: INTRODUCTION}

This report describes progress in the discipline-oriented technological program being conducted to ensure technical adequacy of the FFTF design.

Progress in discipline-oriented technological work is presented in Chapters II through $X$. These chapters generally correspond to the LMFBR Program Plan Elements. Subdivisions of the chapters, however, are based upon specific FFTF components, systems, facilities, and programs. A list of reports issued during the March - June 1970 period is given in Appendix A. 
CHAPTER II. PLANT DESIGN

A. CURRENT VALUES OF FFTF DESIGN PARAMETERS

Values of FFTF design parameters of general interest are given in Table 2.1. The Core Map is given in Figure 2.1.

TABLE 2.1. Current Values of FFTF Design Parameters (June 5, 1970)

Parameter

1. Electrical System

115 kV Supply Feeder

$13.8 \mathrm{kV}$ Supply Feeder

$13.8 \mathrm{kV}$ Transformer

$13.8 \mathrm{kV}$ Transformer Voltage

$13.8 \mathrm{kV}$ Transformer Rating

480 Volt Emergency Generators (Diesel)

Power, Emergency Generators

2. Containment

Containment Bldg.

Diameter

Overall Height

Depth Below Grade

Design Pressure - internal

- external

Design High Temp.

Design Low Temp.

3. Reactor Core

Power Excluding Closed Loops

Peak Flux a $400 \mathrm{MW}_{\mathrm{t}}$

Doppler Coefficient

Drivers

Reflectors
Units Value

$\begin{array}{ll}\text { Number } & 1 \\ \text { Number } & 1 \\ \text { Number } & 1 \\ \mathrm{kV} & 115 / 13.8 \\ \text { MVA } & 22.5 / 30\end{array}$

Number 2

kW each 1200

$\begin{array}{ll}\mathrm{ft} & 135 \\ \mathrm{ft} & 194 \\ \mathrm{ft} & 70 \\ \text { psig } & 10 \\ \text { psig } & 0.2 \\ { }^{\circ} \mathrm{F} & 250 \\ { }^{\circ} \mathrm{F} & (-) 10\end{array}$

$\begin{array}{ll}\mathrm{MW}_{\mathrm{t}} & 400 \\ \mathrm{~N} / \mathrm{cm}^{2}-\mathrm{sec} & 7 \times 10^{15} \\ \mathrm{~T} \mathrm{dk} / \mathrm{dt} & -0.005 \\ \text { Number } & 75 \\ \text { Number } & \mathbf{1 1 1}\end{array}$


BNWL -1394

TABLE 2.1. (contd)

\begin{tabular}{|c|c|c|}
\hline Parameter & Units & Value \\
\hline \multicolumn{3}{|l|}{ Reactor Core (contd) } \\
\hline \multicolumn{3}{|l|}{ Driver Fuel Duct } \\
\hline Outside Width Across Flats & in. & 4.615 \\
\hline $20 \%$ CW Material & & Type $316 \mathrm{SS}$ \\
\hline Wall Thickness in Core & in. & 0.120 \\
\hline In-Core Primary (Safety) Rods & Number & 3 \\
\hline In-Core Secondary (Control) Rods & Number & 4 \\
\hline Peripheral Control Rods & Number & 15 \\
\hline Maximum Velocity, Core Coolant & $\mathrm{ft} / \mathrm{sec}$ & 30 \\
\hline \multicolumn{3}{|l|}{ Irradiation Test Facilities } \\
\hline Closed Loop Capability & Number & 6 \\
\hline $\begin{array}{l}\text { Power Closed Loop - Each of } \\
\quad 2 \text { initial }\end{array}$ & $\mathrm{MW}_{\mathrm{t}}$ & 2 \\
\hline $\begin{array}{l}\text { Temperature Cloosed Loop } \\
\text { Coolant - Maximum }\end{array}$ & ${ }^{\circ} \mathrm{F}$ & 1200 \\
\hline \multicolumn{3}{|l|}{ Closed Test Loops } \\
\hline Test Train Length & ft & 12 \\
\hline Available Test Diameter & in. & 2.5 \\
\hline $\begin{array}{l}\text { Open Test Loops with Specimen } \\
\text { Instrumentation }\end{array}$ & Number & 2 \\
\hline $\begin{array}{l}\text { Open Test Positions with } \\
\text { Proximity Instrumentation }\end{array}$ & Number & 1 \\
\hline \multicolumn{3}{|l|}{ Closed Loop Ex-Vessel Machine } \\
\hline \multirow{3}{*}{$\begin{aligned} \text { "CLEM" Machine } & - \text { Major Diameter } \\
& - \text { Overall Length } \\
& - \text { Weight }\end{aligned}$} & $\mathrm{ft}$ & 8 \\
\hline & ft & 55 \\
\hline & tons & 234 \\
\hline $\begin{array}{l}\text { "CLEM" Heat Removal Capability } \\
\text { Reactor Vessel }\end{array}$ & $\mathrm{kW}$ & 30 \\
\hline Material & & Type $304 \mathrm{SS}$ \\
\hline Overall Height & ft-in. & $43-2$ \\
\hline Inlet Nozzles - Size & in. & 16 \\
\hline
\end{tabular}


TABLE 2.1. (conta)

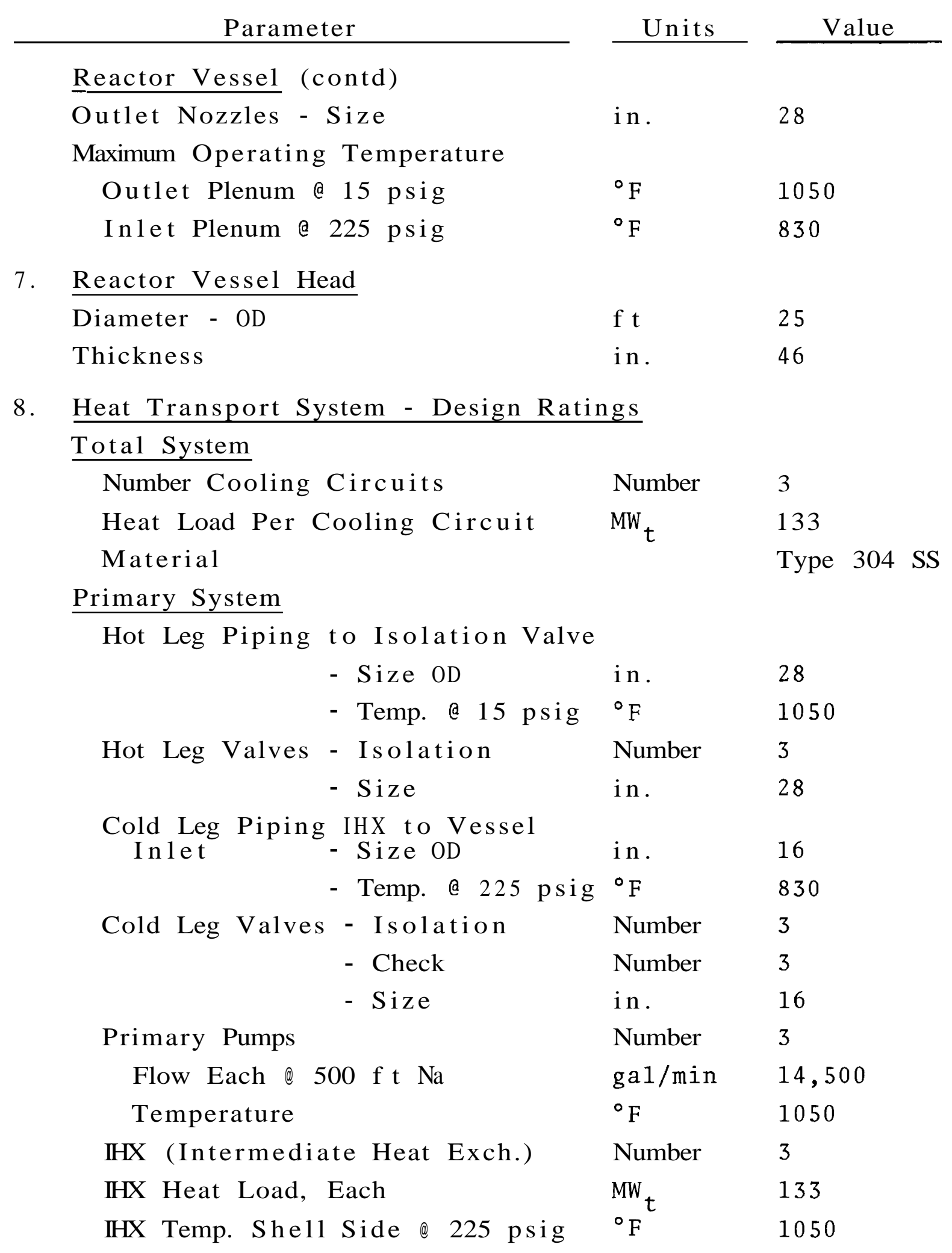


BNWL - 1394

TABLE 2.1. (contd)

\begin{tabular}{|c|c|c|}
\hline Parameter & Units & Value \\
\hline \multicolumn{3}{|c|}{ Heat Transport System - Design Ratings (contd) } \\
\hline \multicolumn{3}{|l|}{ Frimary System (cont) } \\
\hline IHX Temp. Tube Side \& 250 psig & ${ }^{\circ} \mathrm{F}$ & 1050 \\
\hline $\begin{array}{l}\text { IHX Log Mean Temp. Diff. } \\
\text { for Ultimate Conditions }\end{array}$ & ${ }^{\circ} \mathrm{F}$ & 100 \\
\hline \multicolumn{3}{|l|}{ Secondary System } \\
\hline Main Piping Size OD & in. & 16 \\
\hline Branch Piping Size OD & in. & 12 \\
\hline Pipe Headers Size OD & in . & 8 \\
\hline 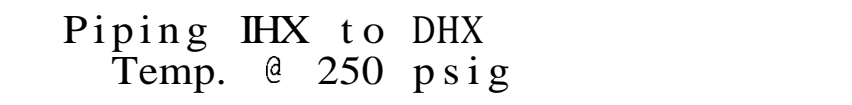 & ${ }^{\circ} \mathrm{F}$ & 1000 \\
\hline $\begin{array}{l}\text { Piping DHX to } \text { IHX } \\
\text { Temp. } @ 250 \text { psig }\end{array}$ & ${ }^{\circ} \mathrm{F}$ & 830 \\
\hline $\begin{array}{l}\text { Valves - Hot and Cold Leg } \\
\text { Temp. @ } 250 \text { psig }\end{array}$ & ${ }^{\circ} \mathrm{F}$ & 1000 \\
\hline Secondary Pumps & Number & 3 \\
\hline Flow Each @ $260 \mathrm{f} \mathrm{t} \mathrm{Na}$ Head & $\mathrm{gal} / \mathrm{min}$ & 14,500 \\
\hline Temp. @ 250 psig & ${ }^{\circ} \mathrm{F}$ & 830 \\
\hline DHX Units & Number & 3 \\
\hline DHX Modules Per Unit & Number & 4 \\
\hline DHX Thermal Rating per module & $\mathrm{MW}_{\mathrm{t}}$ & 33 \\
\hline DHX Tube Side, Temp. @ 250 psig & ${ }^{\circ} \mathrm{F}$ & 1000 \\
\hline
\end{tabular}




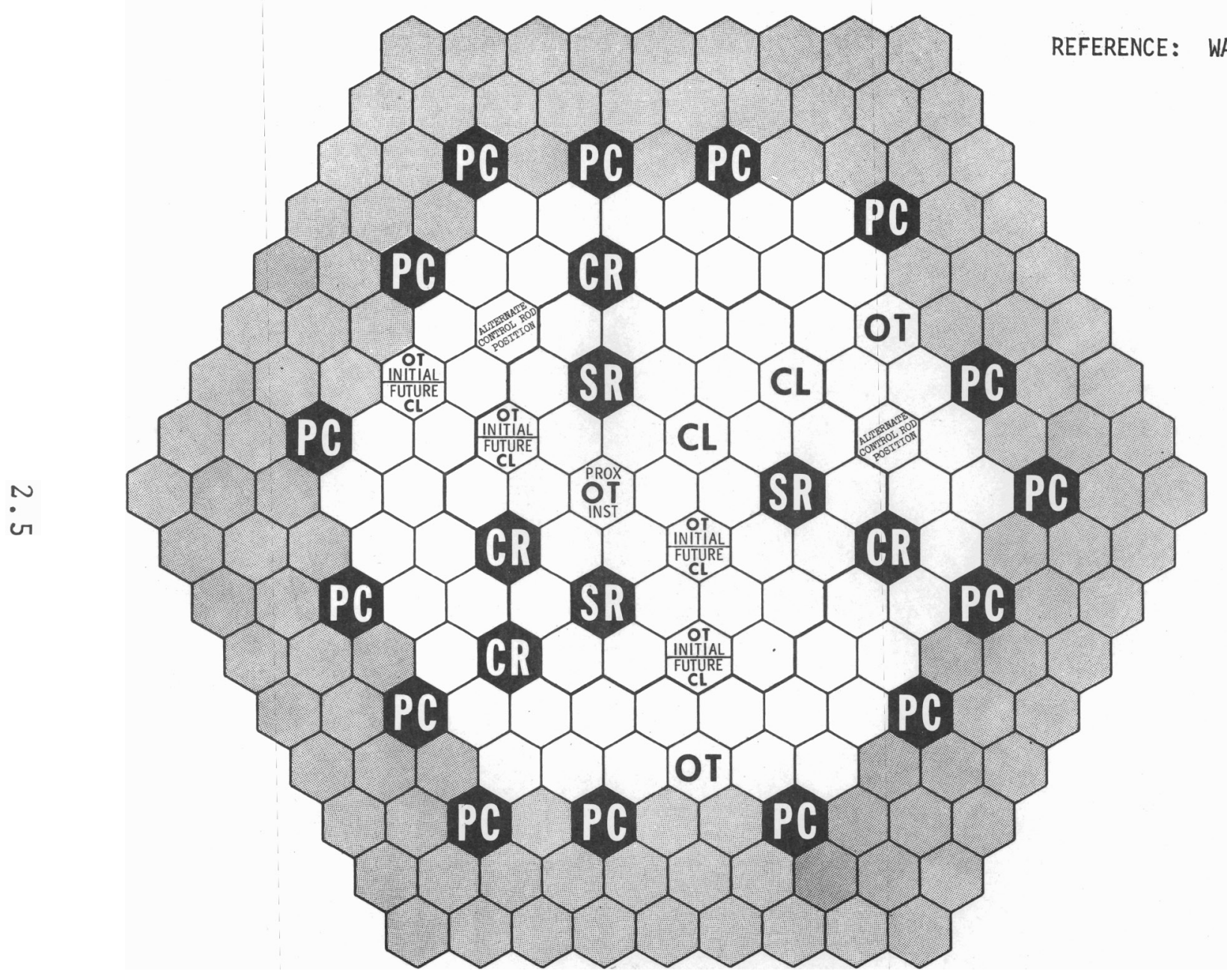

PROX OPEN TEST ASSEMBLY WITH PROXIMITY INST INSTRUMENTATION-1

OT OPEN TEST ASSEMBLIES-6 InItIALLY

CL CLOSED LOOPS-2 INItIALLY (6 FUtURE)

Si safety RODS-3

Ci. in-COre ShIm/SCRAM RODS-4

PG peripheral control rods-15

DRIVERS-27 INNER -48 OUTER

REFLECTORS-III

FIGURE 2.1. Core Map January 1970 


\section{CHAPTER II I .}

\section{A. REACTOR COMPONENIS}

1. Fuel Duct Procurement

R. N. Johnson and R. H. Todd

A contract was placed on March 11, 1970 with Atomics International for the fabrication of prototype fuel ducts.

\section{Duct Gaging System}

R. N. Johnson and R. H. Todd

A contract was placed with Shelton Metrology Laboratory on May 29, 1970, for the design and construction of a gaging system capable of measuring and characterizing the duct components and the completed duct assemblies. Delivery of the gaging system is expected in January 1971.

3. Duct Wear Pad Attachment Studies

W. F. Brown and R. N. Johnson

Tube 62 which was reported in the last quarterly report was thermal cycled 20 times between 400 and $1200^{\circ} \mathrm{F}$ in a salt bath furnace. Visual and liquid penetrant inspection revealed no defects due to thermal cycling. Ultrasonic inspection showed that all spot welds were still bonded; however, there was an indication that two of the spot welds may have less bonded area than the original inspection revealed.

4. Automatic Duct Welding System

W. F. Brown and R. N. Johnson

During the past quarter, BNW completed fabrication of the fixture for the automatic duct welding system (Figure 3.1 and 3.2). Assembly and checkout was completed and the fixture was shipped to Sciaky Brothers, Inc. on the 15 th of May for coupling to the welding power supply and automatic control equipment. 


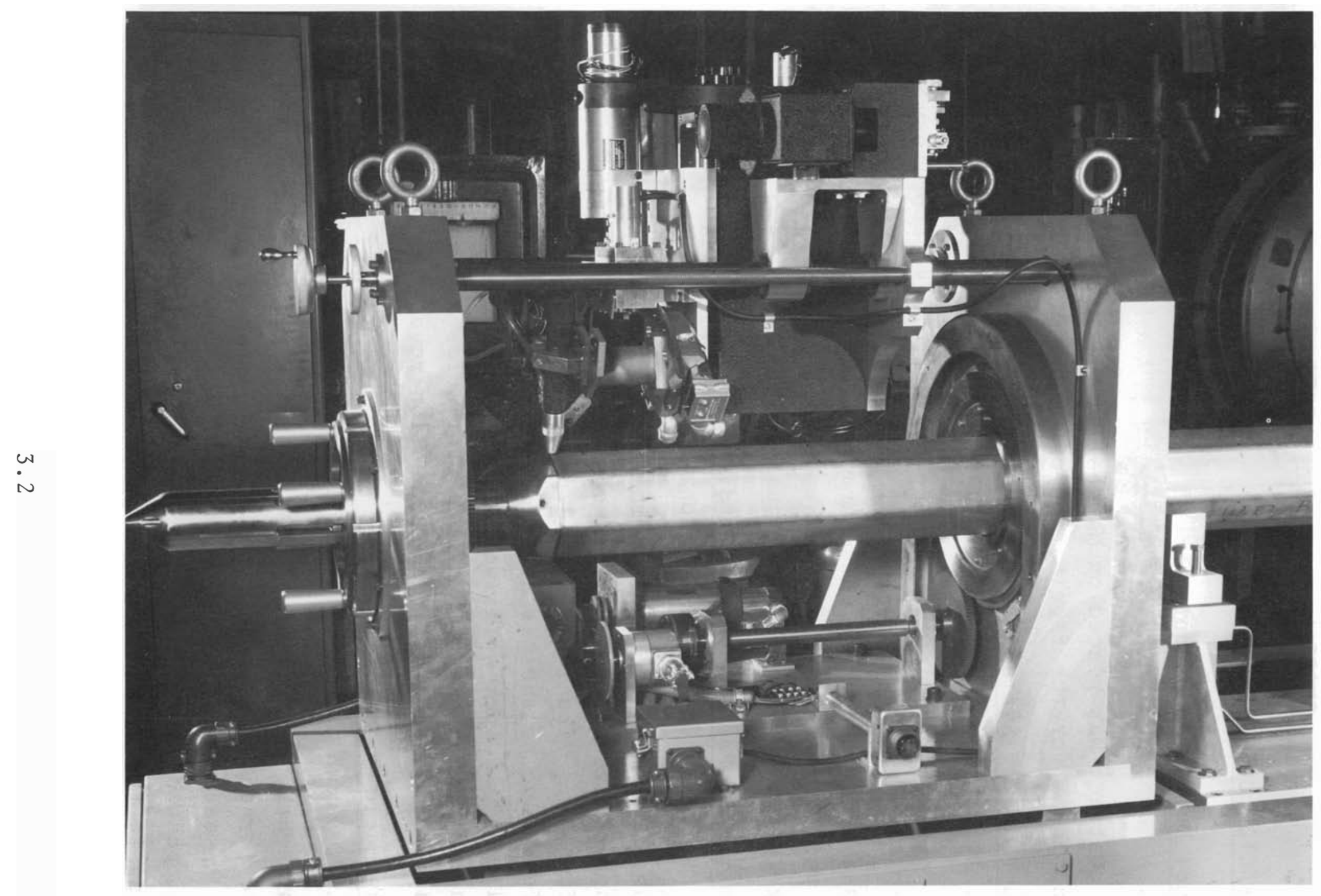

Neg 52163-1

FIGURE 3.1.

Automatic Duct Welding Fixture Showing Sample Fuel Duct in Position for Welding 


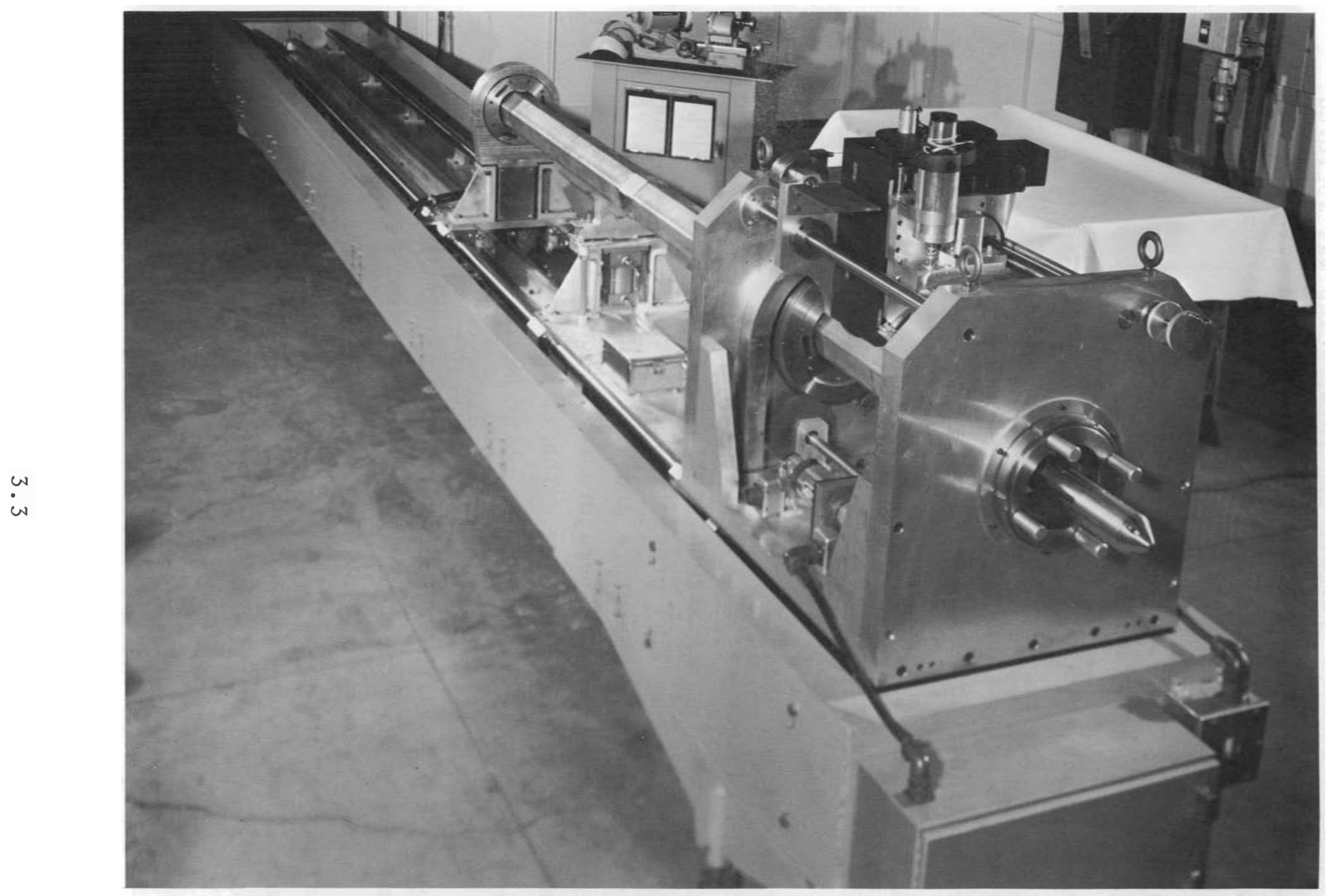

Neg 52163-4

FIGURE 3.2. Automatic Fuel Duct Welding Fixture 
The purchase request for the computer, operator pendant control, and programming software and interfacing was approved by the AEC and the purchase order has been placed with the Sciaky Brothers Company. Sciaky plans to ship the completed system about September 3, 1970.

5. Reactor Vessel

F. J. Kempf and 0. W. Priebe

Agreement was reached on the use of SA-508 Class 2 low alloy steel for the reactor vessel head. This choice was made on the basis of system performance, mechanical properties, cost, schedule, and fabricability.

B. HEAT TRANSPORT PROCESS TECHNOLOGY

1. Detailed Simulation of Piping Stored Heat

A. L. Gunby

Five model approaches were studied for simulating the effect of stored heat in steel pipe walls on thermal transients. Each model used ten axial segments with separate regions for metal and sodium. Material properties and steel-to-sodium heat transfer varied with temperature and flow. Each model was subjected to two example temperature ramps, one with constant flow, the other with ramped flow. The five models were: nodal heat balance, central difference, 2-point backward difference, 3-point backward difference, and mixed difference. (a)

Figure 3.3 shows the responses of the models to an inlet temperature ramp with constant flow. Clearly, the mixed difference case (alternating central and 3-point backward differences) produced the best approximation to the expected outlet transient. The mixed difference model was selected as the reference for evaluating simplified pipe heating models needed for the overall FFTF system simulations. Model simplifications will be investigated during the next report period.

a. For differencing descriptions, see BNWL-2367, "Intermediate Heat Exchanger Modeling for FFTF Simulation," A. L. Gunby, May, 1970. The pipe model is Zike an IHX with zero flow on one side. 


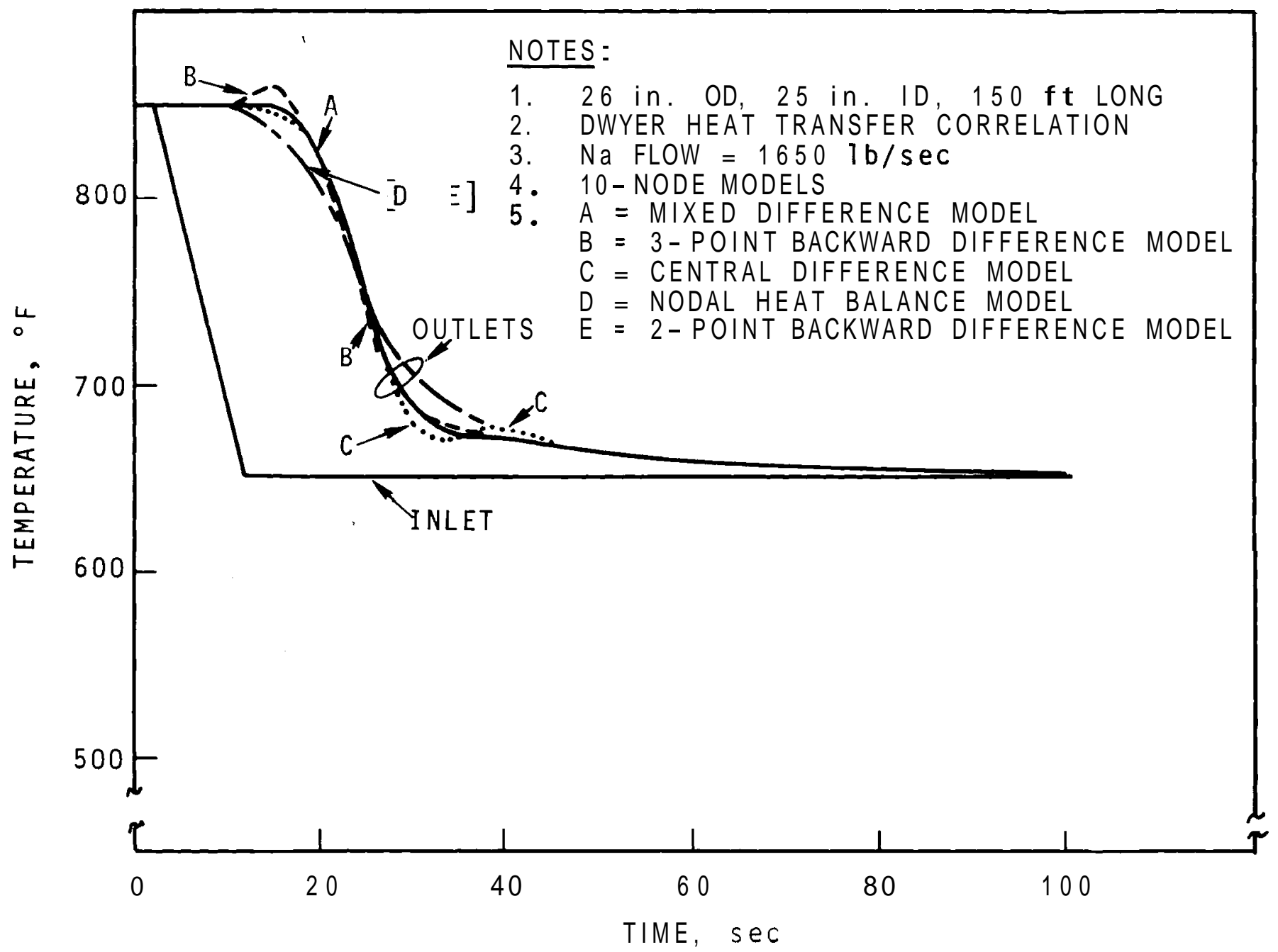

FIGURE 3.3. Piping Stored Heat Study Na Response to Inlet Temperature Ramp, Detailed Models 
2. Heat Transport System Control Study

R. A. Harvey and S. A. Hunt

The first draft of a report on the control of the FFTF Heat Transport System is essentially completed and will be distributed to the $\mathrm{AEC}$ and Westinghouse. The results of the study support the following major conclusions:

a. The control configuration that appears best for reasons of transient suppression, ease of operation, and safety has controllers that:

- Control secondary cold-leg temperature by manipulating air flow.

- Control primary cold-leg temperature by manipulating the set point of the controller (above).

- Control of the primary hot-leg temperature by manipulating the primary flow.

Other configurations that are almost as good control the reactor temperature rise and/or the reactor average temperature.

b. For low power operation, the best transient suppression is obtained when the secondary flow is maintained at the full flow value. Although the primary flow has little effect on transient suppression, full primary flow is desirable in order to maintain a desirable mean temperature difference between primary and secondary loops. Thus, we recommend that an operating mode be adopted that requires sodium flows to be brought up to their full values as soon as possible during startup.

c. The combination of desirable control configuration and the desirability of maintaining full secondary flow suggests that startup could be accomplished by maintaining full flows and allowing the reactor temperature rise to 
increase with power. The primary cold leg would be most easily handled by keeping it at a constant temperature during the startup.

3. Heat Transport System Control Cycles Study

D. P. Schively, H. C. Martin

A set of proposed design cycles were developed, consistent with the vessel procurement specifications and ASME Code, including the rationale for categorizing the cycles. The recommended cycles are shown in Table 3.1. Only the steepest portion of the cycles are tabulated. Return to the start condition is assumed at the normal rate.

TABLE 3.1. Design Cycles for Heat Transport System

\begin{tabular}{|c|c|c|c|c|c|}
\hline $\begin{array}{l}\text { Type of } \\
\text { Transient }\end{array}$ & $\begin{array}{r}\text { Affected } \\
\text { Section } \\
\end{array}$ & $\begin{array}{l}\text { Coola } \\
\text { Temp., } \\
\text { Start } \\
\end{array}$ & ${ }^{{ }^{n+} \mathrm{F}}$ & $\begin{array}{l}\text { Maximum } \\
\text { Rate, } \\
{ }^{\circ} \mathrm{F} / \mathrm{t} \\
\end{array}$ & $\begin{array}{l}\text { Minimum } \\
\text { Number } \\
\end{array}$ \\
\hline \multicolumn{6}{|l|}{ Normal Conditions } \\
\hline Startup & $\begin{array}{l}\text { Hot Leg } \\
\text { Cold Leg }\end{array}$ & $\begin{array}{l}500 \\
500\end{array}$ & $\begin{array}{r}1050 \\
750\end{array}$ & $\begin{array}{l}+50 / \mathrm{hr} \\
+50 / \mathrm{hr}\end{array}$ & 1100 \\
\hline Shutdown & $\begin{array}{l}\text { Hot Leg } \\
\text { Cold Leg }\end{array}$ & $\begin{array}{r}1050 \\
750\end{array}$ & $\begin{array}{l}500 \\
500\end{array}$ & $\begin{array}{l}-50 / \mathrm{hr} \\
-50 / \mathrm{hr}\end{array}$ & 100 \\
\hline \multicolumn{6}{|l|}{ Upset Conditions } \\
\hline Scram & $\begin{array}{l}\text { Hot Leg } \\
\text { Cold Leg }\end{array}$ & $\begin{array}{r}1050 \\
750\end{array}$ & $\begin{array}{l}900 \\
700\end{array}$ & $\begin{array}{r}-150 / \mathrm{min} \\
-16 / \mathrm{min}\end{array}$ & 1000 \\
\hline $\begin{array}{l}\text { OBE Plus } \\
\text { Upset Loads }\end{array}$ & All & & & & 100 \\
\hline \multicolumn{6}{|l|}{ Emergency Conditions } \\
\hline $\begin{array}{l}\text { Scram (with HTS in } \\
\text { at-power cooling } \\
\text { mode) }\end{array}$ & $\begin{array}{l}\text { Hot Leg } \\
\text { Cold Leg }\end{array}$ & $\begin{array}{r}1050 \\
750\end{array}$ & $\begin{array}{l}800 \\
700\end{array}$ & $\begin{array}{l}-17 / \mathrm{sec} \\
-50 / \mathrm{min}\end{array}$ & 10 \\
\hline $\begin{array}{l}\text { Scram (with } \\
\text { secondary pump } \\
\text { seizure) }\end{array}$ & $\begin{array}{l}\text { Hot Leg } \\
\text { Cold Leg }\end{array}$ & $\begin{array}{r}1050 \\
600\end{array}$ & $\begin{array}{r}1100 \\
800\end{array}$ & $\begin{array}{r}+2 / \mathrm{sec} \\
+10 / \mathrm{sec}\end{array}$ & 10 \\
\hline \multicolumn{6}{|l|}{ Faulted Conditions } \\
\hline $\begin{array}{l}\text { DBE Plus } \\
\text { Emergency Loads }\end{array}$ & All & & & & \\
\hline
\end{tabular}




\section{CHAPTER IV. INSTRUMENTATION AND CONTROLS}

\section{A. FFTF INSTRUMENTATION AND CONTROL SYSTEMS}

1. New System' Titles and Numbers

J. W. Mitchell

A new set of system titles and numbers have been adopted to conform with the project breakdown structure as it is presently defined. Table 4.1 presents the old and new titles and numbers.

\section{TABLE 4.1. Instrumentation and Control}

Systems Titles and Numbers

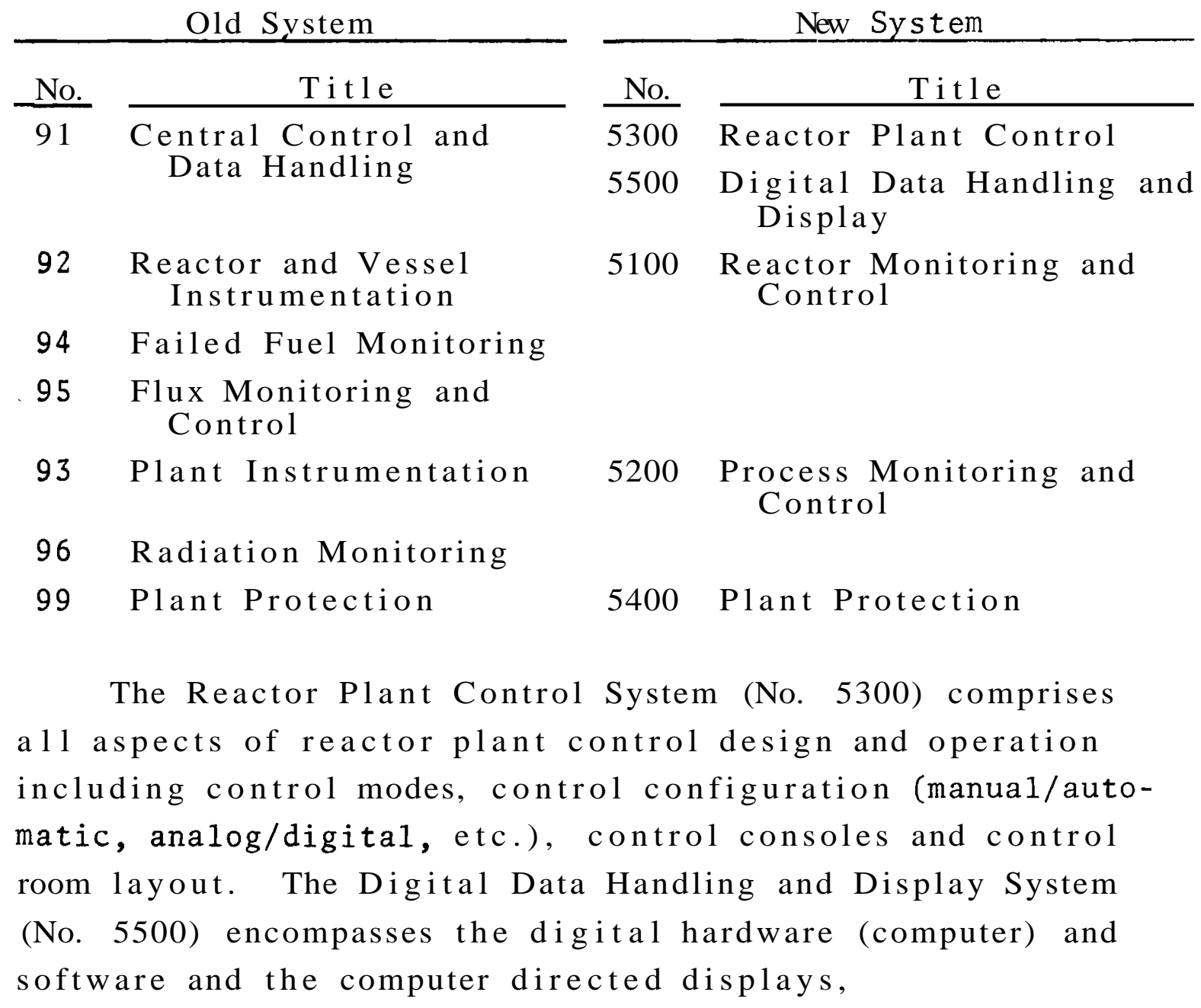


BNWL- 1394

2. In-Vessel Sodium Level Sensor

W. Dalos

An inductive-type level probe has been tentatively selected for in-vessel sodium level measurement. Probe development and testing will be performed at the LMEC. The probe tested must satisfy the following specifications:

- Reference coil is to be located below sensing coil.

- Thimble diameter is to be $1-1 / 2$ in. ID. Level probes with $2-\mathrm{ft}$ and $5-\mathrm{ft}$ ranges will be built and tested.

B. INSTRUMENTATION AND CONTROL DEVELOPMENT

1. Mixed-Mean Coolant Temperature Measurement at Subassembly Outlet

W. Dalos, D. R. Dickinson, and M. R. Wood

An array of three thermocouples are used to measure the temperature in the outlet coolant stream in each subassembly channel. To obtain accurate measurements, mixers are required to reduce the radial temperature gradient across the channel.

Test results on fuel subassembly instrumentation testing in water indicate that a 2.45-in. ID square-edge orifice mixer in a 3.75-in. ID duct will produce satisfactory mixing if the thermocouples are located at least 18 in. downstream from the orifice. The pressure drop across the orifice at rated flow (450 gal/min) is about 8 psi. Further design-test iterations are planned to optimize these measurements.

The following mixing devices were tested in a 3.75-in. ID duct with cold water at flow rates of 100 and $450 \mathrm{ga} 1 / \mathrm{min}$.

- A single 2.45-in. square-edge orifice in a plate 1/4-in. thick.

- Nineteen 9/16-in. holes equally spaced over a plate 1/4-in. thick. 
- A plate with twelve 5/8-in. slanting holes at an angle of $30^{\circ}$ to the vertical. Six holes divert liquid from near the wall to the interior; these alternate with six holes to divert flow from interior to near the wall. The device also has a straight 1-1/4 in. hole on the axis. See Figure 4.1.

Mixing was measured by injecting LiOH upstream of the mixer and taking samples at points along a diameter at positions of 6 and 18 in. downstream.

Although there was not a great difference between the three devices tested, the best mixing appeared to be produced by the one-hole orifice device. However, the pressure drop in this device was the greatest of all designs tested. In addition, mixing was considerably better with the 18 -in. mixing distances than with the 6-in. distances. No significant differences in mixing was noted between 100 and $450 \mathrm{ga} 1 / \mathrm{min}$.

\section{Fuel Failure Monitorinn}

a. Development Plans and Status

R. R. De Russeau

A program plan for the design and development of systems to detect and locate failed fuel in the FTR was completed and transmitted to RDT for approval. The plan was also sent to organizations involved in the LMFBR program, ANL, LASL, GE, $\underline{W}$, and AI for their review. In the interim, the related development programs were directed to conduct limited investigations of a number of proposed concepts for locating failed fuel. These concepts are xenon and krypton gas tagging, conductivity probe monitoring, in-vessel gas separation, fission product deposition, flowmeter monitoring, and bubble source triangulation. Whenever possible, facilities and data were borrowed from existing development programs. 
BNWL -1394

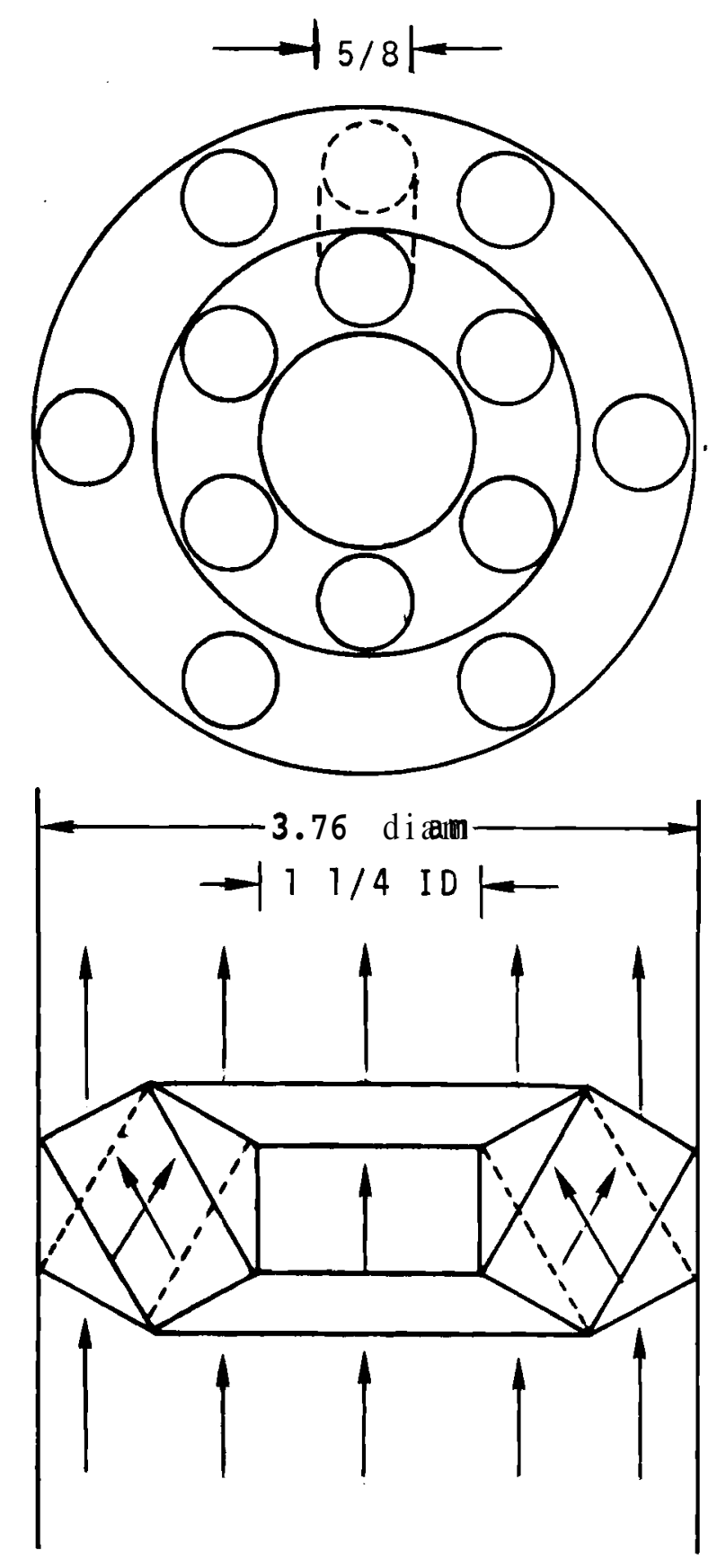

FIGURE 4.1. Mixer for FFTF Instrument Package 


\section{b. Xenon and Krypton Gas Tagging}

(1) Summary (T. J. Kabele). A number of studies were completed on the use of xenon and krypton for tagging the pins of a FTR fuel subassembly. The studies were aimed at the optimized use of available ratios of ${ }^{129} \mathrm{Xe} /{ }^{124} \mathrm{Xe}$ and ${ }^{80} \mathrm{Kr} /{ }^{78} \mathrm{Kr}$ and the reservation of a unique tag for each fuel subassembly in the core. The results of the studies indicated the 80 tags could be mixed, the tag material could be available in time for core fabrication, the cost of material was not prohibitive, and the tags should stay unique throughout the fuel lifetime. One test was conducted at EBR-II in support of both FFTF and EBR-II tagging development programs in which a volume of tag was released in the primary sodium and satisfactorily identified in the cover gas by means of a mass spectrometer.

(2) Xenon and Krypton Tag Ratios (C. A. Mansius).

Eighty unique tags have been specified by using mixtures of natural xenon and increasing volume percentages of xenon enriched in the ${ }^{124} \mathrm{Xe}$ isotope. These tags are based on the isotopic ratios of ${ }^{129} \mathrm{Xe} /{ }^{124} \mathrm{Xe}$ and vary from $220 / 1$ to $7 / 1$. They are spaced by assuming a $\mathbf{3} \%$ differential neutron burnout of ${ }^{129} \mathrm{Xe}$ and ${ }^{124} \mathrm{Xe}$. Table 4.2 iists the 80 distinct tag ratios in order of increasing ${ }^{124}$ Xe enrichments. Figure 4.2 illustrates the volume ratios of natural xenon and enriched xenon mixtures* that are necessary to provide the various tag ratios. The ${ }^{124}$ Xe percent abundance and ${ }^{129}$ Xe/ $/{ }^{124}$ Xe ratio in natural xenon are approximately $0.1 \%$ and $276 / 1$, respectively. Therefore, Mound 1, 5, and $10 \%$ concentrations represent mixtures with the ${ }^{124}$ Xe percent composition increased from $0.1 \%$ to 1,5 , and $10 \%$. Mixing specific amounts of these commercially available enriched mixtures provides the 80 ratios. The major uncertainty in specifying these ratios is the neutron burnout factor.

* As prepared by the AEC's Mound Laboratory 
BNWL -1394

TABLE 4.2. ${ }^{129} \mathrm{Xe} /{ }^{124} \mathrm{Xe}$ Isotopic Ratios for 80 Distinct Tags

$\frac{\text { Tag No. }}{1} \quad \frac{129 / 124 \text { Ratio }}{220} \quad \frac{\text { Tag No. }}{28} \quad \frac{\text { Ratio }}{96} \quad \frac{\text { Tag No. }}{55} \quad \frac{\text { Ratio }}{33}$

\begin{tabular}{|c|c|c|c|c|c|}
\hline & & & & & \\
\hline 2 & 214 & 29 & 93 & 56 & 31 \\
\hline 3 & 208 & 30 & 90 & 57 & 29 \\
\hline 4 & 202 & 31 & 87 & 58 & 28 \\
\hline 5 & 196 & 32 & 84 & 59 & 27 \\
\hline 6 & 190 & 33 & 81 & 60 & 26 \\
\hline 7 & 184 & 34 & 78 & 61 & 25 \\
\hline 8 & 179 & 35 & 75 & 62 & 24 \\
\hline 9 & 174 & 36 & 72 & 63 & 23 \\
\hline 10 & 169 & 37 & 69 & 64 & 22 \\
\hline 11 & 164 & 38 & 67 & 65 & 21 \\
\hline 12 & 159 & 39 & 65 & 66 & 20 \\
\hline 13 & 154 & 40 & 63 & 67 & 19 \\
\hline 14 & 149 & 41 & 61 & 68 & 18 \\
\hline 15 & 144 & 42 & 59 & 69 & 17 \\
\hline 16 & 140 & 43 & 57 & 70 & 16 \\
\hline 17 & 136 & 44 & 55 & 71 & 15 \\
\hline 18 & 132 & 45 & 53 & 72 & 14 \\
\hline 19 & 128 & 46 & 51 & 73 & 13 \\
\hline 20 & 124 & 47 & 49 & 74 & 12 \\
\hline 21 & 120 & 48 & 47 & 75 & 11 \\
\hline 22 & 116 & 49 & 45 & 76 & 10 \\
\hline 23 & 112 & 50 & 43 & 77 & 9 \\
\hline 24 & 108 & 51 & 41 & 78 & 8 \\
\hline 25 & 105 & 52 & 39 & 79 & 7 \\
\hline 26 & 102 & 53 & 37 & 80 & 6 \\
\hline 27 & 99 & 54 & 35 & & \\
\hline
\end{tabular}




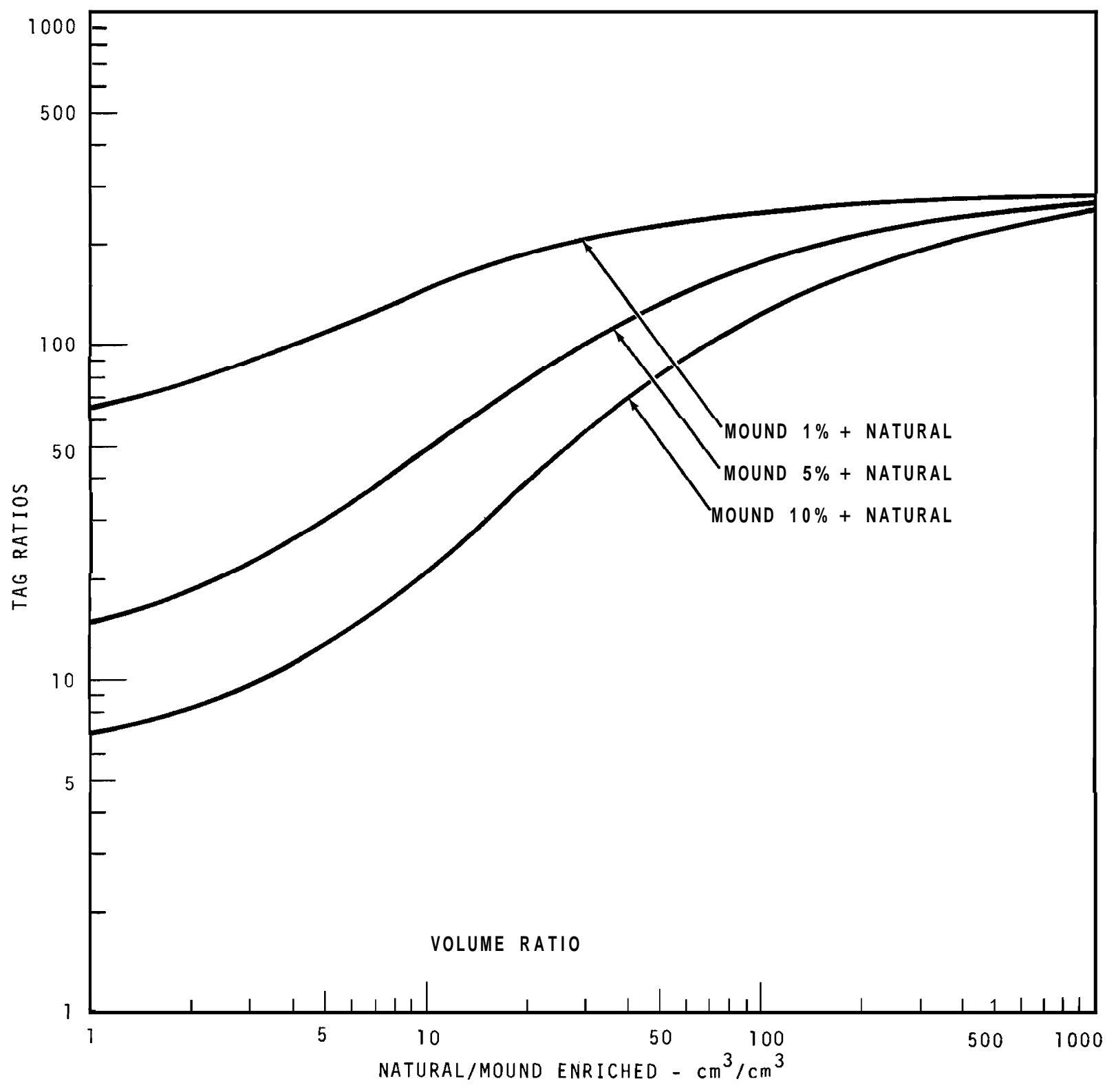

FIGURE 4.2. Mixing of Xenon Isotopes 
(3) Tag Ratio Differential Neutron Burnout (R. E. Schenter). Calculational analysis of the neutron-capture cross sections for ${ }^{78} \mathrm{Kr},{ }^{80} \mathrm{Kr},{ }^{124} \mathrm{Xe},{ }^{126} \mathrm{Xe},{ }^{128} \mathrm{Xe}$, and ${ }^{129} \mathrm{Xe}$ was performed to define the tag ratio differential neutron burnout and the tag spacing. Because of the lack of experimental cross section data in many neutron energy ranges, the calculational results were divided into most probable (top value) and maximum (bottom value) in Table 4.3 for three gas plenum regions in a fuel pin. Each region represents 12 in. of the 36-in. plenum. Averaging the burnout effect over the entire gas plenum and evaluating the effect on the ${ }^{129} \mathrm{Xe} /{ }^{124} \mathrm{Xe}$ tag ratios, it was concluded that the most probable value would cause a $1 \%$ differential neutron burnout (or change) in the ratio. The worst case, using the most probable ${ }^{124} \mathrm{Xe}$ burnout and the ${ }^{129}$ Xe maximum burnout, gives a $3 \%$ differential change in the ratio.

\section{TABLE 4.3. Calculated Tag Isotope Cross Sections}

\begin{tabular}{|c|c|c|c|}
\hline & Bottom Plenum & Middle Plenum & Top Plenum \\
\hline Isotope & $\underline{\text { Region, } a \text { barns }}$ & Region, a barns & Region, a barns \\
\hline${ }^{78} \mathrm{Kr}$ & $\begin{array}{l}0.36 \\
1.29\end{array}$ & $\begin{array}{l}0.398 \\
1.61\end{array}$ & $\begin{array}{l}0.44 \\
1.89\end{array}$ \\
\hline${ }^{80} \mathrm{Kr}$ & $\begin{array}{l}0.40 \\
1.21\end{array}$ & $\begin{array}{l}0.468 \\
1.53\end{array}$ & $\begin{array}{l}0.542 \\
1.82\end{array}$ \\
\hline${ }^{124} \mathrm{Xe}$ & $\begin{array}{l}1.62 \\
2.34\end{array}$ & $\begin{array}{l}2.20 \\
3.16\end{array}$ & $\begin{array}{l}2.82 \\
3.99\end{array}$ \\
\hline${ }^{126} \mathrm{Xe}$ & $\begin{array}{l}0.397 \\
0.952\end{array}$ & $\begin{array}{l}0.43 \\
1.15\end{array}$ & $\begin{array}{l}0.46 \\
1.32\end{array}$ \\
\hline${ }^{128} \mathrm{Xe}$ & $\begin{array}{l}0.281 \\
0.640\end{array}$ & $\begin{array}{l}0.30 \\
0.77\end{array}$ & $\begin{array}{l}0.324 \\
0.88\end{array}$ \\
\hline${ }^{129} \mathrm{Xe}$ & $\begin{array}{l}2.26 \\
3.69\end{array}$ & $\begin{array}{l}2.79 \\
4.91\end{array}$ & $\begin{array}{l}3.27 \\
6.08\end{array}$ \\
\hline
\end{tabular}

${ }^{126}$ Xe was eliminated from consideration because of the limited number of tags that could be mixed and the large difference in burnout fractions between ${ }^{124} \mathrm{Xe}$ and ${ }^{126} \mathrm{Xe}$. The production of ${ }^{128}$ Xe in the FIR from fission is too high to permit its use as a tagging isotope. 
The krypton isotopes, ${ }^{78} \mathrm{Kr}$ and ${ }^{80} \mathrm{Kr}$, have calculated cross sections that are low and similar. There appears to be no burnout problems associated with a limited use of ${ }^{80} \mathrm{Kr} /{ }^{78} \mathrm{Kr}$ tags in the FTR.

(4) Gas Volumes and Costs (T. J. Kabele). The volumes of natural and enriched krypton and xenon gases needed for tagging the first two FTR cores were calculated with four different cases considered. Case 1 used only natural and enriched xenon to mix 80 distinct tags with an isotopic ratio $\left({ }^{129} \mathrm{Xe} /{ }^{124} \mathrm{Xe}\right)$ difference of $3 \%$ to cover the change in the isotopic concentration from neutron burnout over the fuel lifetime. Case 2 used the 40 less-enriched ${ }^{124}$ Xe tag ratios (with and without natural krypton) to produce 80 distinct tags. Case 3 increased the ratio spacing to $6 \%$ and used cost considerations to determine the choice between the xenon tags and enriched krypton mixtures. Case 4 was similar to Case 3 except that the xenon tag spacing was increased to $9 \%$ to cover the uncertainty in the ${ }^{124} \mathrm{Xe}$ and ${ }^{129} \mathrm{Xe}$ neutron capture cross sections. Furthermore, it was assumed that each pin would be loaded with $1 \mathrm{~cm}^{3}$ of xenon tag and in Cases 2, 3, and 4, an additional $1 \mathrm{~cm}^{3}$ of krypton tag. Volume calculations assumed $100 \%$ wastage from loading. The volumes of noble gases needed for one core are given in Table 4.4, while the tag material costs per core are found in Table 4.5.

\section{TABLE 4.4. Gas Requirements Per Core}

\begin{tabular}{|c|c|c|c|c|}
\hline \multirow[b]{2}{*}{ Enrichments } & \multicolumn{4}{|c|}{ Volume, 1 i t e r s } \\
\hline & Case 1 & Case 2 & Case 3 & Case 4 \\
\hline Natural Xenon & 30.0 & 30.0 & 31.0 & 32.0 \\
\hline $1 \%{ }^{124}$ Xe Enriched & 2.3 & 4.6 & 3.4 & 2.6 \\
\hline $5 \%{ }^{124} \mathrm{Xe}$ Enriched & 0.077 & 0.15 & 0.11 & 0.075 \\
\hline $10 \%{ }^{124}$ Xe Enriched & 2.5 & 0.025 & 0.53 & 0.95 \\
\hline $20 \%{ }^{124}$ Xe Enriched & 0 & 0 & 0 & 0 \\
\hline Natural Krypton & 0 & 18.0 & 14.0 & 10.5 \\
\hline $1 \%{ }^{78} \mathrm{Kr}$ Enriched & 0 & 0 & 7.9 & 9.6 \\
\hline $8 \%{ }^{78} \mathrm{Kr}$ Enriched & 0 & 0 & 0 & 4.4 \\
\hline
\end{tabular}


BNWL - 1394

TABLE 4.5. Cost for 80 Unique Tags

Case 1. 80 unique xenon tags (no krypton)

Total Cost $\simeq \$ 48,000$

Case 2. First 40 xenon tags, with and without natural krypton Total Cost $\simeq \$ 9,000$

Case 3. Using every second xenon tag (a) and cost minimizing by using natural and enriched krypton

Total Cost $\simeq \$ 28,000$

Case 4. Using every third xenon tag(a) and cost minimizing by using natural and enriched krypton

Total Cost $\simeq \$ 52,000$

a. Increasing tag ratio spacing to azzow for unknowns in the neutron absorption cross sections for xenon.

c. Deleted 


\section{d. In-Vessel Gas Separation}

R. J. Cash

Fabrication and assembly of a plexiglass model of the in-vessel gas separation concept has been completed, but test results are not yet available. This concept would use the upper portion of the reactor instrumentation guide tube to separate and collect a small portion of the total fission gas and helium released from a fuel pin failure. Gas samples would be withdrawn after a fuel failure and reactor shutdown.

\section{e. Fission Product Deposition}

W. F. Brehm

Tests are being run to study the feasibility of using gettering materials as indicators of failure locations in combination with other concepts. Candidate gettering materials are $\mathrm{ZrO}_{2}$ on zirconium, $\mathrm{TiO}_{2}$ on titanium, "passivated" stainless steel, and electropolished stainless steel. These materials were loaded in capsules made from stainless steel pipe, partially filled with sodium containing 3 to $4 \mathrm{wppm}{ }^{134} \mathrm{Cs}$, and sealed. Tests are being run at 900 and $1050^{\circ} \mathrm{F}$.

f. Flowmeter Monitoring

The use of an instrument package flowmeter for monitoring abnormal amounts of gas coming through the fuel duct is being evaluated at ANL (Chicago). Preliminary tests indicate that a release equivalent to the amount of gas available in a pin near goal burnup causes approximately a $10 \%$ increase in the probe flowmeter signal. The total significance of this result is unknown due to other results not fully understood. Testing will continue.

\section{g. Triangulation \\ R. J. Cash}

The use of ultrasonic detectors on the Hydraulic Core Mockup (HCM) outlet pipes to monitor the passage of entrained 
gas has led to the investigation of triangulating the time per amplitude signals obtained from these detectors to indicate the source of the gas. Preliminary tests were promising, and further tests with an updated HCM core model are planned.

3. Low-Level Neutron Flux Instrumentation

C. N. Jackson, N. C. Hoitink, R. C. Weddle, B. E. Dozer, and D. C. Thompson

a. Objectives

In the FTR, the in-vessel reactor start-up and subcriticality instrumentation will experience severe environmental conditions of high temperatures and greater than $10^{6} \mathrm{R} / \mathrm{hr}$ gamma dose rates. This task encompasses the developmental test and evaluation of sensors, cables and other components for highsensitivity, low-level neutron counting systems capable of operation in this environment. The first objective of this task is the full establishment of a "300 ${ }^{\circ} \mathrm{F}$ System" with the detector and cable contained in the cooled thimble.

\section{b. Long-Term Tests}

Long term (1000 hr) gamma flux tests at $350^{\circ} \mathrm{F}$ on cabledetector "test assemblies" have started in the gamma facility. Figure 4.3 shows a typical detector and cable assembly wrapped with heater tape, ready to be placed in the gamma facility. Tests on one commercial fission counter revealed stable operation with no apparent loss in sensitivity at the 175th hr of the planned 1000-hr test. 


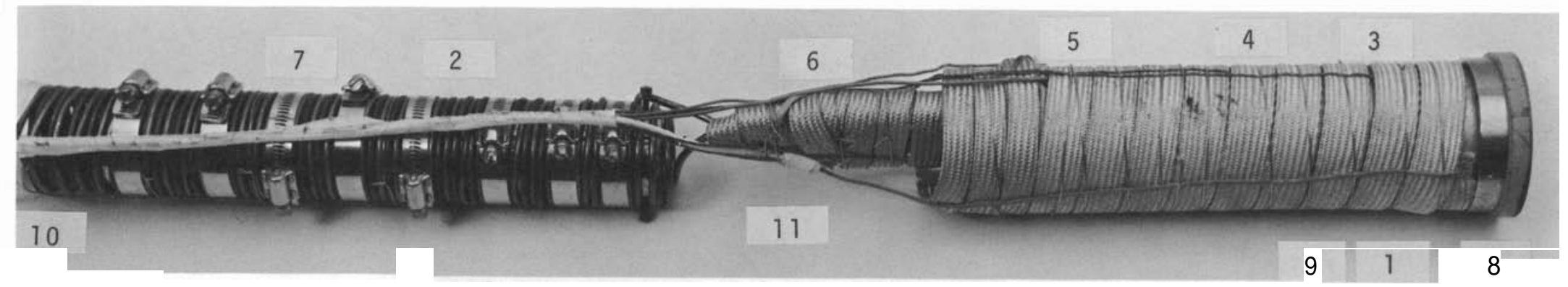

- 1. GUARDED FISSION COUNTER (ABOUT 3 - in. DIAMETER BY $14-$ in. LONG)

w 2. TWO HIGH TEMPERATURE COAXIAL CABLES (0.170-in. DIAMETER BY $25-\mathrm{ft} L E N G T H)$

3-7. CHROMEL-ALUMEL THERMOCOUPLES

8. CERAMIC BASE PLATE (3.75-in. DIAMETER BY 0.5-in. HEIGHT

9. DETECTOR HEAT TAPE (FIBER-INSULATED, RATED TO $1600^{\circ} \mathrm{F}$ )

10. CABLE HEAT MANDREL (2.0-in. DIAMETER BY $12-\mathrm{in.}$ LONG, RATED TO AT LEAST $\left.16000^{\circ} \mathrm{F}\right)$

11. CONNECTOR I NTERFACE (HN STYLE, ALUM I NA D I ELECTR I C)

Neg 700708-1

FIGURE 4.3. Typical Guarded Fission Counter and Two Cable "Test Assembly'' Prepared for Combined Gamma and Temperature Testing 
CHAPTER V. SODIUM TECHNOLOGY

See BNWL-1200-3 and BNWL-1200-4 for reports on sodium technology progress for the period ending June 30, 1970. 


\section{CHAPTER VI. CORE DESIGN}

\section{A. CORE MECHANICS}

1. Core Model

L. R. Besel, W. C. Kinsel, and G. R. Waymire

Fabrication for the basic structural core model (SCM) is complete. Figure 6.1 shows an overall top view of the completed SCM. Note the location of hydraulic actuators and yokes as well as the hydraulic module. Figure 6.2 shows a detailed view of the top of the ducts which more clearly shows attachment of the cast iron pads to the stiffness model (tubing) of the remainder of the duct as well as the detailed design of the yoke.

At the close of this report period, testing in the SCM had been confined to checking out the facility and establishing the initial operating procedures. Clamping forces to approximately 10,000 lb have been applied with no detrimental effects to the facility or alignment of the equipment.

\section{Cladding and Spacer Wire Stresses}

I. L. Metcalf and R. J. Jackson

An analysis has been conducted to determine the effect of irradiation creep, fast neutron metal swelling, and thermal expansion on the fuel cladding and wire wrap stresses. Because the clad is at higher temperatures than the wire, it experiences greater thermal expansion and swelling which is predicted to cause high wire tensile stresses.

Analysis indicates that when irradiation creep is considered, the wire stress is greatly reduced (Figure 6.3). Thus, the severity of the wire-endcap weld problem is greatly reduced by irradiation creep. 


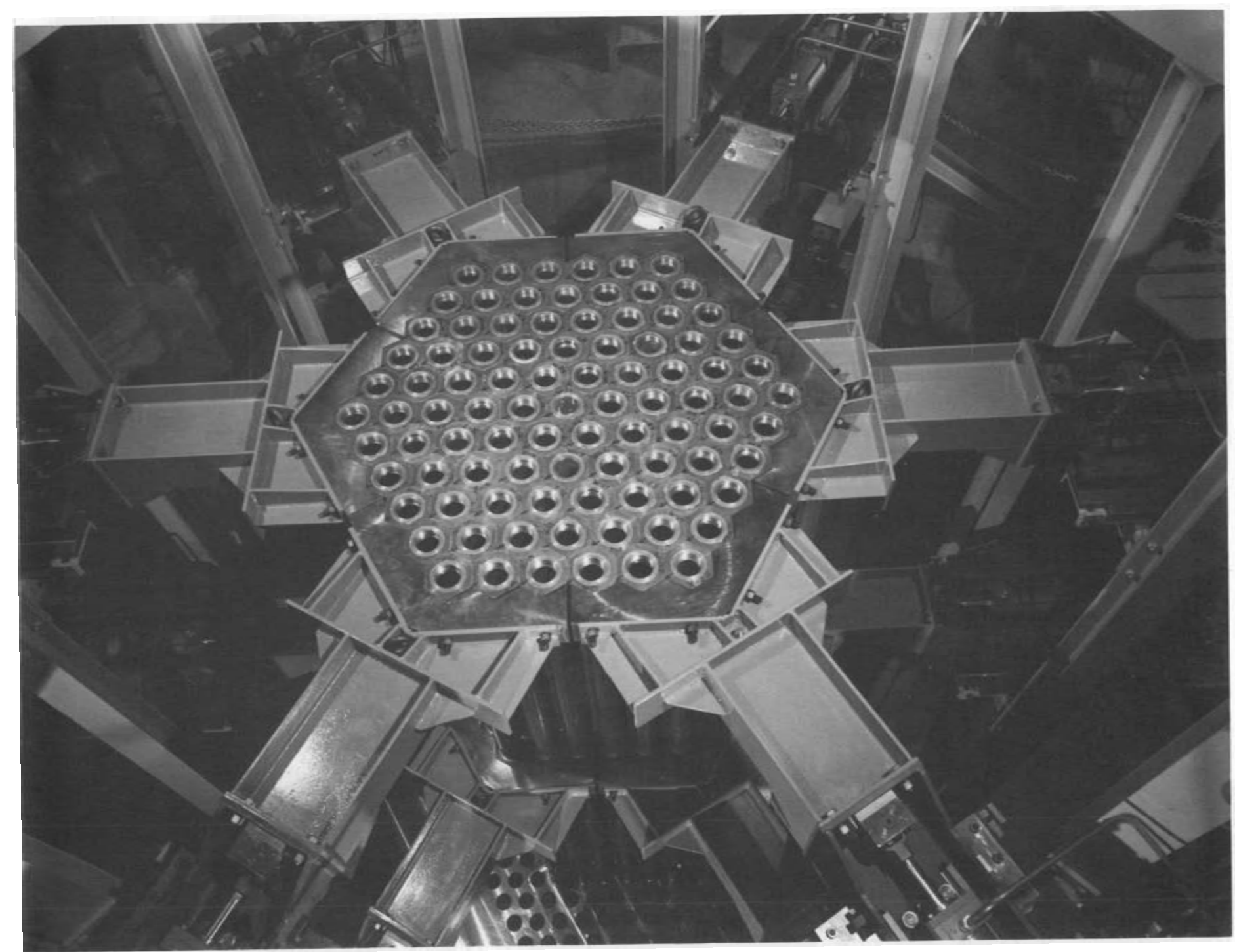

Neg 702639-2

FIGURE 6.1 View of Top of Structural Core Model 


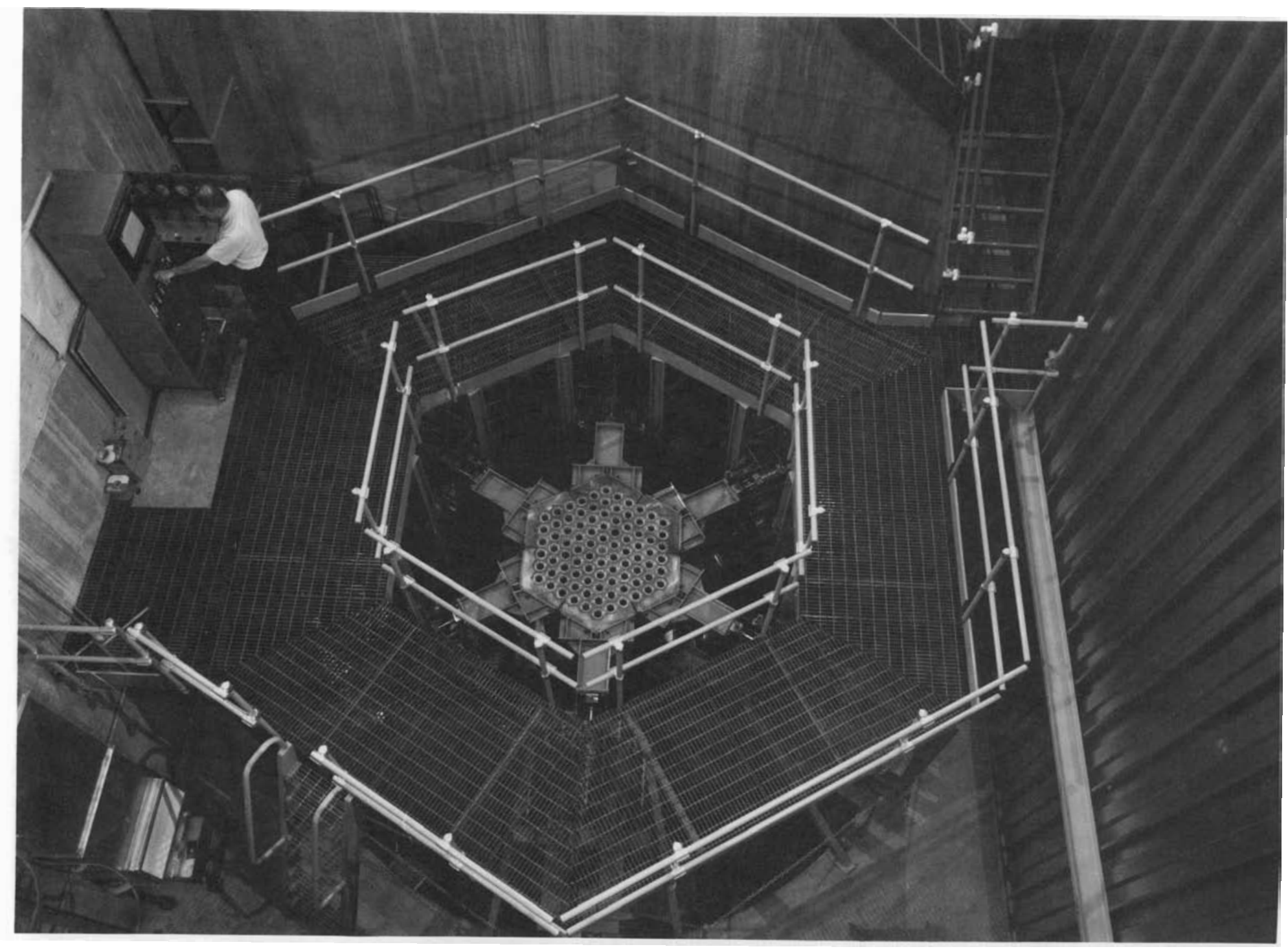

Neg 702639-10

FIGURE 6.2. Overall View of Structural Core Model 
BNWL-1394

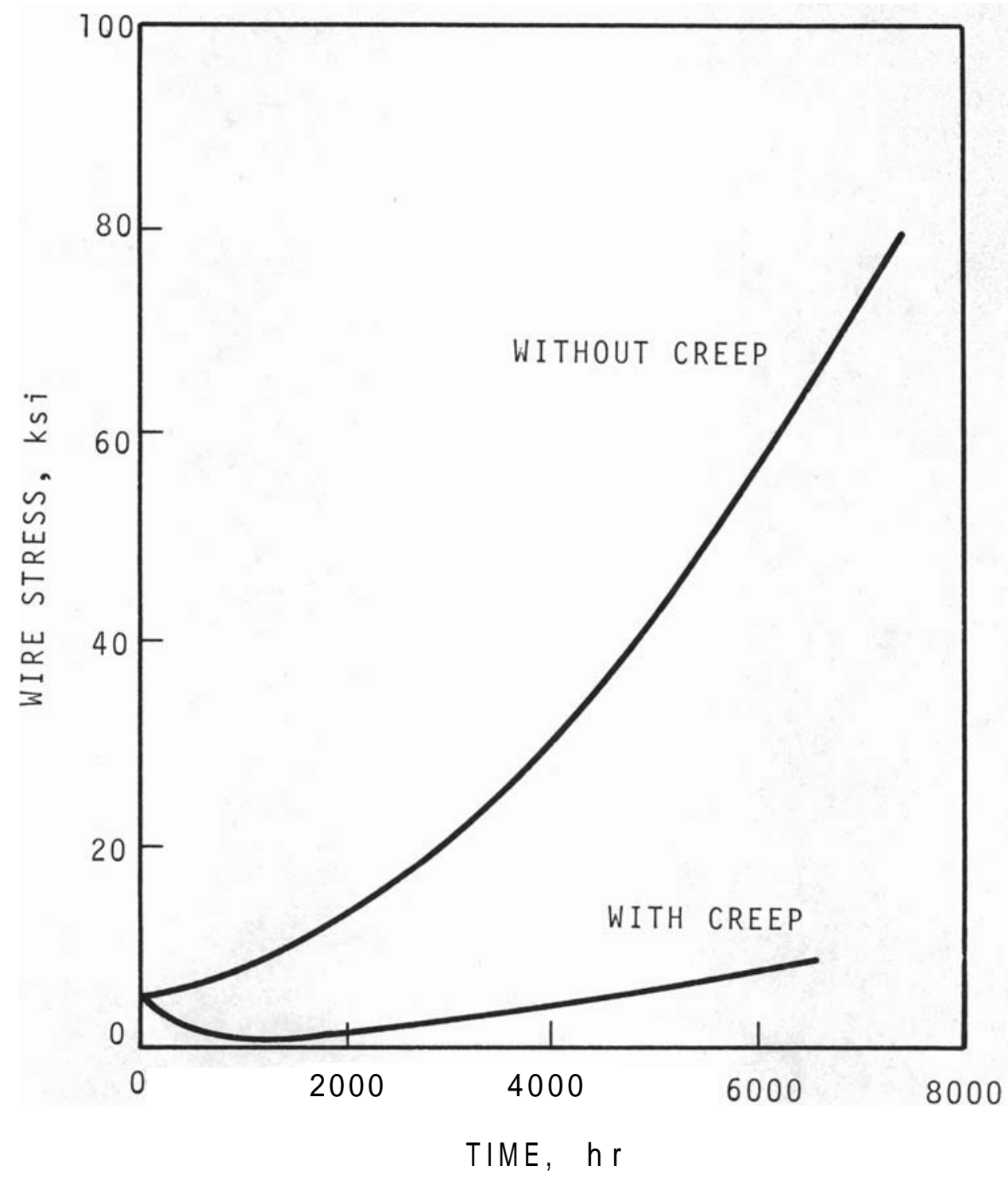

FIGURE 6.3. Wire Stress as a Function of Time, with and Without In-Reactor Creep 
B. CORE PROCESS TECHNOLOGY

1. Core Map

R. J. Hennig

BNW and WARD have agreed on a core map for the initial

FTR loading. The core and reflector consist of the following:

Core (91 Channels)

- 3 safety rods - "primary $\operatorname{rods} v-\mathrm{B}_{4} \mathrm{C}$

a 4 shim/scram rods - "secondary rods" - $B_{4} C$

a 27 inner zone drivers

a 48 outer zone drivers

- 2 fully-instrumented closed loops (6 future)

- 6 fully-instrumented open loops (2 future)

- 1 proximity instrumented open loop

Core Periphery

- 8 peripheral rods $-\mathrm{B}_{4} \mathrm{C}$

- 7 fixed peripheral shim rods - tantalum

$\underline{\text { Reflector }}$

- 111 reflector channels

2. Control Rod Worth Requirements

R. J . Hennig

A re-evaluation of control rod worth requirements produced agreements between RDT, BNW, and WARD as shown in Tables 6.1 and 6.2 . 
TABLE 6.1. Primary System Worth Requirements (a)

$\begin{gathered}\text { Nominal } \\ \text { Requirement, } \\ \% \Delta \mathrm{k} / \mathrm{k}\end{gathered}$
$\begin{gathered}\text { Estimated } \\ \text { Uncertainty } \\ \% \Delta \mathrm{k} / \mathrm{k}\end{gathered}$

Temperature and power ( $400^{\circ} \mathrm{F}$ to Operating)

$1.0 \quad \pm 0.25$

Reactivity Fault and Shutdown Margin

1.2

0.05

$-10.02$

Control Rod Burnup

0.25

Uncertainty in Requirements

2.5

Total Requirement

(Exclusive of Stuck Rod)

Uncertainty in Control

Worth Calculation

0.25

Total Calculational Requirement (Exclusive of Stuck

Rod)

2.75

a. These requirements may change as the iteration in design proceeds.

b. The uncertainties listed are those appropriate for final design. 
BNWL - 1394

\section{TABLE 6.2. Secondary System Worth Requirements (a)}

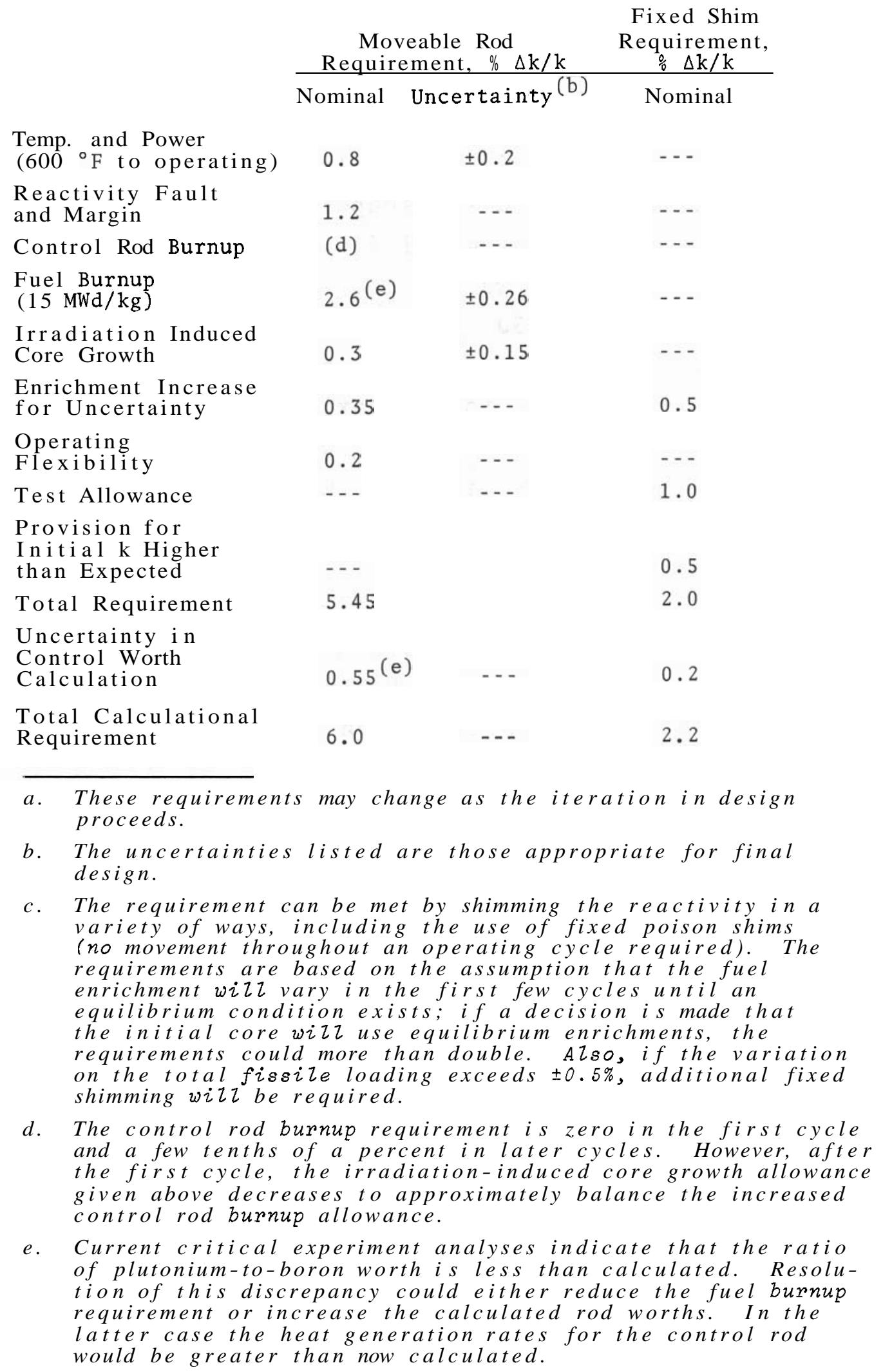




\section{CCTL Mk II Hydraulic Life Test*}

E. G. Stevens

The Mk II full scale fuel assembly, which is to be hydraulic life tested under prototypic hot flowing sodium conditions, was received at Argonne National Laboratory in early March. Alignment fit-up problems between the centering rings of the flow duct and the support webbing of the vessel were corrected by removing metal from the centering rings. In early May, the vessel was filled with sodium, and calibration flow sweeps up to $450 \mathrm{ga} / \mathrm{min}$ at $\sim 400^{\circ} \mathrm{F}$ were successfully conducted. This was followed by heat-up to $\sim 800^{\circ} \mathrm{F}$ and additional flow sweeps up to the maximum test flow of $525 \mathrm{gal} / \mathrm{min}$. Final test conditions are $525 \mathrm{ga} / \mathrm{min}$ and 1100 to $1150^{\circ} \mathrm{F}$. The $9,000 \mathrm{hr}$ life test will run continuously until the latter part of CY-71. Experimented data to be obtained include:

- Sodium coolant-stainless steel clad corrosion and erosion at 1100 to $1150{ }^{\circ} \mathrm{F} ; 525 \mathrm{gal} / \mathrm{min}(\sim 25 \mathrm{ft} / \mathrm{sec}$ through the pin bundle) with typical FTR purity limits of oxygen $<10 \mathrm{ppm}$ and total carbon $<20 \mathrm{ppm}$.

- Gross vibrational behavior of the 217 pin bundle, full-scale prototypic FTR fuel assembly.

- Pressure drop data for the overall bundle and partial increments such as the lower support grid.

- Wire-wrap mechanical behavior with a direct wire-toend cap fillet weld attachment.

Figure 6.4 shows the as-received assembly. Figure 6.5 shows the overall 14 -ft long, Mark II, test assembly and a magnified view of a typical pressure transducer (total of 4 required) which were attached to the duct by ANL just prior to insertion into the vessel. The high-temperature service pressure sensors provide the pin bundle coolant pressure drop data. Figure 6.6 shows the final machined surface of the lower support ring which was reworked to alleviate the

* Also see Item VIII.D.I this report 
BNWL - 1394

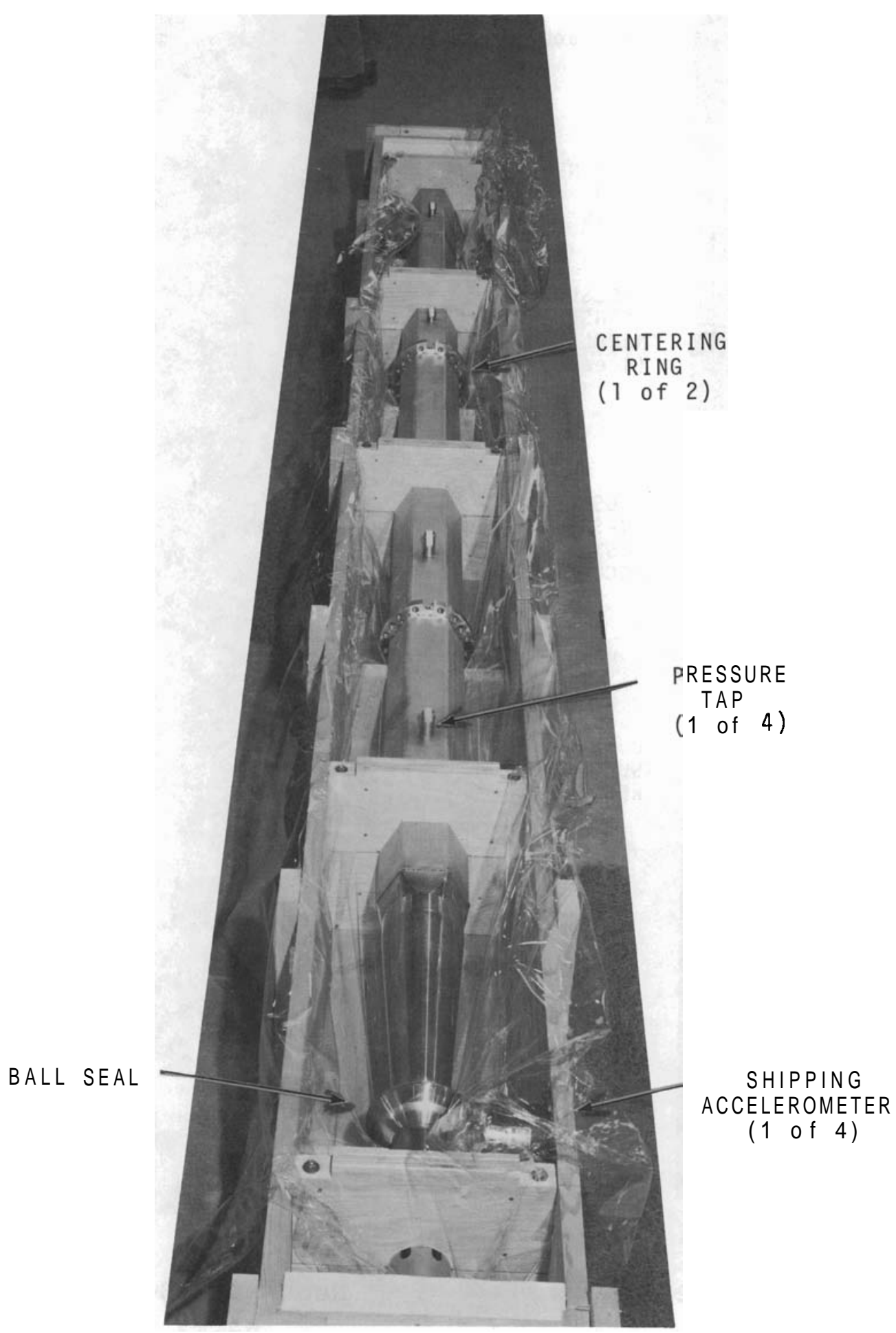

Neg 113-3298

FIGURE 6.4. CCTL MK II as Received a t Argonne

National Laboratory, March 2, 1970 


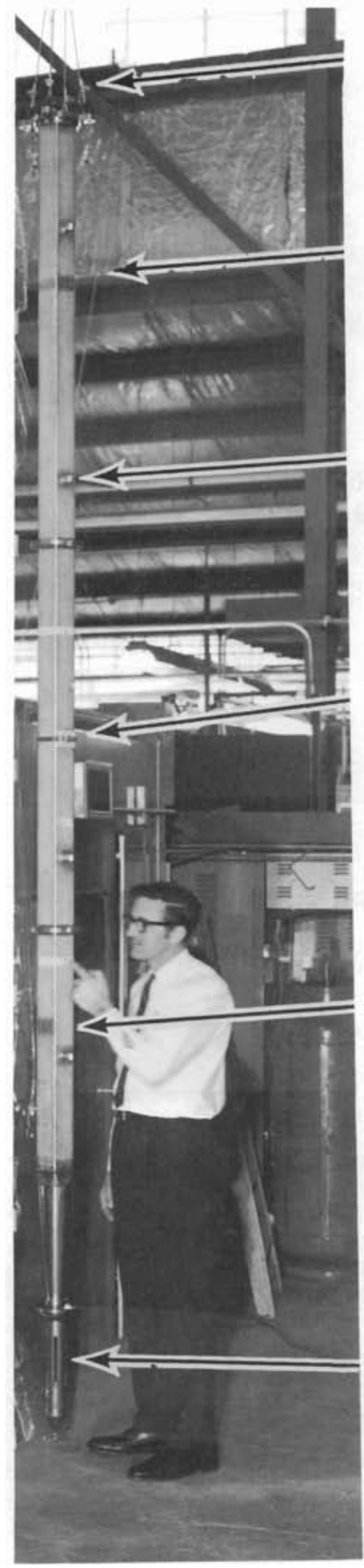

LIFTING

EYES

( 4 each)

UPPER

RETAINER

GRID

WELDS

PRESSURE

TRANSDUCER

NIPPLE

( 4 each)

LUGS FOR

IN - SODIUM

TEST

ACCELERAMETER

BUNDLE

SUPPORT

WELDS

BALL SEAL

AND

NOSEPIECE

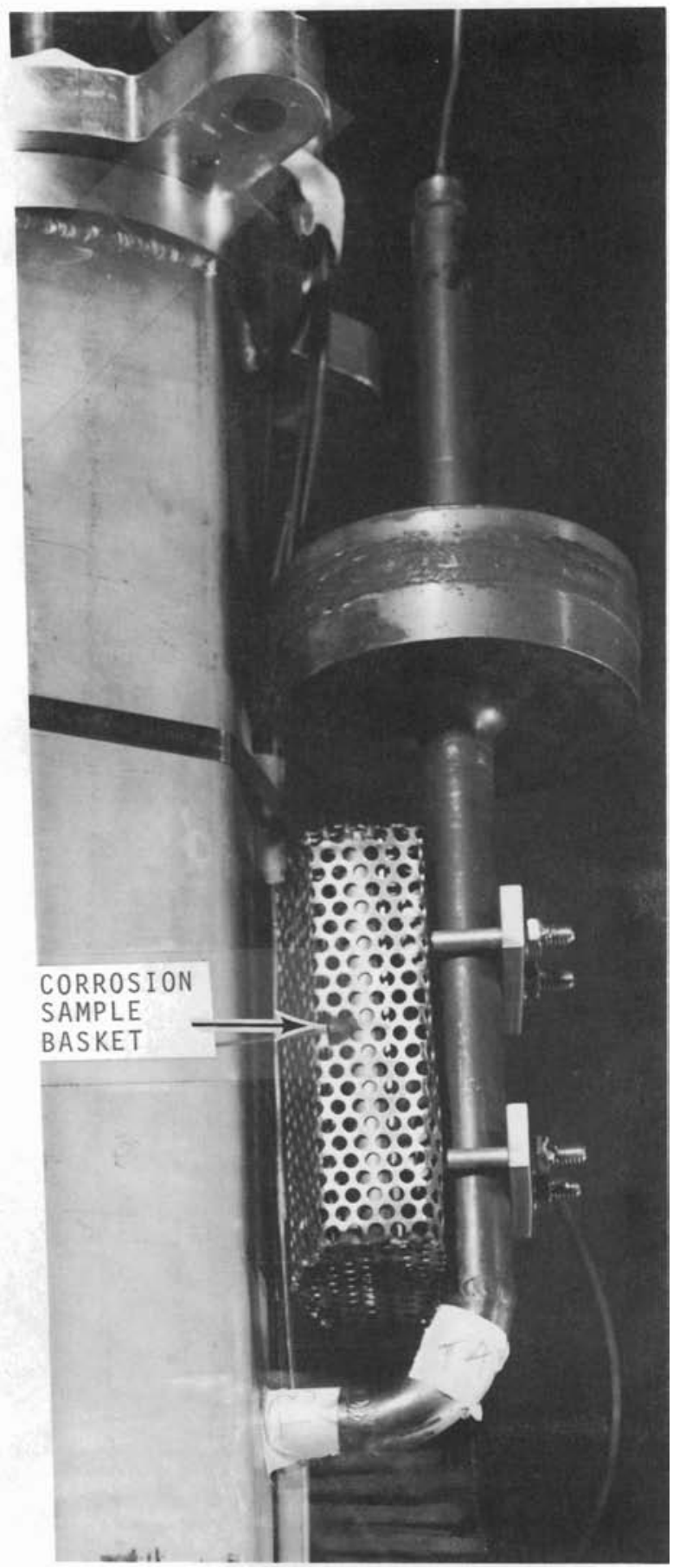

Neg ANL 113-3295

Neg ANL 113-3340

Overall Test Assembly

Pressure Transducer

FIGURE: 6.5. Mark II Test Assembly and Magnified View of Pressure Transducer 
BNWL - 1394

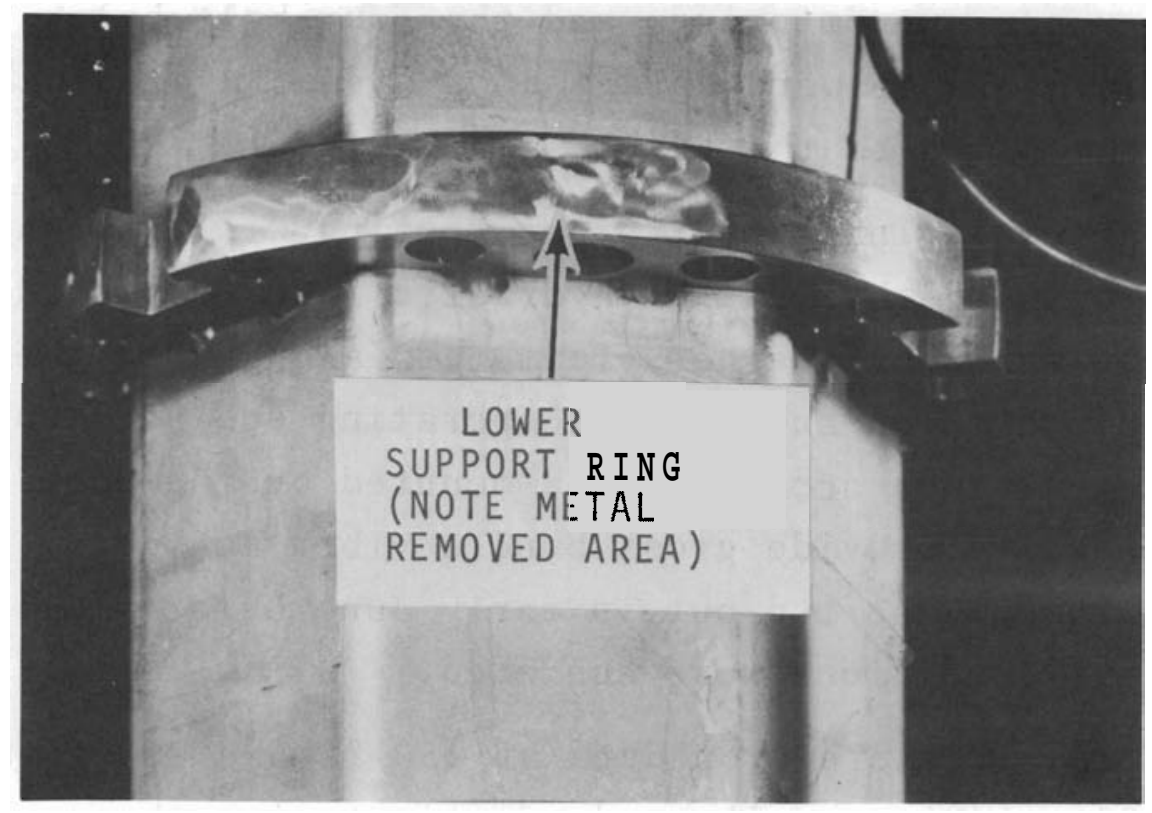

Neg ANI 113-3344

FIGURE 6.6. Magnified View of Final Machined Surface of Lower Support Ring 
assembly-to-vessel fitup alignment problem. A crescent-shaped area, approximately 60 mils wide at the thickest part, was removed from one side of the ring. Metal was also removed from the upper support ring, and the four bolt holes in the top holddown flange were enlarged to effect a good ball-seat seal at the inlet to the test assembly.

Subassembly instrument probe testing will be conducted in conjunction with the Mark II hydraulic life test. Eddycurrent or permanent magnet flowmeters along with thermocouples will supply data on subassembly operating coolant conditions. A high temperature accelerometer mounted on the duct exterior was intended to provide gross bundle vibration data. However, this instrument shorted out in early June before full flow and temperature conditions were achieved.

Initial pressure drop data at $450^{\circ} \mathrm{F}$ and $800^{\circ} \mathrm{F}$ at flows up to $\sim 520 \mathrm{gal} / \mathrm{min}$ are in good agreement with those predicted.

4. Subassembly Hydraulic Testing

R. A. Hildner and T. C. Reihman

The object of the experimental hydraulics program is to evaluate the performance of FTR driver fuel subassemblies in terms of pressure drop-flow behavior, local flow distribution, and coolant mixing. The planned experimental program is divided into three subtasks:

- Pressure drop, local flow distribution, and fluid mixing studies in water for normal and deformed sevenpin hexagonal fuel assemblies. These studies will provide the hydraulic input required for an analytical model of the heated seven-pin fuel assemblies studied under Task TH-A. The effects of bundle-to-flow duct clearance, fuel bundle dispersion, and bowed pins will be investigated.

- Pressure drop, local flow distribution, and fluid mixing studies in water on normal and deformed 37-pin hexagonal 
fuel assemblies. These studies will provide the hydraulic input for the analytical model to extend the results of the heated seven-pin studies to full size 217-pin FFTF fuel subassemblies.

- Pressure drop study in water on mechanically prototypic 217-pin fuel subassembly. This study will provide the experimental verification of the hydraulic behavior of full size fuel subassemblies over the entire rangeof operating conditions.

Assembly of the first seven-pin test section is in progress. All components are on hand and the wire wrapping of the instrumented pins has been completed.

\section{IRRADIATION TESTING}

1. Closed Loop Top Closure Development Program

The objectives of this task are to (a) demonstrate the feasibility of employing remote controlled, mechanicallydriven, tungsten arc welding as a means of making a final seal closure between the closed loop nozzle plug and reactor top face spool piece, and (b) demonstrate reliable remotecontrolled, mechanical cutting methods of the separation of the welded joint to facilitate repeated removal and replacement of the closed-loop test assemblies.

A remote-controlled, mechanically driven, tungstenarc welder has been constructed to demonstrate remote welding capabilities.

Remote welding tests are being performed in an environmental test chamber by using 316 SS work samples to gather statistical data for design optimizations and to evaluate weld repeatability.

Two simulated, closed-loop test specimens were welded during this report period. Both welds were performed by 
using identical test parameters of weld current/time and test temperature. Weld bead appearance is very good. Base material and the weld-filler ring of one test specinen are Type 304 SS, while the spool and nozzle plug of the other are Type 316 SS, with a Type 304 SS weld-insert-filler ring. Both test specimens survived a gas-pressure test at 6000 psig and a temperature of $1000^{\circ} \mathrm{F}$.

A cutter support ring incorporating hard chrome bearings has undergone limited testing in a cutter test stand. Remote cutting was performed on both cold heated stainless steel work samples. The only apparent difference between hot$\left(450^{\circ} \mathrm{F}\right)$ and cold-cutting is the dimensional size of the groove as a result of thermal expansion.

\section{Closed Loop System Desien}

Atomics International (AI) under the technical direction of Westinghouse, completed the conceptual design of the reference $2 \mathrm{MW}$ piped system using electromagnetic pumps. This concept has been recommended as a result of their earlier studies. The development effort recommended by AI includes work on sodium level detectors and on NaK-filled differential pressure cells. In addition to these, a verification test was recommended for the entire closed loop system under anticipated heat loads and at operating temperatures and pressures.

AI compared electromagnetic and centrifugal pumps using many different criteria such as operating history, coolant boundary integrity, safety provisions for the system, moving parts, maintainability and others.

The recommendation was made to use EM pumps for the closed loop application primarily because:

- There are no moving parts.

- They provide a hermetically sealed coolant boundary. 
- Their gas-cooled throats provide an emergency cooling mechanism.

- Their integral location in-cell does not cause any physical disruption above the cell floor for shaft and drive motor.

AI also evaluated the possibility of providing the IHX and the cold trap with removable internals to enhance maintenance. The studies revealed that although a removable tubesheet IHX was entirely feasible, it would complicate the design and increase cost without adding substantially to maintainability. For the cold trap, it was determined that removable internals pose serious feasibility questions and would require a separate shielded handling cask for removal.

\section{FFTF Closed Loop Test Characteristics}

R. E. Keyes

Test characteristics were explored over a range of test assembly sizes from 1.8 to 3.0 in. maximum diameter.

Figure 6.7 illustrates the relations between test dimensions and power for 19-pin and 37-pin bundles of various pin diameters.

Further details are given in BNWL-1251, "FFTF Closed Loop Test Characteristics," R. E. Keyes, June 1970.

4. Open Test Assembly

G. R. Waymire and A. C. Richards

In support of a first issue of an experimenters manual for the FTR, an open test conceptual design was completed using latest design data available. The lance for contact instrumentation incorporates a shear-type remote disconnect which allows initial contact instrumentation in combination with an assembly which can be handled using the IVHM. Figure 6.8 shows the layout drawing. 


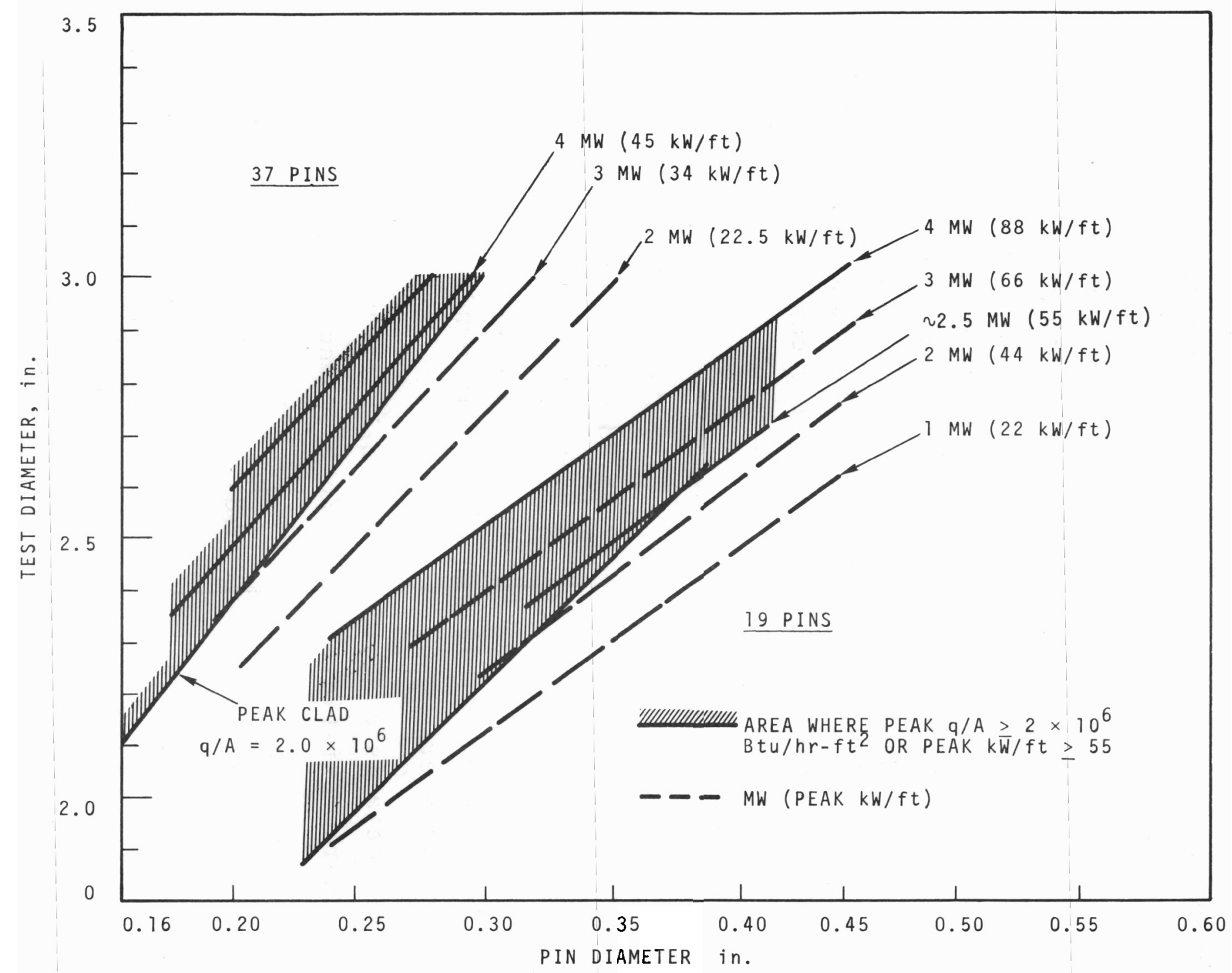

FIGURE 6.7. Closed Loop Test Bundle Capability 

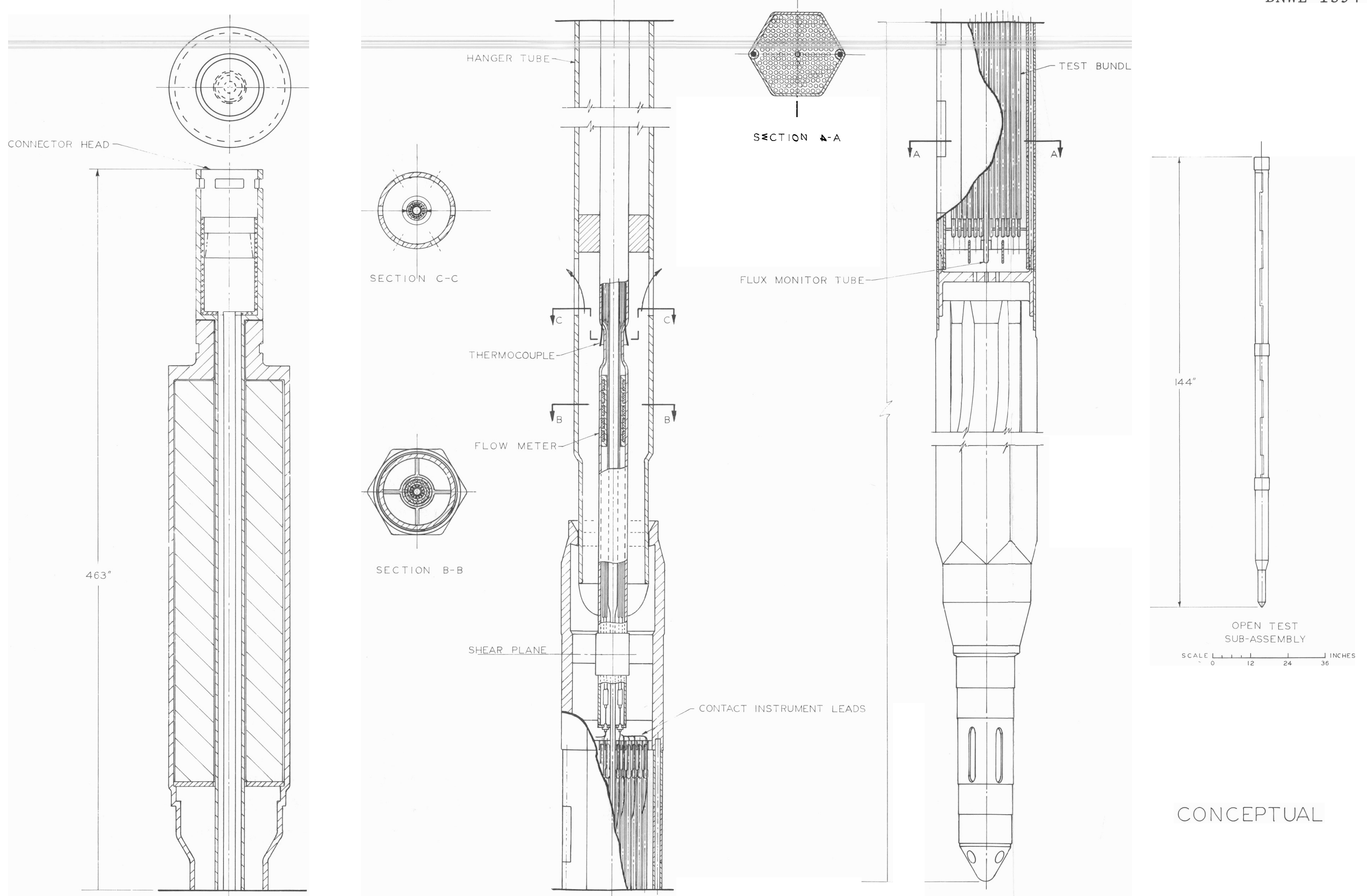

CONCEPTUAL 


\section{OTHER CORE DESIGN}

1. Examination Specimen Decay Heat Removal Development

D. R. Dickenson, T. C. Reihman and C. L. Boyd

The purpose of this task is to provide experimental data to define the requirements for gas cooling of discharged FFTF fuel assemblies during examination and disassembly. The object of the current tests is to determine what axial and transverse flow rates are needed at each state of the transition from axial to transverse flow during removal of the flow duct. In the current tests, both the axial and transverse flow is in suction. These tests are made in air using an electrically heated 169-pin bundle. The pins have a 37-in. heated length, 0.250-in. diameter, and are wire wrapped to give a 0.030 -in. spacing. The bundle is enclosed by a tight-fitting hexagonal flow duct.

Tests were completed with axial flow only, and the results were expressed as a dimensionless cooling efficiency,

$$
E=\frac{P}{\rho C_{p} F\left(T_{\max }-T_{\text {in }}\right)}
$$

where $P=$ power input

$$
\begin{aligned}
& =\text { density of gas } \\
\mathrm{C}_{\mathrm{P}} & =\text { heat capacity of gas } \\
\mathrm{F} & =\text { volumetric flow rate of gas } \\
\mathrm{T}_{\max } & =\text { maximum fuel pin temperature } \\
\mathrm{T}_{\text {in }} & =\text { inlet gas temperature. }
\end{aligned}
$$

Values of the cooling efficiency, E, were measured to be 0.75 , 0.78 , and 0.85 for powers of 8,16 , and $24 \mathrm{~kW}$, respectively; $\mathrm{T}_{\max }$ was in the neighborhood of $600^{\circ} \mathrm{F}$. Expressed in the above form, the data should apply to both air and argon. The power inputs in air of 8,16 , and $24 \mathrm{~kW}$ correspond (in terms of equal Reynolds numbers) to 5,10 , and $15 \mathrm{~kW}$ in argon. 
The maximum pin temperatures were found about $1 / 2$ in. from the downstream end of the heated length and near the center of the bundle. The outer rows of pins had a much lower temperature because of greater air flow around the edges.

The test facility is currently being modified to run tests with transverse flow only. The data with axial and transverse flow alone are required for comparison of data with mixed flow which will be obtained next. 


\section{CHAPTER VII. FUELS AND MATERIAIS}

\section{A. FUELS AND MATERIALS EVALUATION}

\section{EBR-II Structural Materials Irradiations}

The objective of the EBR-II Irradiations Program is to provide coordination and direction for the timely accomplish ment of fast reactor irradiations on structural materials.

Structural materials irradiation experiments are in various stages of design, construction, and irradiation in EBR-II. Manufacture of specimens and subcapsules from 45 different AISI 316 SS compositions for the metallurgical variables subassembly is nearing completion.

On March 26, 1970 BNW Pin No..B-39 was placed in Subassembly X077 and charged in position $8 \mathrm{C} 4$ of the reactor grid. The goal fluence for the subassembly is $5 \times 10^{21} \mathrm{n} / \mathrm{cm}^{2}$ $(\operatorname{tota} 1)$.

Subassembly X021B was discharged from EBR-II on March 1, 1970 for a scheduled pin interchange. Pin BNW-24 was discharged with the intent of replacing it with BNW-25. However, the original pins had swollen so much that it was impossible to reconstitute the subassembly.

Discussions with EBR-II and RDT personnel resulted in a decision to supply EBR-II with four undersized diameter pins $(0.790$ in. in diameter) in order to reconstitute the subassembly. The four pins discharged were 7-2, 7-3, 7-6, and 7-24. These were replaced by 7-25, 7-54, 7-55, and 7-56. The subassembly was reassembled and placed in the reactor for the beginning of Run 42. The purpose and objective of the replacement pins is to determine the effects of fast neutron irradiation on the mechanical properties of both biaxial and uniaxial Type 316 SS specimens having various amounts of cold work. The projected temperature and fluences 
to be obtained during this irradiation are of considerable interest to FFTF and cover the range of variables where no other irradiation in progress or completed will provide adequate informati'on. The goal exposure for the replacement pins will be the remainder of resident time in the reactor for Subassembly X021C (approximately $1 \times 10^{22} \mathrm{n} / \mathrm{cm}^{2}$ ).

Arrangements have been made with Idaho Nuclear to disassemble the discharged experiments in the PNL Facility. During disassembly, a careful examination of the pins and subcapsules will be made to determine the diameter change due to the swelling. This will provide information needed to calculate the operating temperature of the subcapsules.

The purpose and objective of the original experiment (X021) was to determine the effects of fast reactor irradiation on uniaxial tensile, creep, creep-rupture and biaxial stress rupture properties of fast reactor cladding and structural materials.

Materials included in subassembly X021 were mainly 304 and $316 \mathrm{SS}$. The discharged pins contained primarily 304 SS. An exposure of $1 \times 10^{23} \mathrm{n} / \mathrm{cm}^{2}$ was originally planned for a 11 pins. The discharged pins received an exposure of $\mathbf{7 . 3} \times 10^{22} \mathrm{n} / \mathrm{cm}^{2}$.

An updated summary of current irradiation in EBR-II and experiments discharged from EBR-II is given in Table 7.1.

2. EBR-II Subassembly Irradiations

L. A. Pember and E. O. Ballard

\section{a. Subassembly PNL-3, PNL-4, and PNL-5}

These 37-pin experimental subassemblies which contain Type 304 SS cladding, 0.250-in. diameter, mixed-oxide fuel pins continued without incident toward their goal exposures. 
BNWL - 1394

TABLE 7.1. Summary of Experiments Discharged from EBR-II

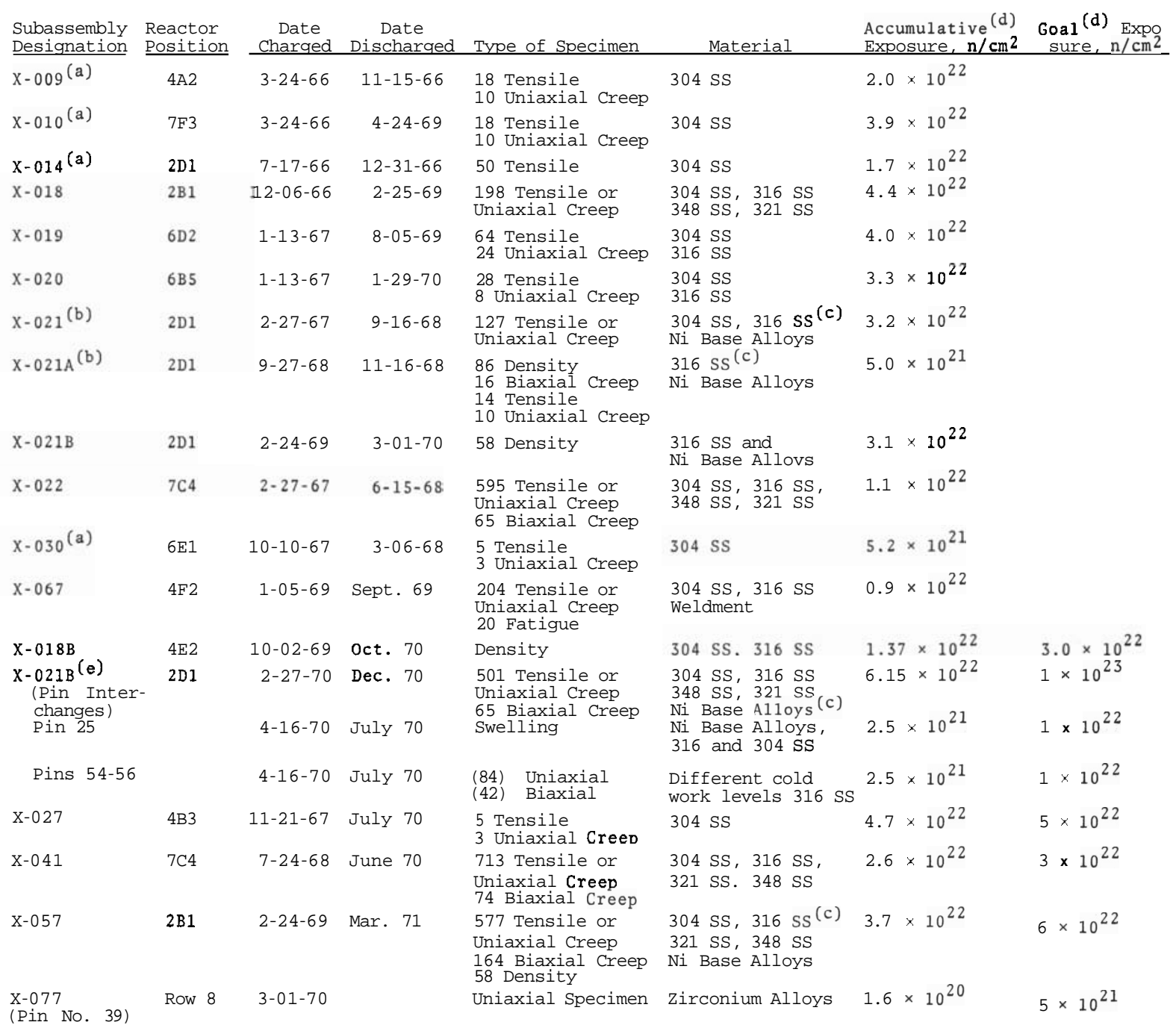

a, Mark A pins irradiated on space avaizable basis, alZ other pins are B-? type.

c. Variety of other azloys also included.

e. Original $\mathrm{X}-021$ subassembly with three pin interchanges. Pins $25,54,55$ and 56 are in now. 
Estimated peak burnups at the end of Run 42 (May 18, 1970) are:

$\begin{array}{lc}\text { Subas sembly } & \begin{array}{c}\text { Burnup, } \\ \text { Mwd/tonneM }\end{array} \\ \text { PNL-3 (X051) } & 21,200 \\ \text { PNL-4 (X059) } & 31,100 \\ \text { PNL-5 (X054) } & 50,300\end{array}$

Subassembly PNL-5 was discharged to the EBR-II in-vessel basket at the end of Run 42. This subassembly will be held in the basket pending availability at the EBR-II Mark E-19 subassembly hardware. The fuel pins will then be subjected to an interim exam, and selected pins will be reconstituted into a lead exposure test in the Mark E-19 subassembly.

\section{b. Subassembly PNL-6, PNL-7, and PNL-8}

These 37-pin experimental subassemblies which contain annealed Type 316 SS cladding, 0.250-in. diameter, mixedoxide fuel pins continue toward their goal exposures. Estimated peak burnup at the end of Run 42 (May 18, 1970) are:

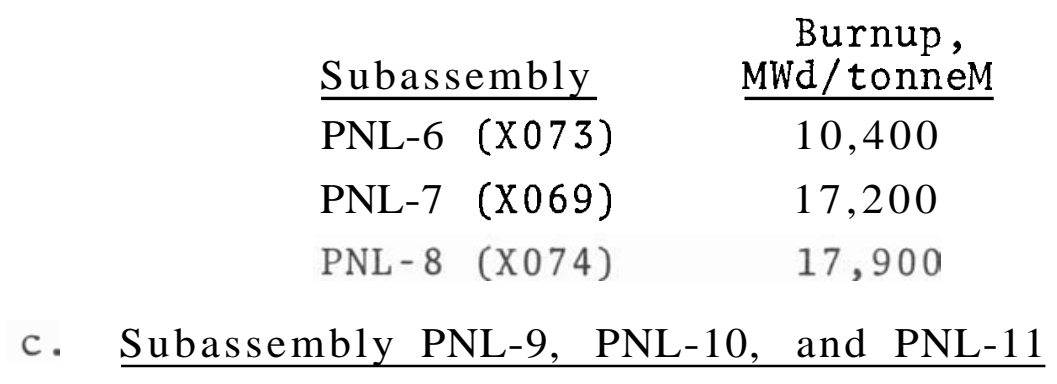

Subassembly PNL-9 (X087) was charged into EBR-II position 5B4 on May 24, 1970. This subassembly contains 61 mixed oxide fuel pins clad in Type 316 SS, 20\% cold worked. The cladding is 0.230-in. OD by 0.015-in. thick. Fuel-to-cladding gap is nominally 0.006 -in. and the resulting nominal smeared density is $85.5 \%$ TD. The power generation of the peak pin will be $5.8 \mathrm{~kW} / \mathrm{ft}$. 
Revision of the PNL-9, PNL-10, and PNL-11 data package is proceeding for EBR-II reactor power levels 50 and $62.5 \mathrm{MW}$ with a depleted uranium blanket.

\section{Irradiation of Hypostoichiometric $\mathrm{UO}_{2}=\mathrm{PuO}_{2}$}

J. W. Weber

This task includes irradiation testing of mixed oxide fuel specimens of different stoichiometries to high burnups in a thermal flux. Substoichiometric mixed oxides are expected to exhibit better fuel-cladding-sodium compatibility at high burnups than nearly stoichiometric oxides currently specified for the FTR. System compatibility, swelling, and gas release characteristics of $\mathrm{UO}_{2}-\mathrm{PuO}_{2}$ fuel as a function of stoichiometry and fuel form must be determined at high burnup before a maximum performance fuel can be designed.

a. Postirradiation Examination of Fuel Pins

The status of the BNW-1 series of capsules is summarized in Table 7.2.

Sample D from fuel pin BNW 1-2 showed a two-phase melted region in the central void. One of the phases extends from the central void along several radial macrocracks into the columnar grains. Preliminary electron microprobe examinations on the two-phase region shows that the phase extending into the radial cracks consists primarily of Mo and $\mathrm{Ba}$. The other phase is mixed oxide fuel. Examinations of the melt region in the central void and the fuel-cladding interface region are continuing.

Chemical burnup analysis on samples from fuel pins BNW 1-3 and 1-5 have been completed. Results show irradiation exposure for BNW 1-3 and 1-5 of 113,500 and 137,200 MWd/MTM respectively. These values are lower than the original exposure estimates for these fuel pins. 
TABLE 7.2. Summary Status of Irradiation Experiments

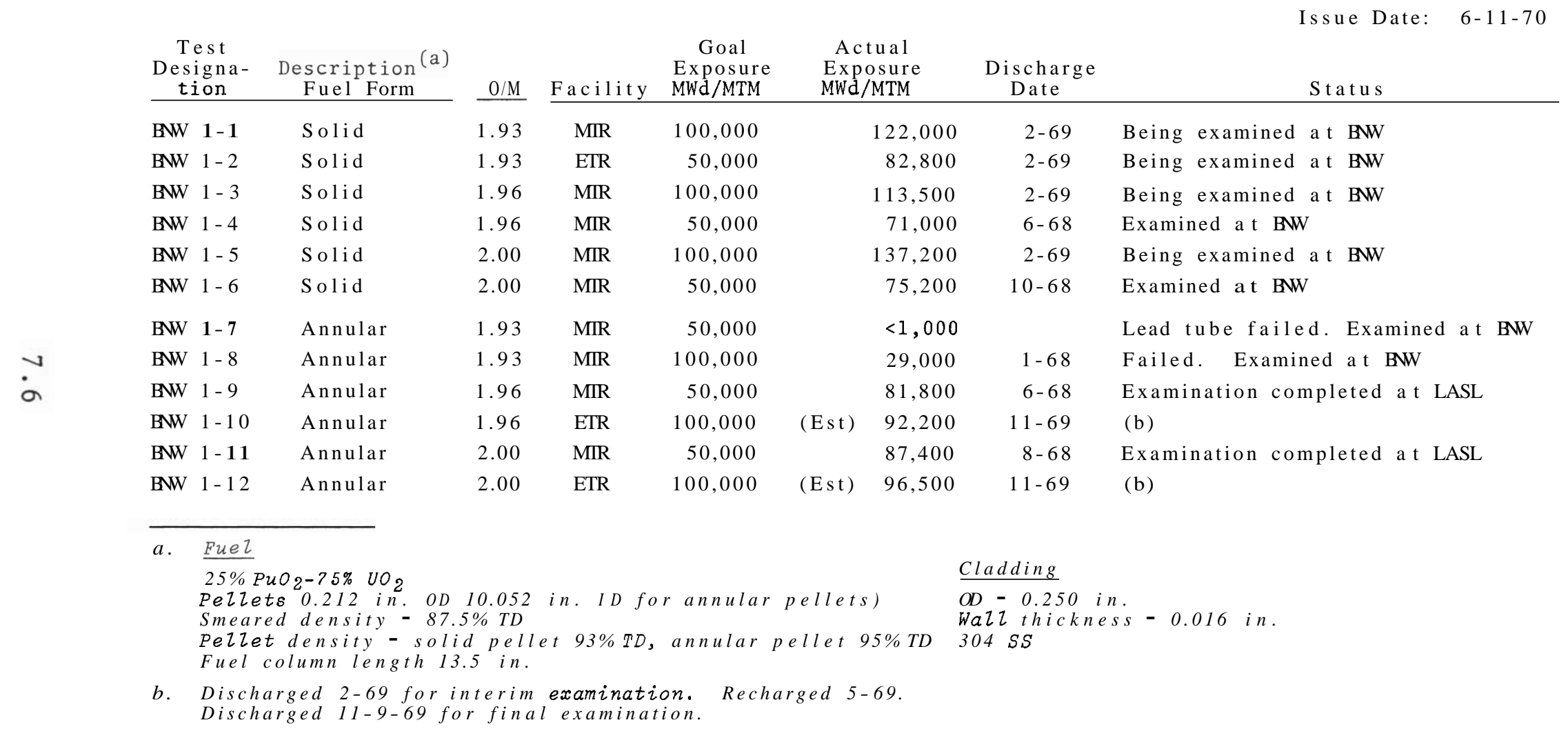


BNWL - 1394

4. Transient Irradiations

G. E. Culley and D. O. Sheppard

A fuel pin (PNL-1-2) that was transient irradiated at the TREAT facility on May 7, 1970 was returned to BNW for examination. The fuel pin became bowed and the fuel column length increased by $1 / 8$ in.

Profilometry data exhibited a significant increase in fuel pin diameter as shown in Figure 7.1. The post-transient data reveal the fuel pin diameter has increased by about $1 \mathrm{mil}$ over the length of the fuel column. This increase is not smooth but suggests fuel-cladding mechanical interaction at the pellet interfaces.

Shown in Figure 7.1 are pre- and post-transient photographs of the fuel pin showing the bowed condition. The magnitude of the bow is about $1 / 8 \mathrm{in.}$ as measured from the photographs. (The apparent decrease in fuel pin length is caused by photographic interpretations and is not real.)

The most striking feature found in examination of a longitudinal section is the disappearance of the pellet-topellet interfaces. Figure 7.2 illustrates the phenomenon which has never been found during the examination of steadystate irradiated PNL-1 pins.

The transient test conditions and $\mathrm{T} / \mathrm{C}$ response for the PNL-1-2 capsule are shown in Figure 7.3. The received transient was very close to that requested.

5. Effect of Cold Work on Irradiation-Induced Swelling of Type 316 SS

J. L. Straalsund, H. R. Brager, and J. F. Bates

Density measurements have been completed on a series of 32 stainless steel alloy specimens, with varying degrees of cold work, which were irradiated in BNW Pin No. 24 in EBR-II. 
BNWL - 1394
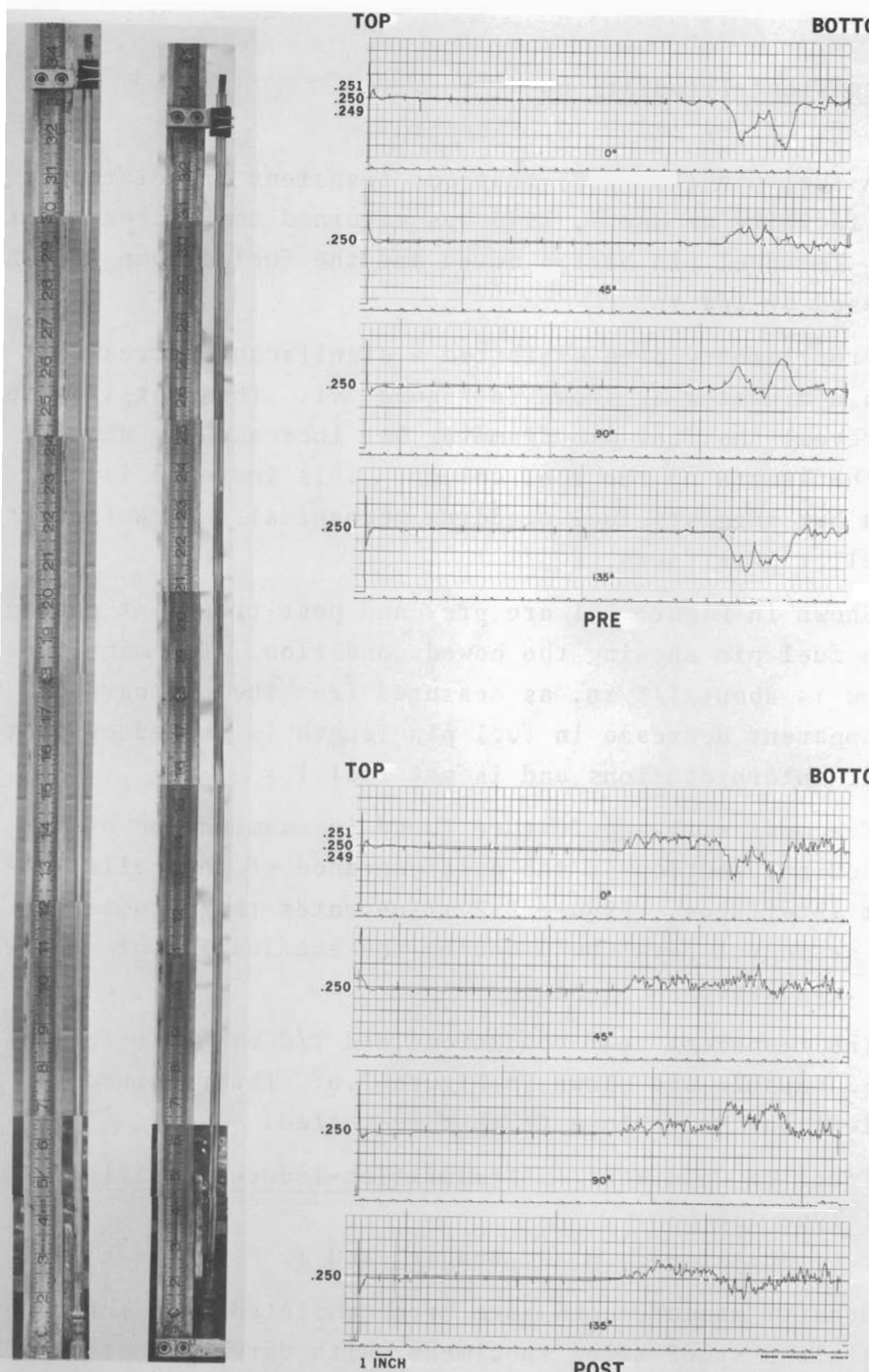

PRE
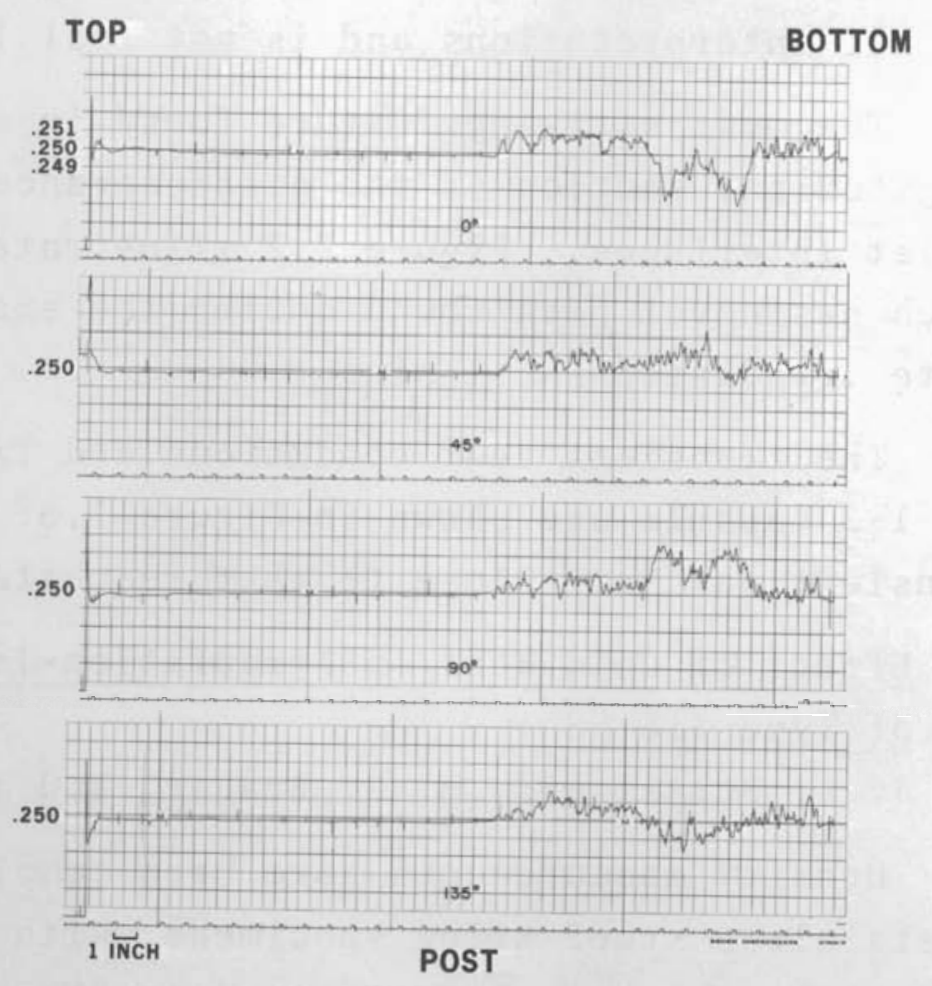

PRE

POST

FIGURE 7.1. Transient Irradiation Changes in PNL-1-2 


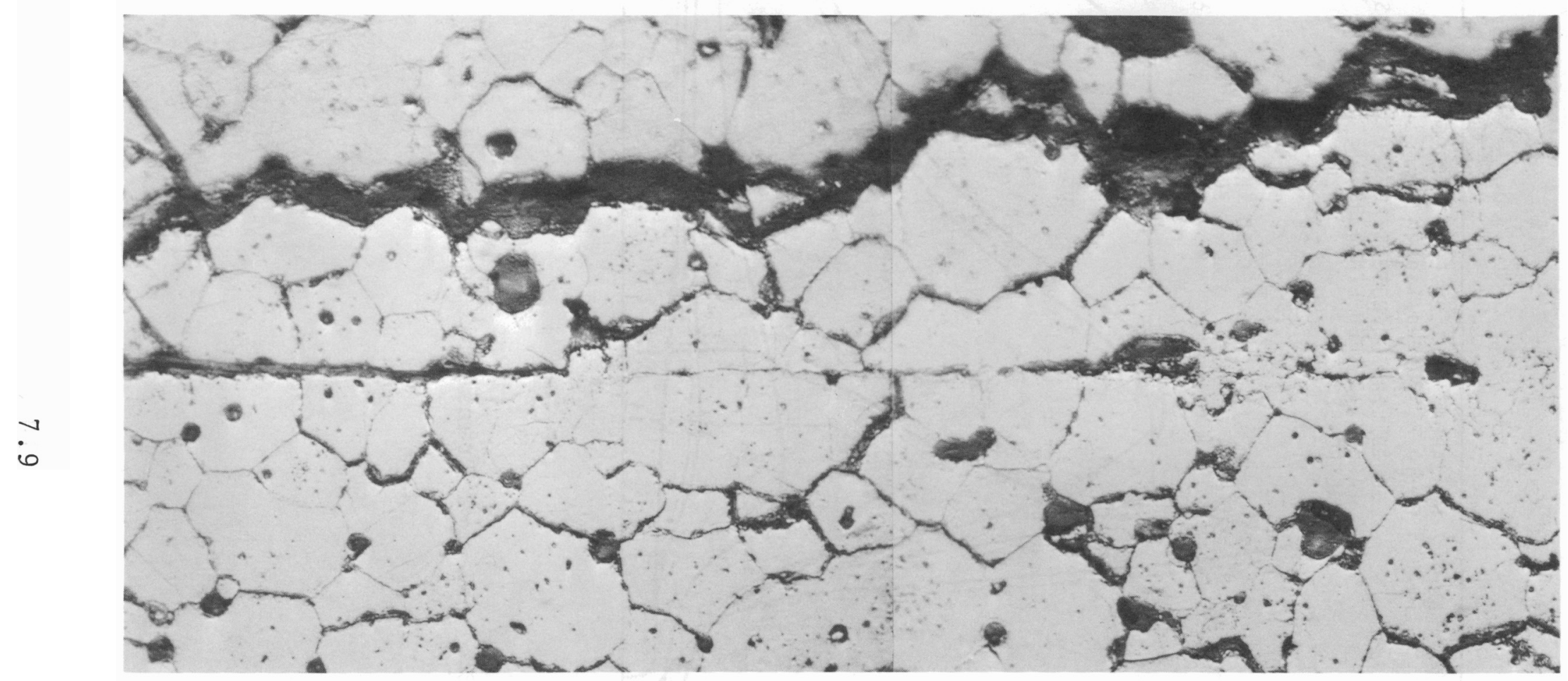

FIGURE 7.2. Fuel Pellet Interface Disappearance in PNL-1-2 Fuel Pin 


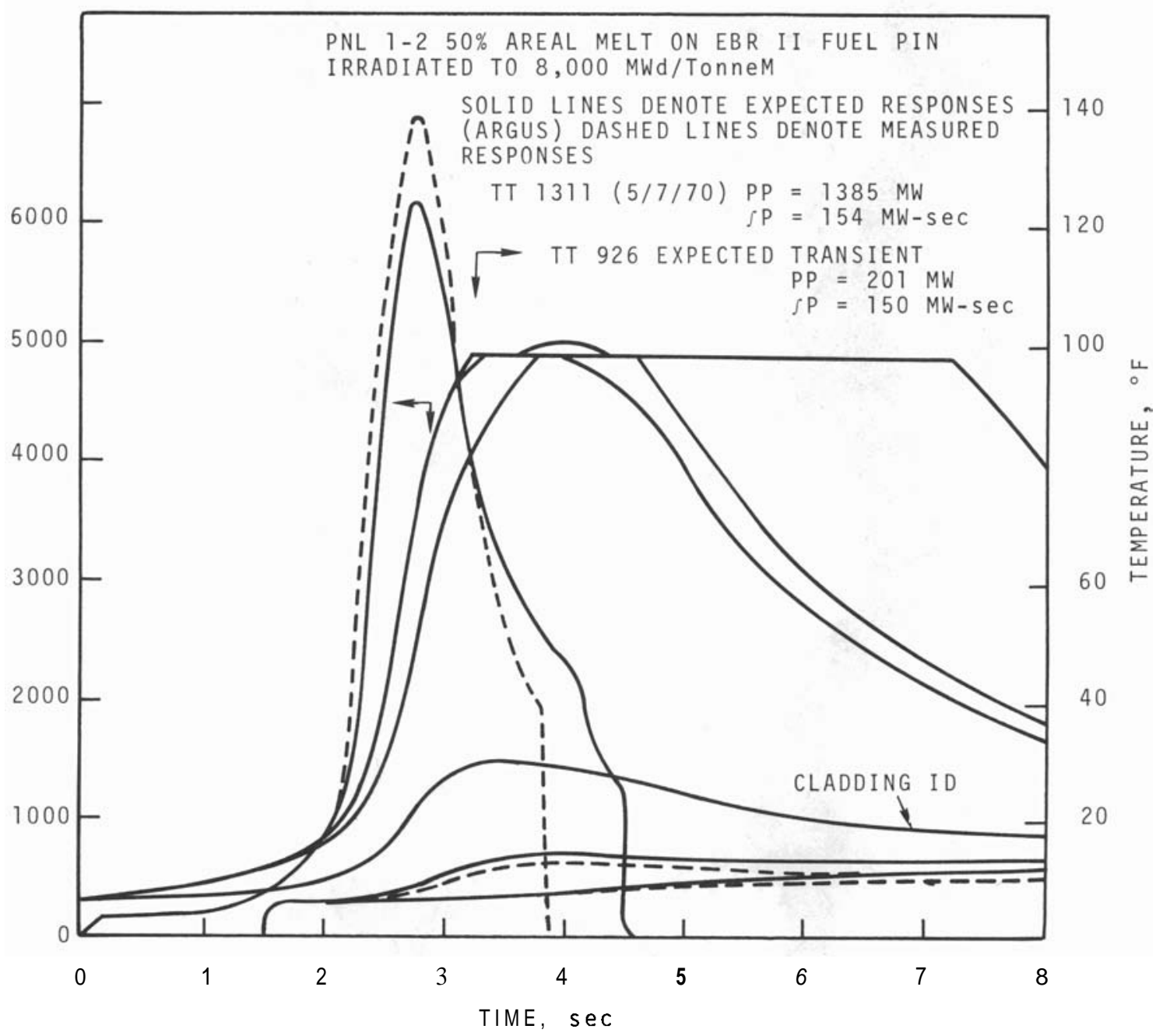

FIGURE 7.3. PNL-1-2 Transient Test Condition 
For irradiation temperatures between 700 and $1400^{\circ} \mathrm{F}$ and fluences between 2 and $3 \times 10^{22} \mathrm{n} / \mathrm{cm}^{2}(\mathrm{E}>0.1 \mathrm{MeV})$, swelling in Type 316 sS cold-worked specimens was negligible.

Test conditions are listed in Table 7.3. The irradiation temperatures were estimated by assuming radial heat flow only and will be revised when more detailed heat transfer calculations are completed. The fluence values were calculated on the basis of the irradiation history given below and will be updated when dosimetry results become available.

TABLE 7.3. Irradiation Data on Pin No. 24

EBR-II Runs

Position

Total Exposure

Calculated Peak

Fluence

\section{3 to 40 inclusive}

2D-1 except for Run 38-B (62 MW) in which the pin occupied position 5D-2 (exposure in this position was 770 MW days)

$10,014 \mathrm{MWd}$

$3.05 \times 10^{22} \mathrm{n} / \mathrm{cm}^{\mathrm{Z}}(\mathrm{E}>0.1 \mathrm{MeV})$

During the next report period cold-worked Type 316 SS specimens will be thermally aged to determine what magnitude of density changes may result from precipitation processes.

6. Damage Analysis for Solution-Treated 304 SS

J. L. Straalsund, H. R. Brager, and J. F. Bates

The objectives of this effort are to establish the irradiation-induced swelling characteristics of FFTF alloys in order to relate fast-reactor induced substructural changes in microstructure to corresponding changes in mechanical properties and to develop means for data extrapolation and interpolation by using both microscopic and empirical approaches.

Development of a self-consistent set of empirical equations describing void size, void concentration, and total void volume (swelling) is continuing. The following set of equations appear to account for all of the trends in the data for solution-treated 304 SS. 


$$
\begin{aligned}
& \frac{\Delta \mathrm{V}}{\mathrm{V}}=(\phi \mathrm{t})^{2.05^{-27 / \theta+78 / \theta^{2}}} \\
& \text { - }\left[(\mathrm{T}-40) \times 10^{-10}\right] \exp \left[-0.015 \sim-\frac{5100}{100}+32.61\right. \\
& \mathrm{d}=(\phi t)^{0.15-24 / \theta^{2}} \exp (7.45-1700 / \mathrm{T}) \\
& \rho=(\phi t)^{1.60-27 / \theta+150 / \Theta^{L}} \exp (-0.015 T+10.253) \\
& \frac{\Delta V}{V}=\mathrm{kpd}^{3}
\end{aligned}
$$

where

$$
\begin{aligned}
\frac{\Delta \mathrm{V}}{\mathrm{V}} & =\% \text { volume change } \\
\phi \mathrm{t} & =\text { neutron fluence }\left(\mathrm{n} / \mathrm{cm}^{2} \times 10^{-22}, \mathrm{E}>0.1 \mathrm{MeV}\right. \\
\mathrm{T} & =\text { temperature, }{ }^{\circ} \mathrm{K} \\
\theta & =\mathrm{T}-623 \\
\mathrm{~d} & =\text { average void diameter, Angstrom units } \\
\rho & =\text { void number density, number } / \mathrm{cm}^{3} \times 10^{-15}
\end{aligned}
$$

A geometric conversion factor, $k$, takes into account the ratio between the average of the cubed void diameters to the cube of the average void diameter. This ratio was determined from the void size distributions.

The principal difference between Equation (1) and the engineering design equation for swelling is the temperature dependent fluence exponent. The current engineering equation uses a constant fluence exponent of 1.71; whereas, Equation (1) predicts a fluence exponent varying from 0.94 at $700^{\circ} \mathrm{F}$ to 1.94 at $1200^{\circ} \mathrm{F}$. Figures $7.4,7.5$, and 7.6 compare the predictions of the two equations with experimental data at 375 , 410 , and $590{ }^{\circ} \mathrm{C}$. As may be seen from the figures, both equations appear to fit the data equally well. 


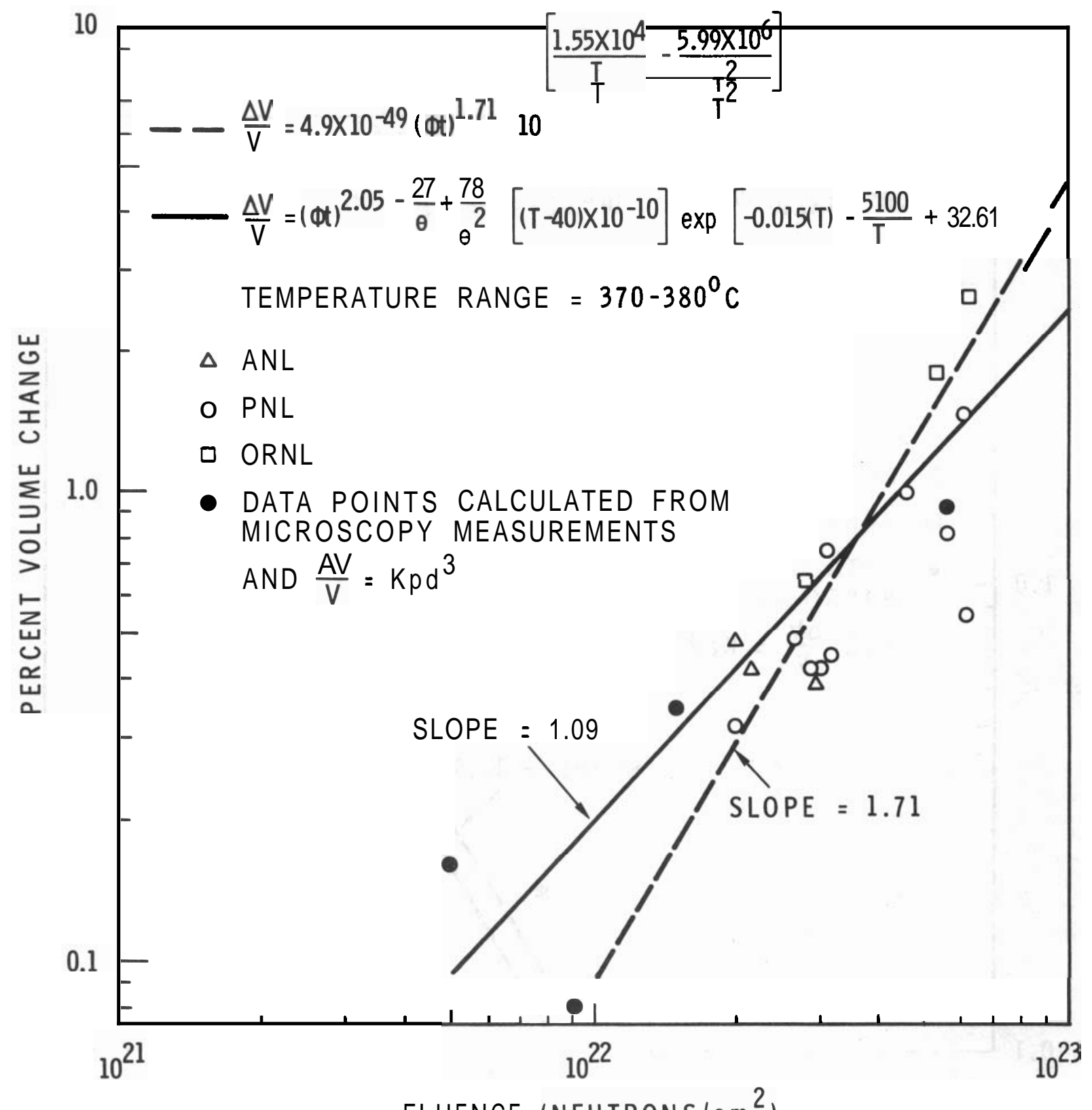

Neg 701864-5

FIGURE 7.4. Swelling in AISI Type 304 SS at 370 to $380{ }^{\circ} \mathrm{C}$ $\left(698\right.$ to $\left.716^{\circ} \mathrm{F}\right)$ 


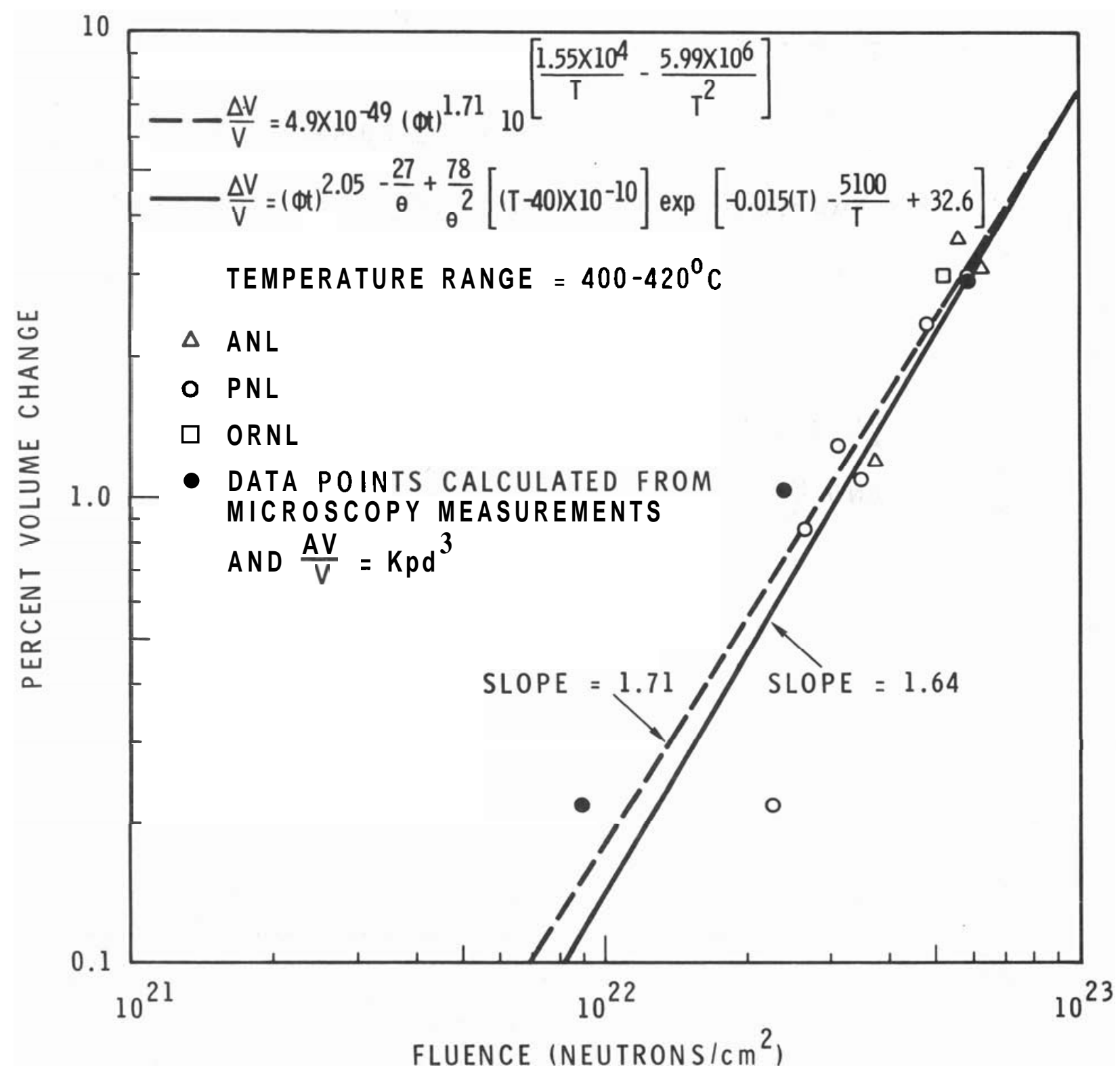

Neg 701864-33

FIGURE 7.5. Swelling in AISI 304 SS at 400 to $420^{\circ} \mathrm{C}$ $\left(752\right.$ to $\left.788^{\circ} \mathrm{F}\right)$ 


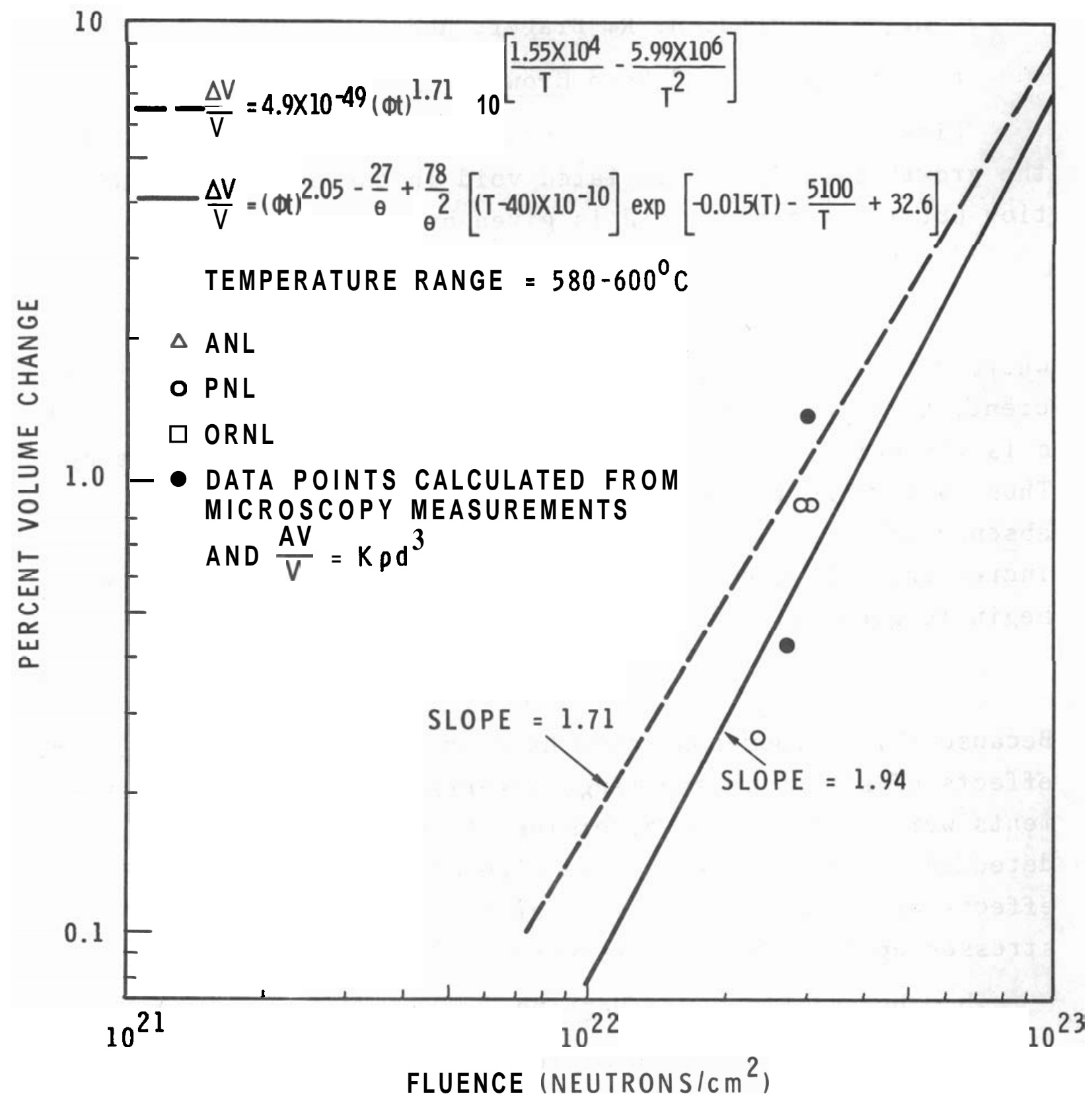

Neg 701864-4

FIGURE 7.6. Swelling in AISI Type $304 \mathrm{SS}$ at 580 to $600^{\circ} \mathrm{C}$ (1076 to $\left.1112^{\circ} \mathrm{F}\right)$ 
7. Analysis of Irradiation-Induced Voids in Stainless Steels J. L. Straalsund, H. R. Brager, and J. F. Bates

a. Stress-Induced Void Growth

Classical thermodynamic and growth theory indicates that the growth rate for an isolated void in the absence of radiation but in a stress field is given by:

$$
\frac{\mathrm{dr}}{\mathrm{dt}}=\frac{\mathrm{D}_{\mathrm{s}} \Omega}{\mathrm{rkt}}\left(\sigma-\frac{6 \gamma}{\mathrm{r}}\right)
$$

where $r$ is the void radius, $D_{s}$ is the self-diffusion coefficient, $k$ is the Boltzman constant, $t$ is the temperature, $a$ is the uniaxial tension stress and $\gamma$ is the surface energy. Thus, according to Equation (1), during annealing in the absence of stress, voids should shrink, but as the stress is increased, the voids should become more stable, until they begin to grow if:

$$
\sigma>\frac{6 \gamma}{r} .
$$

Because this phenomenon could have an important bearing on the effects of stress on swelling, a series of annealing experiments were performed to determine if the effect could be detected. For an average void size of $1500 \AA$, no significant effects of stress on annealing at $1200^{\circ} \mathrm{F}$ was found for stresses up to 12,000 psi (Figure 7.7).

b. Defect Structure Mapping

Transmission electron microscopy is being used to develop a quantitative map, similar to that for voids, describing interstitial cluster formation in irradiated stainless steels. Qualitatively, the structure of the interstitial clusters is strongly temperature dependent. At low irradiation temperatures $\left(370\right.$ to $\left.380^{\circ} \mathrm{C}\right)$ and low fluences $\left[4 \times 10^{21} \mathrm{n} / \mathrm{cm}^{2}\right.$ $(\mathrm{E}>0.1 \mathrm{MeV})$, the microstructure consists of small (200 to $500 \AA$ diameter) faulted loops. The shape of the loops vary 


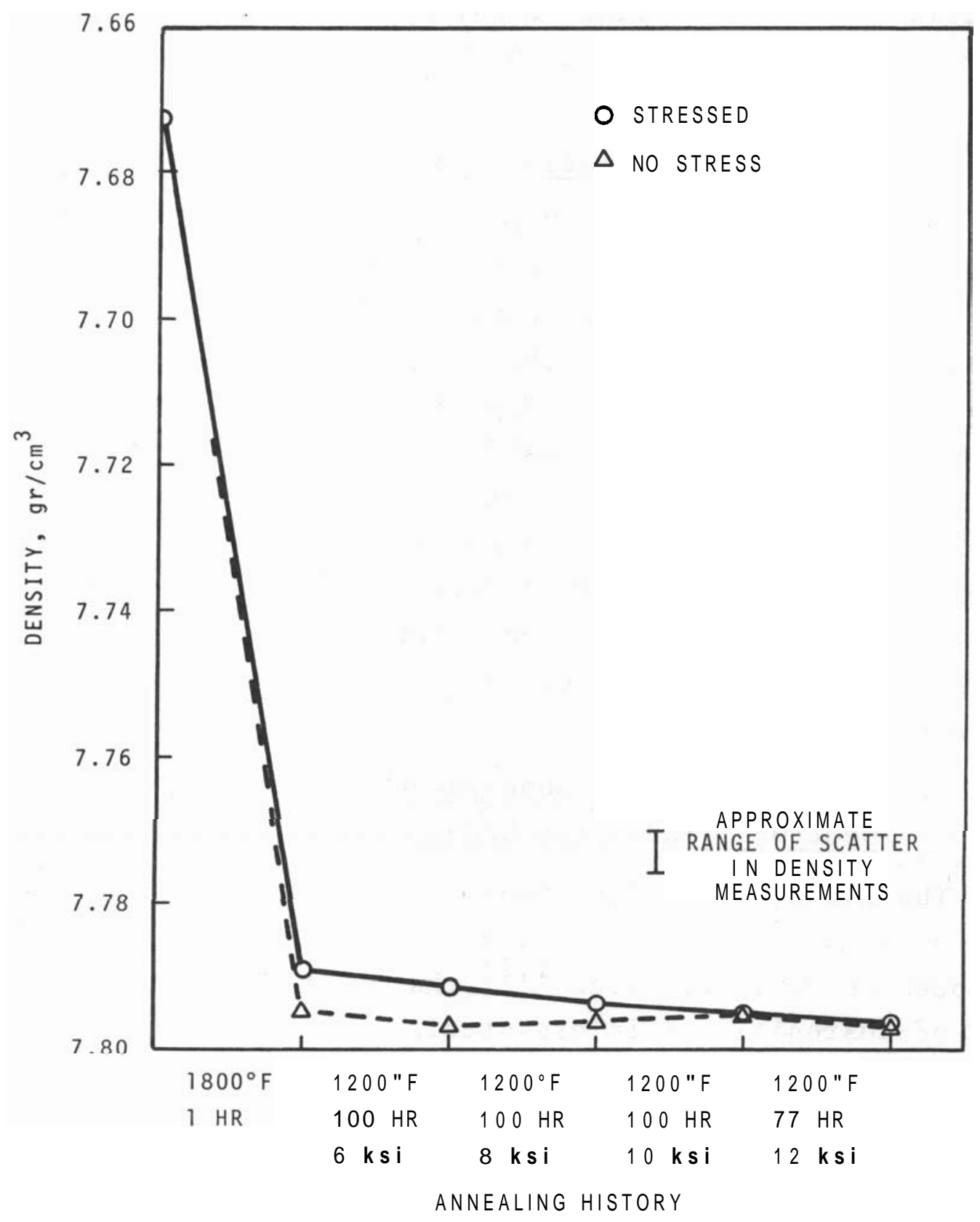

Neg 701067

FIGURE 7.7. Effect of Stress on Annealing of IrradiationInduced Swelling 
from nearly circular to extremely complex shapes. These complex shapes suggest that loops are interacting with other interstitial and/or vacancy clusters. In addition, faulted interstitial clusters exist in the form of curved streamers 2000 to $6000 \AA$ long.

\section{Effect of Irradiation Conditions}

Transmission Electron Microscopy studies of void production in stainless steel have revealed that the shape of the void size distribution changes with irradiation conditions. Figure 7.8 illustrates how the size distributions vary with temperature and fluence for Type 304 SS. As may be seen from the figure, the shape changes from approximately Gaussian at low temperatures to double peaked at higher irradiation temperatures. The reason for the double peaked distribution is not known but it may be associated with either the changing loop structure with increasing temperature or preferential nucleation of voids (or vice versa) on large high temperature precipitates.

d. Use of Heavy Ion Bombardment to Simulate Fast Neutron Irradiation Damage

The use of heavy ion bombardment as a means of simulating fast neutron irradiation damage is being investigated. It has been recently reported $(1,2)$ that high temperature bombardment of austenitic stainless steels produces voids, interstitial clusters, and precipitates.

In tentative results that we have obtained to date from a foil that had been bombarded with $3 \times 10^{16} \mathrm{nickel}$ ions $/ \mathrm{cm}^{2}$ at $500{ }^{\circ} \mathrm{C}$, the voids, loops, and precipitation are similar to that produced from neutron irradiation.

1. R. S. Nelson and D. J. Mazey. "Radiation Damage in Reactor Materials," vol. 11, IAEA Vienna (1967) 517.

2. D. J. Mazey. "The Nature of Faults Formed in Association with Voids in 316 Stainless Steel During $22 \mathrm{MeV}$ Carbon Ion Bombardment," Submitted to J. of Nuc. Materials, December 1969. 
BNWL - 1394

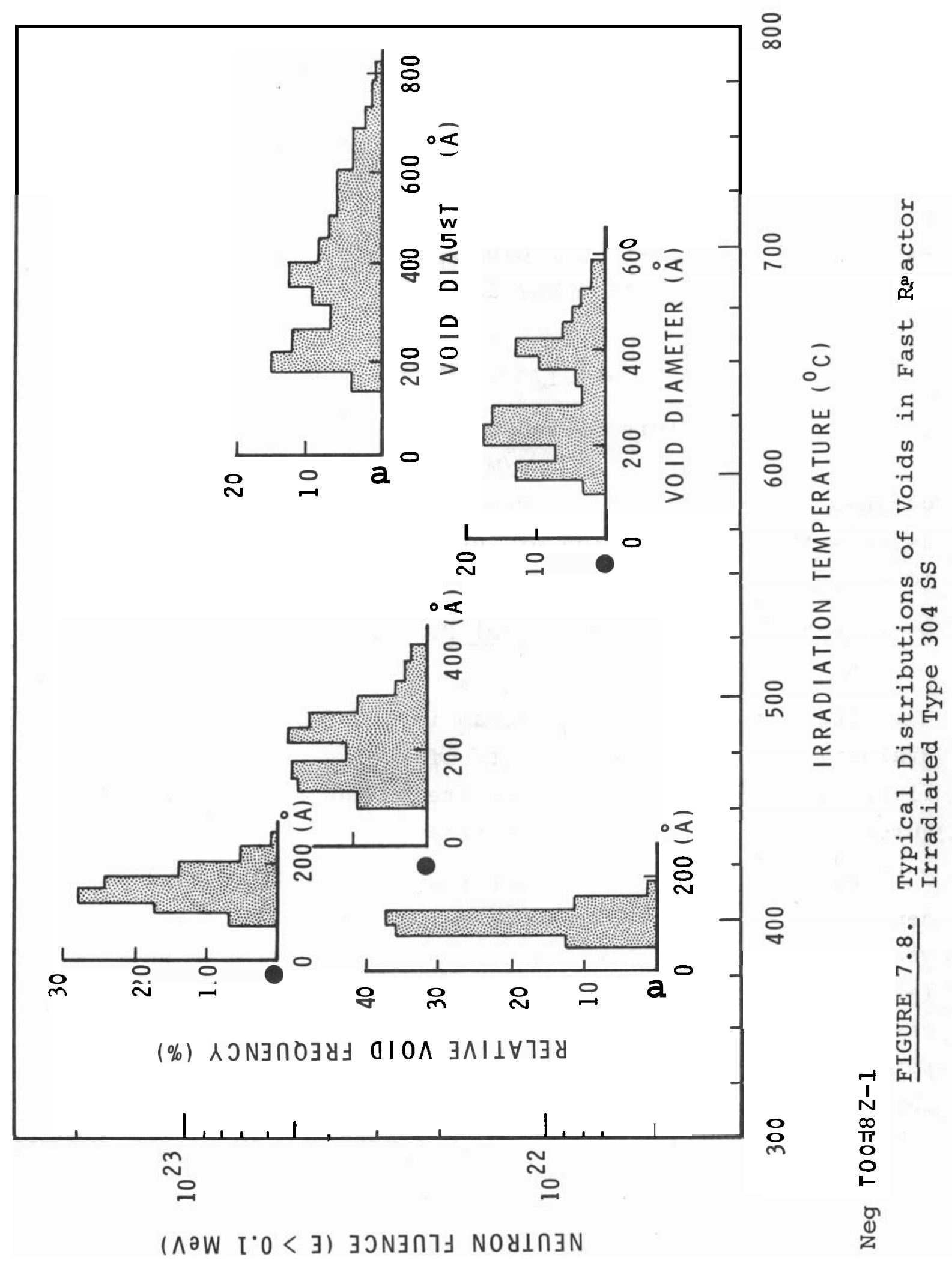




\section{Cladding Thickness Loss}

J . W. Weber

Fuel-cladding reaction layer thicknesses on samples from BNW 1-2, 1-6, 1-8, 1-9, and 1-11 were measured on microphotographs. These data, along with similar data published by GE and NUMEC, were collected and reviewed, and an empirical expression for loss-of-cladding thickness from fuel-cladding, fission-product reaction was determined. The expression for cladding loss

$$
\mathbf{t}(\text { inch })=7.175 \times 10^{-11}[\mathrm{~T}-700][\mathrm{BU}]
$$

where $\mathrm{T}=$ temperature of the cladding inside surface, ${ }^{\circ} \mathrm{F}$

$\mathrm{BU}=\mathrm{fuel}$ burnup in MWd/MTM

defines an upper limit for reaction layer thickness. It assumes that the reaction of fuel and cladding is proportional to burnup.

9. Mechanical Testing of Fuel Pin Cladding

R. L. Fish

The purpose of this program is to provide a basis for evaluating the combined effects of fuel cladding interaction, fluence, and operating temperature on the postirradiation burst and stress rupture properties of fuel pin cladding.

Previously reported burst test results on fueled specimens from the PNL-1 series fuel pins indicated cladding weakening after long periods of internal air exposure ( $>8$ months). The exposure time required for this weakening was longer for cladding that had operated at lower temperatures (below the fuel midplane). Every specimen tested from above the midplane that had been exposed for a sufficient length of time, experienced a low strength, low strain failure. 
Recent burst tests performed on specimens from above the midplane in fuel pins PNL 1-17 and PNL 1-19 have revealed a variation frcm this established pattern. These two burst specimens had been internally exposed to hot cell air for 10 to 12 months but failed with good rupture strength $(65,150$ and 57,120 psi respectively). Strain measurements are not yet available. This behavior is not consistent with previously obtained data on fueled specimens of other pins taken from the same general region and internally exposed to a ir for comparable times.

A detailed investigation of the handling and storage of these particular pins as well as a study of the operating conditions of the pins is in progress. Peculiarities in these aspects of the fuel pin history may have been significant in affecting the burst test results.

10. Controlled Clad Failure Techniques

M. K. Millhollen

Tests are continuing in an endeavor to establish a reliable fuel pin defecting mechanism for in-reactor defect testing in the EBR-II. Two artificial defects, consisting of nickel-plated, Silfos-filled, 0.005-in. diameter holes through the cladding wall, have been flow tested for $100 \mathrm{hr}$ in $950{ }^{\circ} \mathrm{F}$ sodium. In both samples, the Silfos was smeared on the outer surface of the pin around the plugged, defect location to form a base for the nickel which was plated on. The size of this smeared area was $\sim 1 / 8-i n$. diameter.

The sample with the defect hole located approximately in the center of the nickel plate area survived the 100-hr test without difficulty. A sample with the defect hole located at one edge of the nickel-plated area failed. 
11. Detection of Irradiation-Induced Fuel Pin Swelling by Vibration Measurement

D. o. Hunter

It has been suggested that irradiation-induced swelling of fuel pins with a hex fuel duct can be detected through measurement of changes in the subassembly vibration properties. Since irradiation will cause increased stiffness of the assembly, it appears feasible that a correlation between vibrational properties and stiffness can be extended to include correlation between vibrational properties and irradiation damage. It is further expected that the tighter mechanical coupling between fuel pins and hex can at the fuel zone region, due to swelling in the pins, will in itself affect vibrational parameters-perhaps to a greater extent than will increased stiffness. An investigation is being conducted.

An experiment has compared the vibrational behavior of a 90-in. long $\times 2$-in. diameter tube, tightly filled with wirewrapped $1 / 4$ in. diameter thick-wall tubing, against the vibrational behavior of the same assembly, except with several sheet metal screws forced through the 2-in. diameter tube, at the midsection, into the wire-wrapped tubing inside--thus simulating fuel swelling. The vibration changes caused by the screws were unmistakable. Frequencies of vibrational peaks were shifted and generally reduced in amplitude. One new vibrational peak appeared at a very low frequency as a result of the simulated swelling.

12. In-Cell Profilometry on Irradiated Fuel Pins

J. W. Weber

All major modifications to the $324 \mathrm{Bldg}$. East Cell profilometer have been completed. The control console and measuring frame (Figure 7.9) have been installed in the 324 Bldg. and checked out. The profilometer was calibrated, and the first diameter measurements on an irradiated fuel 


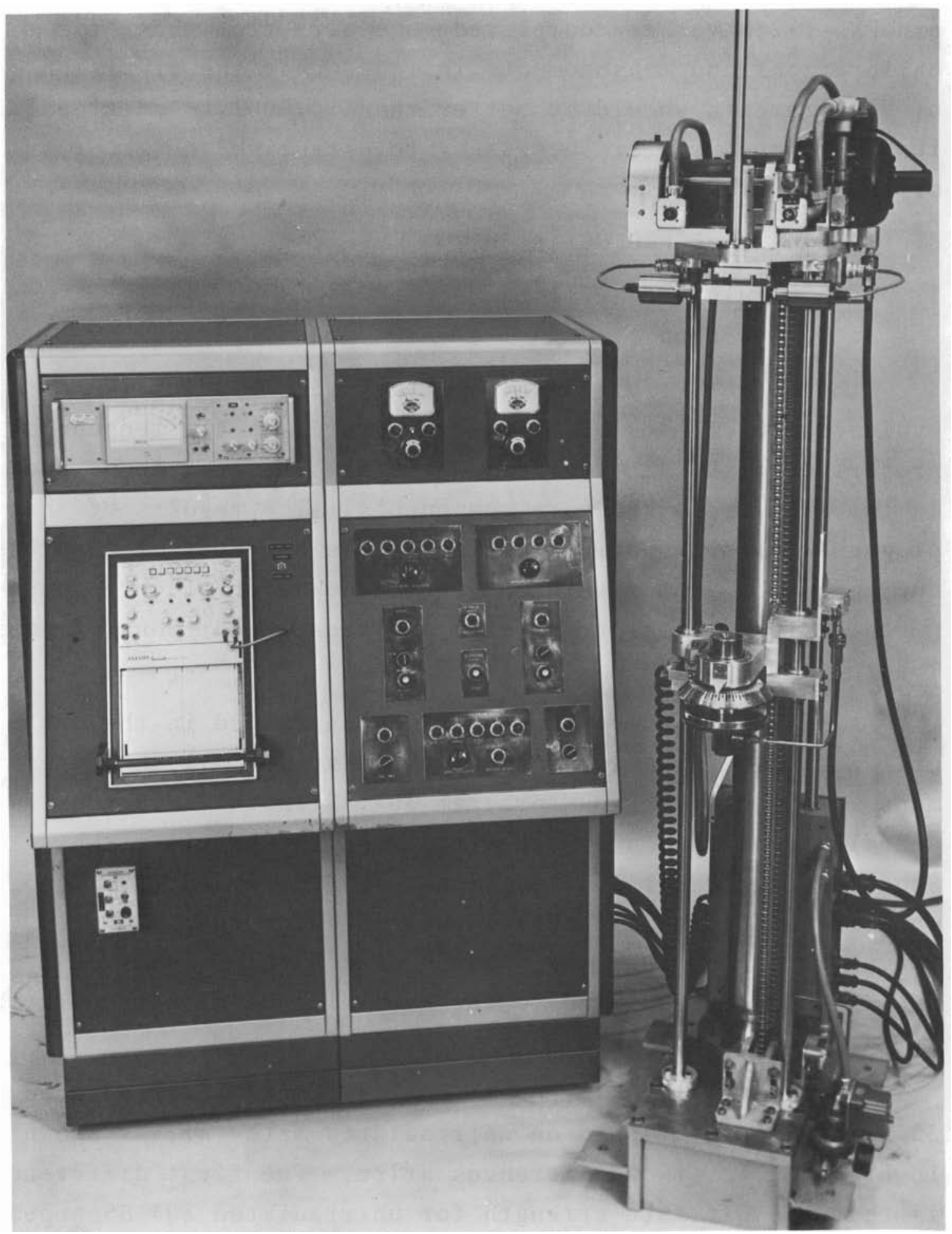

Neg 701864-29

FIGURE 7.9. Measuring Frame and Electrical Control Console for 324 Building East Cell Remote Profilometer 
pin PNL 1-2 have been completed. Results from these first calibrations and measurements indicate that the precision of measurements should be better than \pm 0.0001 . Additional tests and analyses are necessary to establish the accuracy of the measurements.

B. MATERIALS TECHNOLOGY

1. High Strain Rate Effects

J. M. Steichen

The objective of the high strain rate studies is to evaluate the effects of high strain rates on the mechanical properties of LMFBR materials which are expected to be used in the FTR vessel and core components. The results of this program will provide information on the behavior of the vessel during impact from within and on the behavior of core components during thermal transients and other conditions of rapid loading.

A Kraft-Hahn dynamic loader was installed in the hot cell and three irradiated specimens tested. All three specimens were made from IRM program 304 SS in the solutionannealed condition and were irradiated in EBR-II in PNL Subassembly X-022. Two specimens, 15 F 24-1 and 15 F 24-3, were irradiated to a total fluence of about $2 \times 10^{21}$ $\left(\sim 0.09 \times 10^{21} \mathrm{E}>0.1 \mathrm{MeV}\right) 700^{\circ} \mathrm{F}$, and a third specimen, $9 \mathrm{~K}$ 24-1, was irradiated to the same fluence at a temperature slightly above $800{ }^{\circ} \mathrm{F}$.

In comparing the strength data obtained on irradiated 304 SS to that obtained on unirradiated material, as shown in Figure 7.10, two differences arise. The first difference is that the ultimate strength for unirradiated 304 SS appears to remain fairly constant to a strain rate of about $1.0 \mathrm{sec}^{-1}$. At a rate of $10.0 \mathrm{sec}^{-1}$, the strength falls off and then increases with strain rate to a rate of $100.0 \mathrm{sec}^{-1}$. 


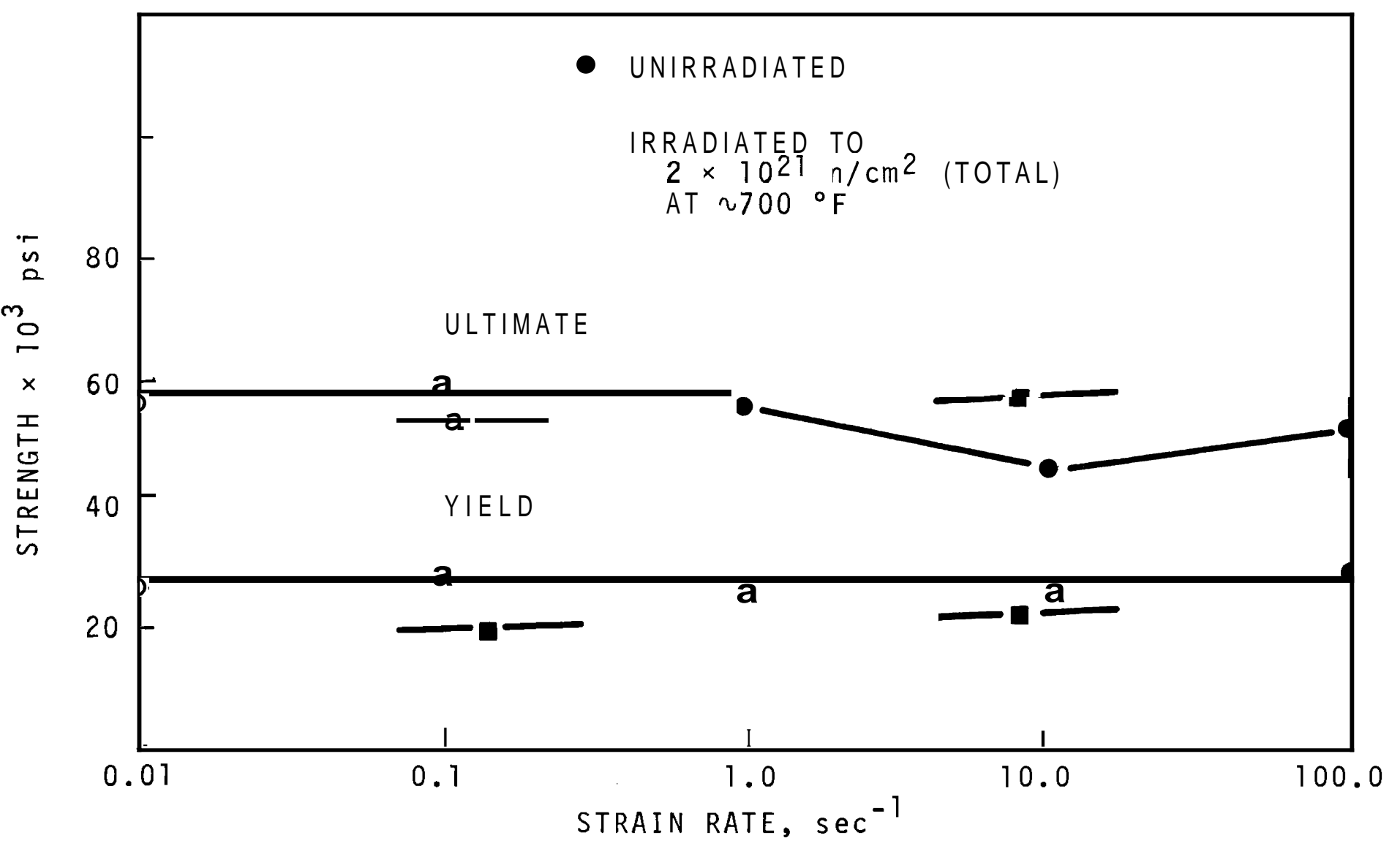

FIGURE 7.10. The Effect of Strain Rate on the Strength of Unirradiated and Irradiated Type $304 \mathrm{SS}$ at $1000^{\circ} \mathrm{F}$ 
The two tests at $1000^{\circ} \mathrm{F}$ on irradiated material indicate that ultimate strength slightly increases with strain rate, and no drop in ultimate strength is observed at a rate of $\sim 10.0 \mathrm{sec}^{-1}$.

The yield strength for the unirradiated and irradiated material appears to slightly increase with strain rate. The slope of the two lines appears to be about parallel. The difference in the yield strength values between the unirradiated and irradiated material probably results from the control specimens being slightly prestrained during machining. Total and uniform elongation appear to be more greatly affected by strain rate in the irradiated material than the unirradiated material as shown in Figure 7.11. In the unirradiated 304 SS, the total and uniform elongation appears to remain essentially constant with strain rate, but the ductility of the irradiated material appears to slightly decrease with strain rate.

The third irradiated specimen, 9 K 24-1, was tested at $600^{\circ} \mathrm{F}$ at a rate of $\sim 10.0 \mathrm{sec}^{-1}$. Only minor variations were observed in the strength values between control and irradiated material, but the ductility for the irradiated material was slightly higher than that of the unirradiated material.

\section{PSAR "Leak-Before-Break''Analysis for Vessel and Primary Piping}

L. A. James

In order to answer questions pertaining to the need for complete NDT inspection of the FTR vessel and primary piping at intervals during inspection, an analysis is being made of cracking behavior which results from the application of cyclic stresses. The concepts of linear elastic fracture mechanics are being used to estimate whether or not it is possible for a fatigue crack to propagate during reactor operations from an initial size associated with the limits of NDT detection to a 


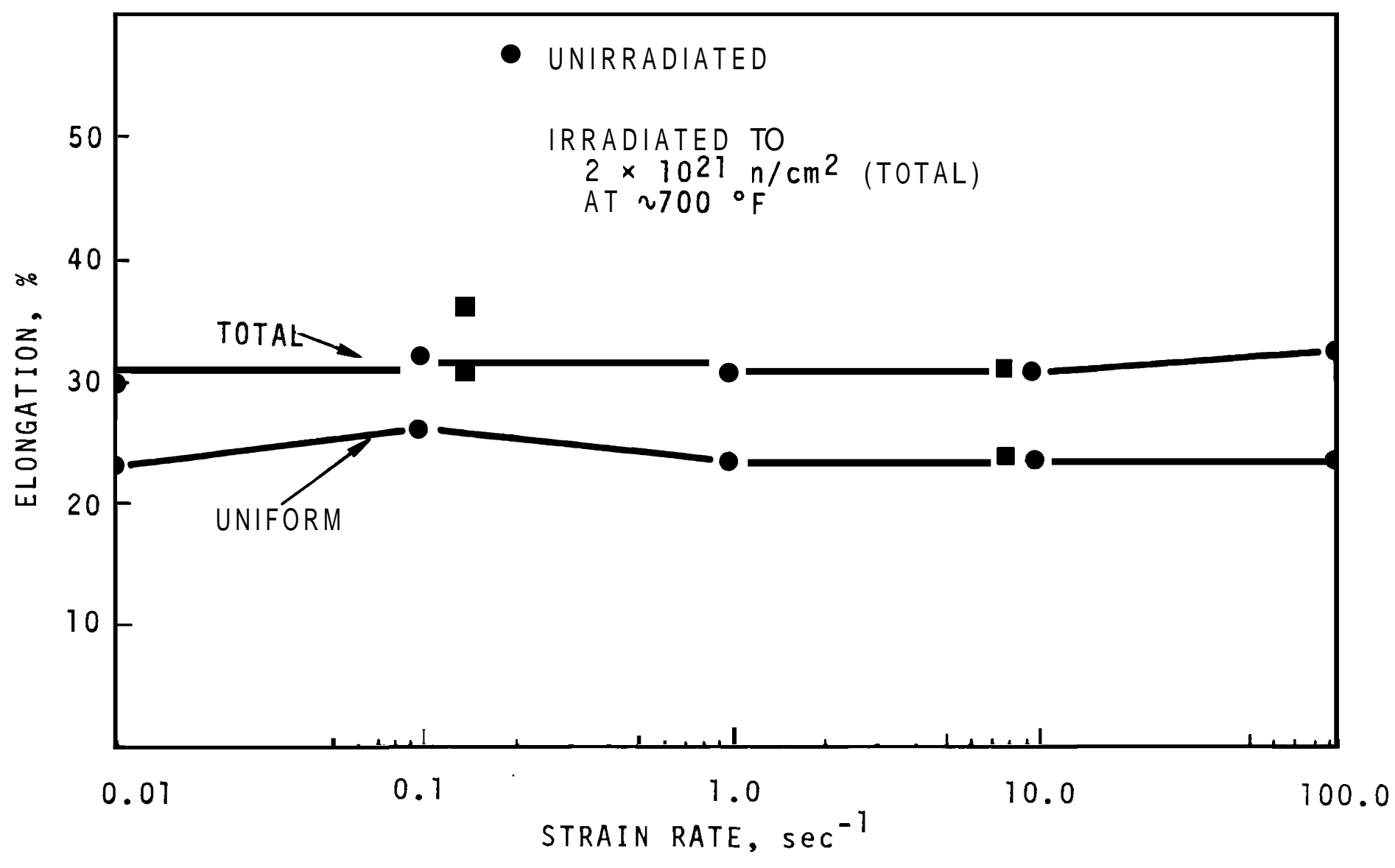

FIGURE 7.11. The Effect of Strain Rate on the Ductility of Unirradiated and Irradiated Type $304 \mathrm{SS}$ at $1000^{\circ} \mathrm{F}$ 
"failure" size and whether the crack would allow a detectable amount of liquid sodium to leak before the "failure" size is reached.

The crack growth test results obtained to-date are summarized in Figure 7.12. Fatigue-crack propagation is a thermally-activated process. Crack growth increases markedly with increasing temperature (for example, at the same value of AK, the crack growth rate is approximately an order of magnitude higher at $1200^{\circ} \mathrm{F}$ than at $75^{\circ} \mathrm{F}$ ). The test results shown in Figure 7.12 were obtained using single-edge, notched specimens cycled in uniaxial tension at a frequency of 4 cycles/min (except for some of the $75^{\circ} \mathrm{F}$ specimens which were tested at higher frequencies). All specimens were tested in air, and none have been exposed to irradiation.

Future program plans call for fatigue testing of specimens in liquid sodium in addition to testing irradiated specimens. Some conceptual planning has been accomplished for the necessary apparatus and fixtures for the sodium testing.

3. Weldment Studies

A. L. Ward, A. J. Lovell, and L. D. Blackburn

The objective of this program is to provide mechanical property and metallurgical stability data for candidate LMFBR vessel and core structural weldment materials in order to ensure adequate lifetime performance under anticipated FTR service conditions.

Review of the tensile test results suggests that the previously reported ${ }^{(1)}$ data must be reinterpreted. Selected specimens were designated "all-weld" and included in the data

1. FFTF Quarterly Technical Report, December 1969, January, Washington, Apriz 1970. 


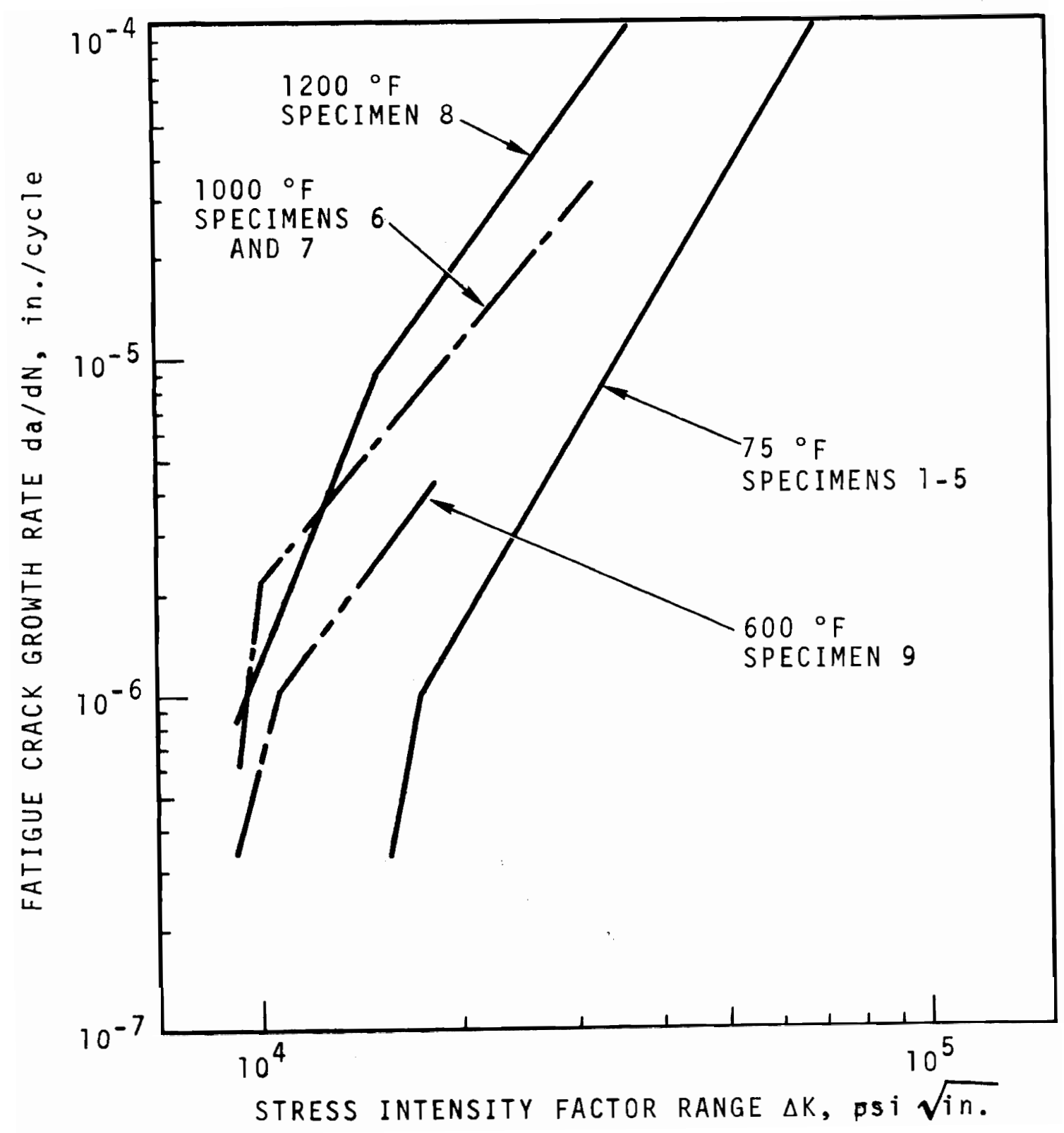

FIGURE 7.12. Summary of Fatigue-Crack propagation Behavior of Type 304 SS 
plots of Figures 7.13 and 7.14. The selections were made on the basis of weld metal distribution and fracture location.

Detailed analyses of these data are not complete; however, the following summary observations, which support earlier conclusions, may be made:

- In all cases, the yield strength of weld metal exceeds that of the base plate, primarily because of the presence of residual welding stresses (Figure 7.13).

- The ultimate strengths tend to be somewhat insensitive to weld process and filler metal variation, with the possible exception of the shielded metal-arc (16-8-2 filler) case, where uniformly higher values presumably result from the solid solution strengthening of $\sim 2 \%$ molybdenum content (Figure 7.13).

- Ductility parameters are generally consistent with the strength values. Reduction in area and uniform and total elongation values for weld metal consistently fall below those for the base plate material (Figure 7.14).

The creep-rupture results from weldment specimens are currently being reviewed in the preparation of a detailed report covering this phase of the program. As an interim summary, the major features of this study are presented here.

The creep and creep-rupture properties of unirradiated weldments can show a significant variation from the properties of annealed Type $304 \mathrm{SS}$; for example, the submerged-arc weld and the gas metal-arc weld exhibit shorter rupture times than annealed Type 304 material, while the gas tungsten-arc weld and the shielded metal-arc weld exhibit longer rupture times than the Type 304 alloy. Minimum creep rates of the submerged-arc weld and the gas metal-arc weld are higher than those of Type 304 material, at least at high stresses. 
$0.2 \%$ YIELD AND ULTIMATE STRESS, ks $i$

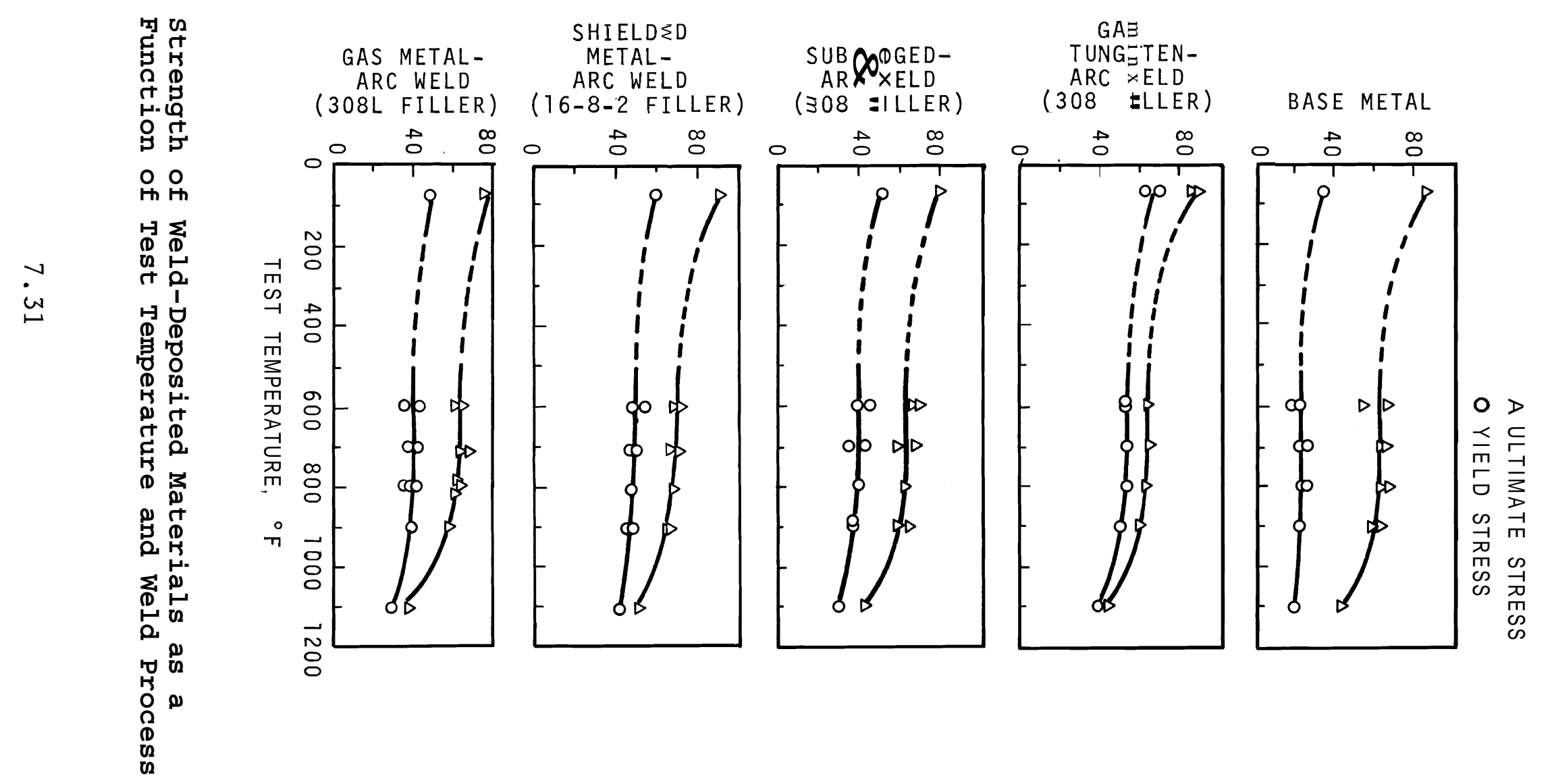




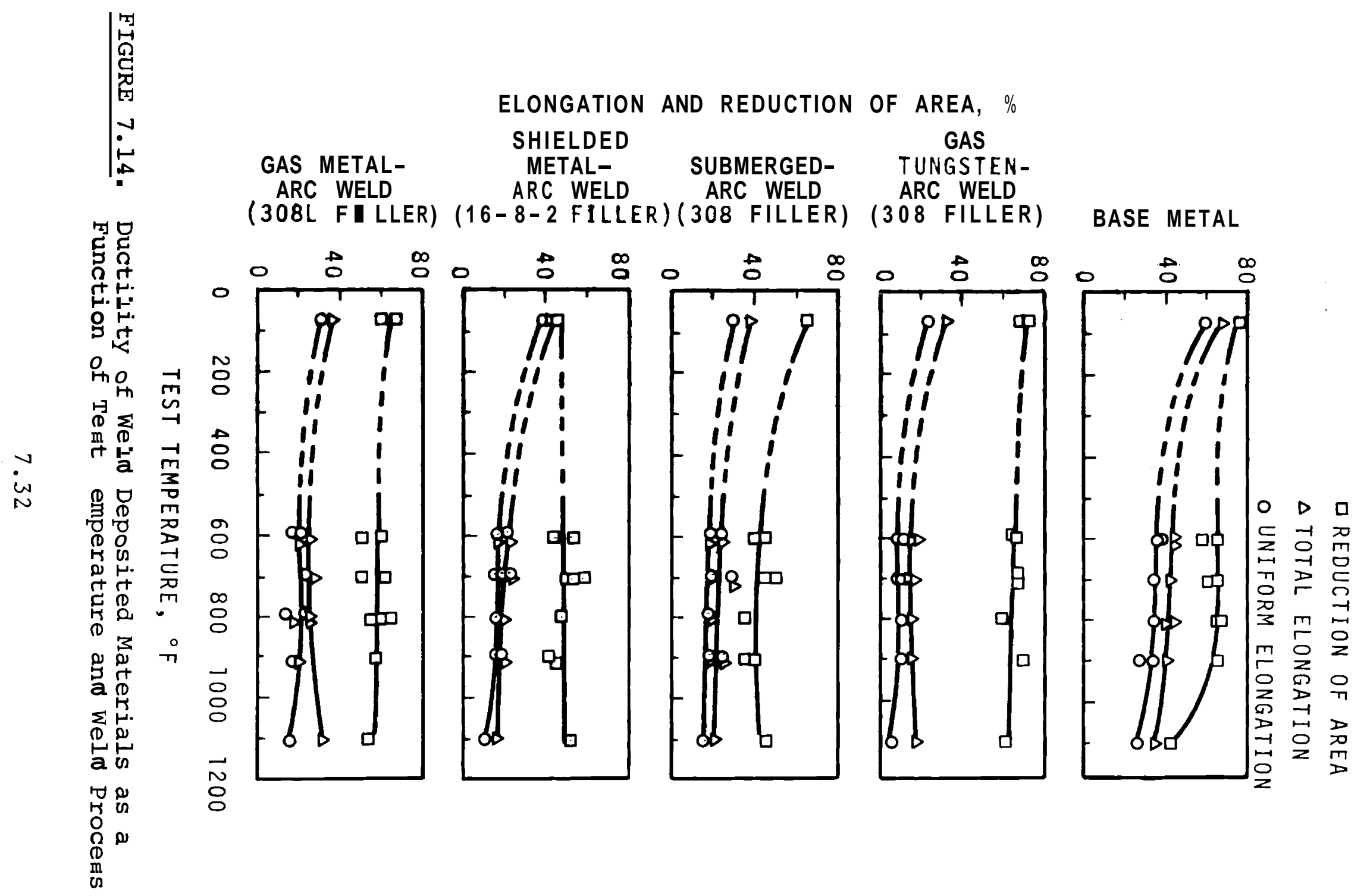


Conversely, the minimum creep rates of the gas tungsten-arc weld and the shielded metal-arc weld are lower than creep rates of Type 304 material, especially at low stresses. The creep ductility, as measured by total elongation, is significantly lower in all the weld materials.

\section{Uniaxial Creep-Rupture}

A. J. Love11 and L. D. Blackburn

Results of postirradiation creep-rupture tests are currently being analyzed in some detail to provide a more complete description of the response of austenitic stainless steels to fast reactor irradiation. This report presents a general summary of the important changes in the creep and creep-rupture behavior produced by irradiation.

The creep-rupture behavior of austenitic stainless steels after irradiation in EBR-II is controlled by the response of the minimum creep rate and of the ductility to the irradiation conditions. The minimum creep rate is given by :

$$
\dot{\varepsilon}=\frac{\varepsilon_{2}-\varepsilon_{0}}{t_{2}}
$$

where $\dot{\varepsilon}=$ the minimum creep rate

$\varepsilon_{2}=$ the strain at the end of second stage creep

$\varepsilon_{0}=$ a strain value obtained by extrapolating a steadystate portion of the creep curve to zero time

$t_{2}=$ the time at the end of second stage creep.

An empirical relationship is found to exist between the rupture life, $t_{r}$, and the end of second stage, $t_{2}$, and is of the form:

$$
t_{r}=B t_{2}
$$

where B is a constant, independent of stress, at constant temperature. 
Substitution of Equation (1) into Equation (2) results in the relation

$$
t_{r}=\frac{B\left(\varepsilon_{2}-\varepsilon_{0}\right)}{\varepsilon}
$$

This equation relates the rupture 1 ife to the minimum creep rate, to the linear creep strain, $\varepsilon_{2}-E_{0}$, and to the tertiary creep stage through the value B. The effects of irradiation on the creep and creep-rupture results determined in uniaxial, constant load creep tests are being analyzed in terms of the quantities in Equation (3).

Annealed Type 316 Stainless Steel

The creep-rupture results determined in uniaxial tests for a range of irradiaton conditions [fluences from 0.3 to $3.5 \times 10^{22} \mathrm{n} / \mathrm{cm}^{2}$ (total) and irradiation temperatures from 700 to $\left.1100^{\circ} \mathrm{F}\right]$ show that $\varepsilon$, B, and $\varepsilon_{2}-\varepsilon_{0}$ are all affected by irradiation.

Minimum Creep Rate. At low test temperatures (for example, 1000 and $1100^{\circ} \mathrm{F}$ ), creep rates are increased after irradiation to the higher fluences [that is, $>0.7 \times 10^{22} \mathrm{n} / \mathrm{cm}^{2}$ (total)]. Reduced creep rates were not observed even though many of the irradiations result in substantial irradiation hardening in elevated temperature tensile tests. The mechanism responsible for the increased creep rates has not been clearly identified, but the effect may be related to second phase precipitation which occurs during most of the irradiations.

At a test temperature of $1200^{\circ} \mathrm{F}$, creep rates are reduced at the higher fluences. Again, a detailed mechanistic interpretation is not yet available, but it is possible that the reduced rates are related to the irradiation defect structure (for example, voids, loops, or dislocation networks). 
The observations of increased creep rates at low test temperatures may be important in understanding in-reactor creep results. First, the postirradiation results may be relevant in establishing whether accelerated in-reactor creep rates are truly a dynamic effect of the neutron bombardment. Second, it is possible that the postirradiation results may establish new mechanisms of accelerated in-reactor creep at high fluences.

Linear Creep Strain. The values of $\varepsilon_{2}-\varepsilon_{0}$ decrease with increasing fluence, but apparently not in a smooth or continuous fashion. Irradiation also causes $\varepsilon_{2}-\varepsilon_{0}$ to become stress-dependent, $\varepsilon_{2}-\varepsilon_{0}$ generally decreasing with decreasing stress for a given irradiation condition. These results indicate that irradiation may cause earlier onset of cracking or a greater amount of cracking, and thus 1 i mit steady-state creep strain.

The values of $\varepsilon_{2}-\varepsilon_{0}$ are quite low at the high fluences; total creep strain values as low as $0.5 \%$ are observed in some cases. These results indicate that strain limitation problems may be encountered at still higher fluences.

Tertiary Creep. The value of $B$ is a measure of tertiary creep; when $B=1$, there is no tertiary creep stage. The results show that $B \simeq 1$ for most of the irradiation conditions throughout the test temperature range. This elimination of tertiary creep suggests a rapid link-up of cracks or rapid crack propagation in the irradiated material.

Rupture Life. The combined effects of irradiation on $\dot{\varepsilon}, B$, and $\varepsilon_{2}-\varepsilon_{0}$ are reflected in the rupture life through Equation (3). Rupture 1 if e is reduced by factors of up to $1 / 100$ at the low test temperatures and high fluences. This loss in rupture 1 ife translates into approximately a $40 \%$ reduction in the stress to produce rupture in $100,000 \mathrm{hr}$. 
Irradiation can therefore have a significant effect on the conventional design allowable stresses. This effect is most significant at low creep temperatures and tends to lower the temperature at which creep strength becomes the controlling factor in determining allowable stresses.

\section{Annealed Type 304 Stainless Steel}

The creep-rupture results determined in uniaxial tests show that $\dot{\varepsilon}, B$, and $\varepsilon_{2}-\varepsilon_{0}$ are affected by irradiation.

Minimum Creep Rate. In this alloy, minimum creep rates at 1000 and $1100^{\circ} \mathrm{F}$ are reduced at the higher fluences [that is, $>1 \times 10^{22} \mathrm{n} / \mathrm{cm}^{2}$ (total)]. This behavior contrasts to that of the Type 316 SS alloy which showed increased creep rates at these test temperatures. Available information on the general features of irradiation defect structure (for example, voids, loop, dislocation networks) gives no indication of significantly different defect structures in the two alloys which would explain the difference in response to irradiation. It may be that second phase precipitation is different in the two materials, so that this factor controls the behavior of the Type 316 SS alloy, while defect structure controls the behavior of the Type 304 SS alloy.

Linear Creep Strain. As in the case of Type 316 SS, $\varepsilon_{2}-\varepsilon_{0}$ decreases with increasing fluence in the Type $304 \mathrm{SS}$ alloy. Very low values of $\varepsilon_{2}-\varepsilon_{0}$ and total creep strain are observed in the Type 304 SS material at the high fluences. Again, this points to possible strain limit conditions at higher fluences.

Tertiary Creep. Values of B for irradiated material are approximately unity at a test temperature of $1000^{\circ} \mathrm{F}$. However, B values tend to be higher at a test temperature of $1100^{\circ} \mathrm{F}$. The presence of the tertiary creep state suggests that the irradiated Type 304 SS material may be somewhat more tolerant to cracking or flaws at this temperature. 
Rupture Life. Reductions in rupture life of the Type 304 SS alloy are generally not as severe as those of the Type $316 \mathrm{SS}$ alloy, particularly at $1100^{\circ} \mathrm{F}$. The reason for this difference stems primarily from the creep rate behavior, the increased rates in Type 316 SS material contributing to larger reductions at 1000 and $1100^{\circ} \mathrm{F}$, and the reduced rates in Type $304 \mathrm{SS}$ material prolonging life at $1100^{\circ} \mathrm{F}$.

5. Tensile Studies

A. L. Ward

The objective of this program is to provide mechanical property and metallurgical stability data for LMFBR vessel and core structural materials in direct support of FFTF in order to provide assurance of adequate lifetime performance under anticipated FTR service conditions.

Tensile test results determined at elevated temperatures for annealed and 20\% cold-worked Type 316 SS provide a direct comparison of the response of these two materials to fast reactor irradiation. After irradiation to $8 \times 10^{21} \mathrm{n} / \mathrm{cm}^{2}$ (total) at $1100{ }^{\circ} \mathrm{F}$, annealed material exhibits substantial irradiation hardening and a loss in ductility. The $20 \%$ coldworked material, however, shows a significant decrease in yield strength at low test temperatures $\left(<1100^{\circ} \mathrm{F}\right)$ after irradiation. Apparently, significant thermal recovery occurred during irradiation of the cold-worked material, but the relationship between thermal recovery and irradiation hardening has not yet been investigated in detail. The ductility of 20\% cold-worked material remains low after irradiation.

Tensile tests have been completed on a series of Type 304 SS specimens following irradiation in the SURV-2 EBR-II surveillance subassembly (Row 12) to a peak total fluence of $3.2 \times 10^{21} \mathrm{n} / \mathrm{cm}^{2}$ at $700^{\circ} \mathrm{F}$. Three types of materials 
are represented:

- Type 304 SS wrought specimens (Code K) which were fabricated prior to the availability of the original EBR-II stock.

- Type 304 SS from the original EBR-II cover-plate stock. (Code P).

Type 304 SS containing a section of weld-deposited Type 308 SS (Code L).

Preliminary examination of the test results indicates that the materials have undergone only minor, if any, irradiation hardening. Slight increases in strength and losses in total elongation are suggested in the Codes $K$ and $P$ specimens, while the Code L specimens exhibit minor ductility losses with no effect on the strength.

Tensile and hardness testing is in progress on Fermi surveillance specimens of Types 304 and 347 SS and Incone1 X750 following accumulation of $21.5 \times 10^{21} \mathrm{n} / \mathrm{cm}^{2}$ (total) at temperatures between 540 and $700{ }^{\circ} \mathrm{F}$.

6. Fluence Limits

R. A. Moen

Fluence limits based on retaining a fixed percentage of total elongation capability at end-of-life are being used in the design of the FTR vessel, core barrel, and core support structure. These limits depend solely on the output of development programs which produce irradiation effects data. As these programs produce the type of data desired, the fluence limits are subject to revision.

Revised fluence limits for Type 304 SS and weldments of the same material compared to previous limits are shown in Table 7.4.

Fluence limits for shielded metal arc, gas-tungsten arc, and gas-metal arc were also prepared. In this re-evaluation 
of data, a 11 thermal reactor data were omitted. The omission of thermal reactor data primarily affects the lower temperature regime, $\left(500\right.$ to $\left.700{ }^{\circ} \mathrm{F}\right)$ where until now there were only thermal reactor data. Now, data from the EBR-II irradiation of base metal and weldments have shown that fast reactor exposures at these lower temperatures are less damaging than thermal reactor exposures. Therefore, with the increasing availability of fast reactor data, it will now become standard practice to use only fast reactor coupon data in the establishment of fluence limits for FIR structural materials.

TABLE 7.4. Fluence Limits for FTR Vessel, Core Barrel and Core Support Structure

Revised Fluence Limit

\begin{tabular}{rlcc}
\hline $\begin{array}{l}\text { Temp, } \\
{ }^{\circ} \mathrm{F}\end{array}$ & $\begin{array}{l}\text { Base Metal, } \\
\mathrm{n} / \mathrm{cm}^{2} \text { (tota1) }\end{array}$ & $\begin{array}{c}\text { Weldments, (a) } \\
\text { n/cm2(tota1) }\end{array}$ \\
\hline 600 & $9.5 \times 10^{21}$ & $7.3 \times 10^{21}$ \\
700 & $1.15 \times 10^{22}$ & $9.4 \times 10^{21}$ \\
800 & $1.19 \times 10^{22}$ & $7.9 \times 10^{21}$ \\
900 & $2.1 \times 10^{22}$ & $4.1 \times 10^{21}$ \\
1000 & $1.55 \times 10^{22}$ & --- \\
1100 & $1.12 \times 10^{22}$ & --- \\
1200 & $\mathbf{4 . 3} \times 10^{21}$ & ---
\end{tabular}

Previous Fluence Limit

Base Metal, Weldments,
$\frac{\mathrm{n} / \mathrm{cm}^{2}(\text { total) }}{6.0 \times 10^{21}} \frac{\mathrm{n} / \mathrm{cm}^{2}(\text { tota1) }}{2.5 \times 10^{21}}$ $6.0 \times 10^{21}$
$1.4 \times 10^{22} \times 10^{2}$ $1.4 \times 10^{22}$ $2.1 \times 10^{22}$

$2.4 \times 10^{22}$

$1.8 \times 10^{22}$

$2.7 \times 10^{21}$ $7.0 \times 10^{21}$ $1.0 \times 10^{22}$ $1.5 \times 10^{22}$ $9.6 \times 1021$ $1.0 \times 10^{21}$

a. For Type 304 SS weldments, using Type 308 SS filler, the submerged arc process and no post-weld treatment.

7. Carbon Transport

Carbon transport is of primary interest to designers concerned with long-term stability of materials used in the FIR primary heat transport system. Without some assurance that carbon transport will not occur, the designer is forced to use allowable stresses for low carbon stainless steels, 
which in turn result in heavier wall thicknesses. A study recently completed concluded that for all sections of the primary heat transport system from the reactor outlet nozzle downstream to the reactor inlet nozzle, decarburization or carbon transport is not expected to occur. This conclusion is supported by theoretical and experimental evidence. (1)

8. Construction Codes for Nonradioactive Sodium Loops at PNL M. T. Jakub

Four small nonradioactive sodium loop facilities (PAL, HTSF, FRTEF, and CRCTA) are being constructed in support of the FFTF. After consultants evaluated various alternatives, RDT and PNL representatives have agreed to use the following construction codes: B31.7, Class II, for piping; Section III, Class C, for vessels; Draft Pump and Valve Code, Class II, for pump casings and valve bodies. Appendix IX (ASME) will be used for all Quality Assurance requirements, but the code stamps will not be required for all components. The quality control provisions (including third-party inspection) are recognized as being of primary importance for quality fabrication.

9. Irradiated $\mathrm{B}_{4} \mathrm{C}$ Pellet Fragmentation

L. R. Bunnell

Irradiated $\mathrm{B}_{4} \mathrm{C}$ from the second Hanford discharge was examined externally to characterize the fragmentation of hot-pressed pellets as a function of original density and to provide a background for metallography. The following trends were observed for these 9 to $13 \% B_{10}$ burnup pellets:

- $65 \%$ TD pellets fractured into small, irregularlyshaped pieces, generally left an irregularly-shaped core. Much fine material was generated.

1. J. C. Tobin and W. F. Brehm, Unpublished Data, BattelzeNorthwest. (Carbon Transport in the FFTF-MMR-36, A-0199). 
BNWL- 1394

- $90 \%$ TD pellets also fractured, left less fine material. The fractures also left core material, but broken pieces tended to take the form of "shel1s," that is, annular rings of $\mathrm{B}_{4} \mathrm{C}$.

- $99 \%$ TD pellets, the most difficult to remove from capsules, contained even less fine material; the fracture habit was extremely shell-like.

The irradiated material was red when viewed in transmission, apparently because of color centers introduced by gamma exposure in-reactor.

Selected $\mathrm{B}_{4} \mathrm{C}$ pellets from the second Hanford discharge were polished and examined metallographically. Figures 7.15, 7.16, and 7.17 show traverse views of the pellets; they follow trends noted previously at lower burnup with radial cracks observed in low-density pellets and circumferential cracks present in high-density pellets. Micrographs of the same pellets showed the presence of microcracks in the 99\% TD pellet with few, if any, present in the lower density pellets. The microcracks observed extend to the center of the high density pellet, and the presence of these cracks, which is beyond the normal range of thermal neutrons, is attributed to radiation damage due to the fast neutron component of the flux.

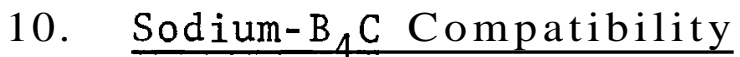

L. R. Bunnel

In order to extend previous data to higher temperatures, hot-pressed $\mathrm{B}_{4} \mathrm{C}$ pellets were exposed to sodium at $600{ }^{\circ} \mathrm{C}$ for 100 hr in compatibility-transport capsules. Metallographic results followed the same trends noted at lower temperatures, with-sodium attack more severe in the $75 \%$ and $85 \%$ TD pellets than in the $96 \%$ TD pellet. Attack was noticeably more severe in the lower density pellets than in the previous $500{ }^{\circ} \mathrm{C} 100 \mathrm{hr}$ experiments. Areas of low density $\mathrm{B}_{4} \mathrm{C}$ were apparently removed 
BNWL- 1394

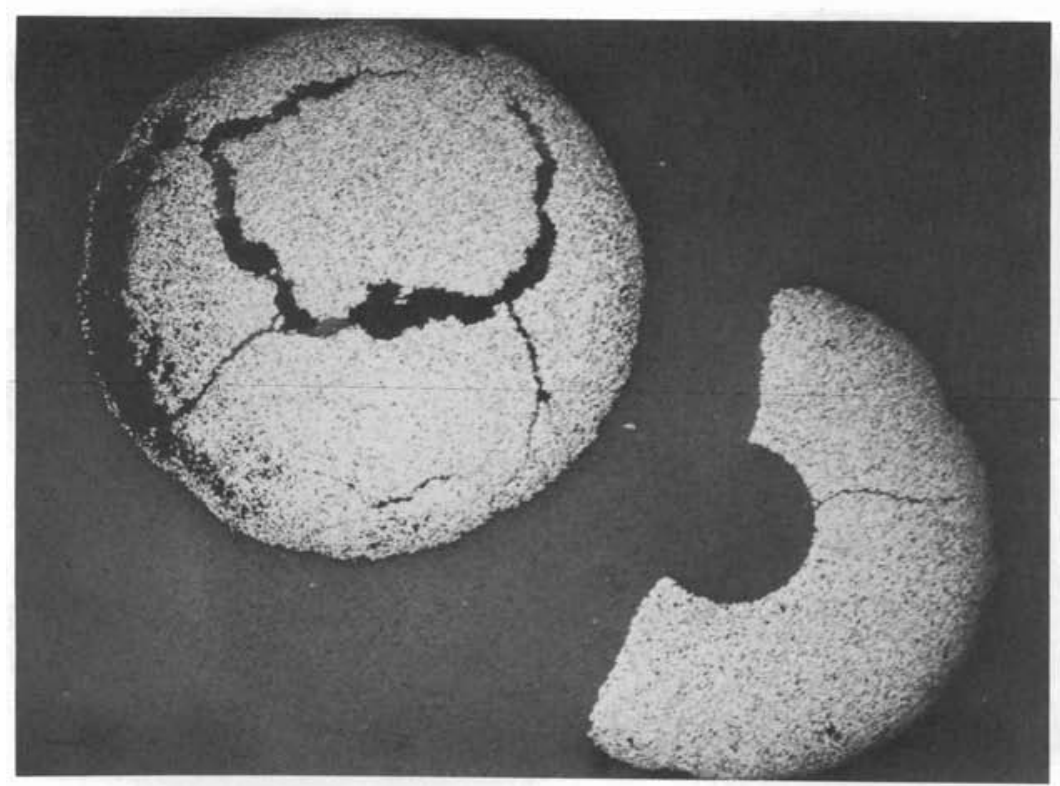

Neg 702409-1

FIGURE 7.15. Macrograph of 65\% TD Pellet (4-5) Irradiated to 11\% Burnup at $350^{\circ} \mathrm{C}$ with Pronounced Splitting and Radial Cracks. (Pellet segment on lower right was drilled for thermocouple.)

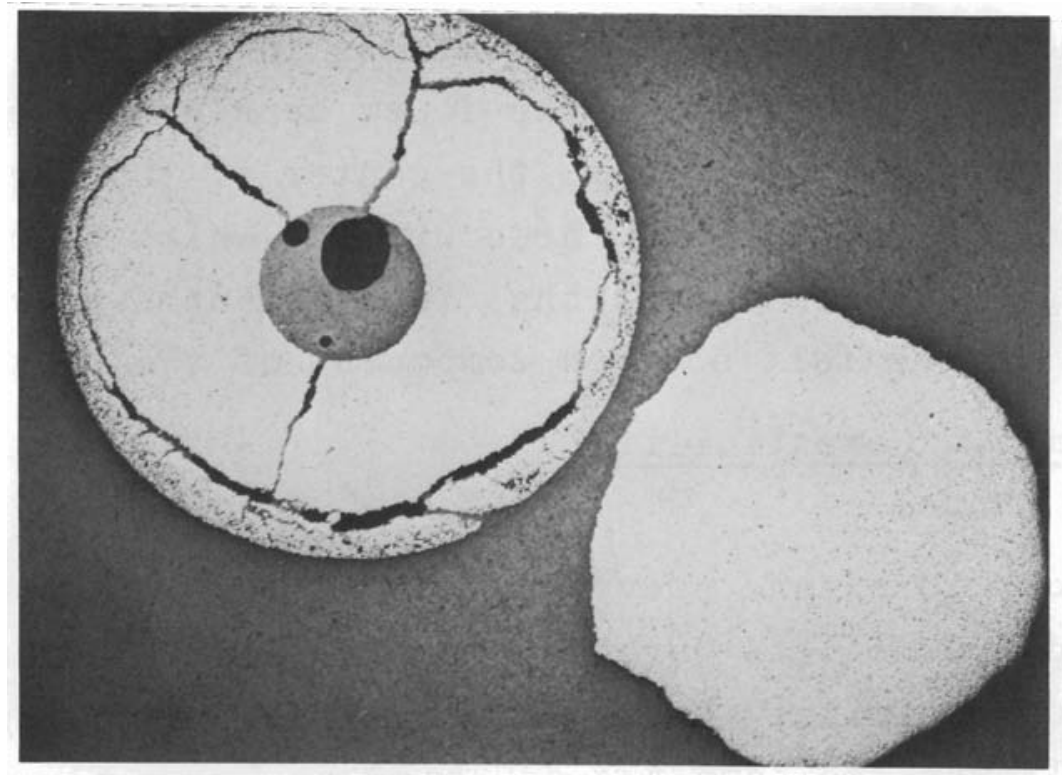

$9 \mathrm{x}$

FIGURE 7.16. Macrograph of 90\% TD Pellet (4-4) Irradiated to 9\% Burnup at $370{ }^{\circ} \mathrm{C}$ and Containing Both Radial and Circumferential Cracks. Central Hole Is a Thermocouple Well and Black Areas Are Bubbles Within a Mount. (Pellet at lower right has lost its outer circumferential shell.) 


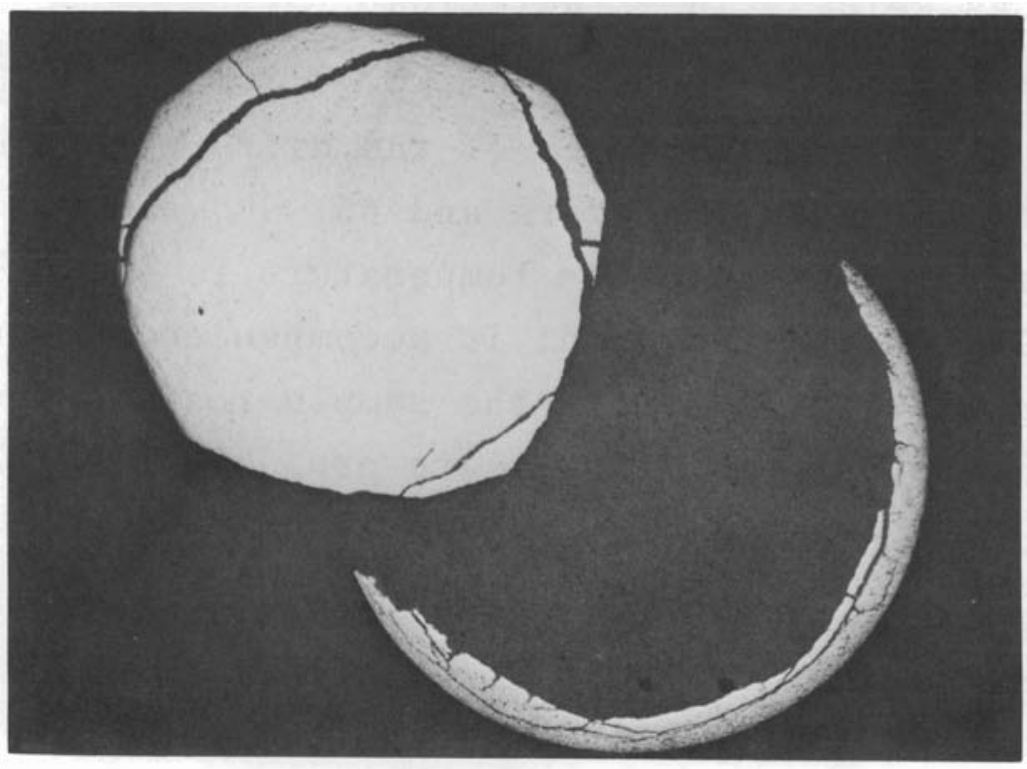

FIGURE 7.17. Macrograph of $99 \%$ TD Pellet (4-14) Irradiated to $\sim 7 \%$ Burnup at $300{ }^{\circ} \mathrm{C}$. (Note absence of radial cracking.)

by the sodium. Metallography of the Type 316 SS capsule revealed no interaction or evidence of carburization; however, chemical analysis for boron and carbon is proceeding.

\section{Lithium-B,C Effects}

L. R. Bunnell

The production of lithium by ${ }^{10} B(n, \alpha)$ reaction prompted an investigation of the effects of lithium on $\mathrm{B}_{4} \mathrm{C}$. At temperatures of $>500{ }^{\circ} \mathrm{C}$ for periods of $\sim 100 \mathrm{hr}$, a gross expansion occurs; it amounts to a $50 \%$ increase in length (factor-of-three volume increase). This length increase was noted in capsule tests and was observed in experiments performed in the inert atmosphere facility. X-ray diffraction analysis showed lithium carbide $\left(\mathrm{Li}_{2} \mathrm{C}_{2}\right)$ initially, with lithium boride ( $\left.\mathrm{LiB}_{11}\right)$ forming after exposure to a moist atmosphere. Similar reaction products have been detected by Secrist. (1)

1. D. R. Secrist. "Compound Formation in the Systems LithiumCarbon and Lithium-Boron," J. Am. Cer. Soc., vol. 50 (10) pp. 520-523. 2967. 
12. $\underline{B}_{\triangleleft} \mathrm{C}$ Gas Release in Irradiation

A. L. Pitner

The gas release behavior of the different forms of boron carbide (60 and $80 \%$ TD powders and 65, 90, and 99\% TD pellets) as a function of irradiation temperature is shown in Figure 7.18. Each data point is accompanied by a number indicating which subassembly the sample resided in. (The results from Subassembly No. 1 are probably the least reliable.)

The percent of gas released from boron carbide appears to increase rapidly when the irradiation temperature exceeds $1000^{\circ} \mathrm{F}$. The $99 \% \mathrm{TD}$ pellets release the lowest fraction of gas. The 65 and $80 \%$ TD pellets do not appear to vary significantly in their gas release behavior, but both release a higher gas fraction than the $99 \%$ TD pellets.

13. Radiation Effects on Tantalum Absorbing Material for Control Rods

A. L. Pitner

Density and length changes of the samples in the tantalum Capsule TA-5 in the EBR-II are given in Table 7.5 along with the estimated exposures and irradiation temperatures. The results from the previously disassembled Capsule TA-4 are also included for comparison, and they agree reasonably well. As noted previously, the irradiation-induced swelling is highest for the lower-temperature samples, even though they received the least exposure.

The tantalum replacement capsules, BTA-6 and BTA-7, have been loaded into the X042 subassembly and are now under irradiation in the EBR-II. Based on the temperature measurement from the SiC pellet in TA-5, tantalum samples in BTA-6 and BTA-7 are expected to reach maximum temperatures of $2300^{\circ} \mathrm{F}$. 


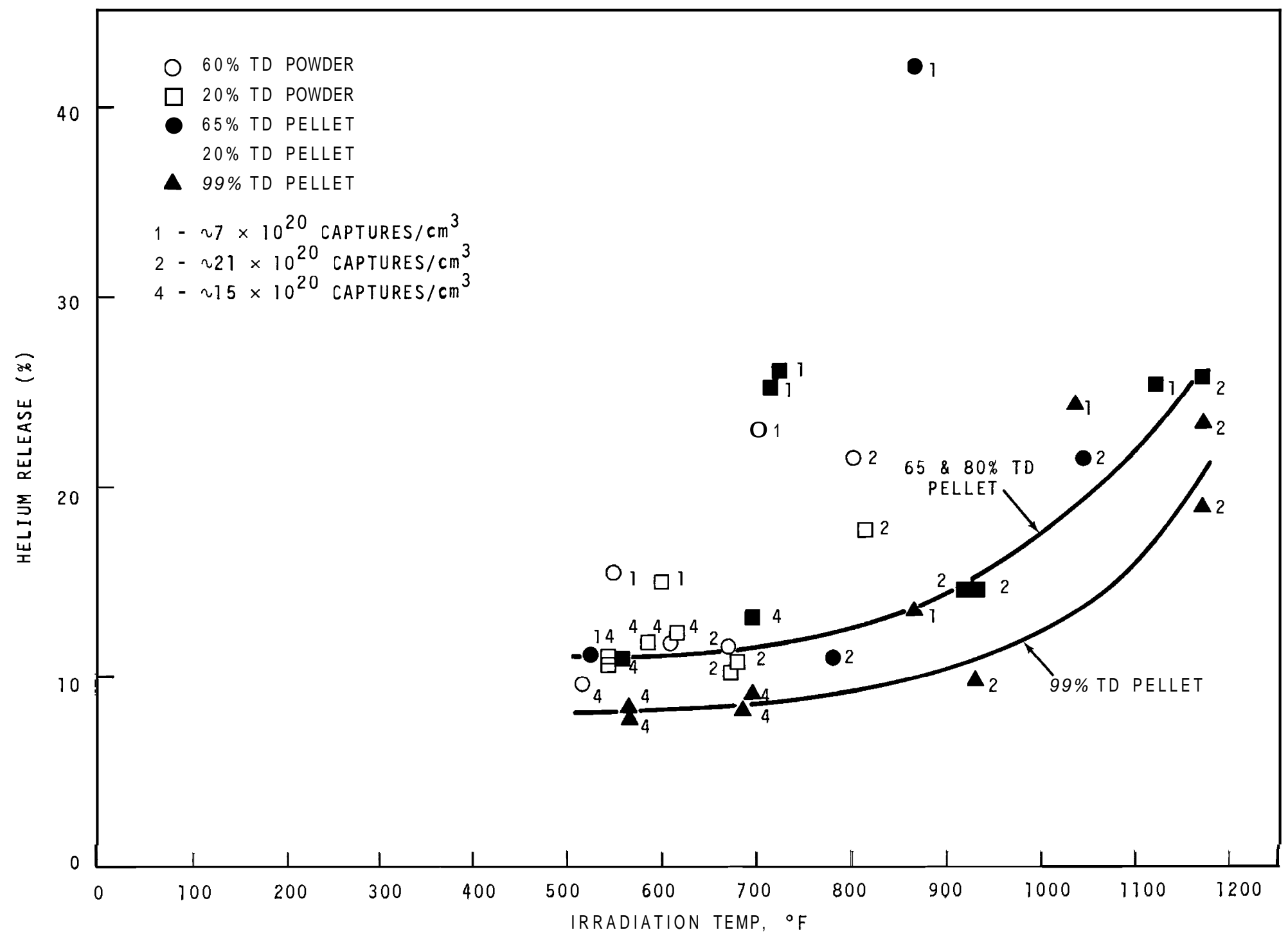

FIGURE 7.18. Helium Gas Release of Boron Carbide Irradiated in a Thermal Flux, 
TABLE 7.5. Swelling of Tantalum Irradiated in EBR-II

\begin{tabular}{|c|c|c|c|c|c|c|c|}
\hline \multirow[b]{2}{*}{ Sample } & \multirow{2}{*}{$\begin{array}{c}\text { Est. } \\
E\end{array}$} & \multirow{2}{*}{$\begin{array}{l}\text { Exposure, } \\
0.1 \mathrm{MeV}\end{array}$} & \multirow{2}{*}{$\begin{array}{c}\text { Temp, } \\
{ }_{F}\end{array}$} & \multicolumn{2}{|c|}{$\mathrm{TA}-4$} & \multicolumn{2}{|c|}{$\mathrm{TA}-5$} \\
\hline & & & & $\Delta L, \quad \%$ & $\Delta \rho, \%$ & $\Delta L, \%$ & $\Delta p, \%$ \\
\hline 1 & 3.0 & $\times 10^{21}$ & 1175 & +0.13 & -0.69 & +0.18 & -0.88 \\
\hline 2 & 4.6 & $\times 10^{21}$ & 1550 & +0.13 & -0.68 & +0.13 & -0.72 \\
\hline 3 & 6.7 & $\times 10^{21}$ & 1875 & +0.11 & $-0.85^{(a)}$ & $+0.07^{(a)}$ & -0.47 \\
\hline 4 & 8.2 & $\times 10^{21}$ & 2050 & -- & -0.58 & +0.06 & -0.53 \\
\hline 5 & 8.6 & $\times 10^{21}$ & 2100 & +0.01 & -0.42 & +0.02 & -0.29 \\
\hline 6 & 8.2 & $\times 10^{21}$ & 2050 & +0.05 & -0.45 & +0.03 & $-0.25^{(a)}$ \\
\hline 7 & 6.7 & $\times 10^{21}$ & 1875 & +0.06 & -0.62 & $+0.10^{(a)}$ & -0.61 \\
\hline 8 & 4.6 & $\times 10^{21}$ & 1550 & +0.09 & -0.63 & +0.11 & $-0.82^{(a)}$ \\
\hline 9 & 3.0 & $\times 10^{21}$ & 1175 & +0.13 & -0.72 & $+0.09^{(a)}$ & -0.58 \\
\hline
\end{tabular}

a. Plating from nearby mezt wire apparently caused measurement to be in error. 


\section{CHAPTER VIII. FUELS RECYCLE}

\section{A. FUELS TECHNOLOGY}

\section{Laboratory Size Moisture Measuring Instrument M. J . Barr}

A compact moisture measuring instrument was built to provide moisture content data on development size powder batches. The instrument is based on a prototype designed by J. E. Sammis and W. F. Bonner (FFTF Fuel Department). The instrument shown in Figure 8.1 is air tight and consists of a $2-1 / 2$ in. OD $x$ 5 in. long aluminum tube with a Panametric moisture sensor and a thermometer mounted in the threaded cap. The instrument will be used to correlate powder moisture content with the pressing behavior of mixed oxide batches.

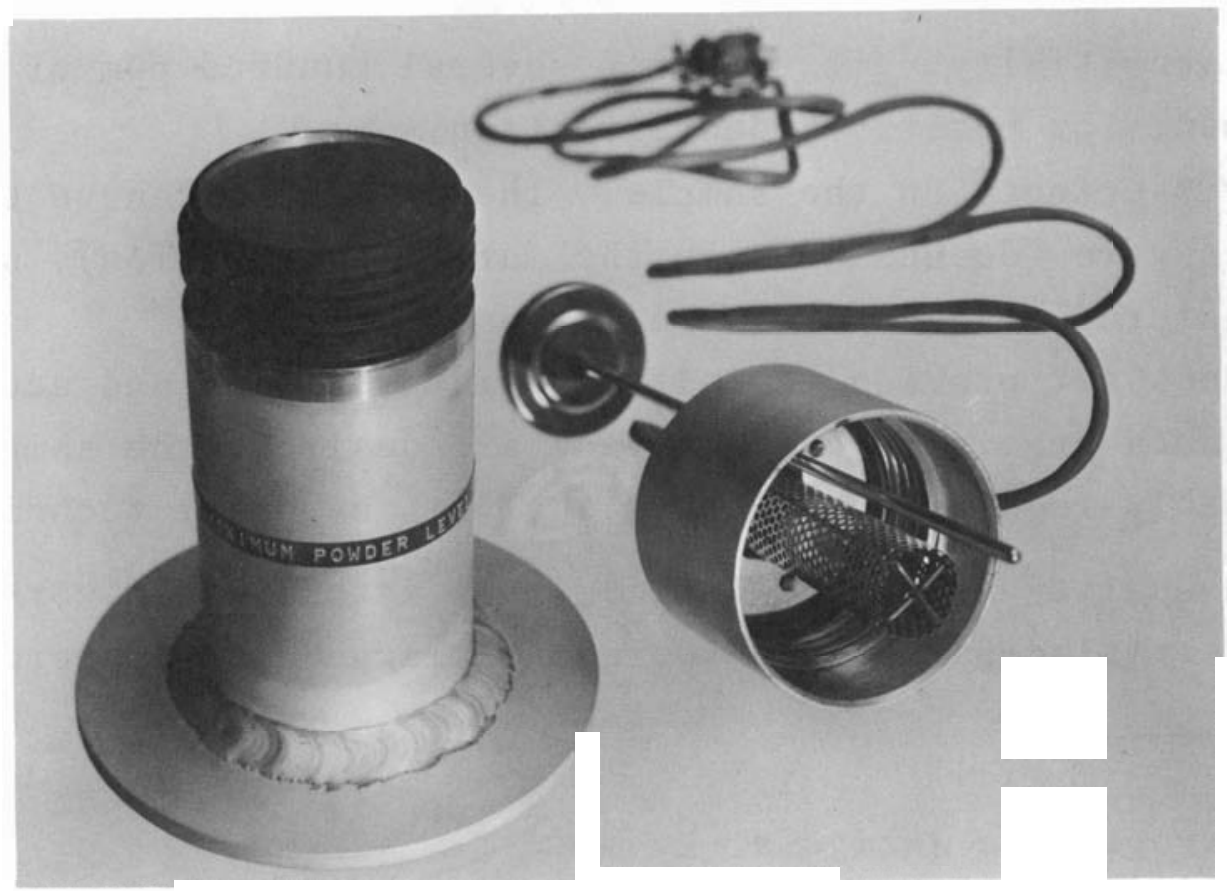

Neg 700969-2

FIGURE 8.1. Laboratory Size Moisture Measuring Instrument 
2. X-ray Fluorescence as a Quality Assurance Tool

H. G. Powers

Recent trial applications of X-ray fluorescence for rapid material analysis and survey hate shown this technique to be useful on a limited basis. Advantages of X-ray analysis in the characterization of materials are:

- Nondestructiveness

- Speed

- Simple emission spectra. This minimizes interference effects since only 2 to $10 \mathrm{x}$-ray lines are detected.

- With proper equipment, many and diverse sample shapes can be accommodated.

- It is specific for elements. For example, it makes no difference whether iron is present as a metal or as any of the diverse iron compounds.

$\mathrm{X}$-ray fluorescence analysis also has disadvantages:

- Low sensitivity. It requires several hundred ppm of an element for positive identification.

- Matrix effects on the sample. These effects can be complex and severe (depending upon the matrix composition), unless an internal standard can be introduced.

- It does not provide the ultimate in precision and accuracy. All such precision and accuracy are desired, the sample will probably require destructive analysis by other techniques." As a quality assurance device, this method would work well if the material discrepancies were of a large order (approximately

* Such as:

- Spectrographic Analysis

- Atomic Absorption

- Wet Chemistry 
0.1 to $0.2 \%)$. For small differences (100 to $1000 \mathrm{ppm})$, a rapid survey would probably not be sufficiently accurate. In such cases, the sample would have to be qunatitatively analyzed, probably in a destructive manner; therefore, other techniques might be more applicable.

$x$-ray flourescence techniques are currently being applied as a means to provide interim overchecks of vendor chemical analysis on as-received hardware. During this reporting period, such an overcheck was made on 302 springs, with lead showing up in an alarming amount. First evaluations of the situation were based upon the assumption that the parent metal contained lead as an impurity; however, further analysis showed a corresponding apparent reduction in indications of iron. Experience has shown that when surfaces are contaminated by heavier metals such as lead, iron emissions are attenuated and cannot be recorded. This accounts for the apparent low concentration of iron. Processing test springs through the 308 cleaning process and re-examining them by X-ray fluorescence resulted in a normal analysis of the 302 springs when they were compared with an NBS standard of similar materials. Further investigations showed that use of lead in lubricants is common in the spring fabrication industry.

The significance of this evaluation is that X-ray fluorescence is not only capable of detecting elemental inconsistencies in alloys, but can also detect undesirable surface conditions. Therefore, X-ray fluorescence may be a valid test for evaluation of process cleaning cycles. The test is fast and relatively cheap, and permanent records are produced for verification and documentation. 


\section{Fuel Pellet Homogeneity Inspection and Testing}

H. G. Powers

Standard pellets have been selected to be used by industry to determine the relative homogeneity of fuel pellets manufactured in the qualification round. Eight fuel pellets of varying homogeneity have been analyzed with an electron microprobe. The concentrations of $\mathrm{PuO}_{2}$ and $\mathrm{UO}_{2}$ at $2 \mu$ intervals across a transverse section of each of the pellets were recorded by the microprobe on paper tape. These data have been transferred to magnetic tape for computer calculation of a figure of merit for each pellet. Five figures of merit have been calculated to date. Three pellets for which figures of merit have been calculated via computer code have also had figure of merit values calculated for them by hand via previously-obtained microprobe continuous chart data. The hand-calculated values are up to $10 \%$ higher than those obtained from the computer code. This low-side bias appears in all the pellets analyzed thus far. Although nothing has been ascertained, problems with the data recorded on the magnetic tape may be the prime cause of the bias.

Seven standard pellets to be used by industry in the qualification round to determine the relationship between allowable $\mathrm{PuO}_{2}$-enriched area size and $\mathrm{PuO}_{2}$ concentration have been fabricated. The pellets have also been mounted, polished, a autoradiographed, and photographed at 50x. Each of these standard pellets was fabricated with both $300 \mu, 30 \mathrm{wt} \% \mathrm{PuO}_{2}$ and $120 \mu$, $100 \mathrm{wt} \% \mathrm{PuO}_{2}$ spheroids in a standard matrix of $25 \mathrm{wt} \% \mathrm{PuO}_{2}{ }^{-}$ $75 \mathrm{wt} \% \mathrm{UO}_{2}$. These spheroids represent the maximum allowable $\mathrm{PuO}_{2}$ enriched area size at the maximum concentration level respectively. The relationship between allowable $\mathrm{PuO}_{2}$ enriched area size and allowable $\mathrm{PuO}_{2}$ concentration in the area is a linear function between these two extremes. 
4. Fabrication of Mixed Oxide Fuel for EBR-II Subassemblies W. E. Warden

Fuel fabrication for PNL-10 and 11 is complete. This fuel consists of $65 \%$ enriched $\left({ }^{235} \mathrm{U}\right)$ mixed oxide in the EBR-II test composition of $75 \% \mathrm{UO}_{2}-25 \% \mathrm{PuO}_{2}$. Sixteen kilograms of fuel, in $4 \mathrm{~kg}$ lots, were sintered for the two subassemblies. Three of the lots were centerless ground and one of the lots (FE-93) was sintered to meet the required diametral tolerance $(0.194$ in. \pm 0.0015 in.). The sintered-to-size fuel represents a major accomplishment in fuel fabrication for irradiation test assemblies. Diametral data from lot FE-93 (see Table 8.1) showed the tight tolerances maintained within the lot. A second lot of fuel (FE-94) was fabricated to establish the process repeat-. ability and for use in PNL-12A. Diametral data from lot FE-94 show the same tight diametral tolerance exhibited by lot FE-93.

The tight control-to-diametral tolerance is representative of fuel fabricated by the high pressure preslug-granulate, lowpressure compact fabrication sequence. Experience has shown that fuel fabricated by this sequence has a smaller pressure gradient in the compacted pellet and less shrinkage in sintering.

TABLE 8.1. Diametral Control Data for PreslugGranulate-Compact Fabricated Fuel

\begin{tabular}{|c|c|c|c|c|c|c|c|c|}
\hline Lot & $\begin{array}{c}\text { Sample } \\
\text { Size } \\
\end{array}$ & $\frac{\text { First }}{\text { Mean }}$ & $\frac{\text { End, }}{\text { in } .}$ & $\frac{\text { Midd }}{\text { Mean }}$ & in. & $\begin{array}{l}\text { Second } \\
\text { Mean } \\
\end{array}$ & $\frac{\text { End, in. }}{\sigma}$ & $\begin{array}{l}\underset{\operatorname{Maximum} \Delta}{\mathrm{M} .} \text { diam, of } \\
\text { One Pellet, in. }\end{array}$ \\
\hline FE -93.0 & 30 & 0.19354 & 0.0018 & 0.19352 & 0.00019 & 0.19340 & 0.00013 & 0.0005 \\
\hline $\mathrm{FE}-94.0$ & 30 & 0.19376 & 0.00023 & 0.19369 & 0.00023 & 0.19354 & 0.00026 & 0.0006 \\
\hline FE- 73.4 & 15 & 0.19656 & 0.00025 & 0.19642 & 0.00021 & 0.19631 & 0.00023 & 0.0004 \\
\hline $\mathrm{FE}-74.0$ & 10 & 0.19699 & 0.00017 & 0.19681 & 0.00026 & 0.19674 & 0.00026 & 0.0006 \\
\hline
\end{tabular}


5. FIR Fuel Specifications

C. A. Strand

Specifications for FIR fuel were written as RDT standards for use in the RFP package for the Vendor Qualification program. These standards and associated drawings were prepared by BNW and WARD. Preparations are being made for finalizing the standards. A listing of the RDT standards and the status of each is shown in Table 8.2.

TABLE 8.2. Status of RDT Standards Preparation for FTR Driver Fuel

RDT Std. No.

E $13-1$

E $13-2$

E 13-3

E 13-4

E $13-5$

E $13-6$

E $13-7$

E $13-8$

E $13-9$

E $13-10$

E $13-11$

E 13-12

E 13-13
Title

FFTF Ceramic Grade Plutonium Dioxide

FFTF Ceramic Grade Uranium Dioxide

FFTF Uranyl Nitrate Solution

FFTF Plutonium Nitrate Solution

FFTF Driver Fuel Pin

FFTF Driver Fuel Pin Fuel Pellet

FFTF Driver Fuel Pin Insulator Pellet

FFTF Driver Fuel Pin Seamless Cladding Tube

FFTF Driver Fuel Pin End Caps

FFTF Driver Fuel Pin Reflector

FFTF Driver Fuel Pin Plenum Spacer

FFTF Driver Fuel Pin Plenum Spring

FFTF Driver Fuel Pin Wire Wrap
Status

Code $(a)$

1

1

2

2

1

1

1

1

1

1

1

1

1

a. Status Code:

1. Draft reviewed and comments submitted to WARD

2. Being prepared by $B N W$ 


\section{Void Size Distribution Measurements}

\section{C. J. Carlson}

A comparison of the average void frequencies predicted by three methods for pellet MEE-63-4-B is shown in Table 8.3 and Figure 8.2. No significant $(>2 \sigma)$ variation exists between the void frequencies obtained by the three methods.

TABLE 8.3. Comparison of Frequency of 8- $\mu$ Diameter Voids in an MEE-63-4 Fuel Pellet as Found by Three Methods

\begin{tabular}{|c|c|c|c|}
\hline Method & $\frac{\text { Void Size, }}{\mu}$ & $\begin{array}{l}\text { Void Concentra- } \\
\text { tion, Voids } / \mathrm{cm}^{3} / \mu \\
\end{array}$ & $\begin{array}{c}\text { Unfolding } \\
\text { Uncertainties, } \\
\text { la level } \\
\end{array}$ \\
\hline $\begin{array}{l}\text { Lineal Micro- } \\
\text { probe Trace } \\
\text { Analysis } \\
\text { (Specimen } \\
\text { current } \\
\text { traces) }\end{array}$ & 8 & $2.6 \times 10^{7}$ & $\pm 0.46 \times 10^{7}$ \\
\hline $\begin{array}{l}\text { Zeiss } \\
\text { Particle } \\
\text { Analyzer } \\
\text { (Photographs } \\
\text { along traces) }\end{array}$ & 8.15 & $3.4 \times 10^{7}$ & $\pm 0.46 \times 10^{7}$ \\
\hline $\begin{array}{l}\text { Lineal } \\
\text { Analysis of } \\
\text { Photographs } \\
\text { Along Trace }\end{array}$ & 8 & $3.2 \times 10^{7}$ & $\pm 0.46 \times 10^{7}$ \\
\hline
\end{tabular}

7. Pellet Sintered Density Control

W. A. Ross and W. E. Warden

Development is continuing on a process to achieve densities of 85 and $87 \%$ TD for a $25 \mathrm{wt} \% \mathrm{PuO}_{2}-75 \mathrm{wt} \%$ normal $\mathrm{UO}_{2}$ mixture.

Methyl cellulose was evaluated as a means of sintered density control. One, two, and three wt methyl cellulose from a 3 wt \% solution was added to standard process powder which was dried, then pressed into pellets at pressures between 


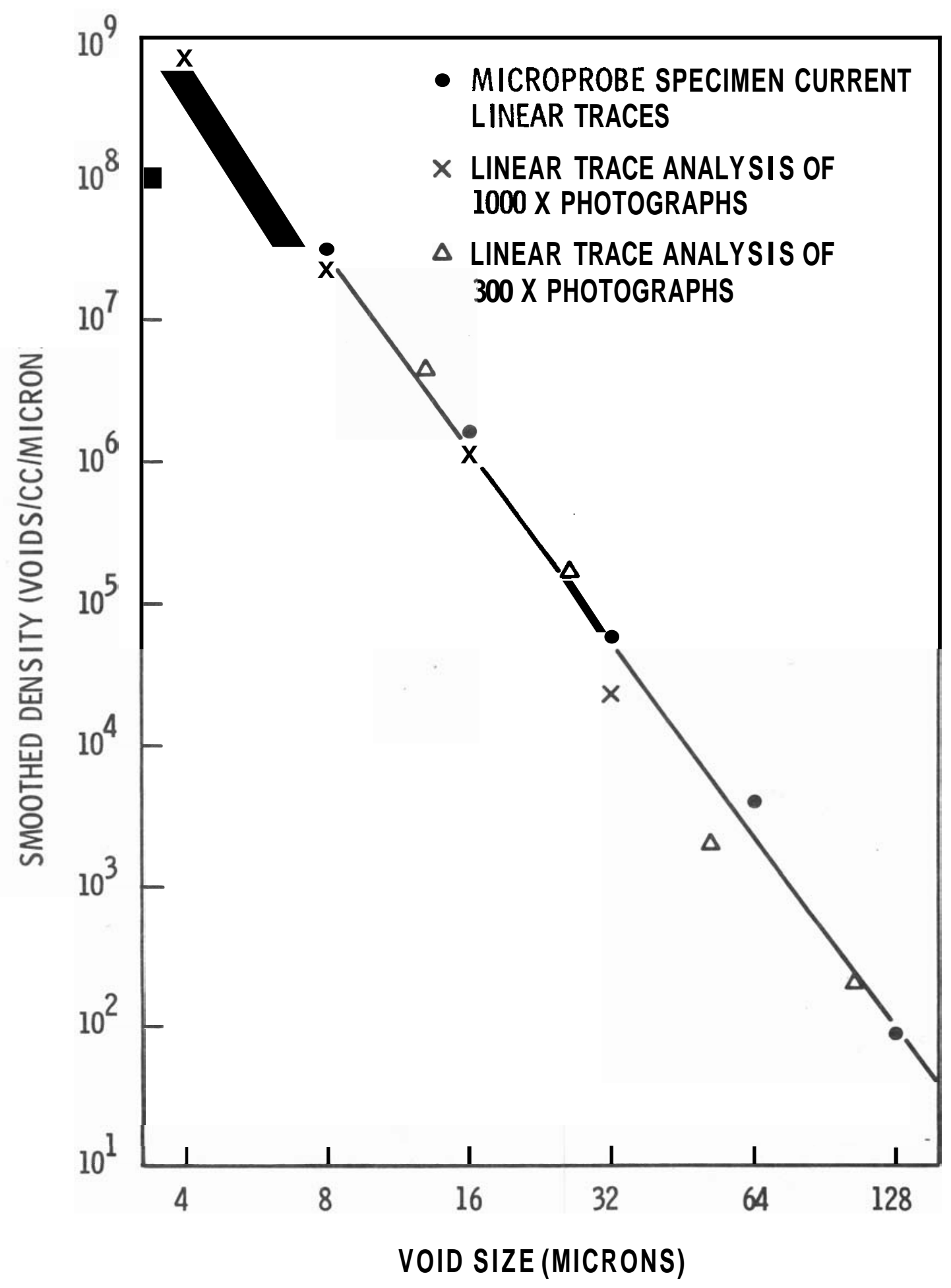

FIGURE 8.2. Comparison of Void Size Distributions Found by Examination of Microprobe Traces and Photographs 
20,000 and $40,000 \mathrm{psi}$. The pellets were then debound in normal cycle $\left(600{ }^{\circ} \mathrm{C}\right)$ and sintered in an all-metal furnace at $1690{ }^{\circ} \mathrm{C}$. As can be seen in Figure 8.3, the effect of the small addition showed a large decrease in sintered density, and the decrease appears to be nearly linear.

8. Pre-irradiation Characterization for Test Fuels M. C. J. Carlson

Analytical modelling of test fuel performance requires quantitative input data on the pre-irradiation condition of the fuel. Such data is needed in order to provide a good understanding of the fuel fabrication - fuel structure - fuel performance relationships. To provide characterization data for both fuel performance modelling efforts and evaluation of the fuel characteristics from standard fuel fabrication methods, a program has been developed for detailed characterization of large sintering lots of fuel material prepared for fuel test subassemblies. An outline of the program is shown in Table 8.4. Figure 8.4 shows a schematic flow sheet for sample progression through characterization steps.

\section{TABLE 8.4. Advanced Characterization Outline}

I. Density Determinations
A. Physical Measurements Density
B. Lattice Parameter Measurements
C. Immersion Density Measurements

II. Porosity Characterization
A. Void Size Distributions
B. Void Spatial Distributions
C. Surface Connected Porosity Determinations

III. Grain Characterization
A. Average Grain Size Determinations
B. Grain Geometry Characterization
C. Grain Size Heterogeneity

IV. Composition Distributions

A. Macrodistributions

1. Uranium

2. Plutonium

3. Oxygen/Metal Ratio

4. Impurities

B. Microd'istributions

1. Uranium

2. Plutonium

3. Impurities

V. Inclusion Characteristics

A. Chemical Content

B. Size Distribution

C. Inclusion Frequency

VI. Examination for Second Phase 


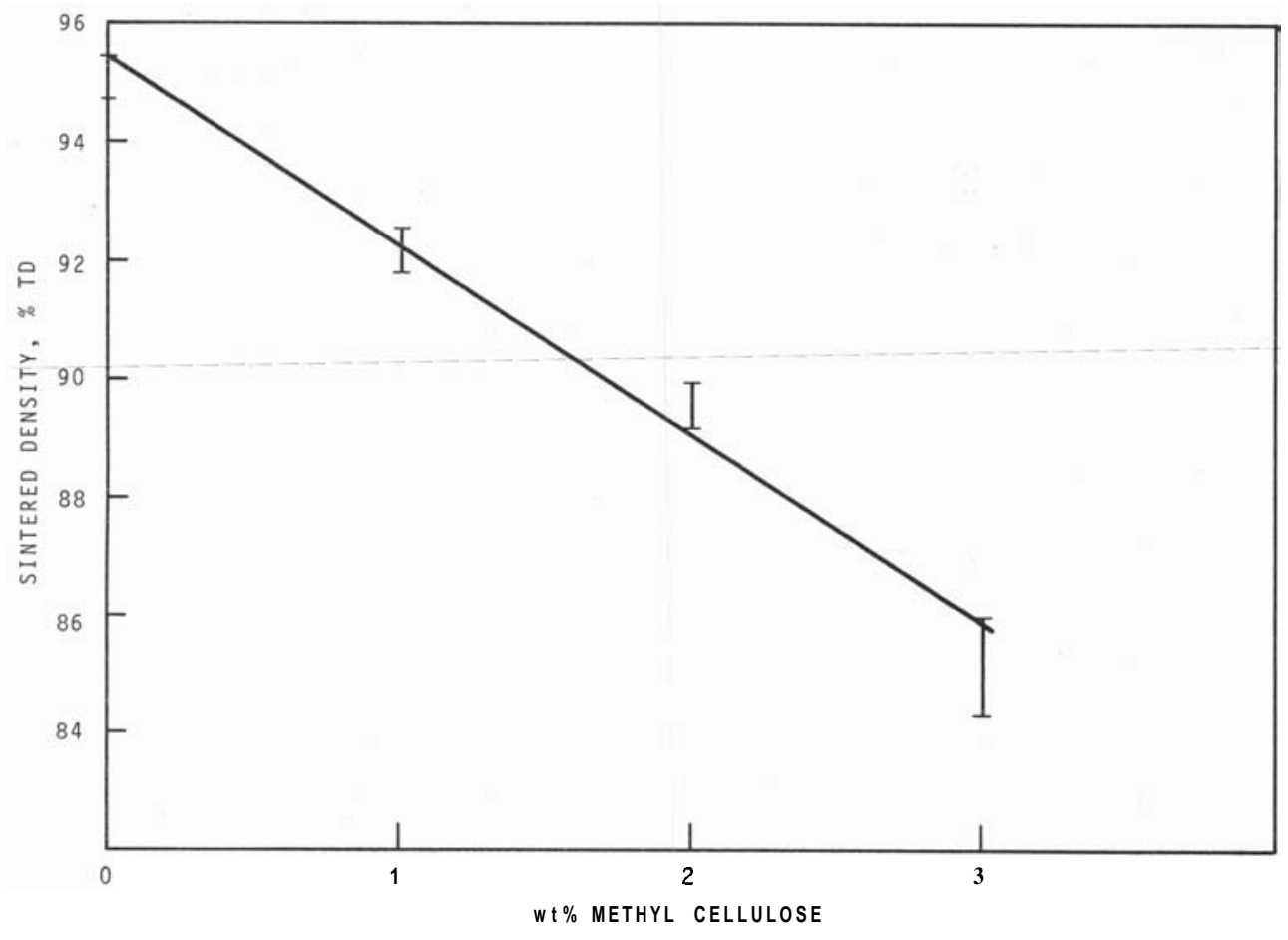

FIGURE 8.3. Effect of Methyl Cellulose in Decreasing Density

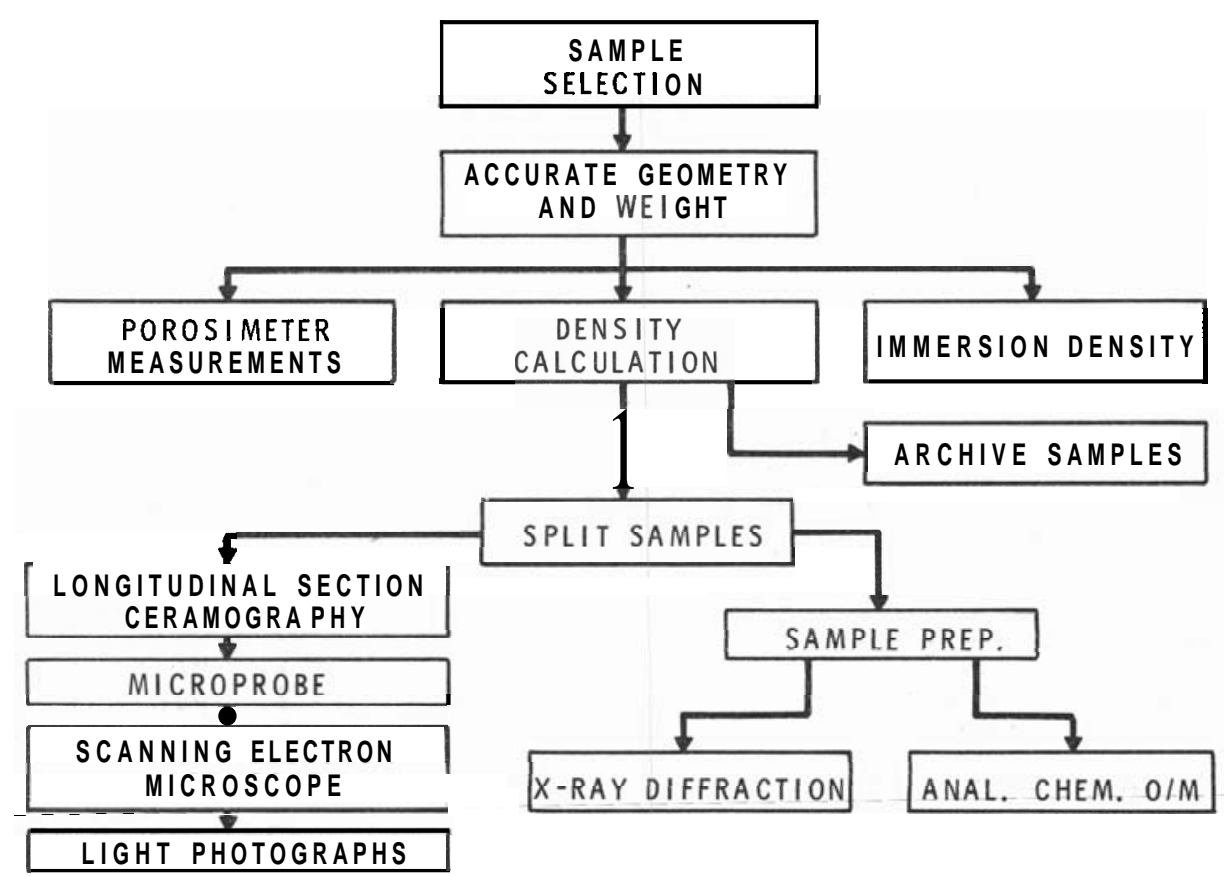

Neg 701096-2

FIGURE 8.4. Proposed Advanced Characterization Schematic 
9. Fuel Performance Prediction and Analysis

R. D. Leggett, R. B. Baker, L. E. Addison,

and D. C. Bullington

Work is in progress directed toward the development of empirically-based and theoretically-based formulations for predicting mixed oxide fuel behavior during irradiation. Detailed analyses of irradiation data are employed to "calibrate" the various mathematical models that best describe fuel performance. The ultimate goal of this task is to develop a comprehensive analytical procedure that can be used to predict fuel performance in LMFBR systems from considerations of fabrication parameters, irradiation conditions, and basic material properties of the fuel and cladding. Both steady-state and transient conditions are being considered.

Programming and upgrading of capabilities have continued with the Hybrid Computer.

A preliminary study was made of the sensitivity of physical properties and heat transfer variables upon the estimated fuel swelling and maximum fuel temperature of a reference FFTF fuel pin operating at $12.2 \mathrm{~kW} / \mathrm{ft}$.

Table 8.5 shows the variables used for the reference calculation.

\section{TABLE 8.5. Reference Data for FFTF Peak Power} Fuel $\mathrm{Pin}(\mathrm{Q} / \mathrm{L}=12.2 \mathrm{~kW} / \mathrm{ft})$

Fuel Pin Length

Extrapolation Distance

Maximum Heat Rating

Clad Thickness

Coolant Mass Flow Rate

Coolant Specific Heat

Coolant Film Coefficient

Fuel-Cladding Heat

Trans. Coef.

Cladding Thermal

Conductivity

$\begin{array}{cl}3.00 & \mathrm{ft} \\ 0.625 & \mathrm{ft} \\ 12.2 & \mathrm{~kW} / \mathrm{ft} \\ 0.015 & \mathrm{in} \\ 830 & \mathrm{lb} / \mathrm{hr} \\ 0.305 & \mathrm{Btu} / \mathrm{lb}-{ }^{\circ} \mathrm{F} \\ 37,500 & \mathrm{Btu} / \mathrm{ft}{ }^{2}-\mathrm{hr}-{ }^{\circ} \mathrm{F} \\ 1,000 & \mathrm{Btu} / \mathrm{ft}{ }^{2}-\mathrm{hr}-{ }^{\circ} \mathrm{F} \\ 11.4 & \mathrm{Btu} / \mathrm{ft}-\mathrm{hr}-{ }^{\circ} \mathrm{F}\end{array}$




\section{TABLE 8.5. (Contd)}

Inlet Coolant Temperature

Temperature Columnar Grain Growth

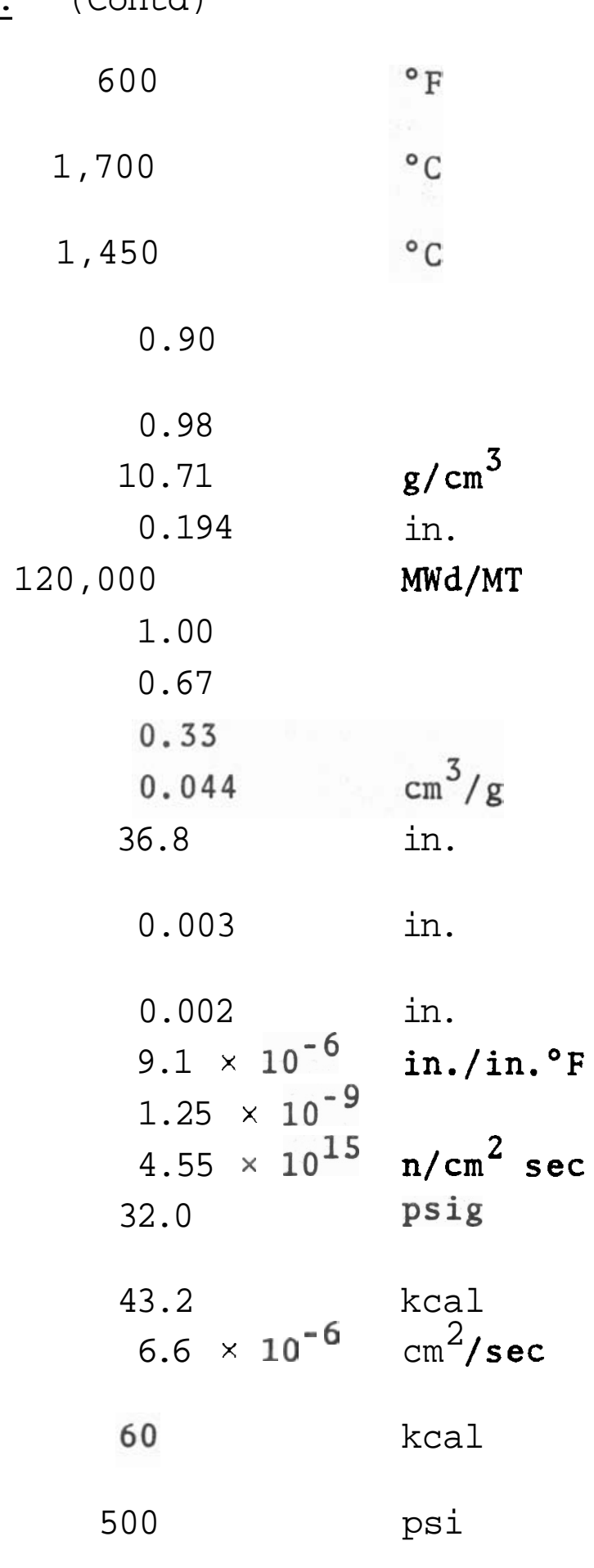

Equiaxed Grain Growth in Fuel

Initial Pellet Theoretical Density

Final Density Columnar Grains

Theoretical Fuel Density

Pellet Diameter

Peak Burnup

Gas Release Inner Zone

Gas Release Center Zone

Gas Release Outer Zone

Adsorbed Gas

Effective Plenum Length

Defects on Inner Clad Surface

Defect Depth Outer Clad Surface

Coefficient 1 in a

Coefficient 2 in a

Peak Flux

External Pressure

Activation Energy Gas Diffusion

Diffusion Coefficient

Activation Energy for Creep of Matrix

Hydrostatic Pressure in Fuel

Swelling is sensitive to the heat transfer between the fuel and cladding for the case examined when the heat transfer coefficient is less than $5000 \mathrm{Btu} / \mathrm{ft}^{2}-\mathrm{hr}-^{\circ} \mathrm{F}$. 
The sensitivity to the activation energy for gaseous diffusion is a strong function of burnup.

Table 8.6 presents a summary of the results of this preliminary sensitivity analysis.

TABLE 8.6. Sensitivity of Unrestrained Pellet Expansion to Variables

\begin{tabular}{|c|c|c|c|c|}
\hline Variable & Range & Expected Value & $\%$ Change & Sensitivity \\
\hline & \multicolumn{4}{|c|}{ Heat Transfer Variables } \\
\hline Sodium Heat Trans. Coef. & 25,000 to 50,000 & 32,000 & -22 to +56 & Verylow \\
\hline Fuel-Cladding Heat Trans. Coef. & 750 to 7,000 & 1,200 & -38 to +480 & $\begin{array}{l}\text { Sensitive below } \\
\mathrm{Hg}=5000\end{array}$ \\
\hline \multicolumn{5}{|l|}{ - Fission Gas Diffusion } \\
\hline Coefficient & $\begin{array}{l}6 \times 10^{-6} \text { to } \\
6 \times 10^{-2}\end{array}$ & $6 \times 10^{-6}$ & $\begin{array}{l}\text { - } 0 \text { to } 4 \text { orders } \\
\text { of magnitude }\end{array}$ & $\begin{array}{l}\text { Moderate for } \\
D_{0}<10^{-4}\end{array}$ \\
\hline Activation Energy & $20-60 \mathrm{kcal}$ & $42 \mathrm{kcal}$ & -55 to +43 & $\begin{array}{l}\text { Very sensitive } \\
Q>40 \text { kcal at } \\
\text { high burnup }\end{array}$ \\
\hline \multicolumn{5}{|l|}{ - Fuel Plasticity } \\
\hline Creep Activation Energy & $60-110 \mathrm{kcal}$ & $\begin{array}{l}\text { (In Pile) } \\
60 \text { kcal }\end{array}$ & -0 to +84 & Moderate - High \\
\hline \multicolumn{5}{|l|}{ - Hydrostatic Pressure } \\
\hline & $500-10,000 \mathrm{psi}$ & $2000 \mathrm{psi}$ & -75 to +400 & Insensitive \\
\hline \multicolumn{5}{|l|}{ - Fission Rate } \\
\hline Linear Power & $6-16 \mathrm{~kW} / \mathrm{ft}$ & Peak - 12.2 & -50 to +30 & $\begin{array}{l}\text { Sensitive at low } \\
\text { linear power }\end{array}$ \\
\hline Pellet Diameter & 0.18 to $0.30 \mathrm{in.}$ & 0.230 & -22 to +30 & $\begin{array}{l}\text { Moderately } \\
\text { sensitive }\end{array}$ \\
\hline
\end{tabular}

10. Prequalification of LMFBR Fuel Suppliers

J. F. Williams

Contractors participating in this program have essentially finished their effort except for completion of final reports.

A quality assurance evaluation of the Fuel Supplier Prequalification Program is being performed to provide a comparison of:

- Quality Assurance systems and operations versus quality assurance requirements.

- Manufacturing capabilities versus product requirements. 


\section{B. CLADDING TECHNOLOGY}

1. Vendor Qualification Criteria

J. V. Tverberg, R. J. Lobsinger,

R. C. Aungst and R. R. Studer

Criteria were established for qualification of the FFTF fuel cladding vendors. These criteria are being published in document BNWL-1417. Briefly, this program outlines a four-step program for qualification.

- Step I - Vendor Prerequisites (go-no-go items).

- Step II - Inspection of Facilities (Audit).

- Step III - Evaluate Fabrication Process.

- Step IV - Evaluation of Vendor's Tubes.

Each vendor must meet the criteria in each step to be qualified. If after qualification the vendor makes a significant change in the process, then the vendor must be requalified before he can produce additional tubing for the program. Both the tubing manufacturer and the steel supplier must be qualified before the vendor can receive a bid package for FFTF tubing.

\section{LMFBR Fuel and Cladding Information Center}

F. R. Shober and B. R. Hayward

The LMFBR Fuel and Cladding Information Center is a computerized system designed to contain detailed data for LMFBR type experimental fuel pins and selected LMFBR core materials. Similarity in data file structures and the use of the Fortran File Process (FFP) generator provides the flexibility required in the formative stage of the system. This flexibility permits any changes made in one file to be made in another, if appropriate. 
The design and operation of the data center system was reviewed and evaluated by a consultant on information systems. His evaluation describes the information center as a system having realistic objectives and goals. He agrees that the modular design and nested file structure also provides for simple operation and projected growth of the files. Some problems related to retrieval and organization are anticipated as the files become larger.

The experimental fuel pin file is operational and data on pin fabrication pre-irradiation measurements are being placed in storage for PNL-3, -4, and - 5 subassemblies.

Two additional files will be added to increase the effectiveness of the data center:

- a special pin file which contains all pertinent data on a small group of highly characterized fuel pins being tested by each contractor. These data will be valid, up to date, and certified by management.

- A fuel pin failure file that contains complete details including observations of all failed fuel pin results.

We expect that these files will be used in conjunction with the fuel performance modelling programs. Preliminary outlines of these files have been made.

The austenitic stainless steel tensile file was increased by 116 data sets bringing its total to 2563, the creep file was increased by 74 data sets bringing its total to 321 and data for three lots of stainless steel cladding was entered in storage. About 110 computer plots were prepared from retrievals made from the mechanical properties file. 


\section{Acceptance Testing and Clad Characterization}

M. M. Paxton

The cladding characterization program is being conducted to ensure that high-quality stainless steel cladding is obtained and used throughout the FFTF fuels development and associated irradiation testing programs. Under this program, selected mechanical properties are being determined and analyzed to evaluate fabrication variables and to assist in vendor qualification.

lnitial data indicate that planetary ball swaged tubing is weaker than the plug drawn tubing when tested biaxially at $1200^{\circ} \mathrm{F}$ for times less than $100 \mathrm{hr}$. The diametrical strain is significantly less for the planetary swaged tubing. Tests are continuing.

4. Interaction of Cladding Defects

R. C. Aungst, R. J. Lobsinger, R. R. Studer and J. C. Tverberg

One of the major problems in establishing the wastage allowance on the fuel cladding is in the amount to allow for defects. One major area of concern is the coincidence of both an OD and ID defect. Analysis was made of both situations in which an OD and an ID defect would have an influence on reducing the cladding wall. This analysis indicated that two defects, both at the maximum size of $0.001 \mathrm{in}$. deep $\times 0.030 \mathrm{in}$. long, one located on the outside and one on the inside of the tubes, can approach within 0.005 in. of each other or $50^{\circ}$ and still not influence each other. However, if the two defects approach closer than this, then there will be an interaction between the two defects, and we will have an effective reduction of the cladding wall. Figure 8.5 illustrates this proximity interaction. From this information, and by analyzing these data as a probability function, we have developed a probability equation:

$$
\mathrm{p}=\left(\mathrm{n}_{\mathrm{o}}\right)\left(\mathrm{n}_{\mathrm{i}}\right)(0.00000545)
$$




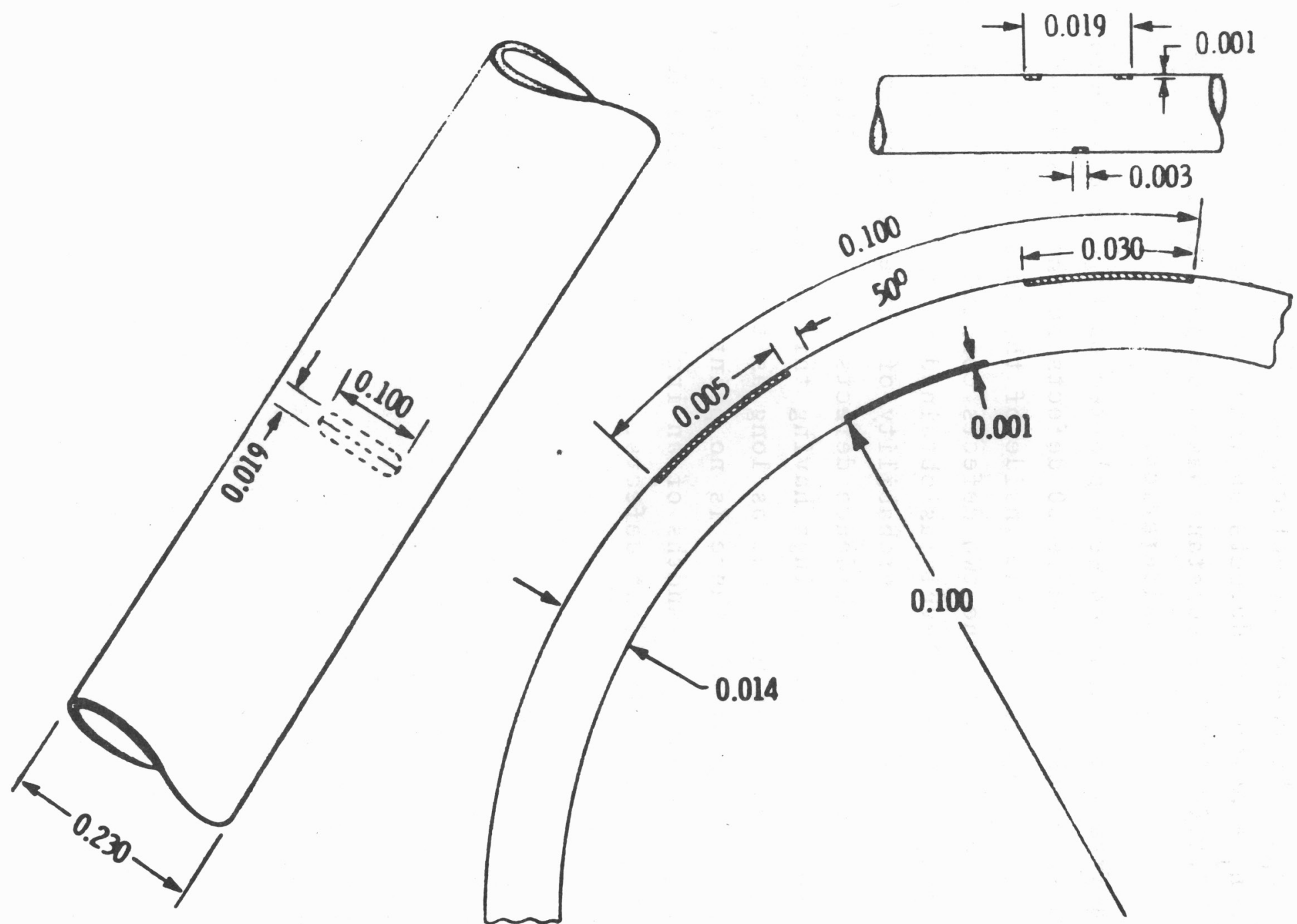

FIGURE 8.5. Schematic Showing Proximity of an OD and an ID Tubing Defect Whereby Combined Defects Will Result in Decreased Effective Wall Thickness 
BNWL- 1394

where

$$
\begin{aligned}
& \mathrm{n}_{\mathrm{O}}=\text { the number of defects on the outer surface } \\
& \mathrm{n}_{\mathrm{i}}=\text { number of defects on inner surface } \\
& 0.00000545=\text { a constant based on geometric } \\
& \text { consideration. }
\end{aligned}
$$

Data from this equation were plotted on Figure 8.6 where the curve shows that if we have 50 defects on the outside of the tube and 50 defects on the inside of the tube, there will be one chance in 100 of the two defects coinciding. However, with our present defect level (as obtained in the prime lot of CarTech tubing), there is a probability of three chances in 1,000,000 of obtaining coincidence defects or a possibility of one tube in 16 FIR core loadings having this situation develop. Thus, it is safe to assume that as long as the present high standards are maintained, there is no point in increasing wall thickness by another thousandths of an inch to compensate for the possibility of coincident defects. 


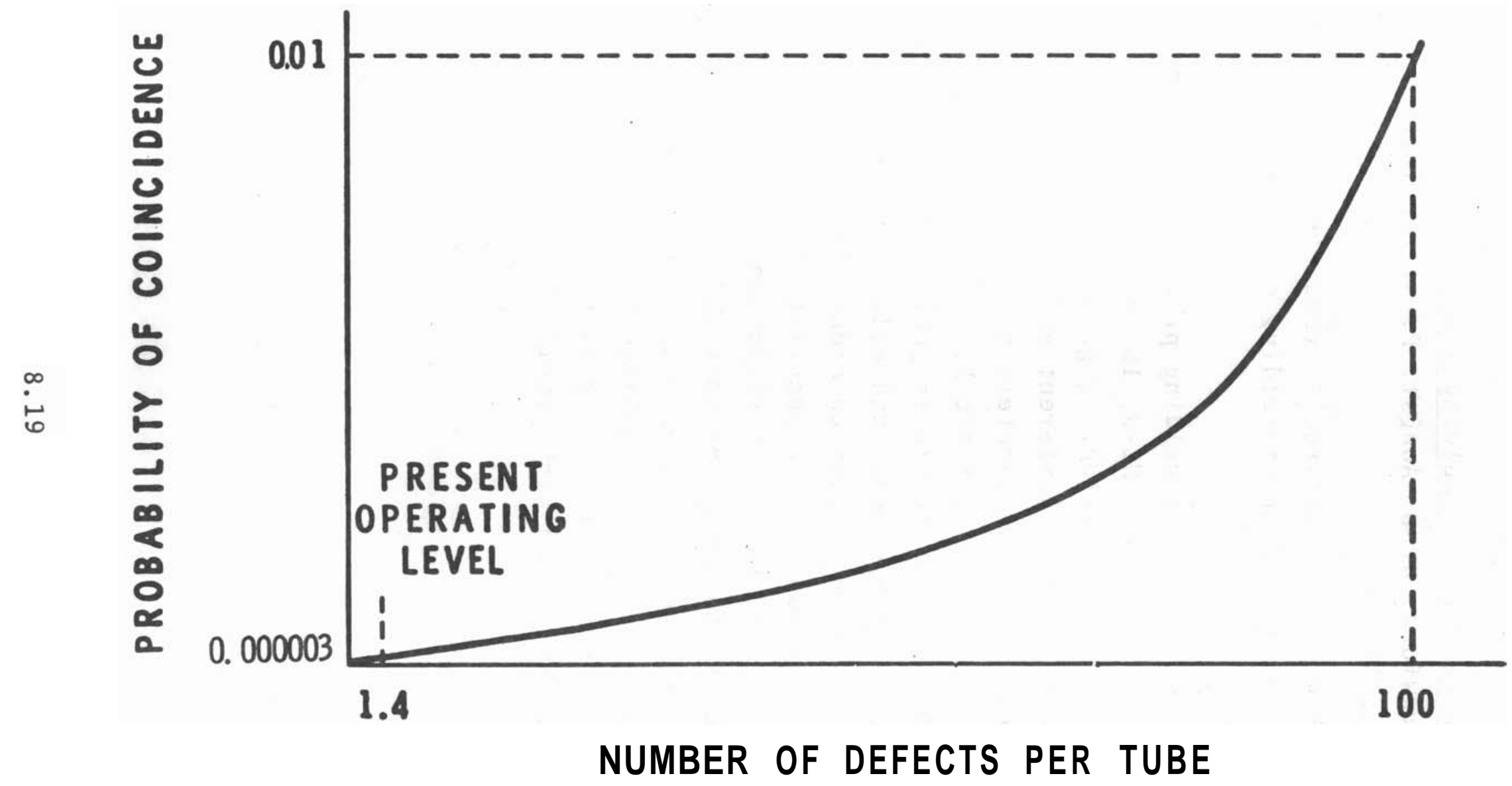

FIGURE 8.6. Curve Illustrating Probability of Coincidence of oD and ID Defects Based on Schematic Shown in Figure 8.1 
C. FUEL PIN TECHNOLOGY

1. Fuel-Pin End-Closure Welding Anomalies

R. M. Crawford, R. D. Aungst, R. J. Lobsinger and J. C. Tverberg

The FFTF welding standard, (1) requires forty consecutive welds made at three different welding conditions to qualify a welding procedure.

Attempts to qualify a welding procedure (Figure 8.7) for irradiation test pins for PNL-9, 10, and 11 encountered extreme variation in weld penetration. Figure 8.8 shows different levels of penetration in different end-closure welds made by using identical welding parameters and end caps made from the same heat (PNL-Lot-L-15) bar stock. Note that the weld penetration in sample SQ-10 is Q0.033 in. while the penetration in SQ-9, made using the same equipment and welding procedure, is 0.054 in. Similar variations were observed among other samples. To determine if the variation in weld penetration was caused by the endcap material or weld equipment variation, a fusion pass was run around several of the end caps that had exhibited high and low penetration. In every case, end caps exhibiting low penetration when welded to a tube also exhibited low penetration on the fusion pass. End caps exhibiting high penetration when welded to a tube also exhibited high penetration on the fusion pass.

1. W. F. Brown and R. M. Crawford. Welding Standards for the Driver Fuel Assembly, BNWL-1271, Battelle-Northwest, Richland, Washington, Apriz, 1970. 


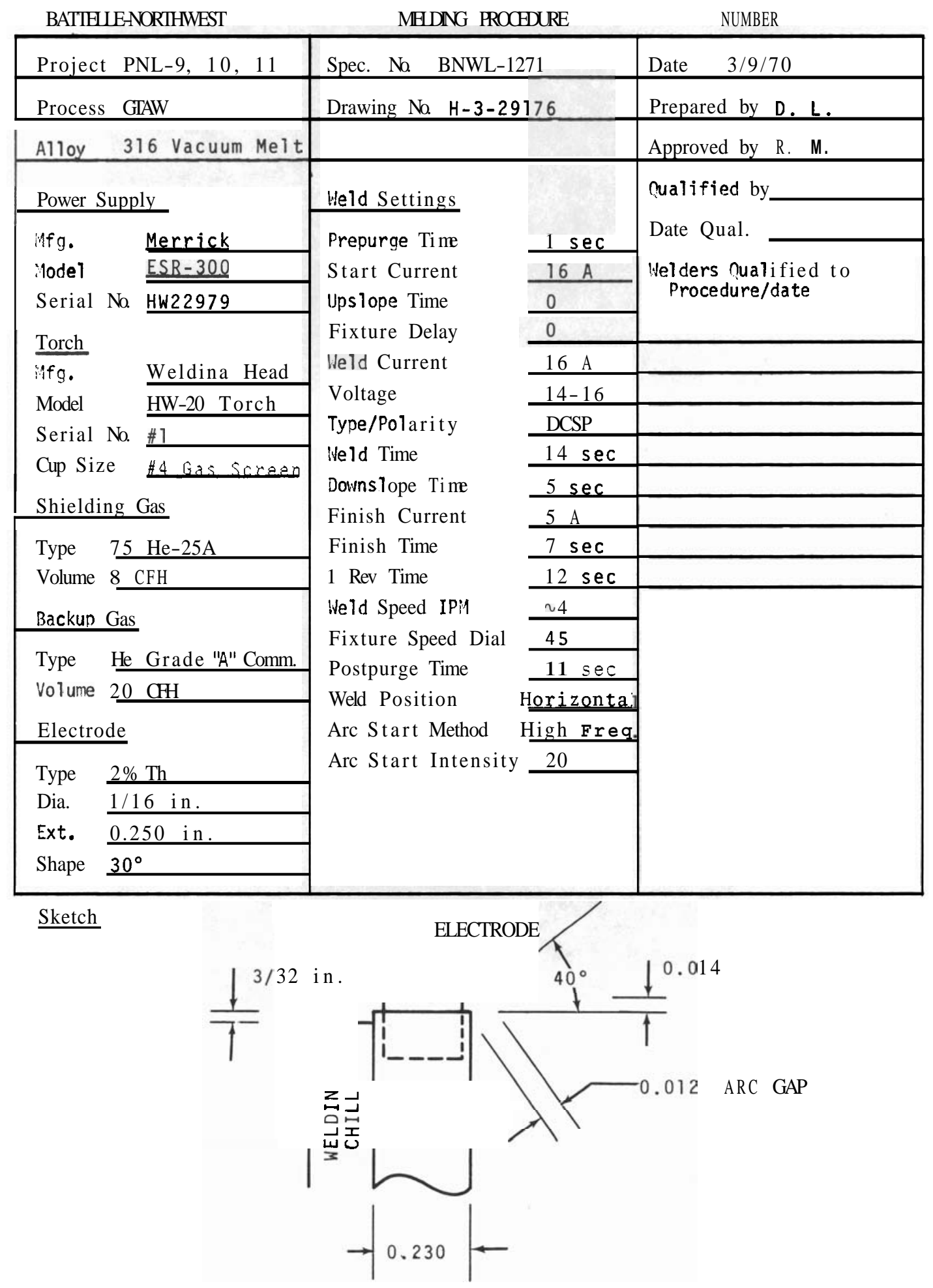

FIGURE 8.7. Welding Procedure for Vacuum-Melted End-Cap Material 
BNWL -13994

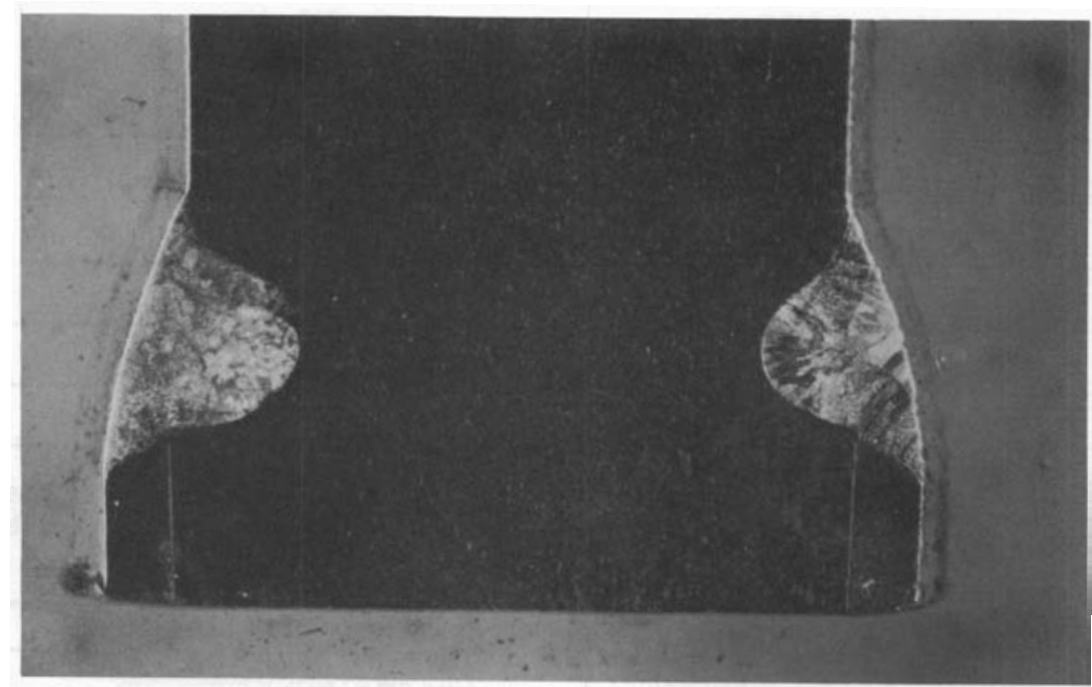

Sample Number sQ-9

$15 \mathrm{X}$

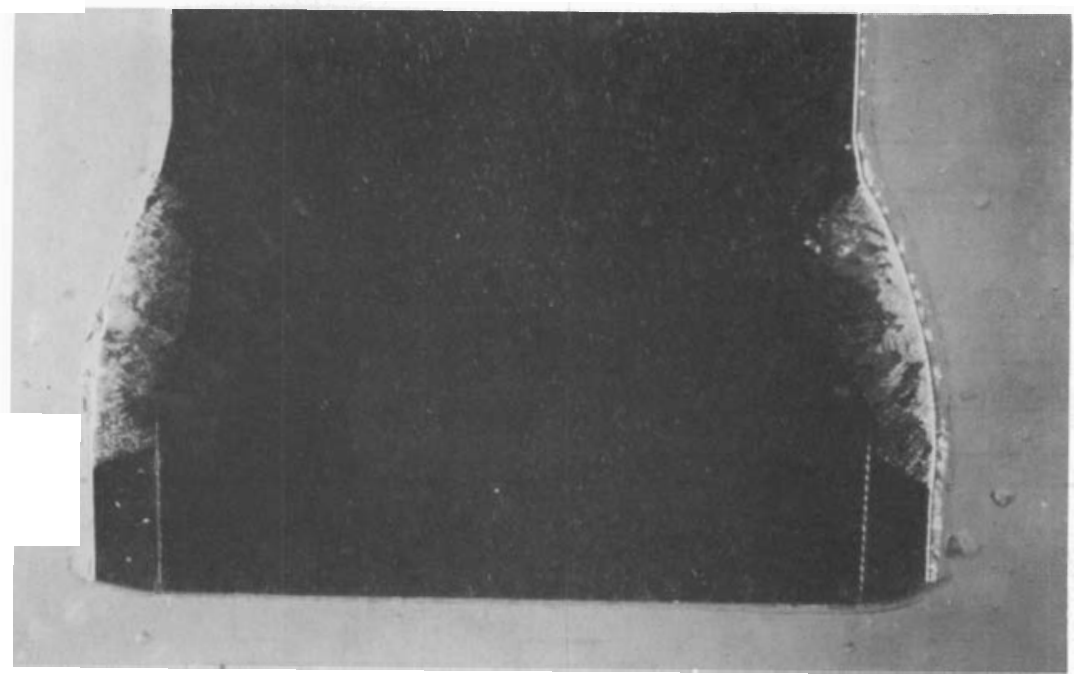

Sample Number sQ-10

$15 \mathrm{X}$

Neg PM 701864-17

FIGURE 8.8. Welding Procedure \#19, 15A, 12 sec/revolution 
An attempt to duplicate the high-penetration weld on endcap material exhibiting . low penetration was made by increasing the welding current. This increased the width of the fusion zone without significantly changing the penetration.

During welding, other differences in the behavior of the material were noted. The material exhibiting low penetration welded "quietly" with a smooth finished bead. The material exhibiting high penetration showed a more active puddle during welding, and the finished weld showed more ripple than welds from low-penetrating material. All the vacuum-melted material tested required more current to weld, had a "quieter" puddle action during welding, and gave a smoother finished weld than the air-melted end-cap material. Samples of material exhibiting high and low penetration were submitted for extensive chemical analysis. Weldability tests run on end-cap material from PNL lots L-14 and L-16 indicated both lots are weldable and acceptable for use. The erratic weld penetration encountered in welding end caps fabricated from Lot L-15 was not found in end cap welds made from Lots L-14 and L-16.

At this time the cause of the variation in welding penetration has not yet been identified.

The vacuum-melted stock in question was supplied as part of a large order of vacuum-melted Type 316 SS. After induction melting, the steel was consumable-electrode, vacuum-arc remelted (CEVAR) into 16 and 18-in. ingots for subsequent reduction. The 4.5 in. diameter bars produced from the 16-in. ingots were used to fabricate $1 / 4$ in. diameter bar stock (Lot L-14), 0.230 in. diameter bar stock (Lot L-15), and 1/4 in. diameter coiled bar (Lot L-16). The L-14 and L-15 lots were received by BNW in as-drawn condition. Subsequently, the material was bright hydrogen annealed; L-14 and L-15 came from different heats and were annealed at different times. 
Chemical analyses and qualitative spectrographic scanning indicate it is unlikely that chemical differences can account for the variation in weld penetration.

Slight but real differences in electrical resistivity were observed between these high- and low-penetration samples from Lot L-15.

Metallography to characterize grain size and inclusion distribution is being performed on the samples for L-15 which exhibit welding variations.

2. Fuel-Pin End-Closure Weld Development

R. M. Crawford

New end-cap dimensional tolerances are being considered. Preliminary tests indicate that acceptable welds can be produced with these tolerances, and maching costs will be reduced. The established tolerances (Figure 8.9) are:

Dimension $\mathrm{T}$, weld lip thickness $0.017 \pm 0.003$ in.; Dimension D, weld $1 \mathrm{ip}$ diameter $0.216 \pm 0.002 \mathrm{in}$; and Dimension C, tube-toend cap clearance 0.0005 in. to $0.003 \mathrm{in}$. The following $2^{5}$ factorial experiment is currently in progress to determine the effect of welding parameter variations and machining tolerances on the finished weld:

\begin{tabular}{|c|c|}
\hline Variables & Ranye \\
\hline Current, A & $\begin{array}{l}A-1=16 \\
A-2=18\end{array}$ \\
\hline Welding Speed & $\begin{array}{l}S-1=1 \text { revolution in } 11 \mathrm{sec} \\
\mathrm{S}-2=1 \text { revolution in } 13 \mathrm{sec}\end{array}$ \\
\hline Weld Lip Thickness, in. & $\begin{array}{l}\mathrm{T}-1=0.020 \\
\mathrm{~T}-2=0.014\end{array}$ \\
\hline Weld Lip Diameter, in. & $\begin{array}{l}\mathrm{D}-1=0.214 \\
\mathrm{D}-2=0.218\end{array}$ \\
\hline $\begin{array}{l}\text { Clearance Tube-To- } \\
\text { End Cap, in. }\end{array}$ & $\begin{array}{l}\mathrm{C}-1=0.0005 \\
\mathrm{C}-2=0.003\end{array}$ \\
\hline
\end{tabular}


BNWL-1394

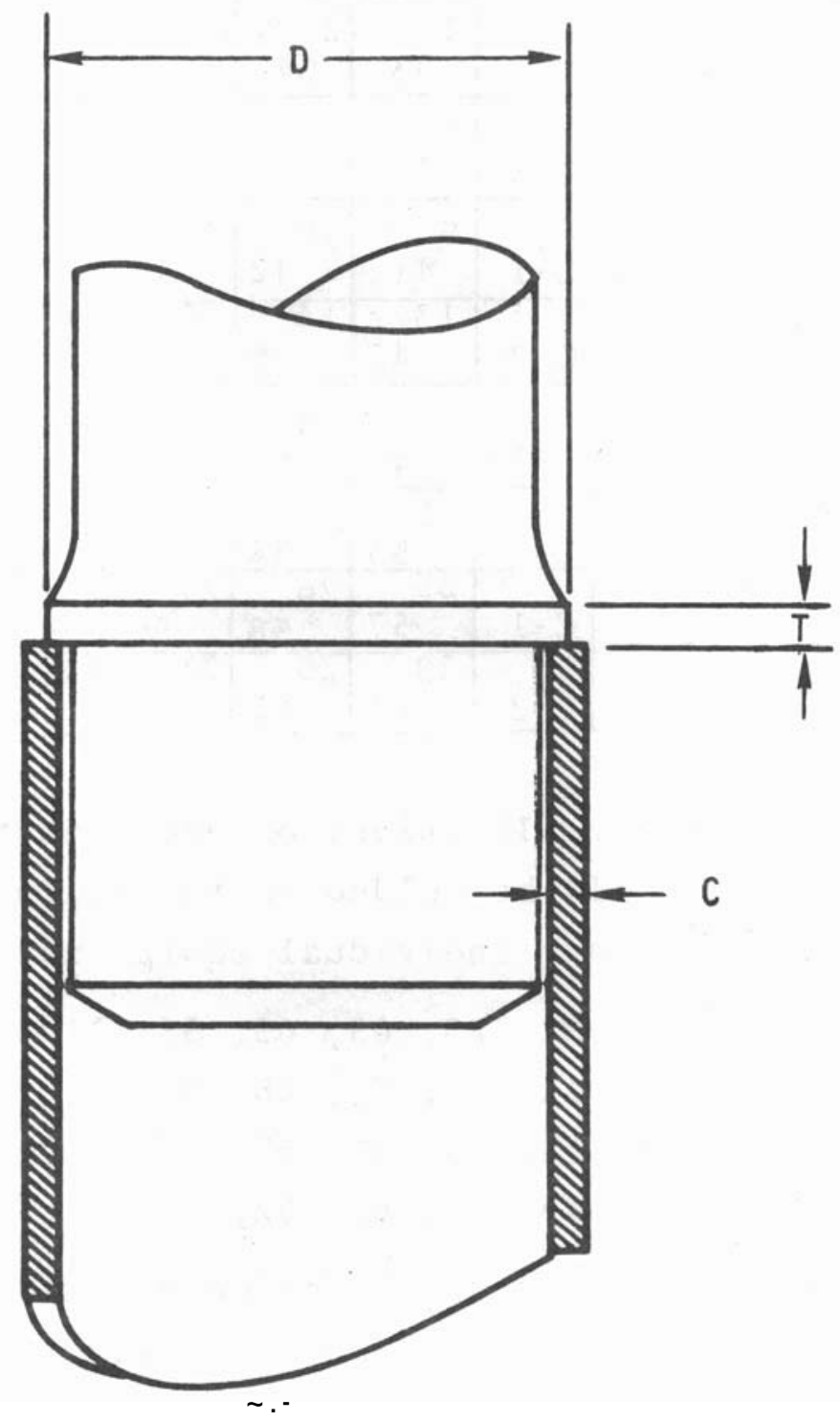

FIGURE 8. 9. Reference FFTF Fuel Pin End Closure Weld Penetration 
BNWL-1394

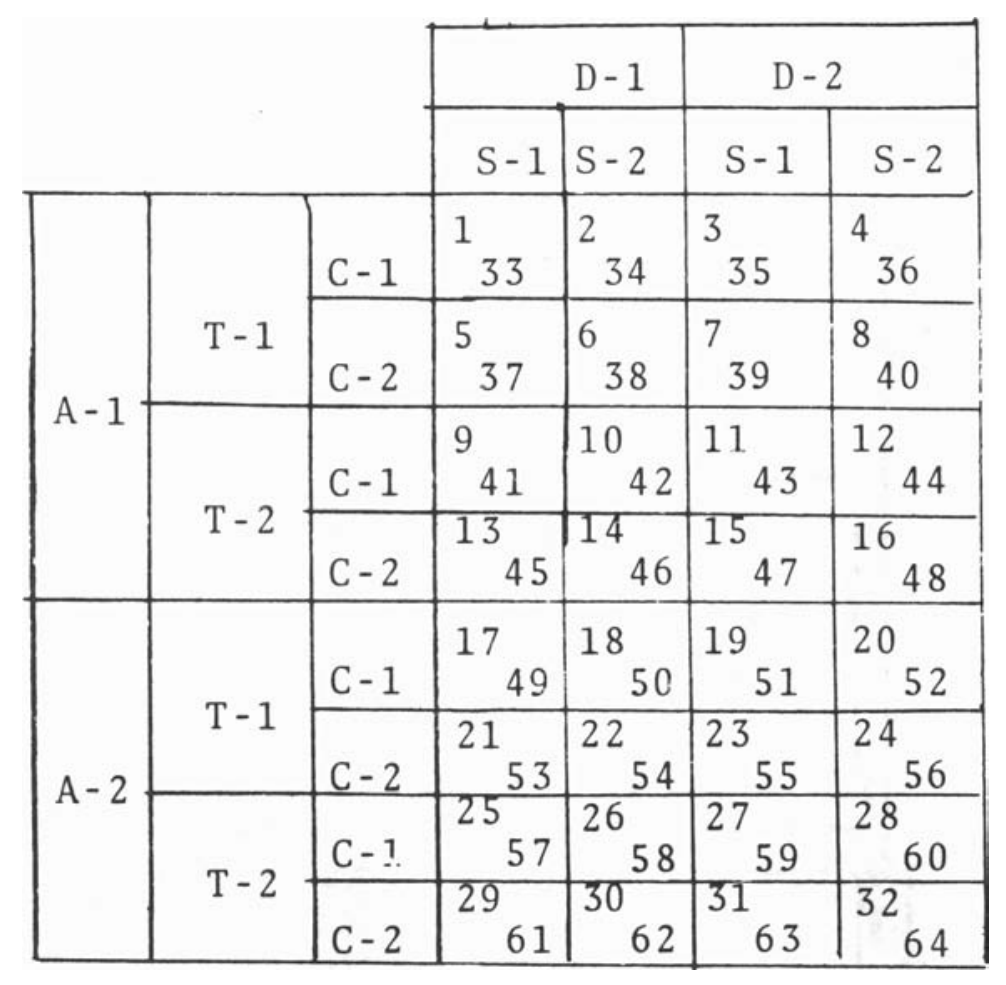

There will be two replications of each combination of levels. The samples will be welded in the following order to minimize the effect of any individual equipment set up:

$54,47,20,10,41,35,22,23,03,05,58,11,08,29,01,25$, $06,45,64,34,42,21,12,09,36,48,30,56,15,07,24,44$, $19,04,32,55,50,16,18,43,17,57,40,13,61,37,31,33$, $59,52,26,28,53,39,46,63,60,02,38,14,62,27,49,51$.

All samples will be measured for weld buildup, radiographically examined in six positions, and metallographically examined for weld penetration, throat thickness, and cracking.

3. Prototypic FTR Fuel Pin Fabrication Development

H. T. Blair

FFTF Engineering Test Plan for Fabrication of FTR Prototypic Fuel Pins, was approved on March 25, 1970. This plan specifies the general requirements for the development 
fabrication of 300 prototypic FIR fuel pins (Figure 8.10) in the fuel fabrication demonstration facility. These fuel pins will be evaluated to preliminary FIR specifications.

\section{FUEL SUBASSEMBLY TECHNOLOGY}

1. CCTL Mark II Test Assembly Fabrication Development*

R. L. Myers

\section{$\underline{\text { Discussion }}$}

A full-scale model of an FFTF Mark II fuel subassembly was built and shipped to the Argonne National Laboratory for flow testing in the Core Components Test Loop. The design for this subassembly is prototypic of the FFTF driver fuel subassembly, except for some deviations which have been allowed to either simulate reactor operating conditions, allow easier fabrication, or shorten the fabrication schedule. Standard fabrication techniques were used except where new designs made it necessary to develop new procedures or alter established ones. Significant development work included setting new parameters for bottom end cap welding, establishing a vertical loading procedure for a small clad-pellet gap, developing a welding technique for the lower grid plates, and developing duct-nosepiece components welding procedures. A quality assurance program was used to verify conformance of each component and the completed subassembly to design requirements and document all deviations.

\section{Fuel Pin}

The fuel pellets were made using natural $\mathrm{UO}_{2}$ in place of $\mathrm{UO}_{2}-\mathrm{PuO}_{2}$ since the CCTL flow test is an out-of-reactor test. The insulator pellet lengths were made identical to those of the fuel pellets, resulting in a column length of 37-in. and simulating the combined fuel column and insulator pellets. Considering allowable tolerances, the pellet-clad gap is expected to range from 0.0021 to 0.0032 in. The pellet lengths and diameters were controlled using a sampling inspection plan. 


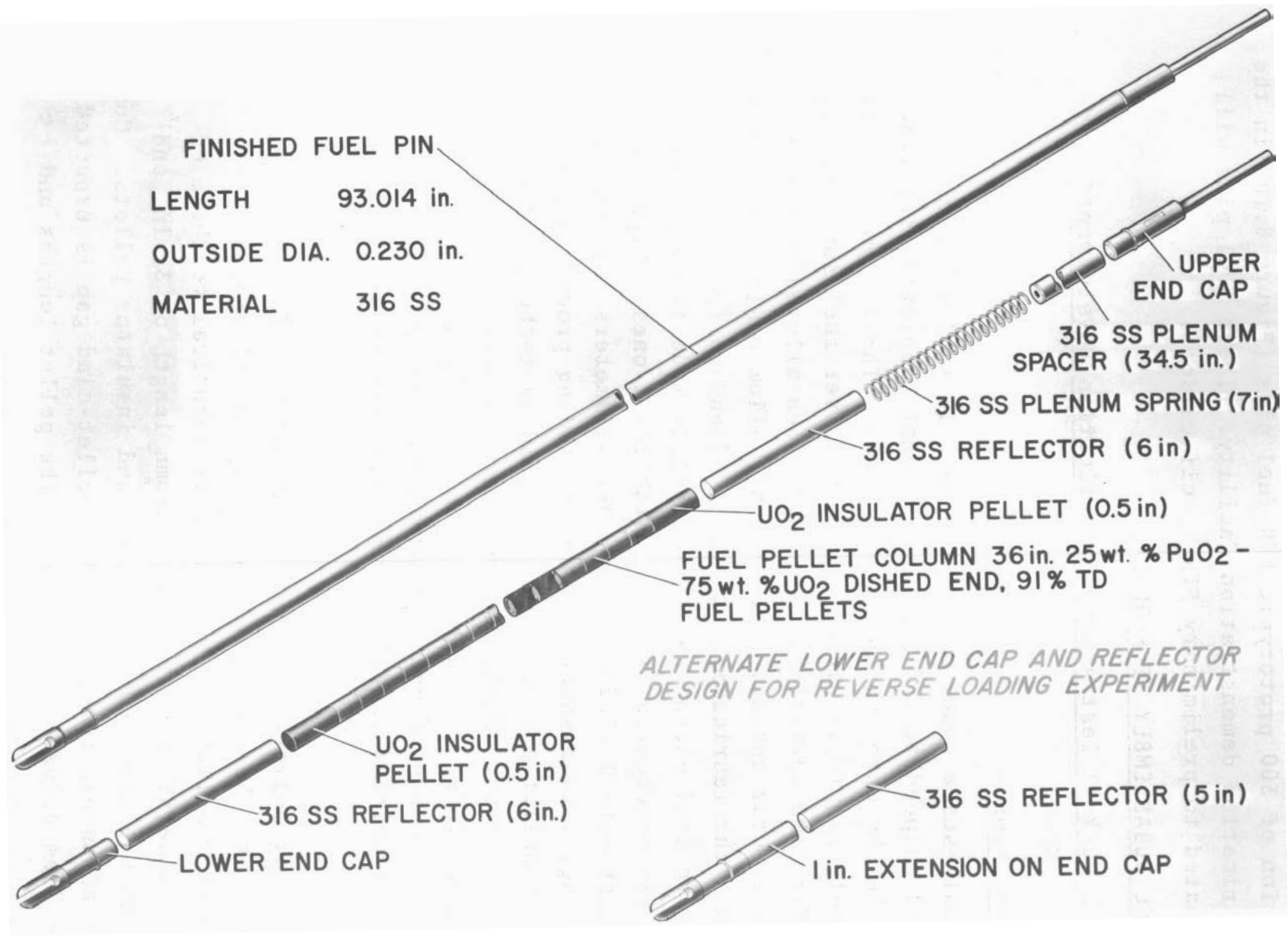

Neg 702158-1

FIGURE 8.10. Prototypic FTR Fuel Pin for Test Demonstration Fabrication 
The close pellet-clad gap made it necessary to load the pins in the vertical position. The new loading procedure was developed. The fuel column was weighed and loaded in 6-in. increments. Each 6-in. increment was seated to eliminate any gaps between pellets (Figures 8.11 and 8.12).

Each pin was wrapped with a 0.056-in. diameter Type 316 SS $20 \%$ cold-work wire (Figures 8.13 and 8.14 ). The wire was attached at each end cap with a 3/32-in. fillet weld.

A summary of fuel pin inspections and acceptance rates is listed in Table 8.7.

TABLE 8.7. Fuel Pin Inspection Acceptance Rates

$\begin{array}{lr}\text { Type of Inspection } & \text { Acceptance Rates, } \% \\ \text { Radiography } & 90.5 \\ \text { Bottom End Cap Weld } & 95.0 \\ \text { Top End Cap Weld } & 100.0 \\ \text { Full Length } & 97.4 \\ \text { Wire Wrap Weld } & 100.0 \\ \text { Helium Leak Check } & 97.0 \\ \text { Loading } & 81.4 \\ \text { Overall } & \end{array}$

\section{Pin Bundle}

The lower grid assembly consists of the lower grid frame, 17 grid plates, and 3 support bars. The fabrication of the plates required a development program to select a method for welding the round rails to the plates. An electron beam welding technique was selected, the weld parameters were determined and sample welds (Figure 8.15) were tested for strength and quality. 


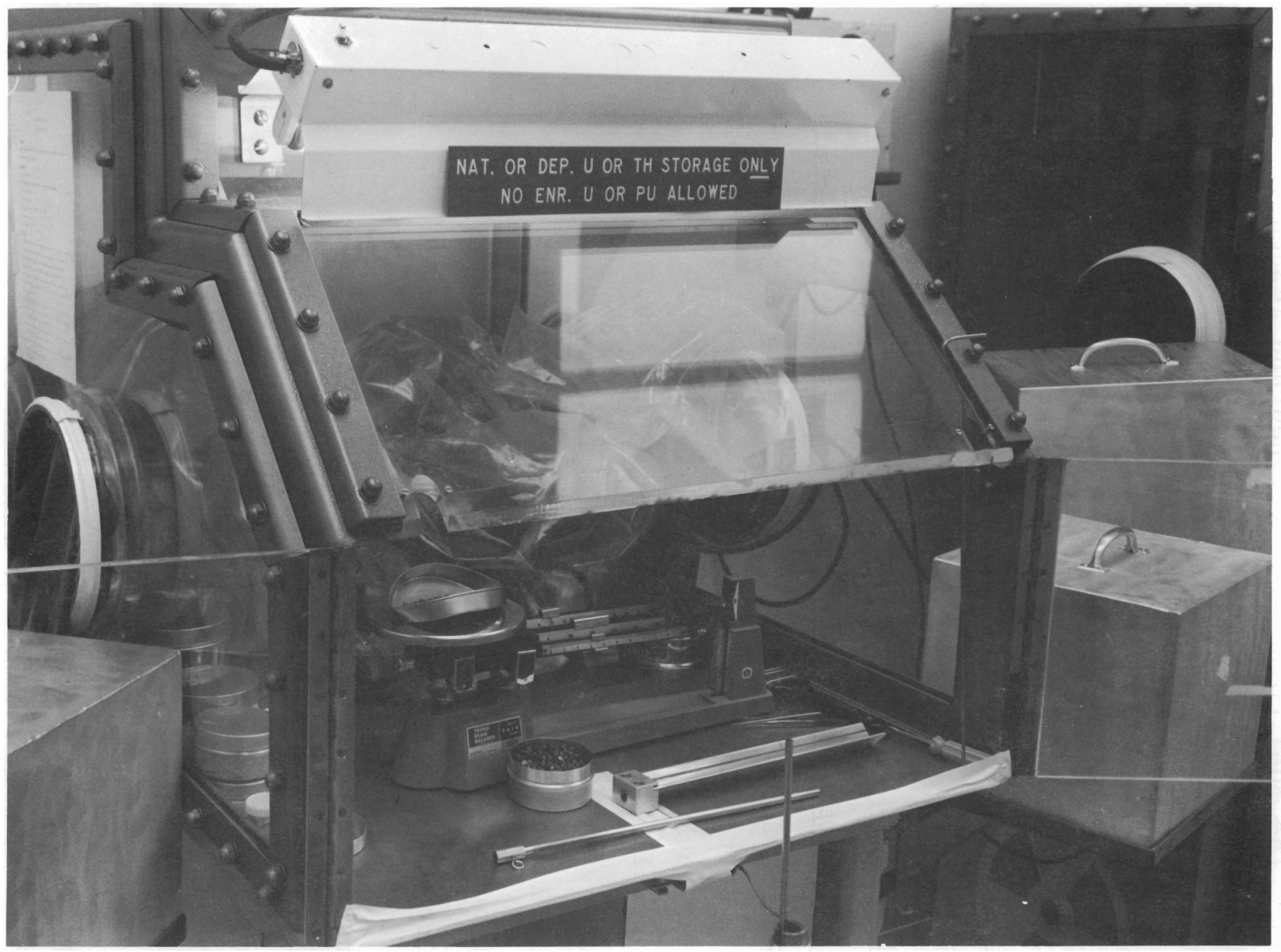

Neg 700273-9

FIGURE 8.11 Fuel Pellet Loading Station 
BNWL-1394

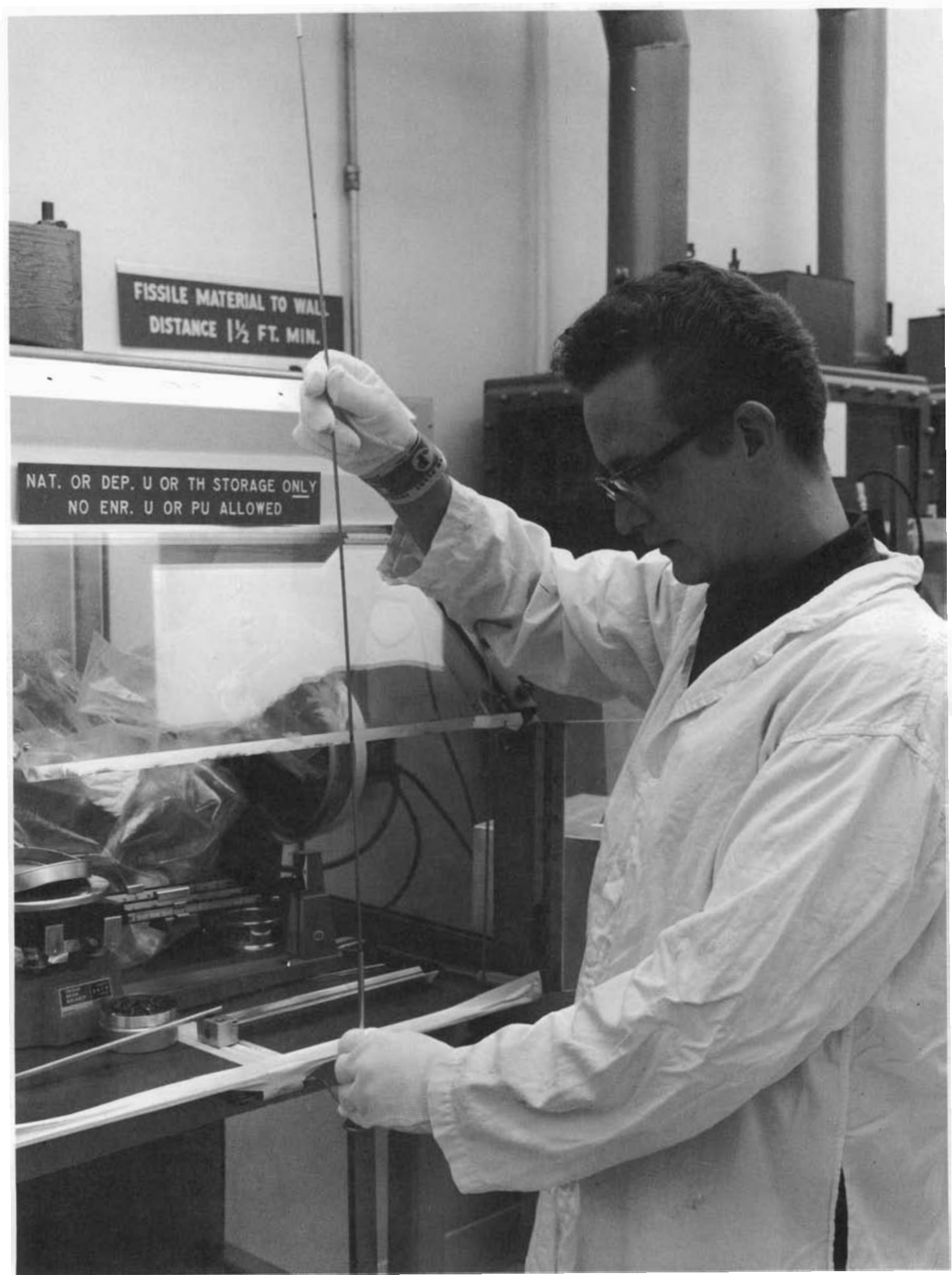

Neg 700273-11

FIGURE 8.12. Fuel Pellet Seating 


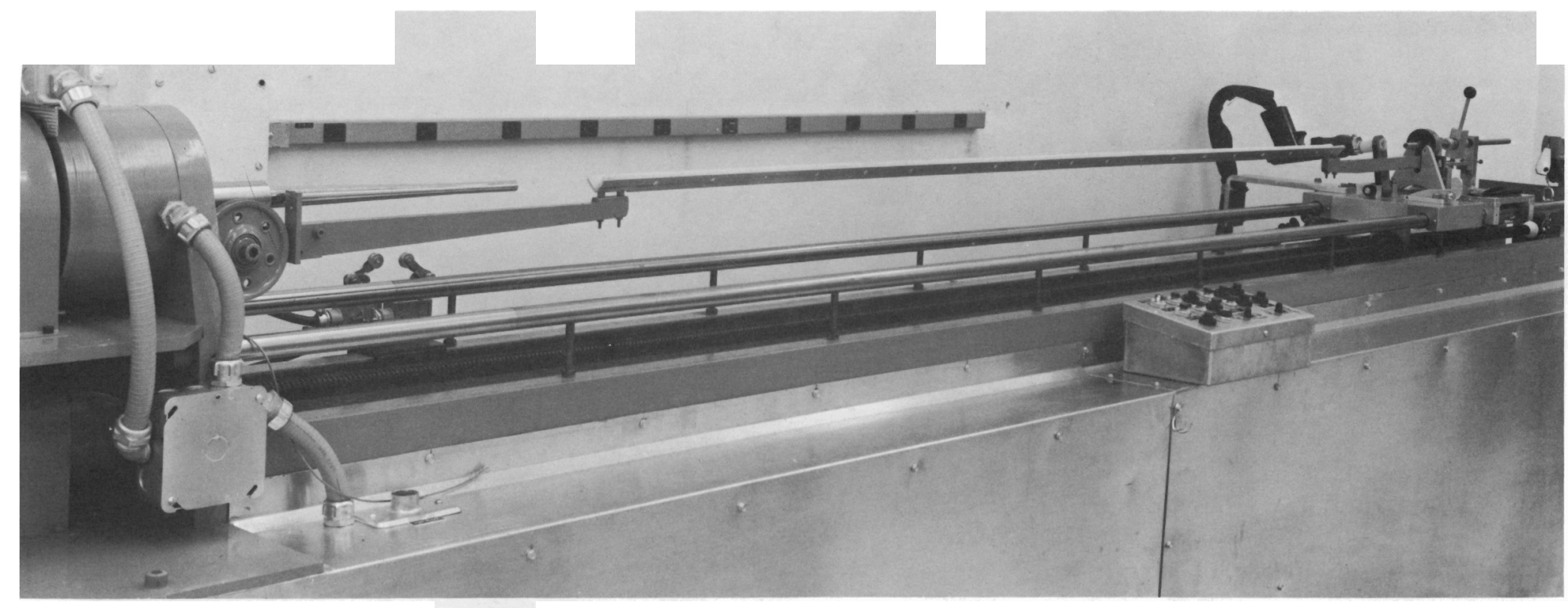

Neg 700611-7

FIGURE 8.13. Wire Wrap Machine 


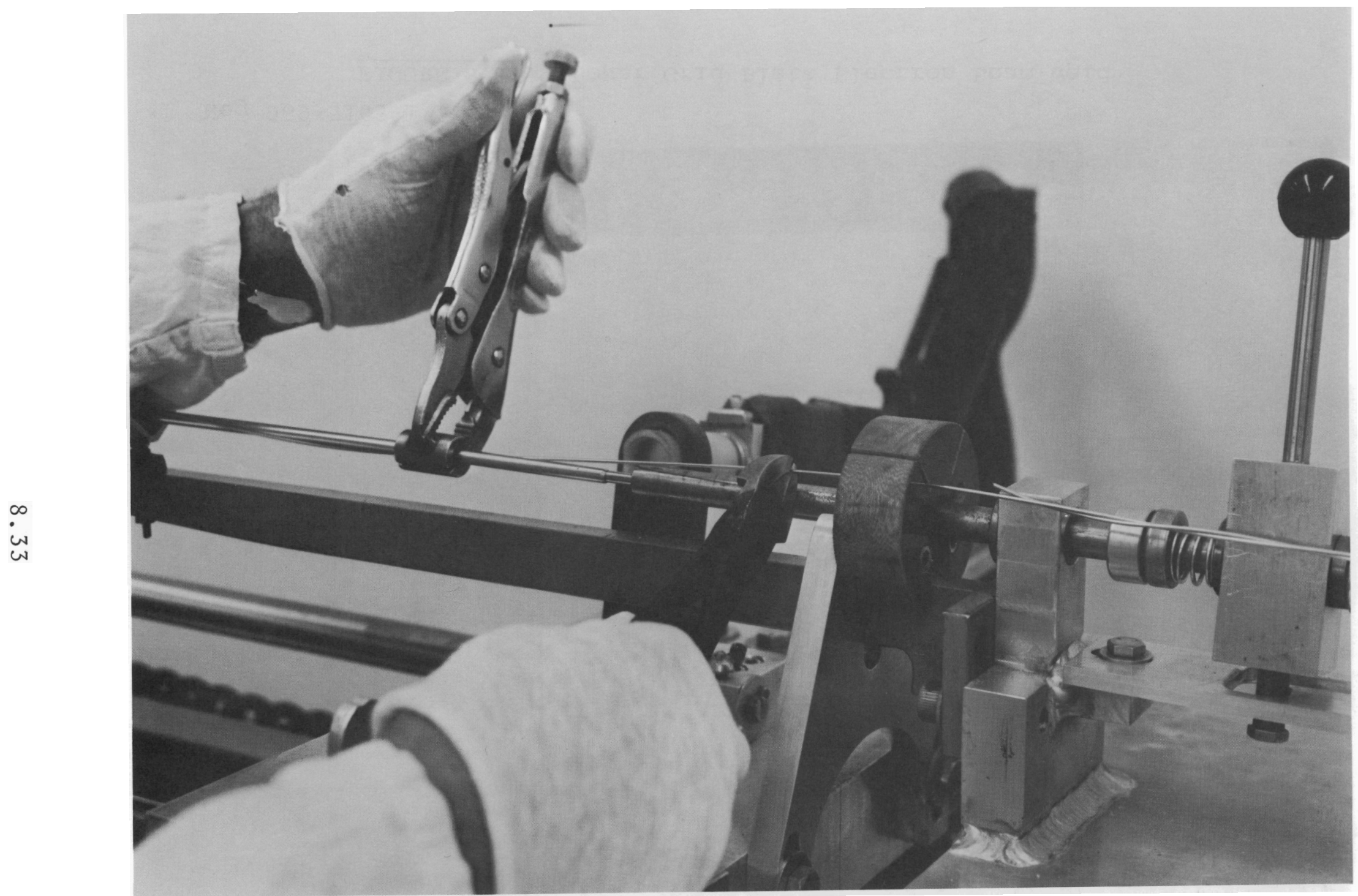

Neg 700611-8

gIGURE 8.14. Removal of gup 1 Pin from Wire Wrap Machine 


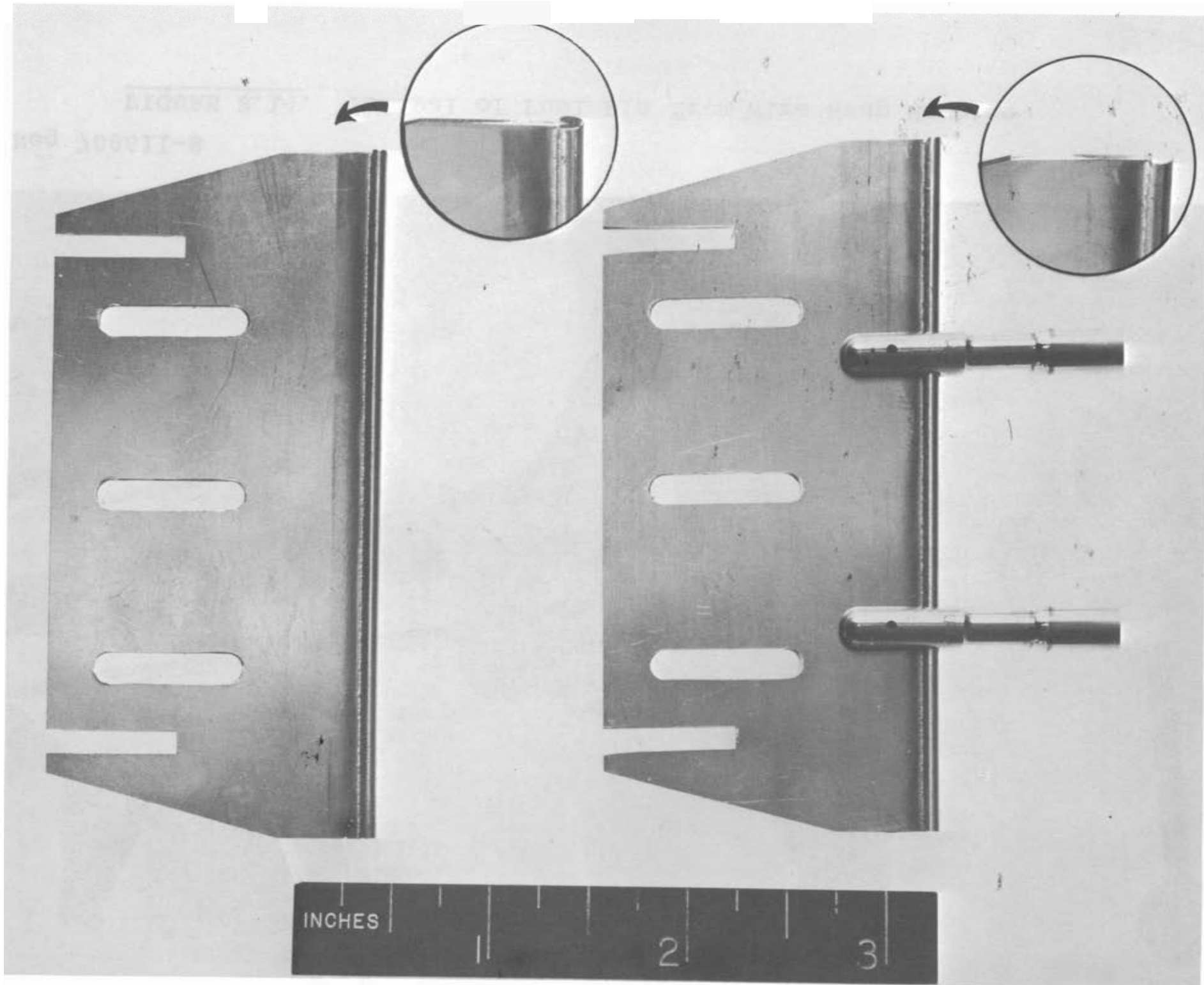

Neg 069-5165-1

FIGURE 8.15. Lower Grid Plate Electron Beam Weld 
The fuel pins were assembled into strip layers by pinning the bottom end caps to the lower grid plates (Figure 8.16') and these strip layers were then assembled into a fuel bundle (Figure 8.17). Thirty of the characterized pins were assembled in predetermined locations in the bundle. Seven extra characterized pins were randomly located throughout the bundle.

The top grid assembly (Figure 8.18) was welded together and put in place on the hexagonal array of pins, a process which proved to be long and tedious due to the problems of lining up a 11217 pins.

\section{Subassembly}

The hexagonal flow duct was expanded 0.054 in. beyond the actual tight bundle dimension. This provides for duct-bundle gap that is anticipated during reactor operation.

A development program using sample pieces to determine welding techniques and parameters was completed prior to welding the actual test assembly nosepiece (Figure 8.19).

Argonne National Laboratory furnished four components of the subassembly--the spherical seal, two guide rings, and the top flange.

The completed test assembly is shown in Figure 8.20.

Quality Assurance

A quality assurance program was used to verify conformance of each component to design requirements and document any deviations. All materials used were certified and traceability was maintained through the fabrication, inspection, and assembly processes. All components fabricated or assembled outside of the FFTF Fuels Department were inspected for conformance to design specifications. All nonconforming items were either refabricated, reworked, or approved in the as-built condition by waiver at Technical Review Board meetings. All design 


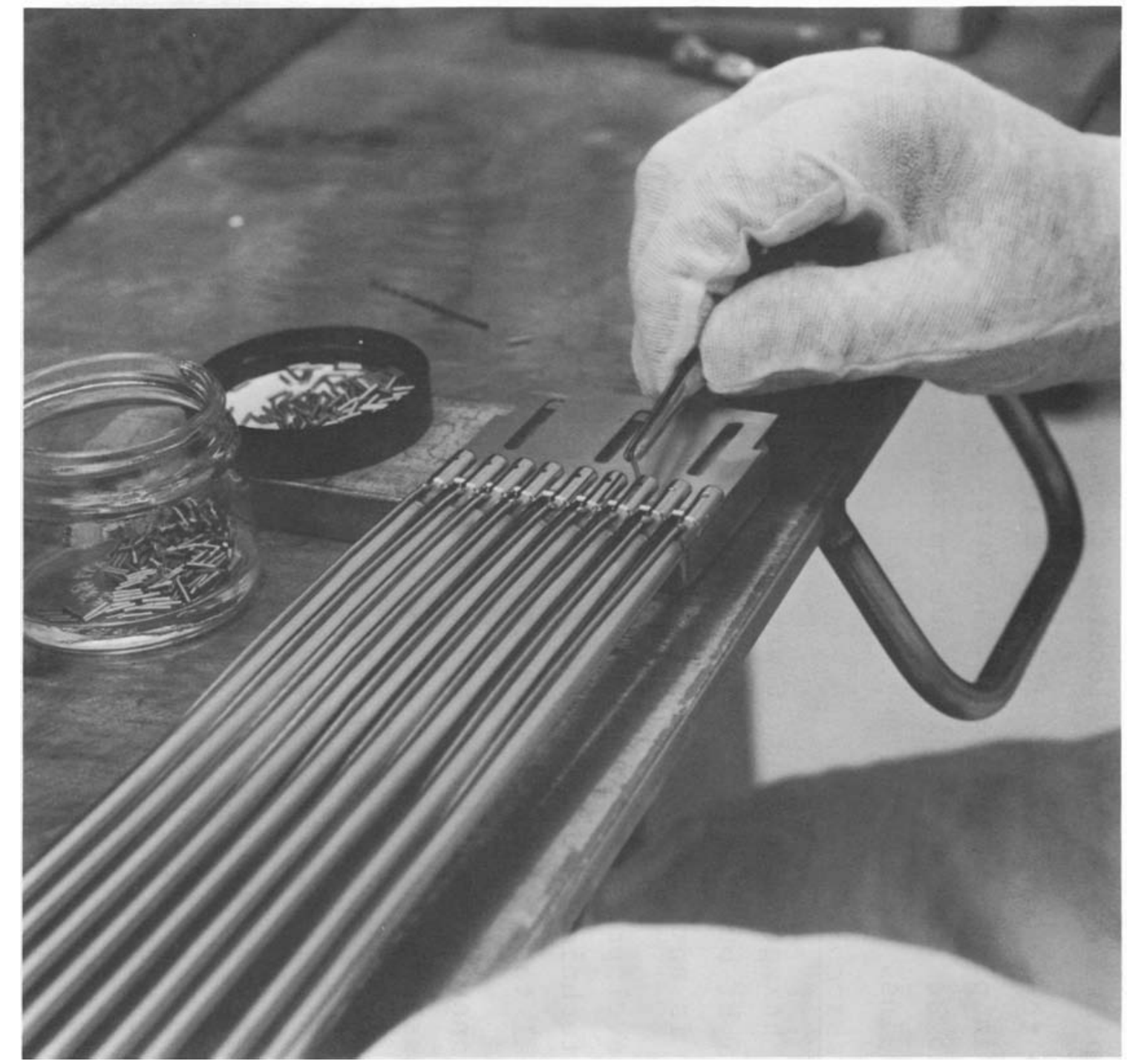

Neg 700611-4

FIGURE 8.16 Strip Layer Assembly 
BNWL-1394

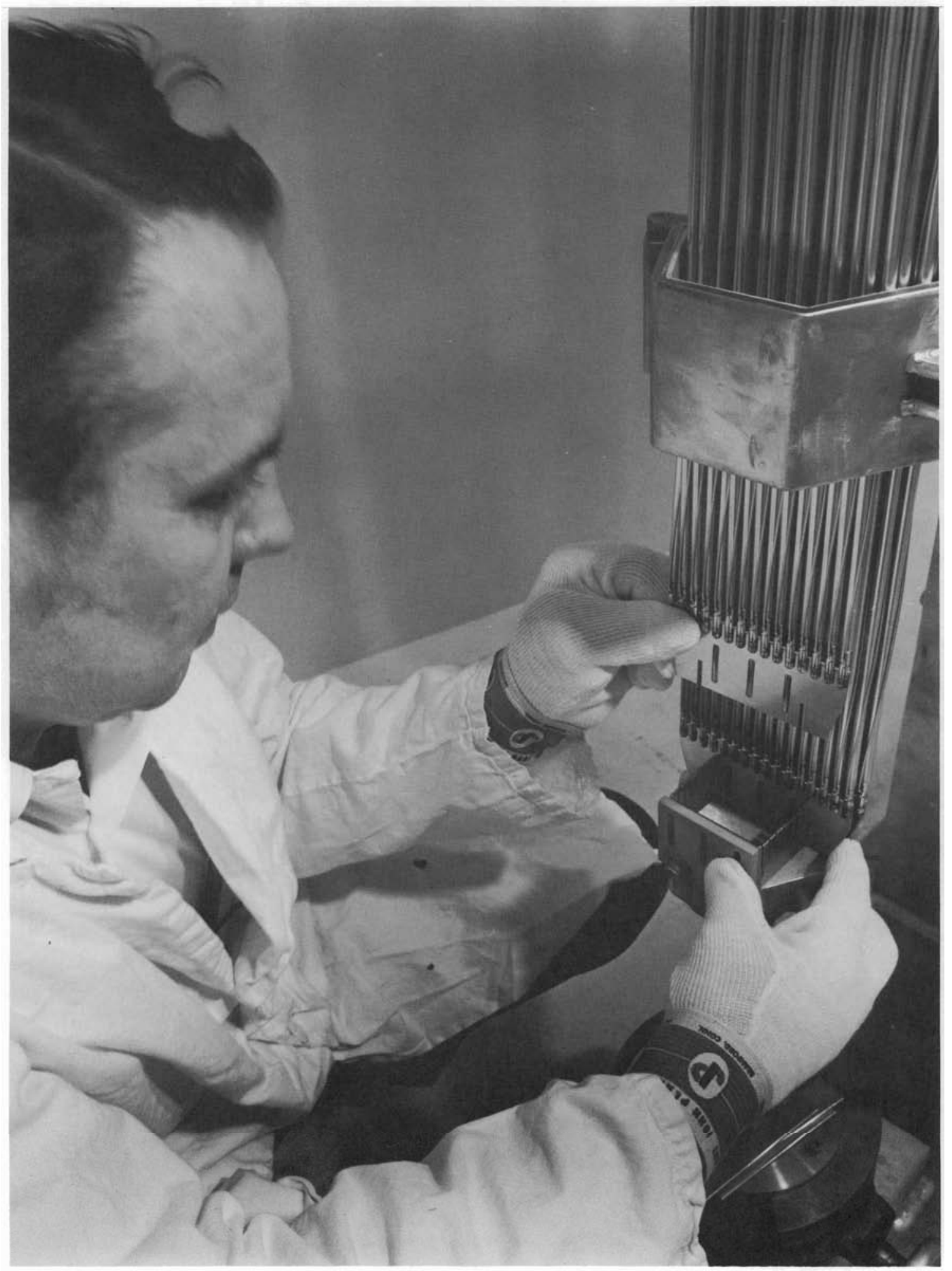

Neg 700611-6

FIGURE 8.17. Pin Bundle Assembly 


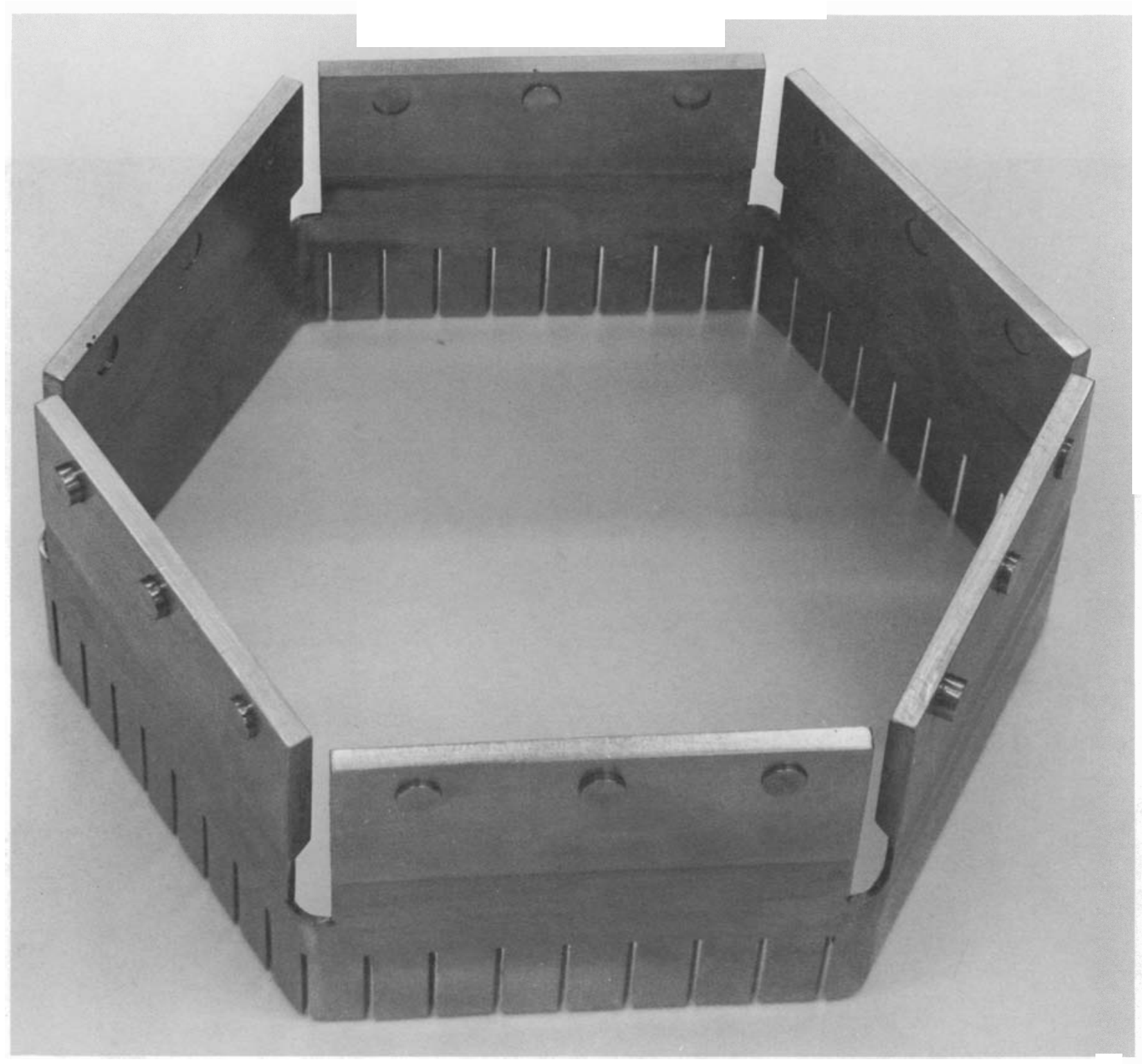

Neg 700611-3

FIGURE 8.18. Top Grid Assembly 


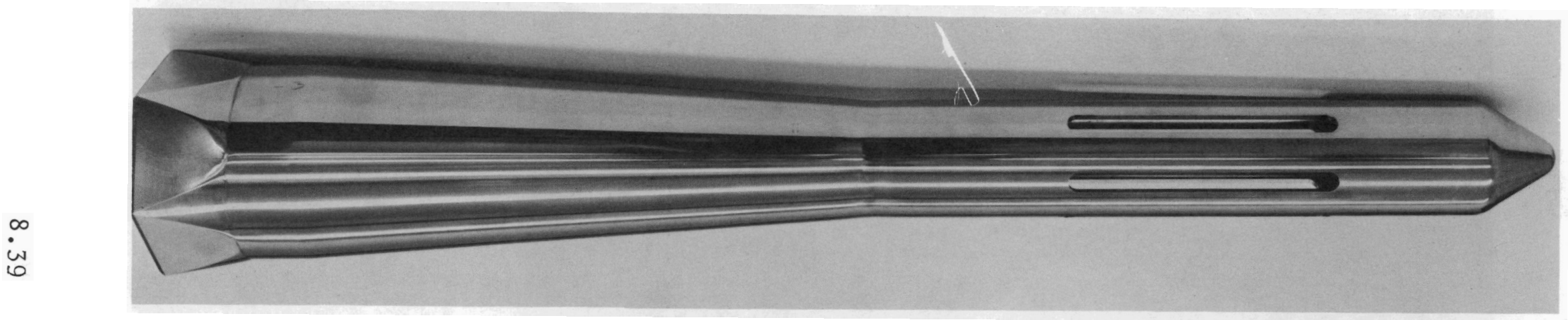

Neg 700611-1

FIGURE 8.19. Nose Piece Assembly 


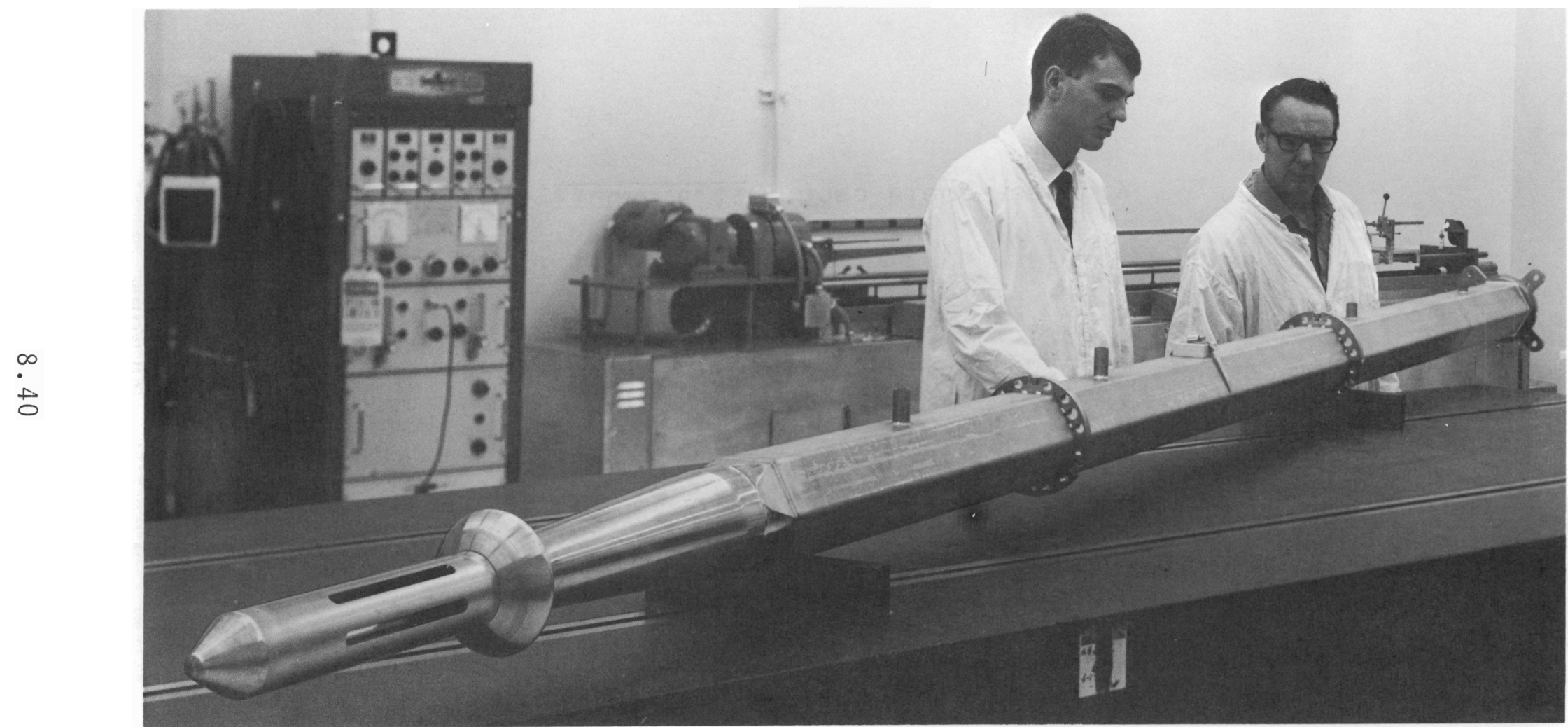

Neg 700760-5

FIGURE 8.20 Completed Subas sembly 
deviations and inspection data are recorded and will be kept for comparison with post-test inspection data. An archive sample of each component part, where possible, and two complete fuel pins are being kept for similar comparisons.

Fuel pin follower cards were generated for each pin at the beginning of assembly recording all of the assembly porcesses and required inspection data. Rejected pins were separated from the acceptable pins which continued through the assembly process.

2. CCTL Mark II Subassembly Compression Test

D. E. Blahnik and R. B. Baker

The purpose of compression testing the CCTL Mark II subassembly was to determine the springiness* that existed within the subassembly when it was compressed symetrically from a nominal internal duct size down to beyond a tight subassembly size. **

* Subassembly Springiness - When a fuel pin subassembly, such as Mark 11, is in the vertical position, the fuel pins cannot bow significantzy towards the center. Therefore, most of the outer pins are randomly forced outward by a combination of their own natural bow and the forces transmitted by the natural bow of internal pins. When a bundle is compressed to a tight subassembly size,** alz of the natural spring is absorbed. If a subassembly is compressed beyond tight subassembly size, the fuel pins react as a combination of leaf and torsion springs.

* Tight Subassembly Size - This is the point at which azz fuel pins and wires are compressed tightly together without any deformation of the subassembly components. There is no outward displacement due to natural bow of the fuel pins and no gaps between wires and fuel pins. When a subassembly is compressed beyond this point, the Zoadcompression deflection curve becomes linear. This term was previously referred to as "bundle theoretical tightness." 
Test apparatus pressure plates (simulating duct walls) were advanced inward against the subassembly in equal increments, maintaining a regular hexagon geometry over a $4-\mathrm{ft}$ span of the subassembly. The spring load on the simulated duct was measured as a function of various across-the-flat dimensions. Figure 8.21 shows a typical curve which can be plotted from subassembly compression test data.

The data is used to:

- Characterize the subassembly's tight size and springiness.

- Analyze the in-reactor cases both of the fuel pins swelling larger than the duct dimensions and vice versa.

- Assist in establishing dimensions and tolerances on the fuel pin OD, wire OD, and the duct inner dimensions to assure proper assembly fit for reactor requirements.

Figure 8.22 shows the compression test apparatus which was used to compress both the CCTL Mark I and Mark II subassemblies. Subassemblies are compressed in the vertical position to minimize the effect of gravity. One side of the test apparatus has a 2 -ft load measurement section so that during subassembly compression or decompression the side load can be measured as a function of hexagonal size.

Figure 8.23 illustrates a summary of the CCTL Mark II compression tests results.

Figure 8.24 compares the summary of test results for Mark II to those for Mark I. 


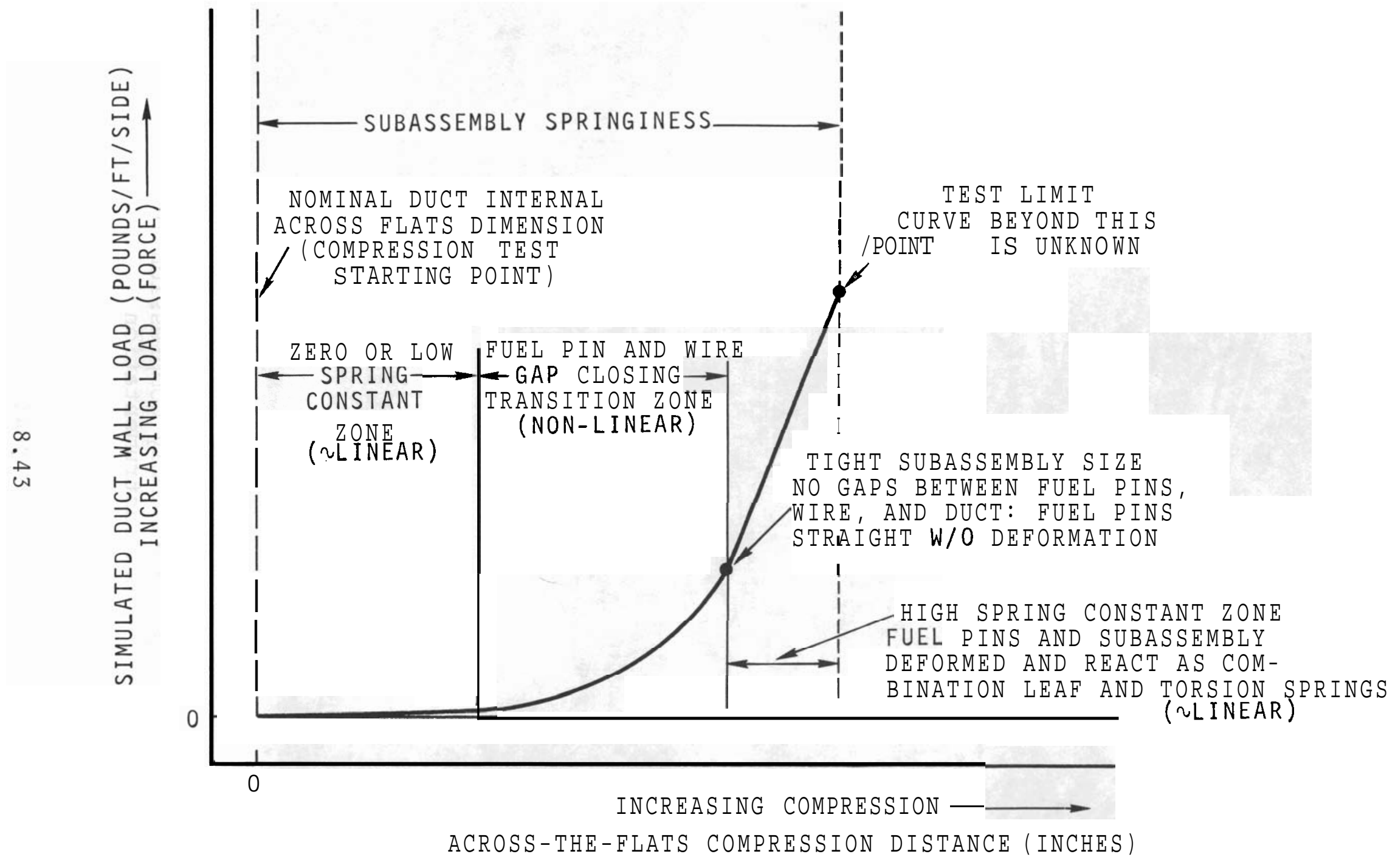

FIGURE 8.21. Typical Subassembly Compression Test Data Curve 
BNWL-1394

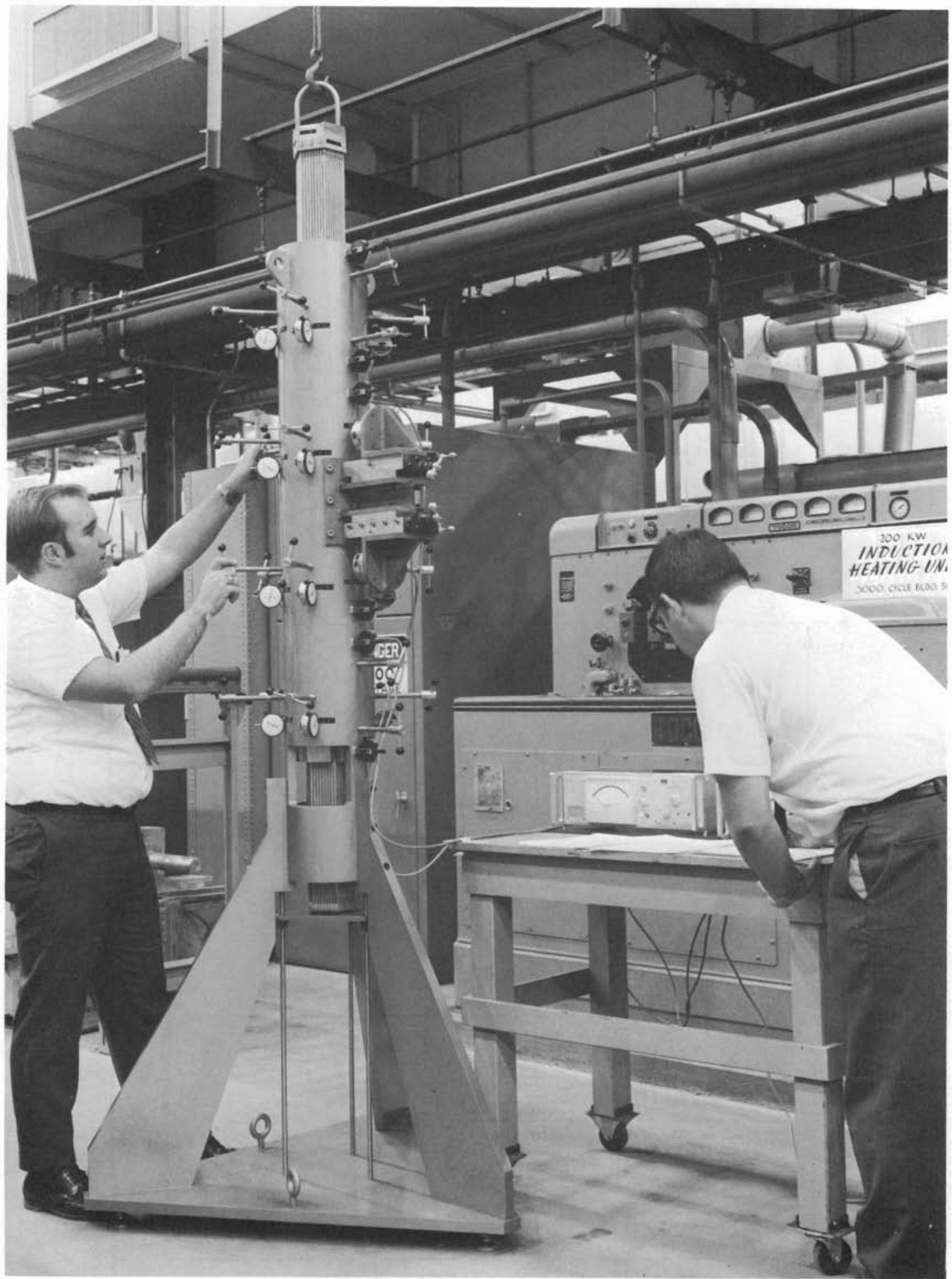

Neg 0694656-4

FIGURE 8.22. Subassembly Compression Test Apparatus and Instrumentation 


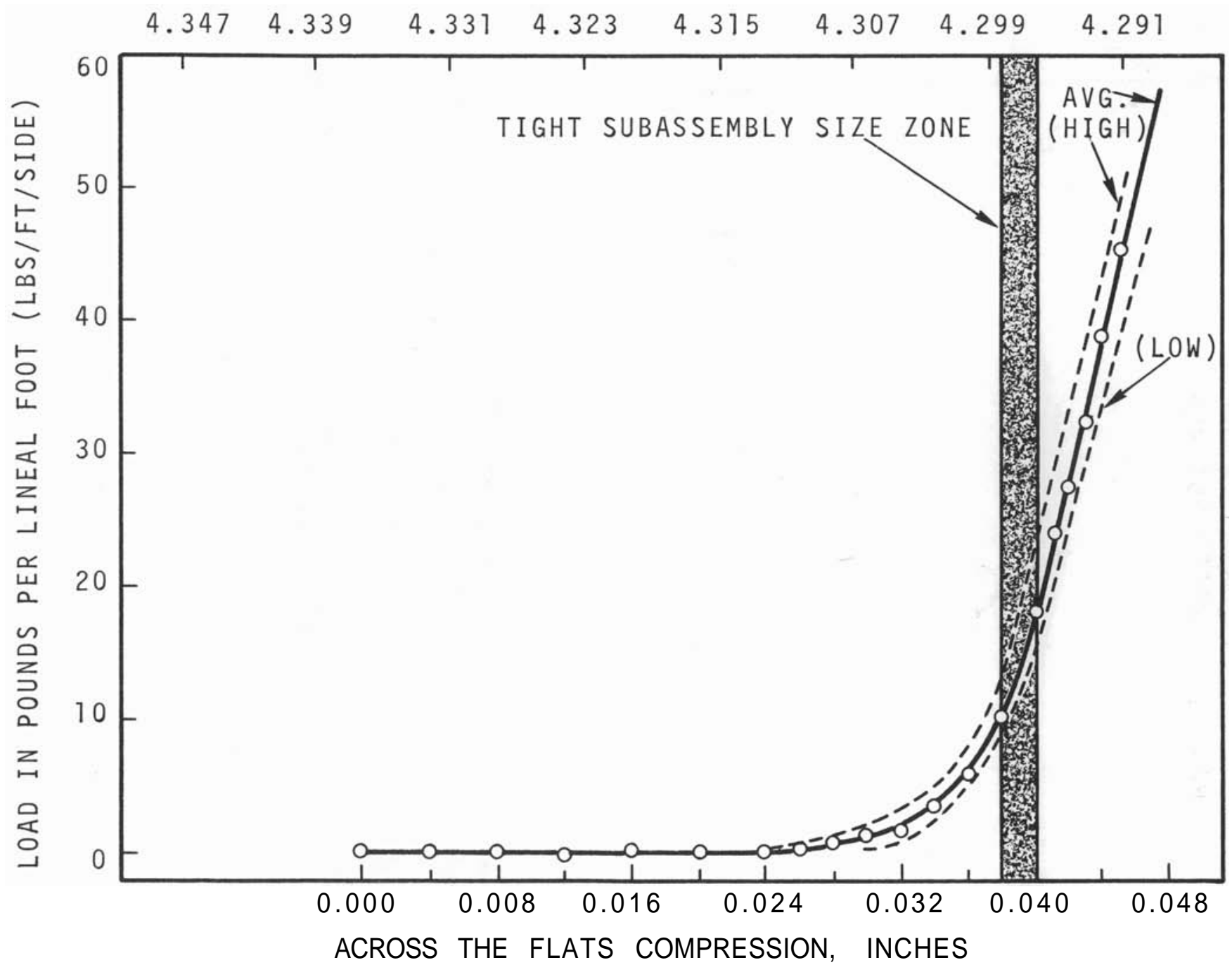

FIGURE: 8.2 3. Summary of Mark II Compressibility Tests Run Numbers: One, Two and Three Average Range 


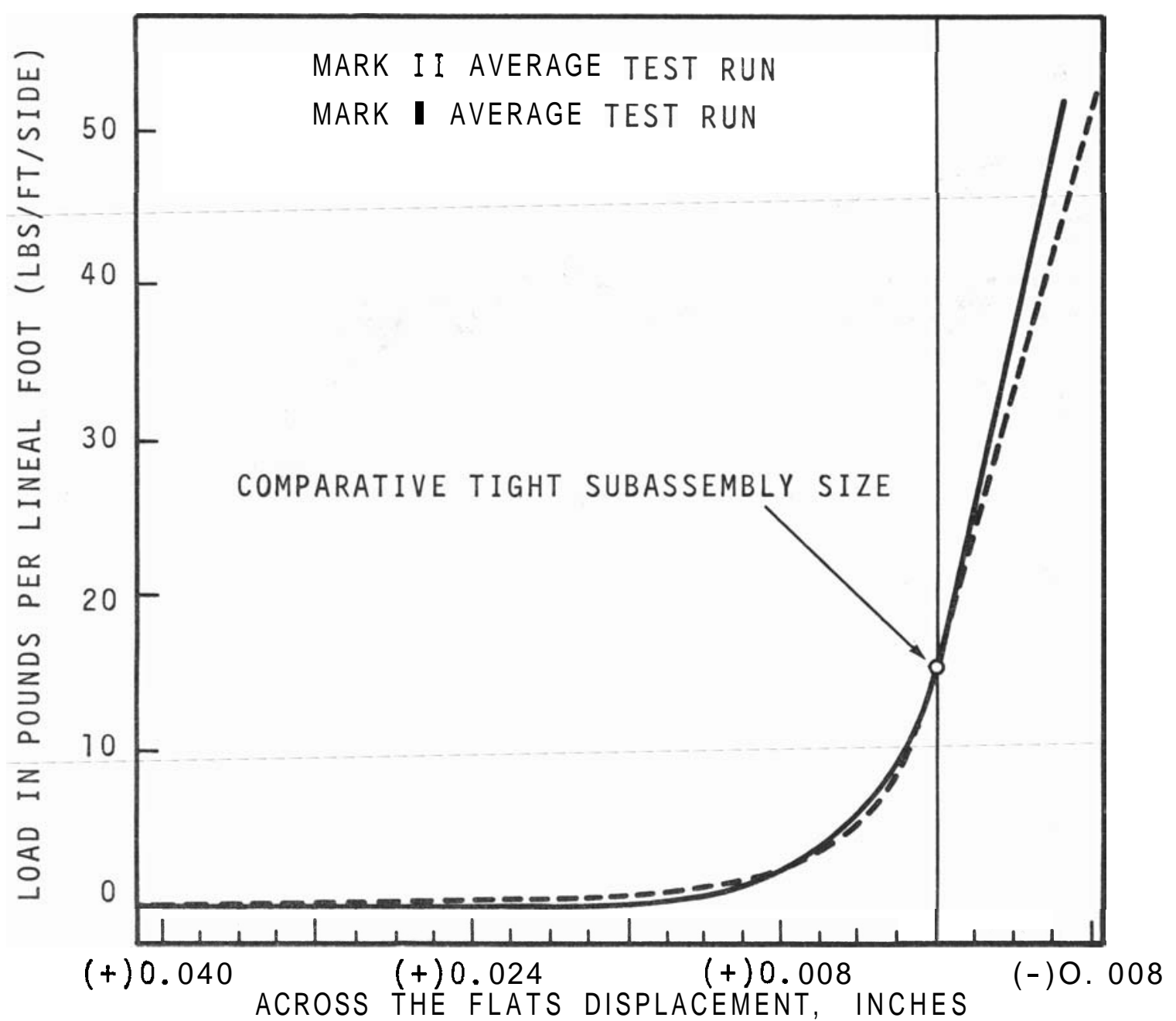

FIGURE 8.24. Summary Comparison of Mark II and Mark I Subassembly Compressibility Test Run Curves 
CHAPTER IX. PHYSICS

A. CORE PHYSICS

1. Dependence of the Diffusion-Transport Correction on the Reactor Composition and the Number of Energy Groups

R. W. Hardie

A series of one-dimensional (spherical geometry) runs were made to determine if the difference in eigenvalue between diffusion and transport $S_{n}$ calculations is strongly dependent on either the reactor composition or the number of energy groups. A description of the four reactors studied is given in Table 9.1.

TABLE 9.1. Reactor Compositions and Dimensions

\begin{tabular}{lllllllll} 
& \multicolumn{2}{c}{ Reactor 1} & \multicolumn{2}{c}{ Reactor 2 } & \multicolumn{2}{c}{ Reactor 3 } & \multicolumn{2}{c}{ Reactor 4 } \\
\cline { 2 - 8 } Item & Core & Refl. & Core & Refl. & Core & Refl. & Core & Refl. \\
\hline${ }^{239} \mathrm{Pu}$ & 0.00394 & 0.0 & 0.00368 & 0.0 & 0.00151 & 0.0 & 0.00164 & 0.0 \\
$238_{\mathrm{U}}$ & 0.005 & 0.0 & 0.032 & 0.041 & 0.005 & 0.0 & 0.0075 & 0.040 \\
0 & 0.010 & 0.0 & 0.0 & 0.0 & 0.010 & 0.0 & 0.021 & 0.0 \\
$\mathrm{Na}$ & 0.010 & 0.005 & 0.0 & 0.0 & 0.010 & 0.005 & 0.006 & 0.0 \\
$\mathrm{Fe}$ & 0.020 & 0.050 & 0.011 & 0.005 & 0.020 & 0.050 & 0.014 & 0.006 \\
$\begin{array}{l}\text { Outer } \\
\text { Radius } \\
(\mathrm{cm})\end{array}$ & 25.0 & 55.0 & 25.0 & 55.0 & 50.0 & 80.0 & 50.0 & 80.0
\end{tabular}

Using a two-and a five-energy group cross-section set, the diffusion and transport theory eigenvalues were calculated by using $1 \mathrm{DX}$ and DTF-IV, respectively. The ratio of the transport theory eigenvalue to the diffusion theory eigenvalue is given in Table 9.2.

TABLE 9.2. Ratio of Transport Theory Eigenvalue to Diffusion Theory Eigenvalue

Number of Groups in

\begin{tabular}{|c|c|c|c|c|}
\hline Cross-Section S & $\underline{\text { Reactor } 1}$ & Reactor 2 & Reactor 3 & $\underline{\mathrm{Ke}}$ \\
\hline 2 & 1.0339 & 1.0069 & 1.0093 & 1.0034 \\
\hline 5 & 1.0401 & 1.0117 & 1.0100 & 1.0051 \\
\hline
\end{tabular}


Two observations can be made from Table 9.2. First, the diffusion-transport difference can vary widely for two reactors of the same size with different compositions. Second, a very small number of groups is not sufficient for accurately calculating the difference between diffusion and transport theory .

\section{2. $\quad$ FFTF Critical Experiments}

a. Program

\section{R. A. Bennett}

Measurements of radial and axial reaction rate distributions were completed in this reporting period. The FTR-3 assembly is now being prepared for measurements of the absolute fission ratios at the core center.

A series of tantalum peripheral control rod experiments is being planned for addition to the FTR-3 program. Tentatively, the experiments will yield experimental reactivity worths of

- $8 \mathrm{~B}_{4} \mathrm{C}$ rods in the presence of $8 \mathrm{~B}_{4} \mathrm{C}$ rods.

- $8 \mathrm{Ta}$ rods in the presence of $8 \mathrm{~B}_{4} \mathrm{C}$ rods.

- $8 \mathrm{Ta}$ rods alone.

- $8 \mathrm{~B}_{4} \mathrm{C}$ rods closed.

It is estimated that these experiments will require approximately 2 weeks of $\mathrm{ZPR}-9$ reactor time.

Additional experiments are to be done using the ORNL noise and source multiplication techniques for subcritical reactivity determinations. These experiments should require less than 2 additional weeks of ZPR-9 reactor time. Hence, the FTR-3 program is now expected to be completed by mid-October 1970 . 
b. The Effect of Heterogeneity on the Worth Calculation of the FTR-2 $B_{4}$ C Control Ring

R. P. Omberg, J. V. Nelson and R. A. Bennett

A number of calculations were made to determine the effect of a heterogeneous-versus-homogeneous representation of the FTR-2 control ring on its calculated worth. The ring is actually composed of alternating layers of $\mathrm{B}_{4} \mathrm{C}$ and sodium (four $\mathrm{B}_{4} \mathrm{C}$ plates and five sodium plates) previously represented in FTR-2 calculations by a homogeneous mixture. The calculations to determine heterogeneity effect were performed in one-dimensional cylindrical geometry with both diffusion theory and S-8 transport theory. The control ring was simulated by five annular sodium rings interspaced with four annular $\mathrm{B}_{4} \mathrm{C}$ rings. This annular arrangement is not exact since some of the $\mathrm{B}_{4} \mathrm{C}$ plates in the physical core were not perpendicular to a radius vector. However, the approximation greatly simplifies the calculation since it then becomes one-dimensional. The diffusion and transport multiplication constants are listed in Table 9.3.

\section{TABLE 9.3. Effective Multiplication Constant}

$\begin{array}{lcc} & \text { Heterogeneous } & \text { Homogeneous } \\ \text { Transport } & 0.99879 & 0.99874 \\ \text { Diffusion } & 0.99285 & 0.99319\end{array}$

The differences in $\mathrm{k}_{\text {eff }}$ are evident in Table 9.4.

TABLE 9.4. Changes in the Multiplication Constant

Transport

Diffusion

Heterogeneous

Homogeneous
$\Delta \mathrm{k} \quad$ (het minus hom) $+0.00005$

$-0.00034$

$\Delta k \quad$ (trans minus diff) +0. 00594

$+0.00555$ 
The differences in $k_{\text {eff }}$ between the homogeneous and heterogeneous calculations are small.

A second set of calculations was made to determine the effect of removing individual $\mathrm{B}_{4} \mathrm{C}$ rings and thus to indicate the interaction between rings and also their relative worth. The second and third rings* were removed individually and then together. When a ring was removed, the space was filled with a sodium-stainless steel mixture. The transport and diffusion multiplication constants are listed below.

\begin{tabular}{llll}
\multicolumn{1}{c}{ Control Ring } & $\frac{k_{t r}}{0.99879}$ & $\frac{k_{\text {diff }}}{0.99285}$ \\
4 het $B_{4}$ C rings in & 1.00312 & 0.99730 \\
3rd $B_{4} \mathrm{~B}_{4} \mathrm{C}$ ring removed & 1.00176 & 0.99592 \\
2nd and 3rd $B_{4}$ C ring removed & 1.00768 & 1.00198
\end{tabular}

The following worths can be calculated from the above numbers.

\begin{tabular}{|c|c|c|}
\hline Problem & $\Delta k_{\text {tr }}$ & $\Delta \mathrm{k}_{\mathrm{diff}}$ \\
\hline 2nd ring removed & 0.00433 & 0.00445 \\
\hline 3rd ring removed & 0.00297 & 0.00307 \\
\hline sum of 2 nd and 3 rd ring & 0.00730 & 0.00752 \\
\hline 2nd and 3 rd ring removed & 0.00889 & 0.00913 \\
\hline
\end{tabular}

Two points are illustrated here. First, the worth of $\mathrm{B}_{4} \mathrm{C}$ decreases rapidly with increasing radius through the second and third rings, as indicated by the large differences between them. This suggests that the agreement between the homogeneous and the heterogeneous ring results could be fortuitous since homogenizing involves transporting $\mathrm{B}_{4} \mathrm{C}$. To resolve this, the worth of $\mathrm{B}_{4} \mathrm{C}$ through the ring will have to be investigated in more detail. Second, the interaction between rings is

* The ring closest to the core is considered the first ring. 
quite large as indicated by the difference between the sum of the worths of the second and third rings removed individually and by the second and third rings removed together.

c. Inferred Experimental Worth of the 'FTR-2 Control Ring R. P. Omberg and R. A. Bennett

One of the principal objectives of Critical Assembly FTR-2 was to measure the reactivity worth of large segments of a peripheral control ring located at the core-reflector interface. A comparison of the calculated and measured worths of the individual segments has been made. (1) As a further check on the correlation between calculation and experiments it would be desirable to compare a calculated and experimental worth for the entire ring. Unfortunately, the experimental worth of the complete ring is not the sum of the worth of its individual segments since $\mathrm{B}_{4} \mathrm{C}$ and fissile material had to be removed in alternating steps, and the interaction between them cannot be disregarded. Thus, a different method for inferring the worth of the entire ring had to be developed.

This method consisted of noting the difference between calculation and experiment in Assembly FTR-1, an assembly which is very similar to FTR-2 with its control ring deleted, and then using this difference to correct the calculated $k_{\text {eff }}$ for FTR-2 with no control ring. The resulting $k_{\text {eff }}$ was called an inferred experimental value. The inferred experimental worth for the ring is then obtained by subtracting the experimental $k_{\text {eff }}$ of FTR-2 with the control ring. This is shown in Table 9.5 .

1. Trans. American Nuclear Society, 1970 Summer Meeting, 
TABLE 9.5 Inferred Experimental Worth of the FTR-2 Control Ring

$$
\begin{aligned}
& \text { FTR-1: } \quad k_{\text {eff }}=0.99711 \text { calculated (c) } \\
& \mathrm{k}_{\text {eff }}=1.00136 \text { experimental (e) } \\
& \mathrm{c}-\mathrm{e}=-4.25 \mathrm{mk} \\
& \text { FTR-2: } \quad k_{\text {eff }}=1.05634 \text { calculated, without control ring } \\
& \mathrm{k}_{\text {eff }}=1.06059 \text { inferred experimental value with- } \\
& \text { out control ring } \\
& \mathrm{k}_{\text {eff }}=1.00098 \text { measured, with control ring } \\
& \text { Inferred experimental worth of the control ring } \\
& =59.6 \mathrm{mk} \text { or } \\
& \rho=5.62 \% \\
& \text { Calculated worth of the control ring } \\
& =48.7 \mathrm{mk} \text { or } \\
& \mathrm{p}=4.64 \% \Delta \mathrm{k} / \mathrm{k} \\
& \mathrm{c} / \mathrm{e}=0.82
\end{aligned}
$$

It can be seen that the inferred experimental worth of the ring is $59.6 \mathrm{mk}$ or $\rho=5.62 \% \Delta \mathrm{k} / \mathrm{k}$. The ratio of calculation to experiment is 0.82. This c/e is somewhat smaller than average c/e of 0.9 obtained for the individual segments of the ring; ${ }^{(1)}$ however, it does fall within $0.9 \pm 0.1$ which was found to be the range of the individual c/e's for the ring segments. It is interesting to note that ANL obtained an inferred experimental worth of the ring of approximately $5-1 / 2 \% \Delta \mathrm{k} / \mathrm{k}$ by a completely independent method. (2) If the interaction between the depleted zone and the $\mathrm{B}_{4} \mathrm{C}$ ring is

1. Trans. American Nuclear Society, 1970 Summer Meeting, Los Angeles, to be presented.

2. A. Travezzi, A. J. UZrich, and J. C. Beitez. "Analysis of Reactivity Changes Associated with Large Perturbations in ZPPR/ETR-2," Trans. Am. Nucl. Soc., 1970 Summer Meeting, Los Angezes, to be presented. 
disregarded and the individual $\mathrm{B}_{4} \mathrm{C}$ exchanges simply added, the ring is found to be worth $5.8 \% \Delta \mathrm{k} / \mathrm{k}$. Thus, the interaction effect is about $0.2 \% \Delta \mathrm{k} / \mathrm{k}$.

\section{d. Control Rod Heterogeneity}

S. L. Engstrom and R. A. Bennett

Rectangular bars of boron carbide used in the FTR Critical Experiments to represent control rods of interest, are usually arranged in patterns that require extremely detailed two-dimensional transport calculations in order to represent them precisely. In fact, as much as is possible, diffusion theory homogeneous approximations of the rods are made for calculations. This is known to introduce errors in the calculations. (1) As a prelude to a detailed two-dimensional transport analyses of actual rod configurations, a series of comparisons of cylindrical calculations of rod worths have been made.

A single cylindrical control rod, of 3.12 an diameter, was represented at the center of a cylindrical reactor closely approximating the early FTR Critical, ZPR-III, Assembly 51.

Four $\mathrm{B}_{4} \mathrm{C}$ arrangements compared were:

- an homogeneous cylinder of $B_{4} \mathrm{C}-\mathrm{Na}-\mathrm{SS} . \quad \mathrm{R}=3.12 \mathrm{~cm}$.

- a small ring of $B_{4} C$, IR $=1.43 \mathrm{~cm}, \quad O R=2.02 \mathrm{~cm}$, imbedded in an homogeneous cylinder of sodium and stainless steel, $\mathrm{OR}=3.12 \mathrm{~cm}$.

- a large ring of $\mathrm{B}_{4} \mathrm{C}, \mathrm{IR}=2.78 \mathrm{~cm}, \mathrm{OR}=3.12 \mathrm{~cm}$, surrounding an homogeneous cylinder of sodium and stainless steel.

- a solid $B_{4}$ C cylinder $\mathrm{R}=1.43 \mathrm{~cm}$, centered in an homogeneous cylinder of sodium and stainless steel, $R=3.12 \mathrm{~cm}$.

1. R. A. Bennett and S. L. DeMyer. Analysis of FTR Phase A Control Rod Experiments in ZPR-111, Assembly 48 and 48A, BNWL-967, Richland, Washington, April 2969. 
For each physical configuration, the mass of $\mathrm{B}_{4} \mathrm{C}$, sodium, and stainless steel was identically the same. Three enrichments of ${ }^{10} \mathrm{~B}$ in boron were used to comprise a set of worths. In Table 9.6 the \% difference in worth given by the exact transport model, and alternative models are given for each rod configuration.

TABLE 9.6. Percent Difference, Approximations Versus Precise Transport Model

\begin{tabular}{|c|c|c|c|c|}
\hline Enrichment & Approximate Model & $\begin{array}{l}\frac{\text { Rod Cor }}{\text { Solid B }{ }_{4}^{C}} \\
\text { Cylinder } \\
\end{array}$ & $\begin{array}{l}\text { Eigurat } \\
\text { Small } \\
\text { Ring } \\
\end{array}$ & $\begin{array}{l}\text { Lon } \\
\text { Large } \\
\text { Ring } \\
\end{array}$ \\
\hline $\begin{array}{l}\text { Natural } \\
\left(19.2 \% \quad 10_{\mathrm{B}}\right)\end{array}$ & $\begin{array}{l}\text { Transport Homog. } \\
\text { Diffusion Homog. } \\
\text { Diffusion Hetero. }\end{array}$ & $\begin{array}{l}+6.22 \\
+6.02 \\
+3.32\end{array}$ & $\begin{array}{l}+1.19 \\
+0.99 \\
+1.58\end{array}$ & $\begin{array}{r}-3.03 \\
-3.22 \\
0.00\end{array}$ \\
\hline $\begin{array}{l}\text { Intermediate } \\
\left(56.1 \div 10_{\mathrm{B}}\right)\end{array}$ & $\begin{array}{l}\text { Transport Homog. } \\
\text { Diffusion Homog. } \\
\text { Diffusion Hetero. }\end{array}$ & $\begin{array}{l}+19.0 \\
+21.2 \\
+11.6\end{array}$ & $\begin{array}{l}+5.26 \\
+7.27 \\
+4.76\end{array}$ & $\begin{array}{l}-2.78 \\
-0.93 \\
+2.31\end{array}$ \\
\hline $\begin{array}{l}\text { Highly } \\
\text { Enriched } \\
\qquad\left(90.7 \% 10_{B}\right)\end{array}$ & $\begin{array}{l}\text { Transport Homog. } \\
\text { Diffusion Homog. } \\
\text { Diffusion Hetero. }\end{array}$ & $\begin{array}{l}+19.7 \\
+26.7 \\
+10.5\end{array}$ & $\begin{array}{l}+7.69 \\
+11.2 \\
+7.25\end{array}$ & $\begin{array}{l}-2.67 \\
+0.53 \\
+3.74\end{array}$ \\
\hline
\end{tabular}

To illustrate the contents of Table 9.6, the homogeneous diffusion approximation of the solid, highly-enriched $\mathrm{B}_{4} \mathrm{C}$ cylinder overestimates the rod worth by $26.7 \%$.

In general, these calculations illustrate that the sign of the disagreement between the worths given by the approximate models depends upon the extent of the moderating material internal to the rod and upon the degree of enrichment. One may make at least two conclusions:

- Calculated worths of FTR enriched control rod designs should be determined with transport theory using at least approximate physical models; that is, $\mathrm{B}_{4} \mathrm{C}$ annuli to represent hexagonal arrays of rods.

a Rod configurations used in critical experiments should be evaluated in detail with good transport approximations. The latter was illustrated in the analysis of ZPR-III 48 central rod experiments. (1)

1. R. A. Bennett and S. L. DeMyer. Analysis of FTR Phase A Control Rod Experiments in ZPR-111, Assembly 48 and 43A, BNWL-967, Richland, Washington, April 1969. 
e. Effect of a Radial Shield on Peripheral Control Worth in FTR-3

3. V. Nelson

A series of 2DBS X-Y quarter core calculations in

13 groups was run to determine the change in peripheral control rod worth induced by the addition of a radial shield to FTR-3. The worth of four $\mathrm{B}_{4} \mathrm{C}$ control clusters, each consisting of four columns, was calculated for two different shield thicknesses as well as for no shield present. One shield was approximately four drawers thick, containing 436 columns of shield material while the other was about nine drawers thick and contained 1060 columns. In both cases, the composition of the shield was 85 vol\% Type 304 SS and 15 vo1\% sodium. The results of these calculations are shown in Table 9.7.

TABLE 9.7. Pheripheral Control Worth Versus Shield Thickness in FTR-3

Shield Thickness (Drawers

0
4
9

Four Control Clusters

\begin{tabular}{|c|c|c|c|}
\hline$\left(\begin{array}{c}\text { In } \\
\text { eff }\end{array}\right)$ & $\left(\begin{array}{c}\text { Out } \\
k_{\text {eff }}\end{array}\right)$ & $\begin{array}{l}\text { Worth of Four } \\
\text { Clusters }(\Delta \mathrm{k}) \\
\end{array}$ & $\begin{array}{l}\% \text { Change } \\
\text { in Worth }\end{array}$ \\
\hline 0.98347 & 0.99125 & 0.00778 & 0 \\
\hline 0.98465 & 0.99274 & 0.00809 & 3.98 \\
\hline 0.98456 & 0.99287 & 0.00831 & 6.81 \\
\hline
\end{tabular}

g. Effect on Reactivity of Changes in Atom Densities J. V. Nelson

A series of calculations was performed to determine the reactivity change in the Engineering Mockup as the result of sequentially altering the atom densities of ${ }^{239} \mathrm{Pu},{ }^{238} \mathrm{U}$, sodium, and ${ }^{16} 0$ in the inner and outer drawer zones. The material compositions of all zones of the model were initially the desired values. Then, the atom densities of each of the four isotopes listed above were changed one at a time from desired to anticipated values in both driver zones. All 
calculations were made using 2DBS in the X-Y mode with a 13-group cross-section set. The reactivity changes at each step are listed in Table 9.8 with the corresponding mass changes used in these calculations from Reference 1 .

TABLE 9.8. Reactivity Changes in Engineering Mockup Caused by Differences Between Desired and Anticipated Atom Densities

\begin{tabular}{|c|c|c|c|c|}
\hline \multirow[b]{2}{*}{ Run } & \multirow{2}{*}{$\mathrm{k}_{\mathrm{eff}}$} & \multirow[b]{2}{*}{$\Delta \mathrm{k}$} & \multicolumn{2}{|c|}{$A M, k g$} \\
\hline & & & D r I & $\mathrm{Dr} I \mathrm{I}$ \\
\hline Base Case & 0.99388 & - & - & - \\
\hline $239 \mathrm{Pu}^{(\mathrm{a})}$ & 0.98421 & -0.00967 & -9.85 & 9.25 \\
\hline 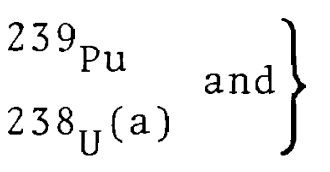 & 0.97934 & 0.00467 & 53.71 & 60.08 \\
\hline $\begin{array}{l}{ }^{239} \mathrm{Pu},{ }^{238} \mathrm{U} \\
\text { and sodium }\end{array}$ & 0.97950 & -0.00004 & -10.60 & 3.62 \\
\hline $\left.\begin{array}{c}239^{\mathrm{Pu}}, \quad 238_{\mathrm{U}} \\
\text { sodium } \\
\text { and }{ }^{16} \mathrm{O}(\mathrm{a})\end{array}\right\}$ & 0.97829 & -0.00121 & 0.69 & -16.88 \\
\hline
\end{tabular}

a. Changed to Anticipated Densities

3. Anomaly Detection in a Reactor a t Power

James R. Sheff

Measurement of neutron and other variable fluctuations in a reactor at full power is useful in seeking reactor anomalies. Theories that describe the full-power fluctuations of the neutron population and reactor temperatures have been developed here ${ }^{(1)}$ and in Japan. (2) Both models provide a method for

1. James R. Sheff. "Neutron Fluctuations at Fulz Power," Japan-United States Seminar on Nuclear Reactor Noise Analysis, 2nd-7th September 1968, Tokyo and Kyoto.

2. K. Saito and Y. Taji. "Theoretical Study of At-Power Reactor Noise," Japan-United States Seminar on Nuclear Reactor Noise Analysis, 2nd-7th September 1968, Tokyo and Kyoto. 
predicting the frequency dependence of the auto and crossspectral density functions for these variables. The timely discovery of anomalies such as coolant flow blockage and vibrations of reactor components may be possible through measurements of neutron, temperature, sodium flow, and system pressure fluctuations.

Development of a means to apply these theories to FTR is underway. The models developed here have been programmed(1) for use on the Univac 1108. The digital computer program, NESAP 2, (2) has been obtained and converted for use on the Univac 1108 as a part of the FTR program for evaluation of these methods. A comparison of the two formulations using the two computer codes is planned as a partial check upon the correctness of both.

4. Reactivity Effects of Incoherent Sodium Voiding Within a Ring of Subassemblies

A. E. Waltar

Although the MELT-I1 neutronics-heat transfer computer program explicitly allows for core radial and axial incoherence reactivity feedback induced by coolant voiding, incoherencies within a radial channel could be quite significant for some cases. Such incoherency could be caused by differences in power density and pin burnup.

In a first attempt to establish the importance of this "third dimension" effect on reactivity feedback induced by voiding, a hypothetical pipe rupture accident which was

1. James R. Sheff. User's Manual for NOISY1 - A Program for Calculation of Space Dependent Spectral Densities in Cubical Reactors, BNWL-1260, Battelle-Northwest, Richland, Washington, 1970 .

2. K. Saito. NESAP2, A Fortran IV Code for CaZculation of Noise Spectra in At-Power Reactors, JAERI-2186, Atomic Energy Research Institute, Tokyo, Japan, May 1969. 
previously investigated for the case of a high sodium void worth was re-evaluated. In the original case (Case A), the six rings of subassemblies were modelled by assuming that a single pin represented all pins within a given ring. Furthermore, goal exposure was assumed throughout the core, and voiding was assumed to result from the release of fission gas at 900 psi through the failed cladding at the top of the core. Rings 4 and 5 began to void almost simultaneously, and because of the large volume of sodium contained in these two rings, the reactivity ramp rate at the time of disassembly was very large.

In the present study (Case B), Rings 4 and 5 were each computatively divided into three equal volume channels to depict three possible power ratings and fission gas driving pressures with each subassembly ring. Since the subassemblies in the corner of the hexagonal core array operate at a relatively low flux level, it was assumed that these positions would be charged with fresh fuel to flatten the core power level whereas subassemblies in the "flats" would remain for higher burnups. Hence, the relative power ratings and fission gas plenum pressures were assumed as follows:

\begin{tabular}{|c|c|c|}
\hline Burnup & $\begin{array}{c}\text { Fission } \\
\text { Gas Pressure, } \\
\text { psi } \\
\end{array}$ & $\begin{array}{c}\text { Relative } \\
\text { Power Change, } \\
\frac{0}{0} \\
\end{array}$ \\
\hline High & 800 & +5 \\
\hline Medium & 500 & 0 \\
\hline Low & 200 & -5 \\
\hline
\end{tabular}

Figure 9.1 illustrates the resulting comparison of reactivity ramp rates caused by sodium expulsion over the time that spans the voiding of subassembly Rings 3 through 5. The numbers in the circle identify the times at which various channels begin to void; for example, 5-1 indicates that the hottest third of the subassemblies in Ring 5 began to void at 


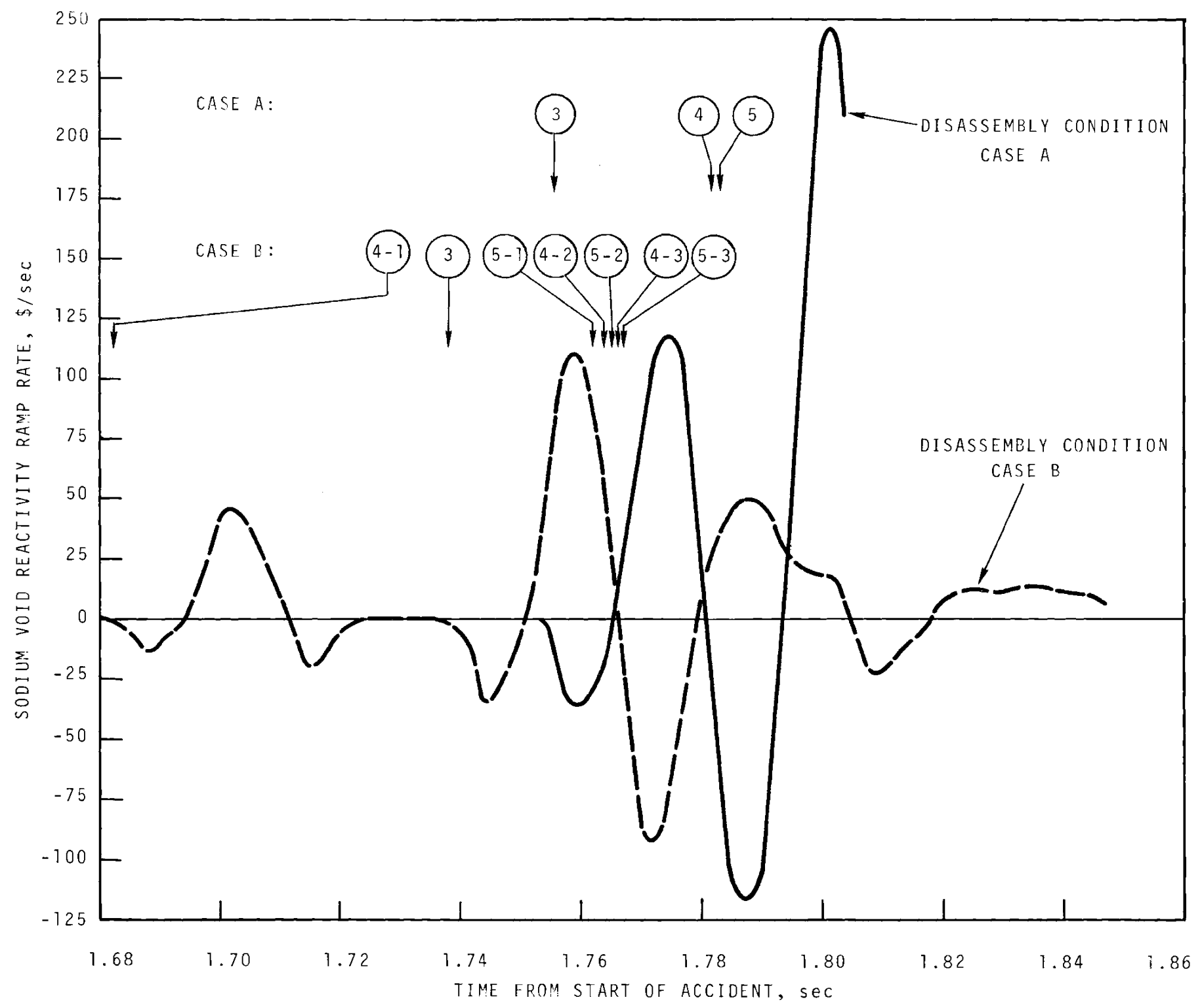

FIGURE 9.1. Reactivity Ramp Rate Variations as a Function of Voiding Incoherences Within a Radial Channel 
1.762 sec after the start of the accident for Case B. As evident, the explicit treatment of incoherencies within a ring results in a smearing out of the reactivity consequences, and the ramp rate at the time of disassembly is much lower than for Case A. However, the assumptions required which determine the basis for incoherencies within a subassembly ring are numerous, and the particular assumptions made certainly will alter the resulting time sequence for voiding. Hence, one can probably generalize that taking account of such incoherence will smear out the reactivity effect and lead to the calculation of lower energy releases, but the degree of such reduction may be quite case dependent.

5. Critical Approach and Exponential Experiments with 25.2 wt\% $\underline{\mathrm{PuO}}_{2}-\mathrm{U}$ (Nat.) $\mathrm{O}_{2}$ Rods in Water

C. L. Brown, L. C. Davenport, and C. A. Rogers

The final data reduction and analysis of a series of critical approach and exponential experiments with 25.2 wt\% $\mathrm{PuO}_{2}-\mathrm{U}$ (Nat.) $\mathrm{O}_{2}$ fuel rods in water was completed. The fuel column in each pin was 0.195 in. diameter $\times 27.25$ in. long; the cladding was 0.015 in. thick Type 316 SS. The plutonium contained $11.88 \mathrm{wt} \% 240 \mathrm{Pu}$ and $1.55 \mathrm{wt} \%{ }^{241} \mathrm{Pu}$. The critical number of pins, material buckling, and extrapolation distance was measured for seven triangular pitch lattice spacings. Summary results are given in Table 9.9. These data will provide an essential part of the criticality safety basis for the handling, storage, and transportation of LMFBR fuels. A final report is in preparation.

Critical approach and exponential experiments are in progress with the above described 25.2 wto $\mathrm{PuO}_{2}-\mathrm{U}$ (Nat.) $\mathrm{O}_{2}$ fuel pins in water containing boron. The objective of these experiments is to establish the boron concentrations necessary to reduce $k_{\infty}$ to unity for the $0.6 \mathrm{in}$. and $0.9 \mathrm{in}$. lattices. These are the lattices for maximum material buckling and minimum critical mass, respectively. These measurements are also 
needed to provide check points for calculational methods. These data will be needed for future criticality safety evaluations involving FFTF fuel reprocessing plants and FFTF fuel transportation. Tentative results obtained from the critical approach experiments are given in Table 9.10. Exponential experiments with 0.6 in. lattice poisoned with $350 \mathrm{ppm}{ }^{10} \mathrm{~B}$ are currently in progress.

TABLE 9.9. Results of Critical Approach Experiments with 25.2 wt\% $\mathrm{PuO}_{2}$-U (Nat.) $\mathrm{O}_{2}$ Fuel Rods for Water

\begin{tabular}{|c|c|c|}
\hline \multirow[b]{2}{*}{$\begin{array}{l}\text { Lattice } \\
\text { Pitch, } \\
\text { in. } \\
\end{array}$} & \multicolumn{2}{|c|}{$\left(11.88\right.$ wt $\left.{ }^{240} \mathrm{Pu}\right)$} \\
\hline & $\begin{array}{l}\text { Number of } \\
\text { Pins for } \\
\text { Criticality } \\
\end{array}$ & $\begin{array}{c}\text { Critical } \\
\text { Mass, } \\
\mathrm{kg} \mathrm{Pu} \\
\end{array}$ \\
\hline 0.450 & $41.0 \pm 5$ & 12.8 \\
\hline 0.600 & $219.2 \pm 0.6$ & 6.74 \\
\hline 0.779 & $156.2 \pm 0.8$ & 4.80 \\
\hline 0.900 & $149.8 \pm 0.6$ & 4.61 \\
\hline 1.039 & $165.0 \pm 0.2$ & 5.07 \\
\hline 1.200 & $232.6 \pm 0.1$ & 7.15 \\
\hline 1.350 & $410 \pm 10$ & 12.6 \\
\hline
\end{tabular}

TABLE 9.10. Tentative Results of Critical Approach Experiments with 25.2 wt\% $\mathrm{PuO}_{2}-\mathrm{UO}_{2} \mathrm{Fuel}$ Pins i n Water Containing Boron

\begin{tabular}{|c|c|c|c|}
\hline \multirow[b]{2}{*}{$\begin{array}{c}\text { Lattice } \\
\text { Pitch, } \\
\text { in. }\end{array}$} & \multicolumn{3}{|c|}{$\left(11.88\right.$ wt: $\left.{ }^{240} \mathrm{Pu}\right)$} \\
\hline & $\begin{array}{c}{ }^{10} \mathrm{~B} \\
\begin{array}{c}\text { Concentration, } \\
\text { ppm }\end{array} \\
\end{array}$ & $\begin{array}{l}\text { Estimated } \\
\text { Critical } \\
\text { Number of } \\
\text { Fuel Pins } \\
\end{array}$ & $\begin{array}{l}\text { Measured } \\
\text { Critical } \\
\text { Number of } \\
\text { Fuel Pins } \\
\end{array}$ \\
\hline 0.600 & 180 & 275 & 334 \\
\hline 0.900 & 133 & 283 & 322 \\
\hline
\end{tabular}


BNWL -1394

B. RADIATION AND SHIELDING

1. Fission Product Decay Heat

D. R. Marr

Emergency cooling requirements after the first few seconds are primarily determined by the fission product decay heat. An extensive literature search was made to determine the total sensible decay energy available from the fast fission of ${ }^{239} \mathrm{Pu}$ and ${ }^{238} \mathrm{U}$, since these values establish the decay heat rate at shutdown. Based on the limited experimental evidence available for fast fission of these isotopes and on a consideration. of the energies available from other fissile isotopes at other energies, values of 14.0 and $18.7 \mathrm{MeV}$ per fission were determined for ${ }^{239} \mathrm{Pu}$ and ${ }^{238} \mathrm{U}$, respectively. These values establish the shutdown decay power for FIR goal exposure fuel at $6.6 \%$ of equilibrium power after $1 \mathrm{sec}$, $4.8 \%$ after $10 \mathrm{sec}, 35 \%$ after $100 \mathrm{sec}, 1.1 \%$ after $1 \mathrm{hr}$, and $0.42 \%$ after $24 \mathrm{hr}$.

For verification of computations, the summation method of calculating decay heat, proved at longer decay times, was extended to the first few seconds of decay by including all the short-lived isotopes that are predicted to occur in the fast fission of either ${ }^{239} \mathrm{Pu}$ or ${ }^{238} \mathrm{U}$. Energies and half lives for these isotopes were empirically determined. The energies give the correct total decay energy release per fission, while the half lives provide an adequate description of the time dependence of the gamma power measured by Fisher and Engle, (1) as seen in Figure 9.2. Although the experimental exposure was of a burst nature, the agreement provides confidence in calculations of the FIR decay power at short times after shutdown.

I. P. C. Fisher and L. B. Engle. "Delayed Gammas from Fast Neutron Fission of $232 \mathrm{Th}, 233 \mathrm{U}, 238 \mathrm{U}$, and $239 \mathrm{Pu}$," Phys.Rev., 134 4B, 1964. 


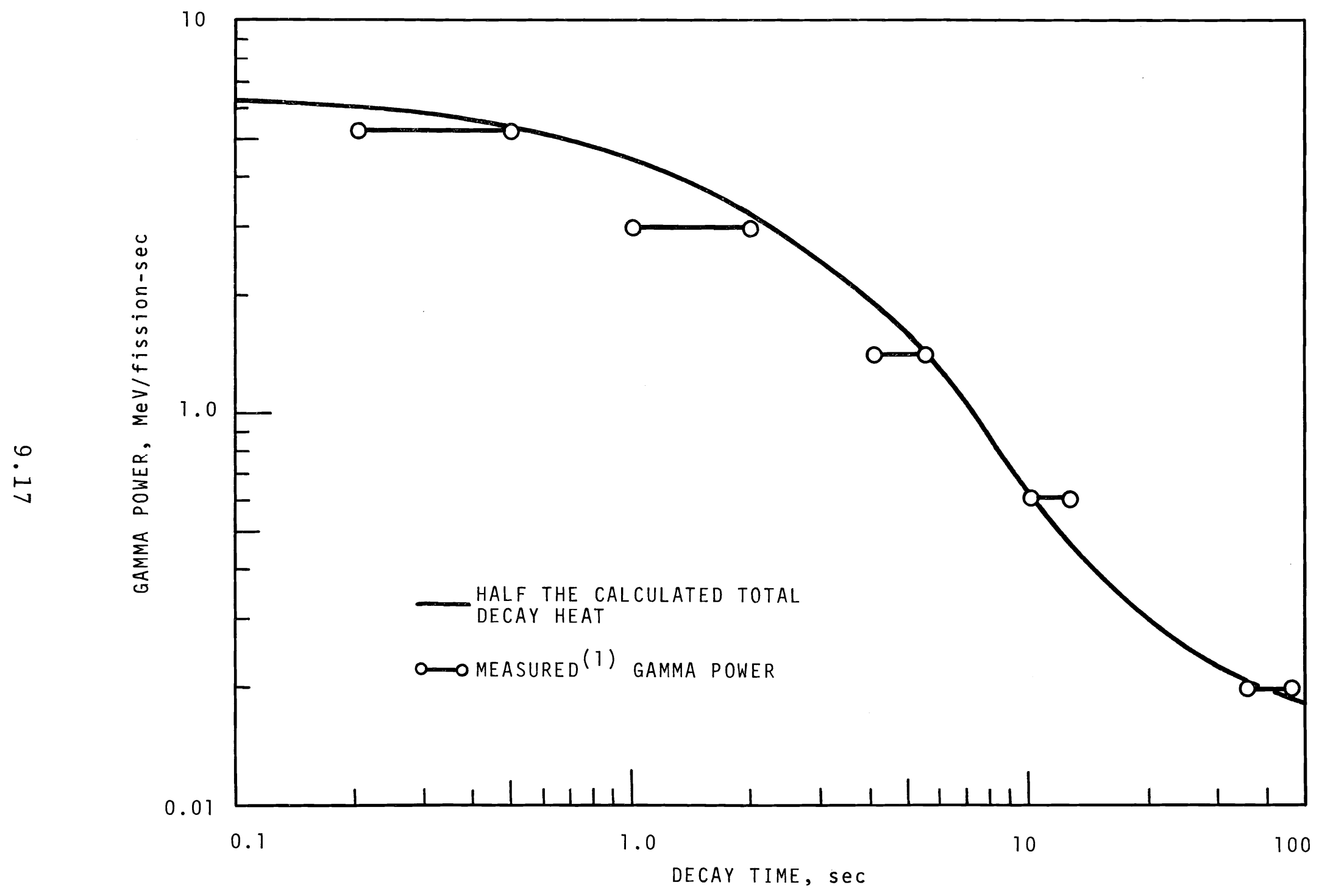

FIGURE 9.2. Decay Gamma Power After a Fast Neutron Burst in ${ }^{239}$ Pu 
2. Na and Mn Disintegration Rate Distributions in the ZPPR E. T. Boulette

Disintegration rate distributions of $\mathrm{Na}(n, \gamma)$ and $\mathrm{Mn}(n, \gamma)$ were measured in the ZPPR, Assembly FTR-2, to provide a partial evaluation basis for the FTR conceptual shield design. Two-dimensional diffusion theory calculations made with 2DBS were compared to the experimental results on an absolute basis. The nuclear data used in the calculations were extracted from the 31-group HOMSET transport-corrected, crosssection library.

The comparison of the $\mathrm{Mn}(\mathrm{n}, \mathrm{\gamma})$ results showed agreement comparable to those previously found for the $\mathrm{B}(\mathrm{n}, \gamma),{ }^{239} \mathrm{Pu}(\mathrm{n}, \mathrm{f})$ and ${ }^{238} \mathrm{U}(\mathrm{n}, \mathrm{f})$ reaction rate distributions. The $\mathrm{Na}(\mathrm{n}, \mathrm{y}) \mathrm{com}-$ parison, however, indicated a significant difference in the shapes of the experimental and calculated distributions. The calculation was significantly biased in the core, where the spectrum is relatively hard. Because of this, the sodium capture cross-sections in the high-energy region were empirically adjusted, and new flux calculations were made. These adjusted cross-sections significantly improved the agreement for the $\mathrm{Na}(\mathrm{n}, \gamma)$ results without adversely affecting the agreement of the other reaction rate distributions.

3. ZPPR Stored Fuel Analysis

E. T. Boulette

The ZPPR shield experiments included fission rate measurements through the radial shield segment, both with and without stored fuel in the shield. Rigorous treatment of these experiments requires three-dimensional calculations, and these are not presently practical. Two-dimensional calculations were made with $2 \mathrm{DBS}$ in $\mathrm{X}-\mathrm{Y}$ and $\mathrm{R}-\mathrm{Z}$ geometry. The $\mathrm{X}-\mathrm{Y}$ calculations rigorously include the finite transverse dimensions of the fuel but not the length; whereas, the R-Z calculations must 
include consideration of a full ring of fuel even though accounting for the finite length. Calculated fission rate distributions for ${ }^{238} \mathrm{U}$ are compared in Figures 9.3 and 9.4 to the experimental results. Differences between the calculations are attributed to the geometrical limitations in incorporating the stored fuel. The X-Y calculation was assumed to be valid at the reactor midplane. At other elevations, spatially dependent correction factors were calculated by taking the ratio of the $\mathrm{X}-\mathrm{Y}$ result to the $\mathrm{R}-\mathrm{Z}$ midplane result and adjusting the $\mathrm{R}-\mathrm{Z}$ values at all elevations by the corresponding ratio. The corrected values for ${ }^{238} \mathrm{U}(\mathrm{n}, \mathrm{f})$ are in reasonably good agreement with the experiment; however, further analyses are needed to treat the other reaction rate distributions.

\section{ZPPR Gamma Ray Shieldine Experiments}

E. T. Boulette and W. L. Bunch

Thermoluminescent dosimeters (TLD's) were irradiated in the ZPPR/FTR-2 configuration to obtain gamma flux distributions for use in evaluating the FTR conceptual shield design. Gamma transport calculations were made in one-dimensional cylindrical geometry by using the multigroup discreteordinates code ANISN in an 18-group, $\mathrm{S}_{8} \mathrm{P}_{3}$ approximation. Preliminary calculations were made with a 10-energy group approximation; however, this was found to underestimate the gamma flux in the core region. The present 18-group calculations include a much finer energy group structure below $1 \mathrm{MeV}$, resulting in better agreement in the experimental data.

The results of the calculations are depicted in Figures 9.5 and 9.6, together with the measured gamma dose values. The calculated curves are based on an integrated irradiation of $750 \mathrm{~W} / \mathrm{hr}$. Figure 9.5 represents the comparison at the ZPPR/FTR-2 core midplane, with stored fuel in the radial shield; whereas, Figure 9.6 is a comparison at the 


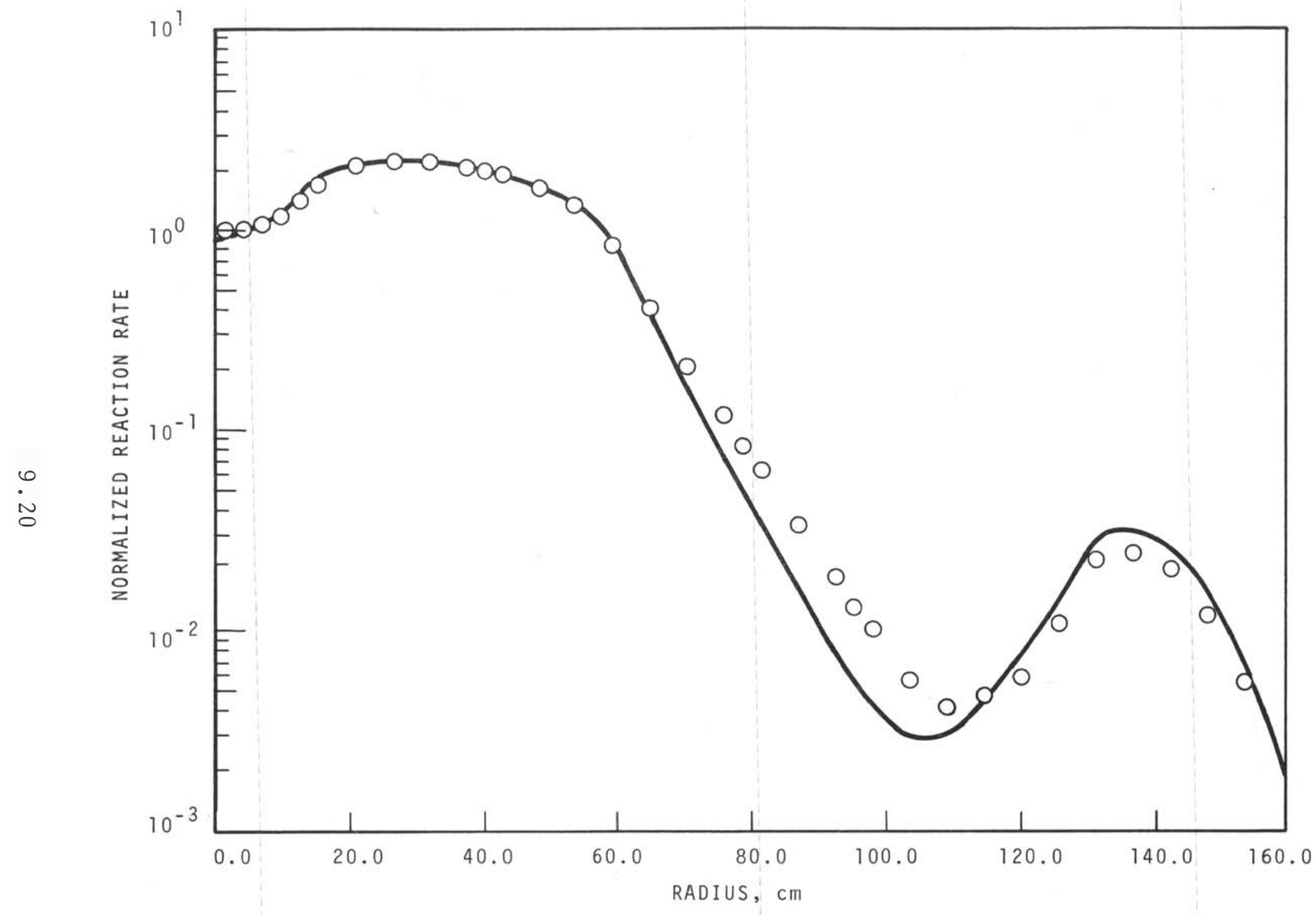

FIGURE 9.3. ${ }^{238} \mathrm{U}(\mathrm{n}, \mathrm{f})$ Reaction Rate Distribution--R-Z Calculation 


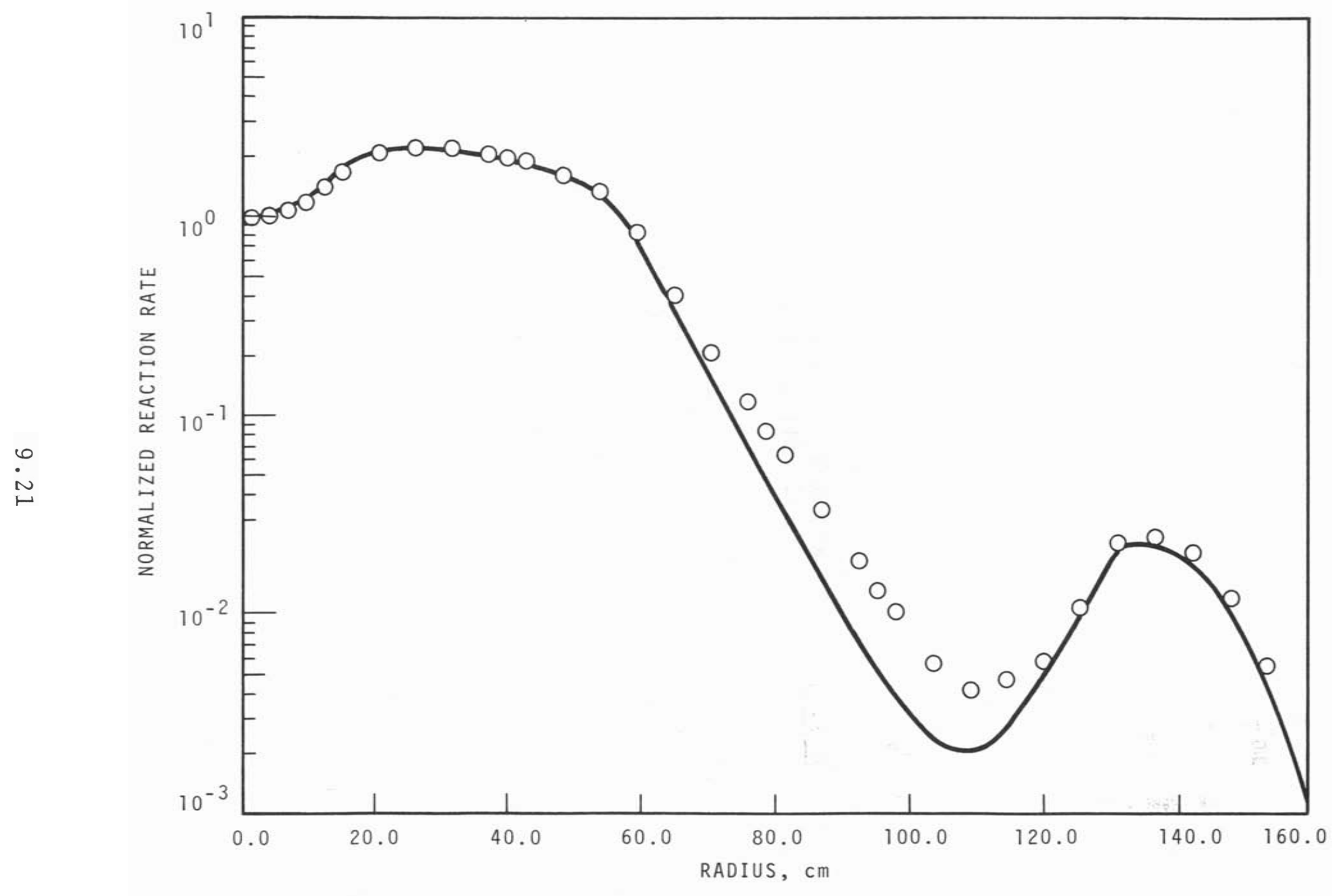

FIGURE 9.4. ${ }^{238} \mathrm{U}(\mathrm{n}, \mathrm{f})$ Reaction Rate Distribution--X-Y Calculation 
BNWL -1394

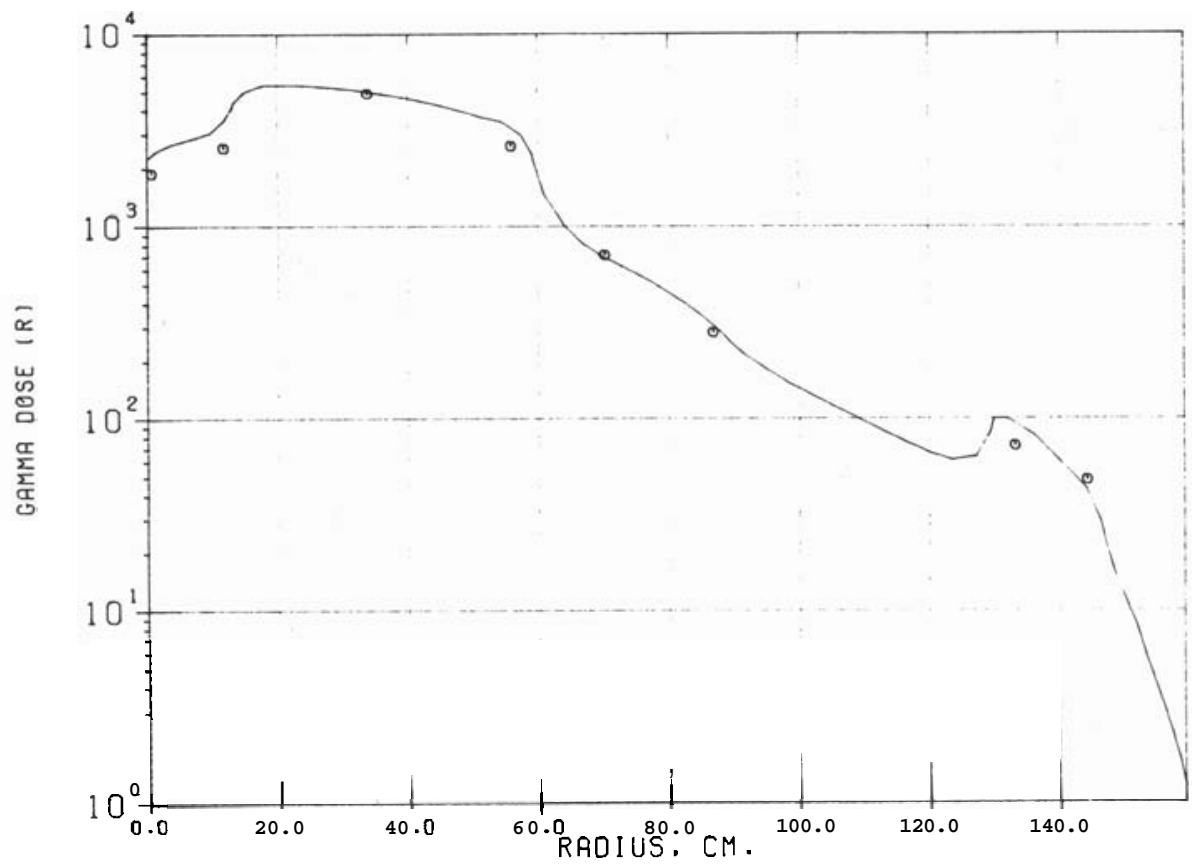

FIGURE 9.5. Midplane Radial Gamma Distribution in ZPPR/FTR-2 with Stored Fuel Present

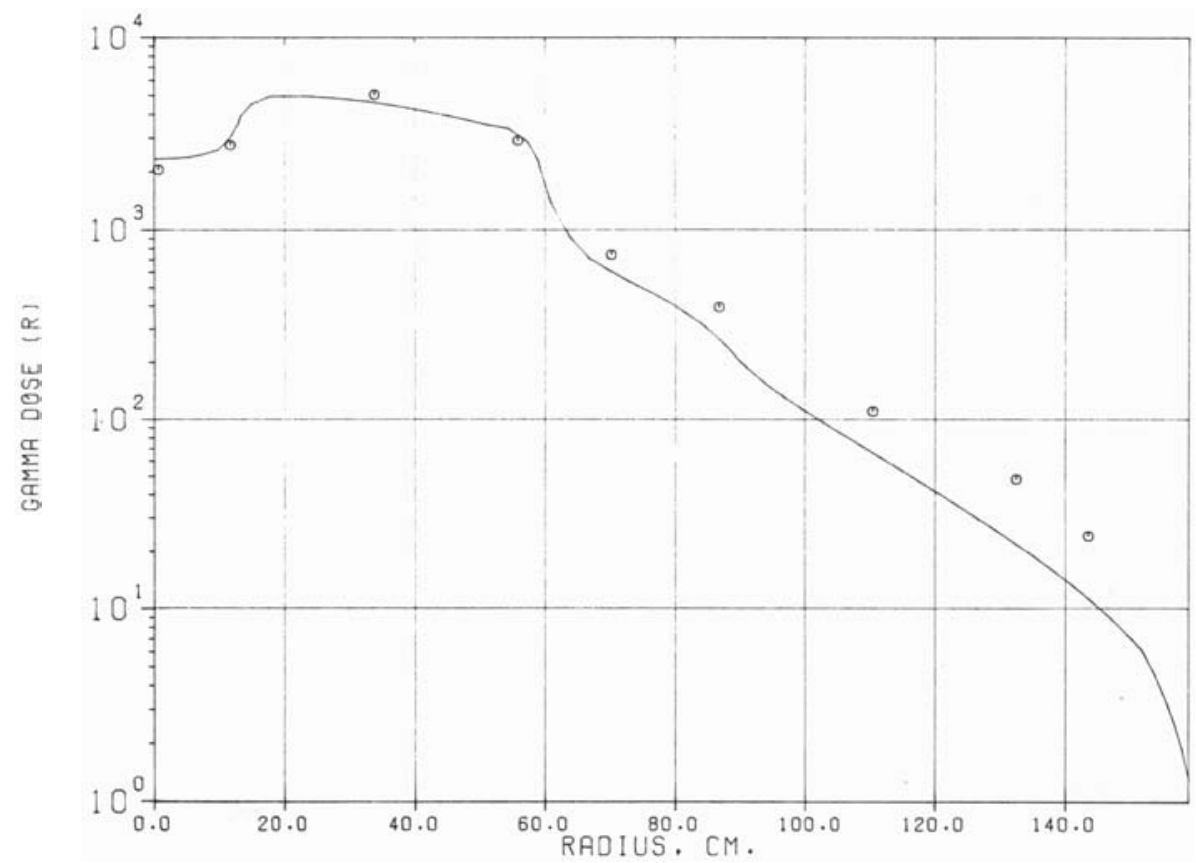

FIGURE 9.6. Midplane Radial Gamma Distribution in ZPPR/FTR-2 Without Stored Fuel Present 
midplane with no stored fuel in the shield. The indicated agreement is believed adequate to permit use of these techniques and data for preliminary design of the FTR.

\section{Decay Heat Measurements \\ W. L. Bunch}

Calorimetric measurements are being obtained of the fission product decay heat associated with the Phenix (plutonium) fuel irradiated in MTR. Two data points were obtained during the first week following shutdown of the reactor. Subsequent data points are being obtained about every 10 days. Calibration data are being obtained using electric heaters. It is estimated that results will be valid to within about $10 \%$. The measurements and data reduction are being carried out by Idaho Nuclear Corporation.

\section{Shield Development Program}

W. L. Bunch

The experimental shield development program to be carried out by ORNL in support of the FFTF project during FY-1971 has been defined. The program is to investigate attenuation characteristics of the FIR cover, including effects of penetrations. In addition, measurements are to be made of lower axial shield mockups. The sodium, iron, steel, and nickel slabs employed in the STIR shielding experiments are being shipped to the Tower Shield Facility for use in this program. 


\section{CHAPTER $X . \quad$ SAFETY}

\section{A. PLANT SAFETY ANALYSIS STUDIES}

\section{Theoretical Work Energy for Core Disassembly Accidents}

A. Padilla

A transient thermodynamic model, SOCOOL-II, has been developed to predict the work energy which may be generated in a hypothetical reactor core disassemby accident. After a core disassembly accident, part of the energy which has been deposited in core materials may be released in a form capable of doing mechanical work. The most efficient process for generating this mechanical work energy is to transfer the energy stored in the molten fuel at the end of disassembly to the sodium coolant and allow the sodium to expand against the system. The SOCOOL-II code computes the rate of energy transfer and pressure generation in a molten fuel-sodium mixture and evaluates the resulting acoustic and inertial work energy.

The geometry assumed for the analytical model is shown in Figure 10.1, . Spherical fuel particles are assumed to be uniformly dispersed in a sodium-fuel region located at a given distance from the nearest free surface of a sodium pool. The temperature and pressure within the sodium-fuel region are assumed to be uniform with no heat transfer between the heated and unheated regions.

The rate of heat transfer is calculated from a unit cell consisting of a single fuel particle concentrically surrounded by sodium liquid. Variable properties for the fuel and sodium, including the heat of fusion of the fuel, are considered. If the time for heat transfer is large compared to the acoustic period of the system (the time for a pressure wave to travel to the free surface and back), then the system 
BNWL-1394

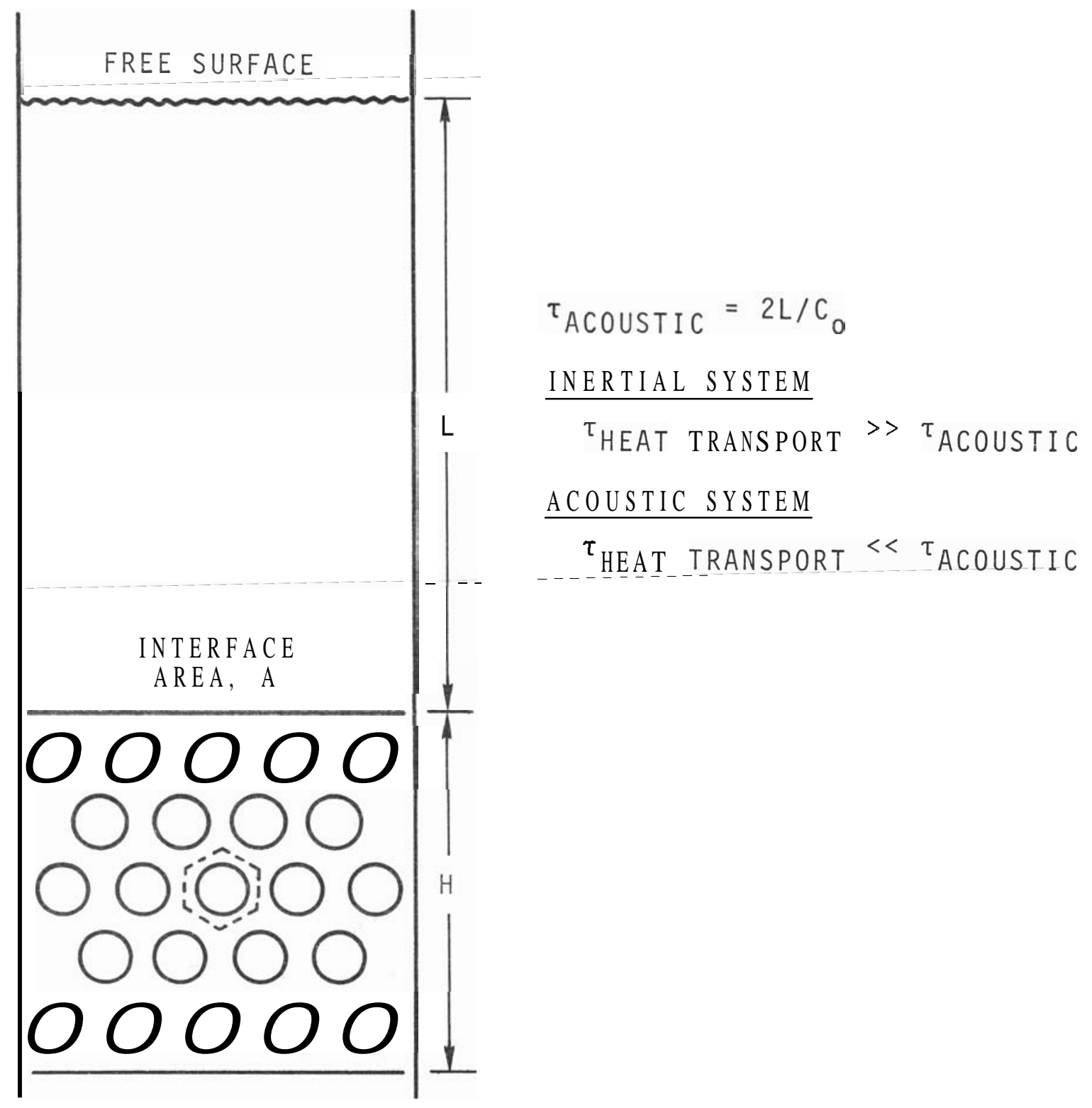

FIGURE 10.1. Model for Molten Fuel-Sodium Interaction 
is under inertial restraint and boiling will occur whenever the sodium reaches the boiling point. If the time for heat transfer is small compared to the acoustic period, then the system is under acoustic restraint and the expansion of the sodium-fuel mixture is inhibited by the unheated liquid resulting in high pressures which suppress normal boiling. The one-dimensional acoustic equations are used to predict the transient pressures within the sodium-fuel mixture until the pressure decreases below the saturation pressure corresponding to the sodium temperature. At the onset of boiling, the fuel particles are assumed to be vapor-blanketed so that no further heat transfer takes place.

The acoustic work energy, generated while the system is under acoustic restraint, is calculated by integrating under the pressure-volume curve to the time that boiling conditions are attained. For analysis of structural damage from pressure waves, the impulse (pressure-time curve) may be more useful. The inertial work energy, generated while the system is under inertial restraint, is calculated from isentropic expansion of sodium to a specified terminal pressure. The entire pressurevolume curve for the process could be used in an analysis to determine the coolant slug acceleration toward the reactor cover.

Parametric analyses have been carried out using the SOCOOL-I1 computer program to assess the effect of various parameters on the magnitude of the theoretical work energy generated from a core disassembly accident. Among the parameters investigated were: fuel fragmentation, energy in the molten fuel, sodium temperature, time for heat transfer, final pressure, and sodium properties.

Figure 10.2 shows the effect of fuel particle size on the work energy, both acoustic (shock) and inertial (blast), when 


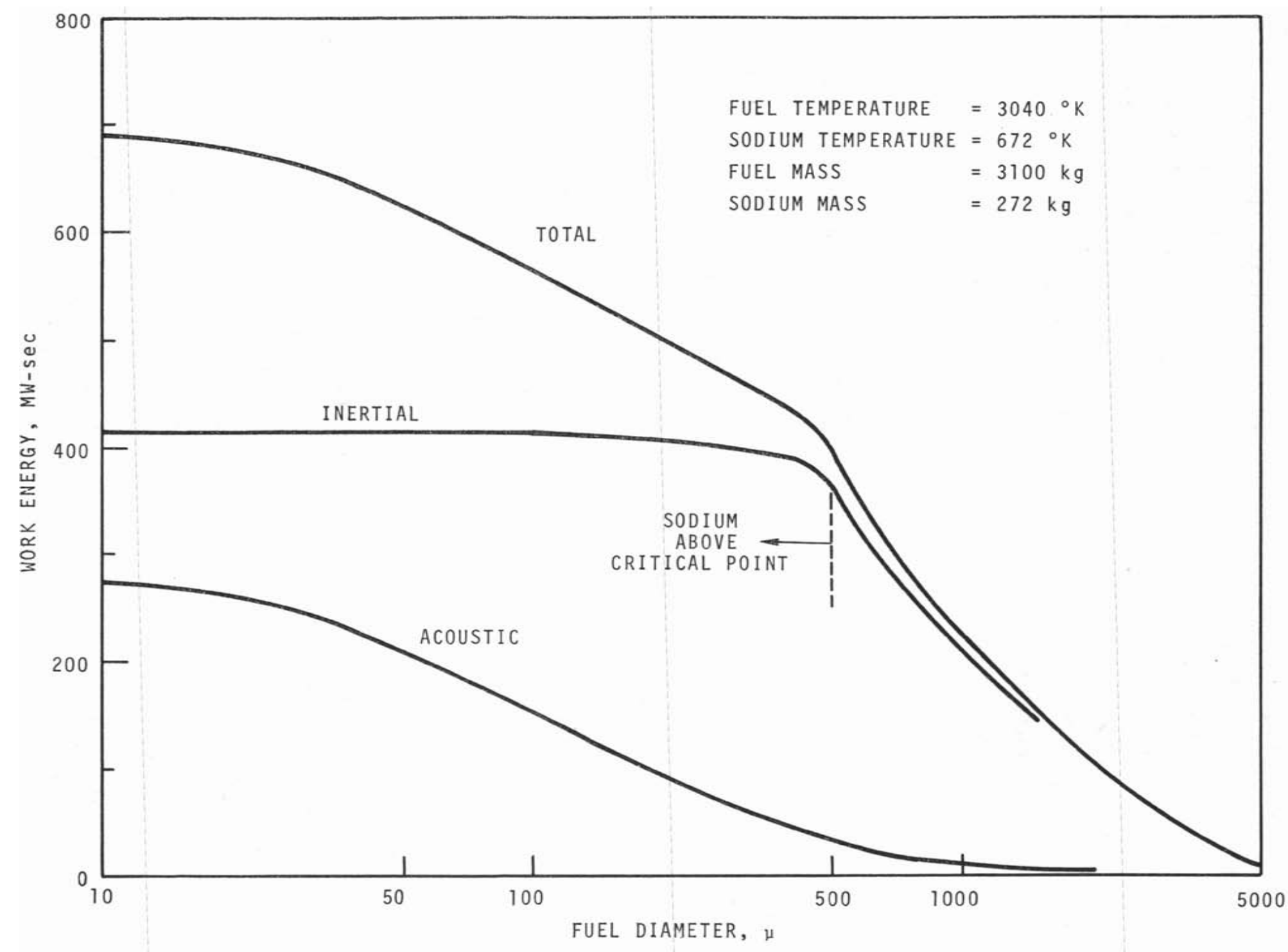

FIGURE 10.2. Effect of Fuel Fragmentation on Work Energy 
all of the fuel in the core is at the melting point and is assumed to mix with all of the sodium in the core. For fuel particles smaller than about $500 \mu$, the sodium is heated above the critical point, introducing greater uncertainties associated with the prediction of supercritical sodium properties.

Figure 10.3 shows the variation in total work energy as a function of the initial fuel temperature when all of the fuel in the core is assumed to be at uniform temperature. The work energy is much more sensitive to the initial fuel temperature when the calculated sodium temperatures are below the critical point.

Figure 10.4 shows the effect of sodium temperature on the acoustic and inertial work energy for constant sodium volume (decreasing sodium mass for increasing sodium temperature). Although the increased compressibility of sodium at the higher initial temperatures results in lower pressures generated within the molten fuel-sodium mixture, these lower pressures result in slower expansion of the system and substantially longer times are required to attain boiling conditions. Therefore, the acoustic work increases with increasing initial sodium temperature due to the longer times associated with the generation of acoustic energy, but lower pressures are involved The decrease of inertial energy at the higher initial sodium temperatures is associated with the decreasing mass of sodium for the same volume. However, the total work energy continues to increase for higher initial sodium temperatures.

2. Containment Transients

R. D. Peak

The CACECO Code (cavity-cell-containment transient code) was used to investigate the early portions of containment 


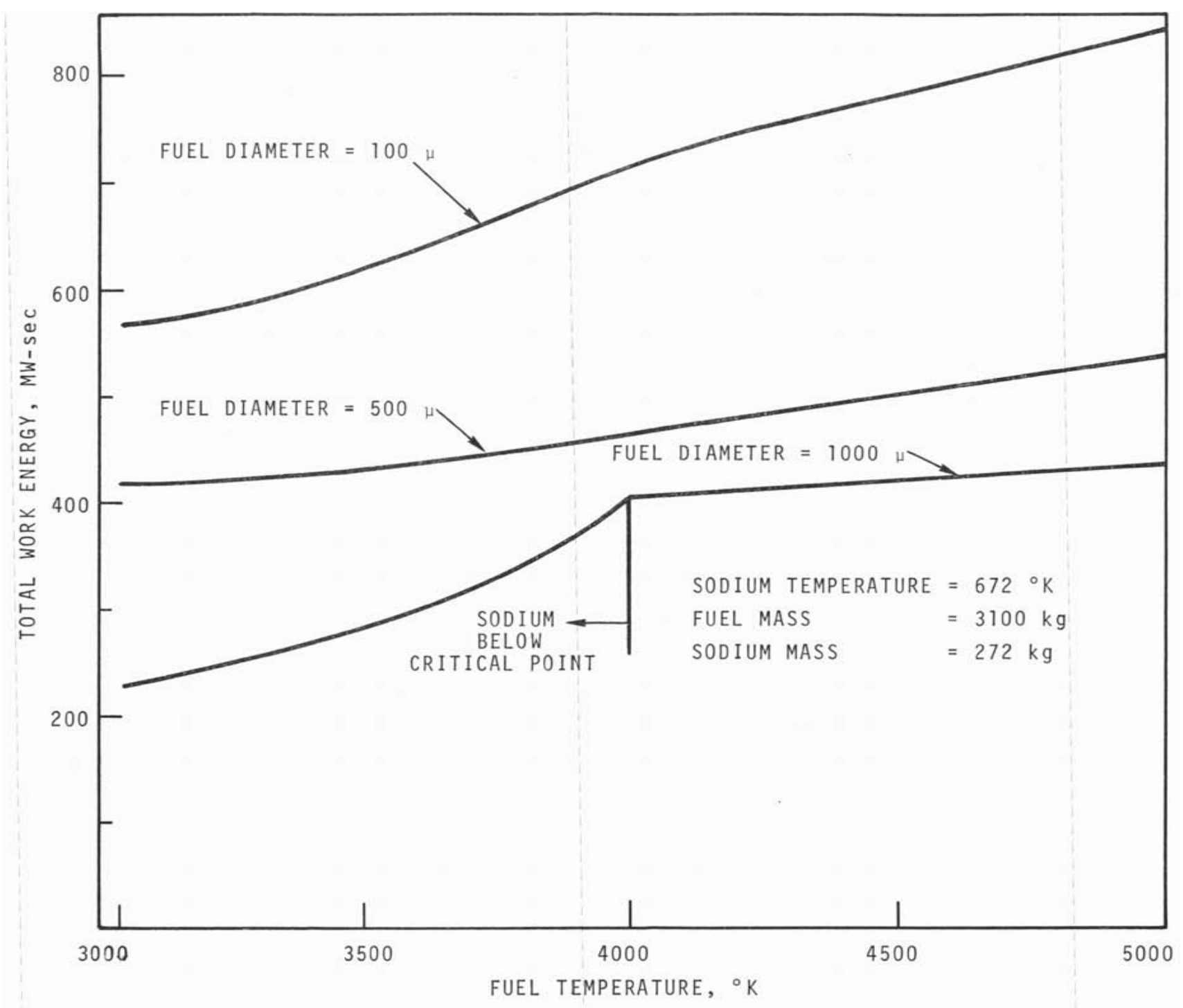

FIGURE 10.3. Effect of Initial Fuel Temperature on Work Energy 


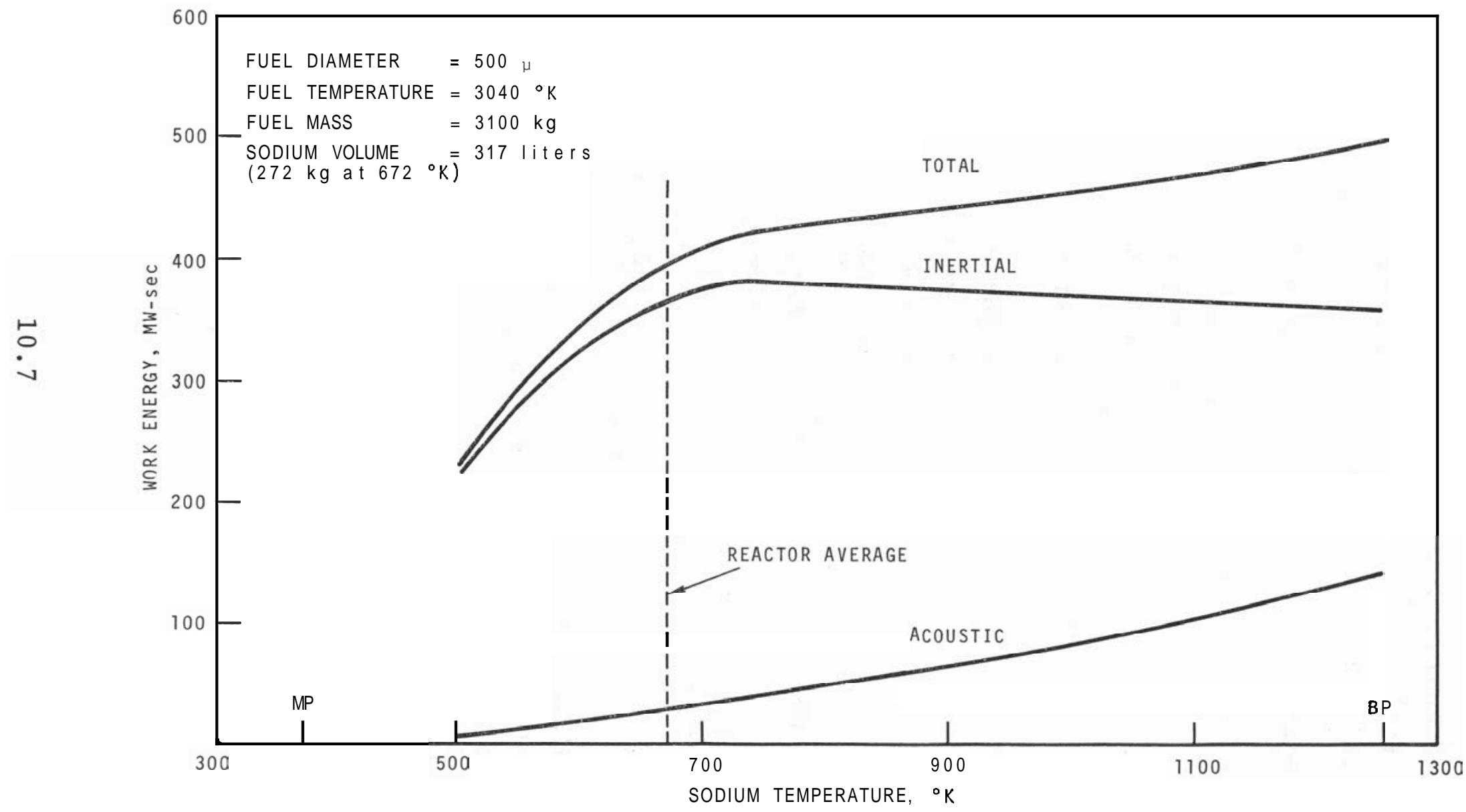

FIGURE 10.4. Effect of Initial Sodium Temperature on Work Energy 
transients following various core disassembly accidents. Also, the FFTF containment model was modified to conform to the latest facility drawings. The present model is summarized below in Table 10.1 .

TABLE 10.1. FFTF Containment Model for the CACECO Code

Reactor Cavity: Volume of atmosphere $32,000 \mathrm{ft}^{\mathrm{S}}$

Number of heat structures 5

Surface area of insulated structures

$6,160 \mathrm{ft}^{2}$

Surface area of steel-concrete structures

Head Box:

Volume of atmosphere

$9,500 \mathrm{f} \mathrm{t}^{2}$

Number of heat structures

$10,200 \mathrm{ft}^{3}$

Surface area of steel structures

6

Surface area of steel-concrete structures

$1,710 \mathrm{ft}^{2}$

Each HTS Ce11: Volume of atmosphere

$2,610 \mathrm{ft}^{2}$

$20,000 \mathrm{ft}^{3}$

Number of heat structures

4

Surface area of insulated structures

$5,725 \mathrm{ft}^{2}$

Surface area of steel-concrete structures

$7,300 \mathrm{ft}^{2}$

The insulated structures of the cavity are the reactor vessel, its guard vessel, the latter's supports, and the primary piping. The steel structures of the head box are the shielding for the closed loop piping and the reactor vessel cover. The insulated structures of the HTS cell are the primary pump and guard vesse1, the intermediate heat exchanger and guard vessel, and the primary and secondary loop piping. The steelconcrete structures are the roof, walls, and floor of each space.

The following case was prepared for the PSAR: In this facility design, the atmospheres of the cavity, head box, and 
each HTS cell are separate in order to prevent spread of gasborne radioactive contamination during normal operation. However, in case of accidental overpressure, a rupture diaphram-relief vent connects the cavity to the head box and the cavity to each HIS cell. In the following analysis, these vents are assumed to have a $1 \mathrm{ft}^{2}$ flow area.

The case is based upon energy released from a hypothetical disruptive accident. This energy would derive from the expansion of some $\mathbf{4 3 4} \mathrm{b}$ (197 kg) of core sodium heated by molten and vaporized fuel to the fiducial pressure of $1 \mathrm{~atm}$. Inherent in this case is the assumption that most of this core sodium condenses quickly in the surrounding sodium inside the vessel except for core sodium vapor vented directly into the head access space through multiple ruptures of the closed loop piping. Another assumption is that upper plenum sodium blown through the peripheral gap of the raised reactor cover is effectively deflected out of the head box into the reactor cavity. The sodium releases into the head box and reactor cavity are assumed complete in about $\mathbf{1 . 1} \mathrm{sec}$ because the driving pressure of core sodium vapor inside the reactor vessel decays in this time due to vapor condensation.

Results were submitted for use in the PSAR.

3. Space-Time Decay Heat Distribution from Fission Products in the Reactor Cavity

P. R. Shire

In the unlikely event of a hypothetical core disassembly accident, fission products may be released to the reactor cavity. Decay heat from fission products is significant for safety analyses treating long-term accident pressures and temperatures within the containment barrier. 
As a limiting case, a 11 of the fission products are assumed to be retained in the reactor cavity along with $60001 \mathrm{~b}$ of reactor fuel and 25 tons (or more) of high temperature sodium. Initially the following species are estimated to be aerosols in the reactor cavity inert gas space: $100 \%$ of noble gases krypton and xenon; $100 \%$ of halogens iodine and boron; $100 \%$ of volatiles tellurium, selenium and cesium; and $10 \%$ of a 11 remaining fission products (ARFP). The fuel mass containing all other fission products is assumed to be deposited uniformly on the $1000 \mathrm{ft}^{2}$ cavity floor, with the sodium pool above it.

Following this event the $10 \%$ ARFP are assumed to settle from the cavity gas space into the sodium pool with a fallout half $1 \mathrm{ife}$ of $\sim 10 \mathrm{~min}$. The halogens and volatiles are assumed to settle into the sodium pool with a fallout half life of $\sim 1$ day. After $\sim 8$ days only, the noble gases remain in the cavity gas space.

Decay heat data was obtained from the RIBD(1) computer code for fuel at 300-day exposure. The time dependent decay heat generation for each isotopic group was multiplied by the distribution percentages.estimated for the fission product release model and allocated to the three fission product carriers: inert gas, fuel and sodium. In order to estimate the radiation energy absorption in the carriers and in the reactor cavity structure, it was assumed that there was an equal division of energy between $\beta$ and $\gamma$ emitters and that both types of radiation could be represented by mono-energetic $1 \mathrm{MeV}$ particles relative to energy absorption coefficients.

1. W. L. Bunch and L. D. O'DeZZ. Fission Product Inventory and Decay Heat Associated with FTR Fuel, BNWL-961, BattelzeNorthwest, Richland, Washington, February 1969. 
The resulting summary of decay heat generation versus time in system components was submitted for use in the PSAR.

4. Sodium Pool Fire Analyses for New FIR Equipment

Cell Volumes

P. R. Shire

- Following revisions in the sizes of primary heat transport system (HTS) cells, sodium pool fire analyses have been repeated using the SOFIRE-I code. Two sets of cases have been analyzed. In the first case, a $20,000 \mathrm{f} \mathrm{t}^{3}$ cell is conservatively assumed to remain gas-tight throughout the transient. In the second case, rupture disks are assumed to relieve gas pressures in excess of $\sim 1$ psi differential to the reactor cavity, 32,000 $\mathrm{ft}^{3}$, and then to the two other HTS cells for a total volume of $92,000 \mathrm{ft}^{3}$. In each case, the initial conditions were as follows:

- Cell gas:

Sodium:

- Cell structure: $1 / 4$ in. steel liner, 5 ft concrete wal

\section{- Cell gas:}

1 vol\% oxygen (99\% nitrogen) and $100^{\circ} \mathrm{F}$ at atmospheric pressure. a 11 a t $100{ }^{\circ} \mathrm{F}$. $1100^{\circ} \mathrm{F}$ and 5,25 , and 75 tons for Case 1. $1100^{\circ} \mathrm{F}$ and 100 tons for Case 2.

The SOFIRE-I code was modified to allow the sodium volume to compress the cell gas adiabatically at time zero and to allow the steel floor liner to attain thermal equilibrium with the sodium at time zero. The results were submitted for use in the PSAR. 
5. Containment Analyses - SOHOT Code

G. L. Fox

The development of the computer program (SOHOT), was described previously. (1) This code predicts pressures and temperatures in the reactor cavity, equipment cells, and containment sphere as the consequence of a boiling sodium pool heated by fission products on the cavity floor. Revisions have been made to this code to permit evaluation of reactor cavity thermal insulation schemes.

Previous SOHOT results have shown that the pressure in the reactor cavity and equipment cells could be suppressed by heat conduction into the structural concrete walls. However, after a sufficiently long time, the concrete temperature rose to a level considered structurally undesirable. Therefore, systems were evaluated which control the atmosphere temperature and protect the reactor cavity liner from the hot sodium.

The analyses showed that the cavity liner temperature may be limited to $250^{\circ} \mathrm{F}$ by insulation and use of cooling coils from space coolers provided for normal operation.

In addition to the sodium boiling accident, two other sodium handling accidents were analyzed. The first analysis examined the effects of a fuel handling accident where one subassembly was dropped, releasing $500 \mathrm{lb}$ of sodium and its fission product decay heat within the containment sphere.

The second analysis examined the terminal phase of a sodium pool fire in a heat transport cell which is open to outer containment. The SOFIRE code calculated the non-nuclear fire for 75 tons of $1050^{\circ} \mathrm{F}$ sodium released on the floor with $100 \mathrm{ft}^{2}$ of vent area from the cell to outer containment.

1. FFTF Quarterly Technical Report, December 1969, January, February 1970, BNWL-1328. Battelle-Northwest, Richland, Washington. April 1970. 
Both of these cases showed the resultant pressures were below the containment design pressure of 10 psig.

6. Site Radiological Analysis

C. L. Fies

Site radiological calculations were updated for bone, lung, and thyroid doses resulting from a hypothetical core disruptive accident. In addition to a base case analysis, several variations were made to evaluate the effect of changes in the basic assumptions. The dose was computed at the site boundary (4-1/2 miles) for both $2 \mathrm{hr}$ and 30 day inhalation times.

Permissible limits are 150 rem to the bone, 75 rem to the lung, and 300 rem to the thyroid. All values computed for doses at the site boundary are well below these limits. 


\section{APPENDIX A}

FFTF BNWL REPORTS AND DOCUMENTS ISSUED

MARCH 1 - JUNE $15^{*}$

\section{TOPICAL REPORTS (FORMAL)}

BNWL

Number

1214

H. T. Blair

1261 M. K. Millhollen, T. J. Bennett, and R. L. Myers

1264 R. W. Hardie and

W. W. Little, Jr.

1271 W. F. Brown and

R. M. Crawford

1286 R. J. Jackson,

C. L. Wheeler,

G. R. Waymire and

W. W. Little, Jr.

1303 R. F. Gilmore

1319 R. N. Madsen

1321 B. R. Hayward

1323 R. L. Fish,

J. J. Holmes and

R. D. Leggett

1324 R. E. Dahl, Jr.

1330 B. E. Dozer

1331 R. L. Myers
Title

Fabrication Report FFTF Prototypic Fuel Pellets for Analytical Chemistry Program

Mark I Prototypic FTR Fuel Element Subassembly Sodium Flow Test

3DB, A Three-Dimensional Diffusion Theory Burnup Code FFTF Welding Standards for the Driver Fuel Assembly

Metal Swelling Effects on FTR Core Components

Open and Closed Loop Top Closure Cutting and Welding Equipment Evaluation

Dynamic Digital Computer Simulation of the FFTF Dump Heat Exchanger

The Application of Image Enhancement to FFTF Fuel Technology'

Interim Burst Test Results on EBR-II Irradiated Fuel Pin Sections

Calculations of Burnup and Damage for Fast Reactor Fuel

FFTF Process Data Display Prototype

Evaluation of Weld Joint Designs Between Wire Wrap and End Cap

* Compized by L. R. Stevens 
BNWL

Numbe

1332

1333 W. L. Bunch

1335 J. R. McBride

1339 C. A. Mansius

1347 J. E. Krajicek

1350 J. P. Hale

1355 J. Ryden, Jr.

1359 J. Ryden, Jr. and

E. F. Perrizo

1367 A. L. Gunby

1376 R. R. Studer

\section{TOP \CAL REPORTS (INFORMAL)}

BNWL

Number

Authors

$\mathrm{Ma}-73$

H. G. Powers

$1111-\mathrm{FF}-1$

A. R. Shade

$1294-F F-1$

M. R. Kreiter,

5. K. Myers and

E. F. Antal

$1374 \mathrm{RD}$

G. E. Culley and

D. O. Sheppard

$1390 \mathrm{RD}$
D. E. Simpson,

A. E. Waltar and

A. Padilla
Title

Evaluation of $3 / 32$ in. Fillet

Wire-End Cap Weld

FFTF Shielding Program

Modified Fermi Control Rod Latch

for the FFTF--Report on the Development and Testing Program

Activation and Shielding of FTR Sodium

Dynamic Simulation of Primary Loop Check Valves for the Fast Flux Test Facility

Site Safety Analysis

An Eddy Current Tube Testing Technique Using a Hybrid Coil Configuration with Sequential Sampling

The Nondestructive Examination of $G$ and $H$ Lots FFTF Fuel Cladding Intermediate Heat Exchanger Modeling for FFTF Simulation Mechanical Cleaning of Small Diameter Tubing
Title

FFTF Fuels Dept. Quality Assurance Manual

Parametric Reactivity Transient Analysis for the FFTF Nuclear Proof Test Reactor

Closed Loop Seal and Creep Compensating Connector Evaluation

Hazards Analysis for the Battelle-Northwest GETR/TREAT Transient Irradiation Test Series

Assessment of Magnitude and Uncertainties of Hypothetical Accidents for the FFTF 
BNWL

Number

Authors

$1398 \mathrm{RD}$ M. K. Millhollen

CC-2369

G. Janson

$\mathrm{CC}-2452$

F. R. Standley

\section{SPEECH AND ARTICLES}

BNWL Number

$S A-2758$

W. W. Little, Jr.,

R. W. Hardie,

L. D. O'de11 and

R. B. Kidman

SA-3093

Vol. 1 P. L. Hofmann

Vol. 2 P. L. Hofmann

$S A-3269$

L. M. Polentz and

E. R. Astley

\section{PERIODICALS}

BNWL Number Authors

325

E. R. Astley and

C. P. Cabe11

1300-2 B. Wolfe

1300-3 B. Wolfe

1300-4 B. Wolfe

1300-5 B. Wolfe
Title

Engineering Test Plan for Mixed Oxide Unencapsulated Fuel Pin Irradiations in EBR-I I (ANL Run-to-Failure Test B)

Fast Reactor Fuel Interaction with a Concrete Floor After a Hypothetical Core Meltdown

Sodium Service Pressure Measurement NaK Capillary System Test Report

\section{Title}

Fuel Management Models and Analysis for the Fast Test Reactor (FTR)

Lecture Series, Fast Reactor Safety Technology and Practices

Safety Practices and Background Information

Accident Analyses

Stainless steel Swelling in

the Breeder Reactor
Title

FFTF Summary Technical Report, January-December, 1966

FFTF Monthly Informal Technical Progress Report February 1970

FFTF Monthly Informal Technical Progress Report March 1970

FFTF Monthly Informal Technical Progress Report April 1970

FFTF Monthly Informal Technical Report May 1970 
BNWL

Number

$1300-6$

B. Wolfe

1328

B. Wolfe
Authors

Title

FFTF Monthly Informal Technical Report June 1970

FFTF Quarterly Technical Report December 1969, January, February 1970 


\section{DISTRIBUTION}

No. of

Copies

OFFSI'TE

1

AEC Chicago Patent Group

G. H. Lee

AEC Division of Reactor Development and Technology

Director RDT

Asst Dir for Nuclear Safety

Analysis and Evaluation Br, RDT:NS

Asst Dir for Plant Engrg, RDT

Facilities Br, RDT:PE

Components Br, RDT:PE

Instrumentation and Control Br, RDT:PE

Liquid Metal Systems Br, RDT:PE

Asst Dir for Program Analysis, RDT

Asst D i r for Project Mgmt, RDT

Liquid Metals Projects Br, RDT:PM

G. J. Mishko

FFTF Project Manager, RDT:PM (3)

Asst D i r for Reactor Engrg, RDT

Control Mechanisms Br, RDT: RE

Core Design Br, RDT:RE (2)

Fuel Engineering Br, RDT:RE

Fuel Handling Br, RDT:RE

Reactor Vessels Br, RDT:RE

Coolant Chemistry Br, RDT:RT

Fuel Recycle Br, RDT:RT

Fuels and Materials Br, RDT:RT

Reactor Physics Br, RDT:RT

Special Technology Br, RDT:RT

Asst Dir for Engrg Standards, RDT

Asst Dir for Nuclear Safety, RDT

215 AEC Division of Technical Information Extension

1 AEC Idaho Operations Office

C. W. Bills, Director

1 AEC San Francisco Operations Office

Director, Reactor Division

$5 \quad$ AEC Site Representatives

Argonne National Laboratory - $\mathrm{CH}$

Argonne National Laboratory - ID

Atomics International

General Electric Co., Sunnyvale

Westinghouse Electric Corporation 
No. of Copies

4

Argonne National Laboratory

LMFBR Program Office (2)

R. A. Jaross

N. J. Swanson

1 Argonne National Laboratory

Idaho Falls, Idaho

F. W. Thalgott

2 Atomic Power Development Associates

Document Librarian

5 Atomics International

FFTF Program Office

2 Babcock and Wilcox Co.

S. H. Esleeck

G. B. Garton

1 Battelle-Northwest Representative

R. M. Fleischman (ZPPR)

$3 \quad$ Battelle Memorial Institute

8 Bechtel Corporation

J. J. Teachnor

1 Combustion Engineering, Inc. (AEC)

W. P. Staker, Project Manager

$1 \quad$ Combustion Engineering

911 West Main St. Chattanooga, Tennessee 37401

Mrs. Nell Holder, Librarian

4 General Electric Co. Advanced Products Operation

Karl Cohen

1 General Electric Co., Pleasanton (AEC)

Nucleonics Laboratory

Dr. H. W. Alter, Mgr. 
No. of

Copies

2

Gulf General Atomic Incorporated (AEC)

D. Coburn

1 Idaho Nuclear Corporation

J . A. Buckham

$3 \quad$ Liquid Metal Engineering Center

R. W. Dickenson

1 Liauid Metal Information Center

A. E. Miller

2 Los Alamos Scientific Laboratory

R. D. Baker

D. B. Hall

$1 \quad$ NASA Lewis Rés earch Center

R. A. Hildebrand

$1 \quad$ Nuclear Materials and Equipment Corporation (AEC)

C. S. Caldwell

2 Oak Ridge National Laboratory

H. G. Duggan

W. o. Harms

1 Southwest Research. Institute

A. J. Pickett

$1 \quad$ Stanford University

Nuclear Division

Division of Mech. Engrg.

R. Sher

1 United Nuclear Corporation

Research and Engineering Center Library

R. F. DeAnge 1 is

11 Westinghou'se' Electric 'Co'rp.

Atomic Power Division

Advanced Reactor Systems

E. C. Bishop

D. C. Spencer (10) 
No. of

Copies

ONSITE-HANFORD

$1 \quad$ AEC Chicaeo Patent Group

R. K. Sharp (Richland)

2 AEC Richland Operations Office

FFTF Program

J. M. Shivley

4 Atlantic Richfield Hanford Company

L. M. Richards

L. B. Christopher

H. P. Shaw

R. E. Tomlinson

$9 \quad$ Battelle-Northwest

Legal - ROB, 221-A

BNW - Technical Information (5)

BNW - Technical Publication (3)

1 Bechtel Corporation

W. A. Smith (Richland)

2 Computer Sciences Corporation

G. L. Otterbein

C. D. Thimsen

$4 \quad$ Douglas United. Nuclear Corporation

R. S. Bell

C. D. Harrington

C. W. Kuhlman

O. C. Schroeder

2 Hanford Engineering Services, Vitro, Inc.

J. M. Frame

G. Kligfield

$5 \quad$ ITT/FSS

J. M. Heffner

W. M. Hunt

T. P. Leddy

M. F. Rice

C. W. Weeks

2 RDT Asst. Dir 'fo'r'Pacific Northwest Laboratory 
No. of

:Copies

WADCO Corp.

W. G. Albert
G. J. Alkire
H. J. Anderson
S. O. Arneson
J. M. Atwood
J. M. Batch
R. A. Bennett
T. K. B Berlein
L. D. Blackburn
C. L. Boyd
D. C. Boyd
C. L. Brown
W. L. Bunch
C. A. Burgess
C. P. Cabe11 $(2)$
J. J. Cadwe11
A. C. Callen
C. M. Cantre11
J. R. Carrel1
T. T. Claudson
J. C. Cochran
G. S. Cochrane
R. R. Cone
J. H. Cox
V. A. DeLiso.
R. V. Dulin
W. H. Esselman
E. A. Evans
T. W. Evans
W. M. Gajewski
E. E. Garrett
S. M. G ill
J. W. Hagen
J. P. Hale
J. E. Hanson
K. M. Harmon
R. A. Harvey
B. R. Hayward
E. N. Heck
R. E. Heineman
J. W. Helm
R. J. Hennig
P. L. Hofmann
J. J. Holmes
J. E. Irvin
M. T. Jakub

B. M. Johnson

H. G. Johnson

R. N. Johnson

E. M. Johnston

J . N. Judy

F. J . Kempf

D. D. Lanning

G. A. Last

F. J. Leitz

H. D. Lenkersdorfer

W. W. Little

C. E. Love

D. Marinos

W. B. McDonald

J . S. McMahon

R. A. Moen

C. A. Munro

C. R. Nash

J. M. Norris

D. J. Oakley

D. P. $0^{\prime}$ Keefe

J . A. Perry

R. E. Peterson

H. G. Powers

o. W. Priebe

H. L. Pringle

J. C. Richardson

B. G. Rieck

W. E. Roake

G. J. Rogers

D. P. Schively

F. H. Shade1

D. W. Shannon

P. F. Shaw

W. F. Sheely

F. R. Shober

D. E. Simpson

J. C. Spanner

D. D. Stepnewski

G. H. Strong

C. D. Swanson

J . W. Thornton

J. C. Tobin

K. G. Toyoda

L. D. Turner

J. C. Tverberg 
No. of

'Copies

WADCO Corp. (contd)
M. A. Vogel
R. C. Walker
T. W. Withers
D. M. Walley
B. Wolfe
E. T. Weber
M. R. Wood
J. H. Westsik
J. M. Yatabe
J. F. Wett- -
H. H. Yoshikawa
J. F. Williams
WADCO Documents Contro1 (15)
WADCO Tech Pubs (703) (2) 